\title{
MIRRORS OF ENTRAPMENT AND EMANCIPATION
}

FORUGH FARROKHZAD

AND SYLVIA PLATH

LEILA RAHIMI BAHMANY

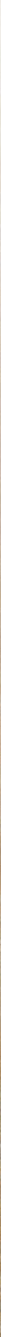


Mirrors of Entrapment and Emancipation 


\section{IRANIAN STUDIES SERIES}

The Iranian Studies Series publishes high-quality scholarship on various aspects of Iranian civilisation, covering both contemporary and classical cultures of the Persian cultural area. The contemporary Persian-speaking area includes Iran, Afghanistan, Tajikistan, and Central Asia, while classical societies using Persian as a literary and cultural language were located in Anatolia, Caucasus, Central Asia and the Indo-Pakistani subcontinent. The objective of the series is to foster studies of the literary, historical, religious and linguistic products in Iranian languages. In addition to research monographs and reference works, the series publishes English-Persian critical text-editions of important texts. The series intends to publish resources and original research and make them accessible to a wide audience.

\section{CHIEF EDITOR}

A.A. Seyed-Gohrab (Leiden University)

\section{ADVISORY BOARD OF ISS}

F. Abdullaeva (University of Cambridge)

G.R. van den Berg (Leiden University)

F. de Blois (University of London, SOAS)

J.T.P. de Bruijn (Leiden University)

D.P. Brookshaw (University of Oxford)

N. Chalisova (Russian State University of Moscow)

A. Adib-Moghaddam (University of London, SOAS)

D. Davis (Ohio State University)

M.M. Khorrami (New York University)

A.R. Korangy Isfahani (University of Virginia)

F.D. Lewis (University of Chicago)

L. Lewisohn (University of Exeter)

S. McGlinn (unaffiliated)

Ch. Melville (University of Cambridge)

D. Meneghini (University of Venice)

N. Pourjavady (University of Tehran)

Ch. van Ruymbeke (University of Cambridge)

A. Sedighi (Portland State University)

S. Sharma (Boston University)

K. Talattof (University of Arizona)

Z. Vesel (CNRS, Paris)

M.J. Yahaghi (Ferdowsi University of Mashhad)

R. Zipoli (University of Venice) 


\section{MIRRORS OF ENTRAPMENT AND EMANCIPATION}

FORUGH FARROKHZAD AND SYLVIA PLATH

Leila Rahimi Bahmany 
Cover design: Tarek Atrissi Design

Cover illustration: Lady with a Mirror, 16th/17th century (watercolor, ink and gold on paper), Rezā 'Abbāsi (c. 1565-1635) / Detroit Institute of Arts, usA / Gift of Mrs Edsel B. Ford / Bridgeman Images

Lay-out: TAT Zetwerk, Utrecht

ISBN 9789087282240

e-ISBN 9789400602076 (ePDF)

e-ISBN 9789400602083 (ePub)

NUR 635

(C) Leila Rahimi Bahmany / Leiden University Press, 2015

All rights reserved. Without limiting the rights under copyright reserved above, no part of this book may be reproduced, stored in or introduced into a retrieval system, or transmitted, in any form or by any means (electronic, mechanical, photocopying, recording or otherwise) without the written permission of both the copyright owner and the author of the book.

This book is distributed in North America by the University of Chicago Press (www.press.uchicago.edu) 


\section{Contents}

Preface 7

Note on Transliteration, Dates and Translation of Persian Poetry 9

Introduction: Women and Their Mirrors 11

CHAPTER 1 - Mirroring in Mythology and Psychology 21

"I am That!": Doubling in the Myth of Narcissus and Echo 21

The Petrifying Look: The Myth of Medusa 27

From Narcissus to Narcissism: Freud's Psychological Exegesis of the Myth 29

The Subject as an Alienated Construct: Lacan's Theory of the

Mirror Stage $\quad 36$

A Spatiotemporal Site of Psychological Interiority: Memory as a

Mirror

Mother-Daughter: The Mutual Mirroring $\quad 49$

Mirroring in Text 53

CHAPTER 2 - Mirror Imagery in the Works of Forugh Farrokhzad 61

A Herstory of a Subject-in-Process $\quad 61$

Captive to the Male Gaze $\quad 66$

$\begin{array}{ll}\text { The Mirror as an Eye } & 79\end{array}$

The Mirror of the Heart $\quad 82$

The Otherness of the Self-image 93

The Mirror of the Memory and of the Imagination 105

The Grotesquery of the Mirror Image 108

The Mirror and the Window 111

Mother-Daughter Reciprocity in the Mirror $\quad 132$

The Emancipated and Emancipating Mirror 137

Self-Mirroring in the Poetry of Forugh Farrokhzad 155 
CHAPTER 3 - Mirror Imagery in the Works of Sylvia Plath 159

The Mirror as the Intersection of Academic and Artistic Talent 159

The Mirror as a Weapon of the Femme Fatale 161

The Childless Woman: A Narcissist $\quad 168$

The Gigolo: Male Narcissism $\quad 171$

Woman as a Mirror of Male Ego $\quad 175$

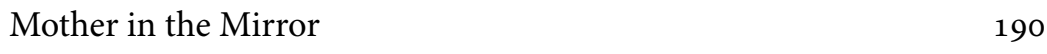

The Monstrous Degeneration Lurking in the Mirror 196

The Promising Mirror $\quad 203$

$\begin{array}{ll}\text { Child as a Mirror } & 208\end{array}$

The Mirror Image Being Identical with the Self 214

The Appalling Otherness of the Specular Self 223

$\begin{array}{ll}\text { Conclusion } & 243\end{array}$

Appendix: Farrokhzad's Poems Discussed in the Text with Their English

$\begin{array}{ll}\text { Translation } & 249\end{array}$

$\begin{array}{ll}\text { Notes } & 301\end{array}$

Bibliography $\quad 355$

$\begin{array}{ll}\text { Index } & 375\end{array}$ 


\section{Preface}

The present study is based on my doctoral dissertation from the Freie Universität Berlin, which I successfully defended in July 2012. First and foremost, I wish to express my deepest gratitude to my supervisors, Professor Ulla Haselstein and Professor Maria Macuch. It has been an honour to be a Ph.D. student under such distinguished professors. I appreciate all their contributions of time and ideas which made my Ph.D. experience productive and stimulating. Professor Haselstein carefully and patiently went over my dissertation several times and provided me with remarkably insightful comments. I benefitted greatly from her courses on literary criticism in the department of graduate studies. Professor Macuch provided me with an opportunity to benefit from her course on Forugh Farrokhzad. Her several careful readings of the part on Forugh Farrokhzad and Persian literature, her extremely helpful suggestions and her unwavering encouragement and support are greatly appreciated. I am deeply grateful for the excellent example my supervisors as eminent and considerate professors gave me.

I would also like to thank the members of the examining committee who conducted my viva voce at the John F. Kennedy Institute for North American Studies, Professor Laura Bieger, Professor Andrew S. Gross and Professor Sabine Schmidtke, complementing the work of my supervisors. I wish to thank them for their scrutiny of my thesis and their insightful questions. I feel especially grateful to a dear friend, Professor Sabine Schmidtke, for her support and encouragement. I should like to thank her for her readiness to help at all possible and impossible times and also for making my stay in Berlin comfortable and enjoyable. I am particularly indebted to Professor Dawud Gholamasad and Professor Sieglinde Lemke for their trust and for making my dream of continuing my education in a distinguished university possible. Professor Lemke's initial guidance is acknowledged.

I should also like to acknowledge gratefully the funding source that made my Ph.D. work possible. I was funded by a generous scholarship from the Friedrich Ebert Stiftung, Bonn. I especially wish to thank it for 
its faithful support and for the extremely useful programmes it offers its Ph.D. students. I extend my grateful thanks to Dr. Ali Asghar Seyed-Gohrab for carefully reading my manuscript. I should like to thank him for his unwavering support and encouragement. My gratitude is due to Professor Alireza Korangy and the other anonymous reviewer for their diligent reading of my manuscript and for supplying me with judicious reviews. I would like to thank Steve Millier, Shirin Rajavi, Dr. Pouneh Shabani-Jadidi, and particularly Kate Elliott for reading the whole or parts of my dissertation and for their insightful suggestions. My heartfelt thanks also go to Russell Harris, whose skillful editing transformed my manuscript into a readable text. I should also like to express my deep appreciation of the support and encouragement of Andreas Schmidt, Marjan Afsharian, Professor Sonja Brentjes, Dr. Susanna Brogi, Haida Farkhundeh, Professor Axel Havemann, Dr. Annabel Keeler, Dr. Rita Kuczynski, Professor Setrag Manoukian, Ali Miransari, Marziyeh Mirkarimi, Ursella Müller, Professor Osman Gazi Özgüdenli, Professor Nasrollah Pourjavady, Behnaz and Reza Rahimi Bahmany, Professor Ali Ravaghi, Professor Vahid Ravaghi, Manya Saadi-nejad, Professor Orhan Söylemez, Parvaneh Uroojnia, and Djalil, MohmmadReza and Parviz Bagheri Azarfam, who helped me in different ways in the years I was working on this book.

Finally, my heartfelt gratitude goes to my mother, Soraya Bagheri Azarfam, for her love and constant encouragement and particularly to my loving, encouraging, and patient husband, Dr. Reza Pourjavady, who supported me more than anyone else. Thank you for being so patient and selfsacrificing, and always giving me strength and hope. I also thank my son, Mehran who was born during my Ph.D. programme, for giving me so much love, hope and happiness. 


\section{Note on Transliteration, Dates and Translation of Persian Poetry}

This study has followed the German DMG system (Deutsche Morgenländische Gesellschaft) for the transliteration of Persian and Arabic words. For Persian proper names and for the words which have been adopted into European languages (e.g. Islam and purdah) I have diverged from the DMG system and used the most familiar transcription. For convenience, in the notes and bibliography, I have included dates in the heğrī-ye šamsī (Islamic solar) calendar current in Iran, followed by the Gregorian date separated by a slash.

I have endeavoured to translate the poems as literally as possible, with little concern for the poetic rhythms and forms. For the translation of the poems from the original Persian into English I have benefitted from the translations listed below:

Farrokhzad, Forugh. Bride of Acacias: Selected Poems of Forugh Farrokhzad. Translated by Jascha Kessler and Amin Banani. New York: Caravan Books, 1982.

. A Rebirth: Poems by Foroogh Farrokhzaad. Translated by David Martin. Lexington, Kentucky: Mazda Publishers, 1985.

Another Birth: Selected Poems. Translated by Ismail Salami. Tehran: Zabānkade, 1381/2002-2003.

- Sin: Selected Poems of Forugh Farrokhzad. Translated by Sholeh Wolpé. Fayetteville: The University of Arkansas Press, 2007.

- Another Birth and Other Poems. Translated by Hasan Javadi and Susan Sallée. Washington, DC: Mage Publishers, 2010.

Karimi-Hakkak, Ahmad. An Anthology of Modern Persian Poetry. Boulder, Colorado: Westview Press, 1978: 137-159. 



\section{Introduction: Women and Their Mirrors}

Owing to the extremely complex and ambivalent nature of the mirror phenomenon, responses to the mirror or any specular reflection-the reflection provided by any mirror-like surface-have been ambivalent and contradictory. The mirror's power in reiterating a simulacrum of reality, elusive and delusive, has given rise to a cornucopia of similes and metaphors. The mirror metaphor of divine reflection, conceptualized to describe, as well as to prescribe, the nature of man's relationship with his God, is one of the most popular of these metaphors. Recurrent since the Middle Ages, it has been adopted by philosophers and poets both of the West and the Islamic lands. Moralists and theologians have embraced this mirror of divinity (and also the mirror as a tool of self-knowledge, often regarded as a prerequisite to the knowledge of one's God), adopted it in their texts repeatedly and further contributed to its becoming a key constitutive metaphor. On the other hand, they reject it vehemently when it fails to reflect God and man's relationship with Him. Once it fails to reflect God and his imago, the mirror becomes a tool in the hands of Satan and his fellow devils-themselves reversed simulacra of God-facilitating man's downfall by blocking his path to God with the sins of vanity and envy. This is why it is forbidden for Muslim pilgrims to look at themselves in the mirror during the hajj ceremony in Mecca. Likewise, the mirror has often been associated with witches, sorceresses and femmes fatales.

The rejection of the mirror appears more accentuated when it is associated with the feminine gender. The mirror reflects only the external and visible aspect of the subject, i.e. the body, and women have always been regarded as particularly interested in their external appearance. Hence, a close and complex relationship between a woman and her mirror is frequently posited. Woman-with-mirror imagery has usually been considered a symbol of vanity, indicating the vice of self-love, self-worship and "narcissism." The mirror's reflection of the subject's physical exteriority and the cultural assumptions of womanhood as well as women's complex, at times 
paradoxical associations with their mirror images are indeed inextricably interwoven with the male gaze on women.

The mirror and the woman have both long been regarded as delusory and guileful, responsible for man's downfall. Woman's highest ambition is seen as to impress and seduce men with her outward image; just as the image in the mirror astounds and captures the person in front of it. Through the woman-with-mirror imagery, patriarchal culture further strengthens its conceptualization of women as sexual objects, as beings of mere appearances, always on the side of the seen. Women are historically regarded as essentially created for the gaze of the male and his desire. Woman-withmirror imagery is thereby laden with negative values. It reinforces the conception of woman as vain, superficial and self-idolatrous, spending long periods of time in front of a mirror, taking particular delight in observing her reflection. This explains why Christian nuns were forbidden to look at their mirror-image and why in Iran young girls are forbidden to carry a mirror at school. On the other hand, the mirror, often accompanied by a pair of candlesticks, remains an integral part of a woman's dowry in Iranian culture. It is believed to bestow marital bliss and function apotropaically, safeguarding conjugal happiness against the evil eye. The mirror and candlesticks are treated as objects that the bride should always carefully keep and dearly cherish.

For men, by contrast, the mirror has traditionally symbolized mental reflectiveness and truthfulness. For them, contemplation of the specular self frequently hints at the virtue of prudence through self-knowledge. While women have generally been depicted as, and therefore consigned to, being obsessed with their specular reflection-even to the extent of being metaphorized into mirrors themselves-men have been credited with an interest in mental reflection. This aligns with the much discussed feminist notion of gendered binary opposition, which bespeaks the sphere of culture for men and nature for women. Concentrating on mirror imagery, this gender discrepancy exposes the different value loads that the mirror reserves for men and for women. Within the architecture of our gendered cultures, images of mirrors have been constructed as gender-differentiating "moralizing tableaux" personifying virtue or vice when they are not presented as mere "household appliance[s]," functioning as "ethically neutral, nonjudgemental [sic] representations."

As manifested in numerous cases in art and literature, the mirror or looking glass has generally been held to be a female symbol of objectivity, and passivity. ${ }^{2}$ The mirror's objectivity, passivity and its reflecting characteristic 
have made it a popular metaphor for women and their historically objective position. Women were considered merely as selfless objects useful only for reflecting the male other and thereby granting him fake identity and delight in the patriarchal context. The objectivity of mirror/woman gives all other functions of both the mirror and the woman a matter of factness which is of course not true; the other functions such as passivity are indeed metaphorical as well as ideological. The same features have made the mirror a lunar symbol, too. The moon, like the mirror, has no light of its own; as a feminine symbol, it reflects the light of the sun while its nature remains totally unaffected. ${ }^{3}$

In her illuminating work, Herself Beheld: The Literature of the Looking Glass, La Belle observes that the theme of women gazing in the mirror solely as an indication of vanity can be found until the nineteenth century when a new trend in the study of the psychological implications of self-contemplation started to flourish. ${ }^{4}$ In the nineteenth and twentieth centuries, the mirror was no longer a mere locus of self-representation; it had become a site of identification and ego formation as well. Ever since the term "narcissism," based on the Greek mythological figure of Narcissus, was coined in psychoanalysis, the term "narcissistic" has gained widespread usage. Despite the psychoanalytical definition of narcissism as a primary human need, it has been ethically loaded with negative values and usually attributed to women. The stigmatization of women as narcissists has been systematically enforced by a cultural onslaught of stereotyped imagery, a system of stock concepts and tropes, and rhetorical and interpretive strategies, all of them contributing to encoding the definitions and norms of womanhood.

The abundance and persistent power of these imageries, or the "figurations of womanhood," which Meyers aptly names "cultural noise pollution," have led to their historical internalization by women and the fossilization of these gender norms within the geology of our culture. ${ }^{5}$ These figurations have sometimes had a devastating influence on women's self-portraits and self-narratives, undermining their agency and self-determination. By internalizing these imageries, women have indeed incorporated them into the structure of their selves, to the extent that they have even turned into the mouthpiece of patriarchy by echoing these noises. Meyers further explains:

Pernicious as well is the particular narcissistic economy that cultural norms impose on women. Not only does this economy obstruct women's self-determination, but, perversely, it also undermines their narcissistic 
satisfaction. The stereotype of the narcissistic woman and the ubiquitous pictorial tropes and narratives that keep it alive encode a no-win feminine psychodynamic of eroticized estrangement from self-a subjectivity of self-doubt, perplexity, and frustration that defeats authentic narcissistic agency. ${ }^{6}$

The recurrent mirror imageries and metaphors represent and forge women as entities definable in their totality by their specular self. These imageries are structured to conceptualize women as reflective tableaux for the satisfaction of desire and the gaze of men. By ignoring and systematically repressing women's inner complexities, these mirror imageries inextricably trap women within a "distressland," to draw upon Kristeva's terminology; a distressland of fragmentation, "self-doubt, perplexity, and frustration." ${ }^{8}$ Here Kristeva alludes to Lewis Carroll's stories of Alice's Adventures in Wonderland, and his Through the Looking Glass, in which Alice steps through a looking-glass into a wonderland. On the other hand, these figurative meanings of the mirror have provided many female writers with a starting point of self affirmation and self reflection, which in turn allows for one to lead an interrogation of social images of women (as is the aim of the present study).

Though the mirror is an external apparatus, there is a complex and ambiguous psychological interiority to it. The psychological interiority of the mirror provides a woman with a space within which she can search for a proof of her existence and the quality of her identity. ${ }^{9}$ As Spencer notes, the activity of gazing and contemplating one's mirror image by women is more "an act of self-exploration" than one of "self-expression." 10 Contrary to the popular cultural beliefs depicted in the traditional presentation of women, particularly in male texts, it is not always out of appeasing vanity, but often out of desperation that a woman observes herself continually in the mirror. It has been noted that in a time of psychological crisis, women turn to their mirror with higher frequency. In her careful study of women's behavioural patterns in asylums, Elaine Showalter, the American feminist literary critic, observes that schizophrenic women in particular are obsessed with continual observation of themselves in mirrors for a confirmation of their existence:

The "withness" of the flesh, and its proper management, adornment, and disposition, are a crucial and repeated motif in the schizophrenic women's sense of themselves as unoccupied bodies. Feeling that they have no secure identities, the women look to external appearances for 
confirmation that they exist. Thus they continually look at their faces in the mirror, but out of desperation rather than narcissism. ${ }^{11}$

In this regard, the mirror, for women, is not a thing turned to for narcissistic self-satisfaction out of sheer joy; on the contrary, it is often associated with pain and distress. It is a tool that a woman in her existential-psychological angst turns to in the hope of finding her lost identity, her true self. Particularly when a woman receives no acknowledgement of her existential identity in her society, the mirror can seem to be the only answer. That is why women turn to the mirror more and more in times of personal crisis. But the mirror does not necessarily provide the distressed woman with the answer she is looking for. The mirror can submerge a depressed woman further into the depths of disillusionment and pain. Evoking the famous story, Kristeva describes the trapped woman's anguished position thus:

Like an Alice in distressland, the depressed woman cannot put up with mirrors. Her image and that of others arouse within her wounded narcissism, violence, and the desire to kill-from which she protects herself by going through the looking glass and settling down in that other world where, by limitlessly spreading her constrained sorrow, she regains a hallucinated completeness. ${ }^{12}$

This "hallucinated completeness" which the female subject can only conceive within the space of her mirror follows what Lacan discussed as the first identification of a child with her mirror image in its totality as a whole, complete singular entity, which is indeed a misrecognition. Thereupon, some feminist critics plead for a cure for women's fatally wounded narcissism. They speak out for these women's need for "an emancipated narcissism": a narcissism in which a satisfying normal relationship with one's image is established. This emancipated narcissism will grant women the self-esteem essential to prevent their falling into the trap of self-effacement enforced as the norm by "cultural noise pollution."13 Schultz explains Kristeva's pleas in these words:

In light of the strictures imposed, in light of the drowning of our particularity in a society flooding us with ready-made images and clichés, Kristeva pleads for rescuing Narcissus-an idiosyncratic figure if ever there was one, a figure ex negativo, a figure that stands for our right to give our selves to our own images. ${ }^{14}$ 
As Schultz observes, Kristeva is arguing for more genuine figurations of womanhood, "a figure ex negativo," defined or presented as what a woman actually is not or what she excludes. These figurations should embrace the plural multiplicities and peculiarities of the concept, rejecting all stereotyped images and clichés.

The highly ambivalent essence of the mirror accounts for the ambiguous, even contradictory responses that the motif of the mirror elicits from modern female authors and feminists. These women break the mirror, totally rejecting it when it represents women's being manacled to the patriarchal images of feminine vanity and mere appearance. These authors spurn the mirror when it appropriates them as the object of male desire and his gaze, confounding their agency and incarcerating them within the realm of visibilities. On the other hand, paradoxically, they espouse the mirror when it becomes a medium for self-awareness, a site for constructing a true female self. They cherish the mirror when it becomes a means of facilitating the development of their emancipated narcissistic relationship with their own bodies and subjectivities as well as with the world around them.

For the reasons mentioned above, some feminist writers, poets and artists have taken up the task of deconstructing the cultural images and the linguistic codes of what "woman" means. They have struggled to reconceptualize women's relationship with their mirrors in different feminist terms, for instance, by creating imagery in which women reject their own specular images in favour of more mental reflectiveness, by being involved in reading or writing, by choosing their own forms of outward appearance not necessarily in line with culturally-established dictates, and by speaking up about their own experiences rather than mimicking the dominant cultural voices or even by enjoying their own images not in terms of the other. Through inscribing the reality of their lives into their texts and by giving voice to even their most private and personal experiences, these women have provided us with alternative modes of selfhood and identity.

The mirror's close reciprocity with subjectivity and Weltanschauung, with one's body, voice and agency, is especially evident in the works of two controversial and iconic female poets of the post-Second World War twentieth century, the Iranian Forugh Farrokhzad (1935-1967) and the American Sylvia Plath (1932-1963). A study of their oeuvre reveals remarkable similarities in tone and subject, despite the fact that no link or any sort of influence can be traced between them. Plath did not read Persian and Farrokhzad had no acquaintance with foreign languages at the beginning of her short 
career, beside the fact that both women were hardly known at the time they wrote. They achieved world-wide fame only after their deaths. In their artistic works, Farrokhzad and Plath both draw heavily and with remarkable honesty on their personal, most private life experiences.

Farrokhzad and Plath, who constitute the focus of the research in this book, both faced extreme difficulties in reconciling their own predilections and artistic ambitions on the one hand and the stringent expectations of patriarchal culture on femininity on the other. Their troublesome marital lives had devastating impacts on their psycho-emotional states and both their marriages ended in divorce. They experienced mental breakdowns over and over again and were hospitalized in psychiatric clinics where they both underwent electroconvulsive therapy. They both exhibited selfdestructive behaviour in several suicide attempts and they both died young, in their early thirties. Farrokhzad and Plath were incessantly tortured by the extreme discrepancy they realized between their self-image as artists (containing their ideal image) and the images of true womanhood that their culture continuously and systematically forced on them. These disturbing discrepancies are portrayed meticulously and with marked vivacity and candidness in their highly subjective works. The clashing confrontations between their self-image and the cultural image of womanhood, as well as their constant adaptations of images and identities, are documented most markedly through their encounter with their mirror images as well as through their employment of mirror metaphors.

This study consists of three chapters. In Chapter One a general overview is provided of some of the most dominant mirror imageries and the most influential theories on the mirror and the phenomenon of mirroring. It is against this backdrop that I will locate the individual experience of these female poets, Farrokhzad and Plath, with their mirror. The analysis begins with a study of two popular myths, that of Narcissus and Echo and that of Medusa, both of which have mirroring and gaze as their locus. Ovid's myth of Narcissus and Echo, as presented in his Metamorphoses, is the first significant example of specular self-imagery and the consequences of self-recognition, or even misrecognition, in literature. Ovid, who became a canonical author over the centuries, had an extensive influence on Western thought. Ovid combined the two meanings attributed to the mirror, vanity and cognition, in his male character Narcissus. He also combined the story of the male Narcissus with that of the female Echo, recognizing their common theme of doubling and the inseparable dynamics of one's self-image and one's voice. After reflecting on the myth of Narcissus, I will move on to 
another myth in which the mirror, reflection and immobilizing gaze are key elements: the Medusa myth. These two Greek myths have both descriptive and prescriptive functions, portraying the already existing cultural views as well as further solidifying those views.

Thereafter the two most influential pertinent theories in psychoanalysis are succinctly addressed: Freud's theory on narcissism and Lacan's theory about the mirror stage. Moreover, I will study the mirror's spatiotemporal feature, which renders it into an ideal metaphor for the memory and imagination. I will further link the mirror of memory/imagination to the motherdaughter reciprocal mirroring, their merging of identities and women's fearful anticipation of old age, degeneration and death. Finally, in this chapter, the similar functions of text and mirror as subjective semiotic modes are discussed. Both mirror and text provide women with a means of selfrepresentation as well as self-construction. When women existentially need reflectiveness, objectification and assertion of the self, especially in a context where no other means of proving that existence is left open to them, texts and the mirrors can supply this interchangeably. The mirroring function of the text becomes undeniably evident in the autobiographical writings of women when the experience of the self is translated into the textual self. Although all the myths and theories discussed in this chapter have emerged in the West, they can be drawn upon (maybe with a few exceptions in detail) to penetrate deeper into the intricacies of Farrokhzad's metaphoric use of the mirror, as I attempt to demonstrate in the following chapter.

In Chapter Two, I will study Forugh Farrokhzad's use of mirror imagery and the psychology of mirroring in her poems. In her poetry, Farrokhzad employs two of the most recurrent mirror imageries of classical Persian literature, namely the mirror as an eye and the mirror of the heart, which is used in a mystical as well as in a non-mystical sense. Farrokhzad's desperate search for an authentic subjectivity and voice, and herstory of turbulent personal and artistic development, a chronicle of subject in process within her mirror-text, is discussed. Her mirror imagery reveals how she sets out on a lonely, tempestuous quest for an authentic self image; initially departing from psycho-emotional captivity to the male gaze and the internalization of the images of womanhood imposed by her culture, and then moving on to her symbolic desire to break that mirror and set herself free. In her process of becomings, Farrokhzad passes through troubling times when she is frightened by the otherness of her image. The monstrous grotesquery of her image is caused by the distance she keeps from her culture's established figurations of womanhood. In her quest for the self, Farrokhzad ultimately 
reaches a stage where she acknowledges the mirror's powers in granting self-consciousness. Now she can openly acknowledge the mirror's power in constructing the emancipated subject. Farrokhzad also draws on the temporal and virtual features of the mirror when adopting it as a metaphor for the memory and imagination. She also reveals her initial ambivalent feelings towards her mirroring of the image of her mother and her adaptation of her mother's face, identity and life story. Farrokhzad ultimately hails this mutual mirroring and merging with the mother in her mirror. Finally, the text, for Farrokhzad, functions like her mirror. The mirror-text becomes not only a site for searching after and representing her true self but also a site for reconstructing it.

In Chapter Three, I will study Sylvia Plath's aesthetic use of her kaleidoscopic mirror images. I attempt to show how these ambivalent images can give us a portrayal of Plath's tumultuous herstory of relating to her own image and to those beyond her. Plath draws upon some of the most recurrent mirror images associated with womanhood from the repertoire of classical English literature, one of these being the mirror as a powerful and dangerous tool in the hands of envious witches and femmes fatales. ${ }^{15}$ Plath also employs the popular image of the barren woman as a spider trapped within her own web of solipsism, a cultural idea that is further promoted by Freud. Plath aesthetically portrays the brutality of male Narcissa and how they can immobilize women by turning them into their own flat mirrors in which they can see only a delusive reflection of themselves. Plath's wielding of the images of reciprocal mirroring between mother and child is also studied. Like Farrokhzad, Plath unveils a fearful resentment towards the adaptation of her mother's face and the merging of identities through an image dislocation that takes place within her mirror. In this chapter, some examples of Plath's encounter with her contradictory mirror images are analysed. The faces in Plath's mirrors leave Plath and her readers with an overwhelming shock due to their terrifying alienated otherness, their grotesque monstrosity as well as their turning into a coveted desirable object of gaze - a radiant Venus.

In the Conclusion, I weave together the mirror images of Forugh Farrokhzad and Sylvia Plath studied in Chapters Two and Three. I discuss their commonalities and their differences, as well as the implications of these for further research. Finally, at the end of the book, I include an appendix in which readers may find the complete version of those poems of Farrokhzad quoted in part in the text together with my translations of them. Some of these poems have been translated for the first time. 



\section{Mirroring in Mythology and Psychology}

\section{“I am That!": Doubling in the Myth of Narcissus and Echo}

Ovid's myth of Narcissus falling in love with his own image and pining away, depicted in Book 3 of his Metamorphoses, is one of the first great mirror tales ever recorded. The myth manifests this classical poet's deep understanding of the psychodynamics of mirroring, echoing, the limits of self-knowledge, and the probable-even fatal-consequences of self-realization.

Narcissus is conceived out of divine violence when the river God Cephisus ravishes the fair water nymph Liriope. Shortly after a boy, Narcissus, is born, Liriope takes counsel of the blind, unerring sage, Tiresias, to find out whether or not her son will reach old age. Tiresias answers that he will have a long life if he never knows himself: "If he shall himself not know." Paradoxically, self-knowledge in this case will be fatally destructive for Narcissus. It is paradoxical in the sense that the very popular imperative wisdom of the Delphic god of light, healing and prophecy, Apollo, was "Know thyself." ${ }^{2}$ Tiresias's parody of Apollo's imperative becomes an intertextual mystery calling for an exegesis which will only be provided later in the story. Narcissus grows up into a wonderfully beautiful vain young man, whose callous pride makes him inaccessible to all his female and male suitors.

Apparently Ovid was the first to bring the two stories of Echo, a vocalis nymphe (voiced nymph), ${ }^{3}$ and Narcissus together, shrewdly recognizing their common theme of doubling, and the direct relationship between one's self-image and one's voice; echo is indeed an aural reflection, while reflection is a visual echo. The goddess Juno punishes the wood nymph Echo for using her voice in conspiracy against her. Echo is robbed of her speaking power as a transformation punishment-where the mode of punishment inflicted is metamorphosis. Echo can no longer be the originator of her voice. She can only speak, 
If any other speak and cannot speak

Unless another speak, resounding Echo.

Echo was still a body, not a voice,

But talkative as now, and with the same

Power of speaking, only to repeat,

As best she could, the last of many words.

... when speaking ends,

All she can do is double each last word,

And echo back again the voice she's heard. ${ }^{4}$

Echo is not the agent of her speaking act. She has no originality in her voice. All she can do is to repeat the last words her ear catches. One day Echo sees Narcissus wandering alone in a dense secluded forest and falls in love with him right away. She grows warm with love and follows him secretly. Echo longs to reveal to Narcissus her love,

... but nature now opposed;

She might not speak the first but-what she might-

Waited for words her voice could say again. ${ }^{5}$

Eventually, taking up and doubling the final words of Narcissus, who was searching for his party, Echo can declare her love for him. As with the rest of his lovers, Narcissus cruelly spurns her. "Shamed and rejected," Echo hides in the woods and pines away in her unreciprocated love. Echo, who initially had a visible body and a voice of her own, now finds her body turned into stone and all that is left is her mimetic voice: vox manet. "Only her voice and bones are left; at last/Only her voice, her bones are turned to stone."6

On the other hand, Narcissus, who is doomed by the same misery of unrequited love, sees himself in a placid pool and falls head over heels in love with his own reflected image. The reflected image in the pool precipitates Narcissus to develop a desire, a hope-"A hope unreal and thought the shape was real."7 Narcissus gazes into his own eyes in the pool and burns for union with his image, "That false face fools and fuels his delight." ${ }^{8}$ arcissus is so in love with his own image that he cannot leave it for a second. He becomes fixated to that place, peering into the water all the time. At some point, Narcissus abruptly realizes that the image is none other than his own, uttering: Iste ego sum: "I am that." Despite this epiphanic selfrealization, Narcissus still remains enthralled, unable to leave his reflection in the water: 
Oh, I am he! Oh, now I know for sure

The image is my own; it's for my self

I burn with love; I fan the flames I feel. ${ }^{10}$

Surprisingly this knowledge does not release Narcissus from his perpetual fixed gaze. He does not leave his image in the pool for a moment, not even to rest or eat, and gradually melts away in grief. Meanwhile, Echo observes his misfortune and pities him, but all she can do is to repeat his despairing lament "Alas" and "alas! The boy I loved in vain!", as well as his final word of defeat: "farewell." ${ }^{11}$ At the end of Ovid's story, there remains nothing of Narcissus's body but a flower, "White petals clustered round a cup of gold!" and the nymphs called this blooming flower by his name, Narcissus. ${ }^{12}$

The figure of Echo as a marginalized feminine character with an unauthentic or "non-originary" voice, as Spivak calls it, has been understandably appealing for feminist critics in their uncovering of the historically marginalized position of women and their voicelessness, a position de Beauvoir calls women's "immanence." ${ }^{13}$ Echo is deprived of a voice of her own and is ultimately petrified. This presumably has to do with the fact that the mirror reflects the external appearance, hence the public visibility, of a person, whereas in antiquity women were often kept in the home and were not allowed to appear in public. ${ }^{14}$ In later re-readings of Ovid's myth and the subsequent elaborations of the theory of narcissism, the female Echo has simply disappeared while Narcissus has gained an even more prominent position.

Echo has, in this as in other instances, been relegated to the margins, if not totally repressed. This occurs despite the fact that Echo is actually the mirror image of Narcissus in the sense that they are both linked by an attachment, Narcissus to his self and Echo to the other, i.e., to Narcissus. The latter is fatally consumed by his loving attachment to himself, and Echo by her loving attachment to the object. Narcissus has a grandiose view of himself and is unable to hear the voices of others. Echo, on the other hand, has a fragile sense of self-esteem and is deprived of a voice of her own, and is able only to mimic those of others. Depriving one of one's own voice is a violent act of petrification - an act of robbing her of her own agency and thereby immobilizing her. The bodies of Narcissus and Echo are ultimately consumed by their passionate attachment and transformed into a flower and stone, respectively.

Narcissus's recognition of his specular self in the pool, Iste ego sum! "I am that!" is based on the recognition of the discreteness of the reflected 
image and what he experiences as self; that is the reflected self versus the experienced self. Grosz asserts,

On a global level, the coincidence of the image with the experience of a self (extroception and introception, respectively) is not guaranteed: there is no cenesthesia (images directly projected from bodily zones, organs, and sensations and thus capable of representing them directly for consciousness). ${ }^{15}$

It is this split and discrepancy between the image and the self that initially made Narcissus suffer, leading to his death; therefore, paradoxically, Narcissus was suffering from a lack of self-knowledge, initiated by his image reflected in the water. What makes Narcissus pine to death is the knowledge that the subject and object, active and passive, or "that which introspects" and "that which is introspected," as Nuttall describes it, are never identical and can never be united. ${ }^{16}$ It is only after Narcissus gains the knowledge of this discrepancy, inflicted by a reflecting surface, and the impossibility of its unification, that he utters in agony, "But now we two-one soulone death will die."17 In this story, the mirror paradoxically serves as an instrument for depriving one of self-knowledge. It obstructs one's path to acquiring self-knowledge by giving back a "fooling" metaphoric/metonymic image; an image Ovid calls a simulacra fugacia, "a fleeting image." ${ }^{18}$ Narcissus was in love with his own mirror-image, double, shadow, a "nonobject," "a mirage", as Kristeva calls it: "on the one hand there is rapture at the sight of a nonobject, simple product of the eyes' mistake; on the other, there is the power of the image." 19 Narcissus's attachment to this nonobject image, Kristeva continues, was "the vertigo of a love with no object other than a mirage." ${ }^{20}$ Neither does Kristeva forget to emphasize the overriding power of that delusory image.

On the other hand, Echo has no original reflection of her own; neither specular or vocal, nor mental; therefore she has no agency or selfdetermination whatsoever. Narcissus remains her desired object and her ideal self. Echo has no identity of her own. This separateness of her real self from her ideal self proves to be fatal for her. Echo represents feminine subjective annihilation. Meyers further expounds on the nature of Echo's love for Narcissus:

Echo can speak only fragments of Narcissus's prior utterance, is desolate as she witnesses her beloved's lovelorn suffering, but she is powerless 
to prevent his suffering from culminating in death. To be loved by a woman who has no voice of her own is to be loved by an individual whose capacity to deliberate and act is gravely impaired. Narcissus's dying while Echo helplessly looks on dramatizes the insight that a love constituted by one partner's dumb mirroring of the other is a love at risk. ${ }^{21}$

While Spivak reads Echo as "an instantiation of an ethical dilemma: choice in no choice," Mitchell defines Narcissus's position as "confined in intrasubjectivity."22 Spivak describes the Narcissus story as "a tale of the construction of the self as object of knowledge" and elsewhere as "a tale of aporia between self-knowledge and knowledge of others." ${ }^{23}$ For Spivak, this sort of self-knowledge is mortiferous because it is a limited knowledge that excludes the (true) knowledge of others: "Narcissus marks an arrest where there should be a passageway to others or the Other." ${ }^{24}$ And in Narcissisme de vie, narcissisme de mort, Green writes, "Narcissism is the effacement of the trace of the Other in the Desire of the One." ${ }^{25}$ Mitchell also affirms that Narcissus's desire for himself could be fulfilled only in death: "all Narcissus wanted was himself and, as all he wanted was himself, he could only have himself in death - the other half of himself, his own shadow."26 Narcissus has to die because he loves a non-object, a mirror-image of himself, and as Kristeva discusses, Narcissus's "object of love is a metaphor for the subject." ${ }^{27}$ She further explains:

The object of Narcissus is psychic space; it is representation itself, fantasy. But he does not know it, and he dies. If he knew it he would be an intellectual, a creator of speculative fictions, an artist, writer, psychologist, psychoanalyst. He would be Plotinus or Freud. ${ }^{28}$

Kristeva and Andreas-Salomé have both tried to uncover the creative impetus of narcissism; however, they diverge in locating the source of this creativity hidden in the phenomenon. Andreas-Salomé sees narcissism as a function of plenitude, whereas Kristeva sees it as functioning from a void. Andreas-Salomé holds that the ecstatic overflow of the self onto the object of love enables creativity. For her, artists symbolize the "ineffable" plenitude whence the self emerges, and with which narcissism periodically reconnects:

the Narcissus of legend gazed, not at a man-made mirror, but at the mirror of Nature. Perhaps it was not just himself that he beheld in the 
mirror, but himself as if he were still All: would he not otherwise have fled from the image, instead of lingering before it? And does not melancholy dwell next to enchantment upon his face? Only the poet can make a whole picture of this unity of joy and sorrow, departure from self and absorption in self, devotion and self-assertion. ${ }^{29}$

Therefore, the creativity of Narcissus remains a function of void, a negotiation of "the gap between body and image, sign and signification," as well as between the self and the "encompassing, undifferentiated All" from which the self emerges. ${ }^{30}$ Shultz argues that Kristeva believes:

He [Narcissus] lives in all the poets and lovers who speak in metaphors, who figure a "fake" self in linguistic images or "conveyances of meaning" that muddle the borders between having and being, self and other, subject and object. ${ }^{31}$

Ovid's Narcissus narrative has had an immense and wide-ranging cultural and philosophical influence on the history of Western thought. Though the mythological figure of Narcissus was originally a man, depicting vanity and the fatal lack of knowledge within a male figure, nevertheless the concept of narcissism in Western gender constructions underwent such a radical shift that it was more often ascribed to women as their particular negative tendency. Vanity, lack of self-knowledge and obsession with one's mirror image have become attributes of female figures. This deviation in the trend happened within a more general transformation. Originally the concept of love, the beloved and the definition of beauty in the ancient Greek and Hellenistic world were defined by male homosexuality as the cultural ideal. It was only in later discourse that heterosexist norms became solidified and, along with them, narcissism was reassigned to women. ${ }^{32}$

It is worth mentioning here that the ancient Greek word nárkissos was traditionally connected, by virtue of the plant's narcotic or sedative effects, with nárké, which signifies being astounded, stupefied, benumbed or suffering from torpor. It is worth nothing that to both flower and mirror are attributed a common power of astonishing, stupefying and benumbing. In classical Persian literature, the term narges, referring to the same flower, is invariably a metaphor for the eye, particularly the wide-open or intoxicated and intoxicating eye of the beloved. Due to its whiteness, it may also refer to blindness and the blind eye. Moreover, it has sometimes been associated with jewellery. ${ }^{33}$ Like the eyes, it is often deployed in pairs: in the dual form 
of nargesān (narcissi) or do narges (two narcissi). At times it can also convey a negative connotation of bewitching, fooling and deceit.

\section{The Petrifying Look: The Myth of Medusa}

The acquisition of true knowledge of the self has traditionally been considered an undeniable source of empowerment and salvation. In ancient times, this was made explicit by the aphorism attributed to Apollo, god of light and healing: "Know thyself!" In Islamic cultures, it has circulated in the form of the Prophet's saying: "He who knows himself, knows his Lord." ${ }^{34}$ Paradoxically, this very self-knowledge-virtuous, empowering and redemptional imperative for men-is regarded as extremely noxious if acquired by a woman, especially if she is not guarded or guided by a man. If she acquires self-knowledge by herself, she will be punished by being doomed to having a Medusa-like look:

Without Perseus to hold the Gorgon's head, without the mirror's reflection of woman's submerged evil nature, woman's glance would become the glance of knowledge, of the most dangerous kind of knowledge: knowledge of forbidden things, self-knowledge. ${ }^{35}$

In Greek mythology, Medusa was the only mortal of the three hideous Gorgon sisters. Ancient stories recount that she was originally a woman of striking beauty; a beauty so striking that everybody was arrested by it-hence turned immovable. Medusa was even attracted to herself. When she was impregnated by Poseidon in Athena's temple, the virgin goddess became enraged. ${ }^{36}$ Out of jealousy, Athena transformed Medusa into a hideous creature. Her hair was converted into hissing serpents and the sight of her would turn an onlooker into stone. In the end she was decapitated by Perseus with the help of a mirror-the polished brass shield given to him by Athena. To hide Medusa's head from view and render it invisible and harmless, Perseus buried it in a kibisis, a pouch, a deep hunter's shoulder bag, symbolizing women's repression and their forced invisibility. Later on, Medusa's head was to become apotropaic, being used to ward off evils; evils that the head itself embodied.

In his essay "Medusa's Head," Freud equates the decapitation with castration and explicitly links the fear of castration-as-decapitation to the fear of seeing the adult female genitals, represented in the Medusa myth in the 
form of phallic snakes. He also equates the petrification, caused by the sight of Medusa's head, with male erection. Freud does not fail to locate it within its context of antiquity:

Since the Greeks were in the main strongly homosexual, it was inevitable that we should find among them a representation of woman as a being who frightens and repels because she is castrated. ${ }^{37}$

The story of Medusa has had a great fascination for many feminists, who consider her a sign of primordial, powerful (phallic) womanhood, as well as a sign of emancipation. Society's fear of womanhood and the powers of women, as well as the means it constructed for deflecting that power, are reflected in the Medusa story. Hertz believes that the Medusa figure is "a recurrent turn of mind: the representation of what would seem to be a political threat as if it were a sexual threat." 38 Therefore, to safeguard the hegemonic male knowledge (of the self), essential for the maintenance of the patriarchal order, this feminine threat has to be subdued and punished.

Cixous provides us with a crucial reading of the Medusa myth in her article "The Laugh of the Medusa." This article presents a simultaneous exposition and hence condemnation of women's historical repression through inscribed phallocentrism. Moreover, by emphasizing the powers of écriture feminine, the writing specific to women advocated by French feminists, the article is a call to women to write. Cixous finds the decapitated head of Medusa not only not terrifying and deadly, but also beautiful and laughing: "You only have to look at the Medusa straight on to see her. And she's not deadly. She's beautiful and she is laughing." ${ }^{39}$ There are also some arguments over the association of Medusa with artful eloquence, another female threat to the patriarchal order which requires silencing and punishment. ${ }^{40}$ For Cixous, Medusa represents a subversive figure, capable of disrupting "phallologocentrism," embodied in her laughter. Relying on the two premises of Freud's interpretation, i.e., that fully exposed male genitals signify power, and that Medusa's decapitated head represents female genitals, Cixous argues that men have always tried to conceal and to prohibit a woman's access to her sexual self-knowledge, and therefore, to power. Paparunas elaborates further by invoking the historically metaphorical function of women as mirrors to the male ego:

The woman's look into the glass is not only threatening because she might achieve sexual self-knowledge, thus power, but also, because of 
her function as a reflector of man the glance into the mirror literally visualizes the possibility of losing phallic potency. The look into the glass can hence be read as an apotropaic gesture, at once fascinating and empowering but also intimidating. This double articulation lies at the very heart of the mirror as a visible object and as a figure of thought. ${ }^{41}$

If the female subject is to function as a mirror held up to man, to reflect back his image, then she is and should be on the side of the seen, the gazed-upon, the introspected, not the gazer or the see-er. ${ }^{42}$ In this sense, the woman's function remains pivotal for the male ego to take its shape. Therefore, she has to become effaced and selfless to be able to give him back the face he desires. Once the woman herself is turned into a blank mirror, her looking into the mirror can become dangerous, even deadly, to the male ego.

In the following part, another metamorphosis will be discussed: a metamorphosis of a different nature. I will explain how the myth of Narcissus is metamorphosed into the language of psychoanalysis, developed and propagated by Sigmund Freud in his essay "On Narcissism: An Introduction." Meyers ingeniously calls Freud's and the following psychoanalytic elaborations on narcissism as "the modern mythology of psychoanalytic theory" for the reasons that will be set out below. ${ }^{43}$

\section{From Narcissus to Narcissism: \\ Freud's Psychological Exegesis of the Myth}

It was not until the end of the nineteenth century that a psychological neologism based on the figure of Narcissus was coined and Ovid's mythological story began to be subjected to psychological exegesis. In 1898 the British sexologist Havelock Ellis used the term "narcissus-like" in his article "Autoeroticism: A Psychological Study" to describe a psychological attitude: "a tendency for the sexual emotions to be lost and almost entirely absorbed in self admiration." ${ }^{44}$ Later, in his 1899 review of Ellis's article, Paul Näcke introduced the term Narzissmus for the first time as a clinical term describing a sexual perversion. Translating Ovid's myth of Narcissus into the language of psychoanalysis, Näcke described the term Narzissmus as "in love with oneself" (Selbstverliebtheit) and as "the most serious form of autoerotism." 45 Freud took up this term to present the first coherent theory of narcissism as a psychological phenomenon in many of his essays, mainly in his 1914 
so-called metapsychological essay "On Narcissism: An Introduction." Freud's theory of narcissism has created an immense fascination with the subject and markedly influenced later studies. ${ }^{46}$

\section{Freud's Primary and Secondary Narcissism}

Not only does Freud totally reject the notion of narcissism as a perversion, but he also believes it to be "the libidinal complement to the egoism of the instinct of self-preservation." ${ }^{47}$ Accordingly, narcissism is actually necessary as an intermediate stage, in certain aspects and measures, for the regular sexual maturation of the self and for the sense of self-preservation in the psychological structure of all human beings. This stage must be traversed on the way to full socialization. Human beings develop an image of themselves and they like this self-image, which they try to present to others and defend against any criticism in their act of self-preservation.

Freud believes that infants, prior to the constitution of the ego, are born into an undifferentiated state of perfect and blissful self-love, unable to distinguish between themselves and their environment, other people and other physical objects. They live in an undifferentiated union with their mothers. When an infant feels good (e.g., when he is fed by his mother's breast), he feels that the mother's breast belongs to him; when he feels bad (e.g., when he is hungry), he feels that his own body does not belong to him. This inability to distinguish anything other than one's own feelings and needs leads to primary narcissism, in which the ego is the exclusive object of the infant's love. This primary narcissism makes its early appearance in the infant's sexual and ego instincts-attached to and dependent upon each other in the early stage-by the auto-erotic sexual satisfactions experienced for the purpose of self-preservation.

Freud asserts that the residue of the individual's primary narcissism never fully disappears. It remains one of the three sources of one's selfconcept, a cognitive aspect of the self, related to one's self-image which embraces one's confidence, pride and sense of attractiveness. Self-concept is the sum total of a being's mental and conceptual understanding of his existence and is constructed by his conscious reflections about self-image. Although by the term self one generally means an object, an entity separate from other(s) or from its environment, the perception of the self unfailingly influences one's perception of the world and things in it. In other words, it is impossible to perceive or interpret the world and the things in it independently of one's self-concept. The two other sources of the self-concept are, 
according to Freud, the imaginary perfection of the individual's ideal ego and the satisfaction one gets when one's love is reciprocated.

Later, as the child matures, his libido which was directed inwards towards his ego changes its direction and tends to bind to other objects. This is because, as the child grows older, he begins to learn the distinction between himself and others. That is when the mirror stage-i.e., secondary narcissism-begins: now the child identifies with his mirror-image, i.e., with his external appearance, as it looks to others, and he becomes invested in its mirror-image in the sense that he wants to be what others want it to be. However, there always remains a libidinal economy with a permanent and proportionate relationship between the ego-libido directed inwards and object-libido directed outwards. The increase in one diminishes the other as it is best manifested respectively in autoerotism as well as in the state of being deeply in love, someone whose libido is so cathected in the object that his personality is attenuated. ${ }^{48}$

In defining his notion of "secondary narcissism," Freud states that if the transition from the subject-directed libido to that of the object-directed libido is disturbed in the developmental progress of one's ego, it leads to a regression into the previous phase of introversive narcissism. With the continual persistence of this pattern of regression, the pathological state called "secondary narcissism" or "narcissistic neurosis" reveals itself. Freud defines this "secondary narcissism" in the following manner: "The libido that has been withdrawn from the external world has been directed to the ego and thus gives rise to an attitude which may be called narcissism." ${ }^{49}$ In such cases the self habitually becomes the source of pleasure and gratification; the narcissist prefers this mode of deriving gratification to that of relying on the other objects and thus he remains introverted and self-centred.

Freud further writes that as the child grows he also begins to fight for the mother's or father's attention, regarding others as rivals. This is a major step into culture, and explains why human beings are so concerned with their outward appearance-to draw attention to oneself, to be loved, to be desired. This also reveals why they absorb the norms of behaviour transmitted by authority figures, starting with parents at home and then continuing in schools, religious institutions and so on: children are docile, sweet, and they wish to learn in order to be accepted and loved, and that continues in life-this is the IMAGINARY. It is governed by fantasies, modes of identifications and introjections: identifications with cultural ideas of what the self is and what others are (namely like me or not like me). By consistent exposure to the external intrusion of cultural prescriptions and expectations 
and by the internalization of all these factors, the subject creates an imaginary idealized projected image of himself within himself called by Freud the Idealich or ideal ego. The creation of the ideal ego disrupts the early primary narcissism of childhood. The child who used to love his actual self now evolves to love this ideal ego against which he measures his actual self and aspires towards it. Attempting to fulfill the ideal ego's expectations, the self becomes the source of libidinal gratification.

In the next step the Oedipus complex emerges, when children develop infantile sexual desire: males and females take the parents as sexual objects, but that is of course forbidden by culture, and the parents are usually not interested. This is the moment when children conflict with the Symbolic order of the sexes, and finally submit to this order. Since mothers are physically closer to children, boys concentrate on the mother, experience rivalry with their father whose male body-image they share (the mirror is crucial here), and are afraid of the father's revenge (the phantasy that he might cut off the male sexual organ-castration complex). That is why they give up sexual desire for the time being, identify with the father as the stronger male and develop the cultural identity of a male. When they become adults, they look for a woman as a substitute for the first sexual object, the mother (a relation which Freud calls anaclitic). Male secondary narcissism is thus responsible for the boy's identification with the father, and it remains a strong force throughout life: men are ambitious; they pump iron in order to be attractive to women and so on.

On the other hand, according to Freudian psychoanalysis, when girls reach the oedipal stage, they also take their mothers and fathers as their sexual objects. However, the girl realizes that she lacks the boys' sexual organ-she of course has one, but it is inside the body and compared to a boy she lacks something. This is the condition of the Imaginary which is built on body-images. In addition, there is also the cultural privileging of masculinity, which exacerbates the situation. The girl feels rage at belonging to the less important and apparently physically deprived sex-penis-envy. She gives up the idea of sexually possessing the mother, not out of anxiety about the father's revenge, but out of contempt (the mother is also physically deprived after all). She concentrates her desire on the father.

Moreover, according to the logic of the Imaginary, the daughter must identify with the mother whose body-image she shares (again mirror becomes crucial here). The girl develops a female identity according to the Symbolic Order. Just like the boy, she stops sexually desiring anyone until adulthood, when she will look for a male partner who reminds her of the 
father. However, because she feels physically deprived, as far as her bodyimage is concerned, she will, to a certain extent, always remain fixated on her body-image, compensating for the imagined lack by loving herself, by dressing up, and making it attractive for the male gaze. Female life and sexuality, in Freud's view, always have a stronger narcissistic component than male life and sexuality.

In other words, as the child grows up, according to Freud, primary narcissism takes two different divergent routes, depending on the sex of the child. Men generally develop a complete object-love of an anaclitic or attachment type that leads to an overvaluation of their love object, the impoverishment of their ego and attenuation of their original narcissism. Men often choose their love objects on the basis of resemblance to their original love objects, their mothers. There also exists another type of man which chooses its sexual objects not according to the model of its mother, but according to that of its own self-both types are still considered normal. On the other hand, as women and their sexual organs mature, their original narcissism is intensified, disfavouring the development of their object-choice. In Freud's own words,

Women, especially if they grow up with good looks, develop a certain self-contentment which compensates them for the social restrictions that are imposed upon them in their choice of object. Strictly speaking, it is only themselves that such women love with an intensity comparable to that of the man's love for them. Nor does their need lie in the direction of loving, but of being loved; and the man who fulfills this condition is the one who finds favour with them. ${ }^{50}$

In other words, what Freud says is that it is themselves that women love and they desire to be loved by men; therefore, their sense of love for the other is left undeveloped. In this sense, no man is ever actually loved by a woman. It should also be noted that men find narcissistic women, despite their apparent coldness, care-freeness and cruelty, more attractive, because these women seem invulnerable and self-contained. This is one of the manifestations of the Freudian idea of complete asymmetry between the sexes. According to Freud's gender-differentiating object choice, men are inclined to the active position of loving while women tend to the passive position of being loved. Still, passivity is not assigned by Freud to the same level of importance as self-absorption (as in the case of Narcissus). Here Freud does not ignore the role of beauty of a woman and the socially restrictive 
demands of passivity in the formation of her narcissism. Apparently, Freud does not-at least explicitly-consider beauty as a culturally defined entity. Furthermore, Freud is evidently not criticizing or even questioning those social restrictions. In fact, he believes that this exaggerated female narcissism compensates for those restrictions as a sort of defence mechanism.

Freud finds an outlet for women's narcissism where their libido can be directed to the other. Women can experience love of the other only when they bear children; this love still remains the continuation of their own unquenchable narcissism. Women's parental love for their children, being in some sense a part of themselves, is, for Freud, "nothing but the parents' narcissism born again, which, transformed into object-love, unmistakably reveals its former nature." ${ }^{51}$ One could conclude that in the case of narcissistic woman, according to Freud, there are three options: (a) she longs to be loved by a man, (b) she can bear a child and love that child as a biological part, a specular extension of herself, or (c) she can long for a male love object as a stand-in ideal self.

These three options have been depicted by ample examples in literature. In the first option, there are many literary examples where women recurrently refer to their mirrors in order to check how they appear to the male gaze out of their desire to be loved and to be the object of their gaze. In their mirrors, they are continually involved in the act of creating, recreating and assimilating their outward appearance, mainly through make-up and cosmetic surgery, to attract the gaze of male observers and to conform to their culture's strict definitions of feminine beauty.

The second case is also recurrently portrayed in many literary texts. For instance, women see their offspring, especially their daughters, who carry the greatest physical resemblance to them (as well as sharing a common fate in patriarchal cultures), as the mirror images of themselves. There are also ample examples in literature in which the daughters see their mothers as their mirror images. This Doppelgänger motif between mother and daughter, depicted through the mirror metaphor, is amply represented in our cultural repertoire.

Finally, the third option open to the narcissistic woman is when she identifies and incorporates her lover as her alter ego or ego-ideal, and aspires to catch up with him. This is best demonstrated in the presentation of a woman as a mirror to her male beloved or husband. It is also demonstrated by women's historical echoing of men's voices, and considering everything pertaining to their female bodies and female experiences as taboo or inferior, thus perpetuating their inferior status quo. 
Freud also categorizes four different directions for the love of a narcissist. A narcissistic type may love (a) what he himself is in his present state, (b) what he was before, (c) what he wants himself to be (in accordance with his ideal-ego, including another person who is like the one he wants to be), or (d) finally, someone who was once part of himself, like his children. At first sight, we may consider Ovid's Narcissus to be suffering from the first type of Freud's secondary narcissism, since he loves what he is at present, how he is reflected by the water.

Feminist criticism-Freud's treatment of gender relations and sexuality has evoked harsh criticism from different sides, especially from feminists, gender and queer theorists. Feminists have taken issue with the picture Freud has provided and his assumedly pseudo-scientific language which has been persistently used to push women further into their marginalized subordinate position by dictating what is most natural and normal for them. Feminists argue against Freud's views discussed above mainly for three reasons: first, because Freud seems to accept and propagate the view of femininity as physically deprived. Of course, later Lacan has somehow corrected this: both male and female children experience a lack (they are both unable yet to have sex). There is the mirror-image according to which the girl sees herself as lacking what males have, plus the social privileges accorded to males, which explain why women are envious of males and more narcissistic.

Second, they criticize femininity's representation as a masquerade: women learn to behave as men expect them to be. In this view, female narcissism is primarily a self-protective device, ensuring social acceptance and love. In Freudian definition, as Mitchell observes, a woman's secondary narcissism is in fact "a narcissism of becoming a sexual object-a woman who makes herself beautiful for men." 52 This explains why the narcissistic woman who identifies with her lover as her ego-ideal becomes melancholic when the other, the lover, is absent. Grosz explains that, while the narcissistic woman desperately needs this male "subject to affirm her," she would feel "worthless, a mere fragment of a person," once the male subject becomes absent. ${ }^{53}$

Finally, in reaction to the picture Freud provides, feminists have also argued that women should attack and change cultural values: they should not merely copy male behaviour, male ways of thought, male reason and male voice. Women should proudly honour female ways of talking and thinking as more poetic, less hierarchized, more fluid and more physical. The female look into the mirror can become an invaluable starting-point 
for inquiring both into what one sees and what one does not see, as well as for developing a female mode of writing.

\section{The Subject as an Alienated Construct: Lacan's Theory of the Mirror Stage}

Je est un autre

I is an other ${ }^{54}$

Rimbaud

Jacques Lacan's theory of "The Mirror Stage," argued in his paper "The Mirror Stage as Formative of the $I$ Function as Revealed in Psychoanalytic Experience," has gradually gained such significance that it is now considered by many, including Tallis, as "the cornerstone of Lacan's oeuvre." ${ }^{5}$ This theory is a conflation of Henri Wallon's mirror theory, which maintains that the mirror ordeal forms a crucial stage in the development of the individual's sense of self, and certain ostensibly unrelated ideas of Freud, such as the narcissistic structure of the ego, ideal-ego and Oedipus complex, all founded on his gendered "binary opposition" of anatomical completeness/defect, presence/absence (lack) and the fear of castration/penis envy. ${ }^{56}$ Lacan considered himself Freudian and called his own works an authentic "return to Freud." 57

In his theory of the mirror stage, Lacan emphasizes the essential role of the mirror image in the development of the human psyche. He argues about the cardinal significance the mirror image has in the individual's entrance into linguistic and social identity. Initiated by Freud's conceptualization of the ego as something one is not born with, but that is developed, Lacan holds that the mirror stage is a developmental stage in the formation of the I, or the sense of self. It begins at about the age of six months when the child abruptly recognizes the image in the mirror as his own for the first time. ${ }^{58}$ This recognition is accompanied by a great sense of delight, and it ends at about the age of eighteen months when the acquisition of language starts.

This latter stage marks a crucial turning point in Lacan's tripartite psychic structure: the Real, the Imaginary and the Symbolic. In the earliest stage, prior to the association or (mis)recognition of the self-image as that of self in the mirror stage, the infant lives in an imaginary identity with the mother or the primary caregiver. He has no concept of self or the boundaries separating it from the $(\mathrm{m})$ other. At this stage the infant is unable to distinguish 
between inside and outside, or between the self and the (m)other. The Real continues to remain, after the mirror stage and even after the acquisition of the language, as the irreducible perceptual surplus of "outside world" that resists being turned into language; it does not enter into the realm of the Symbolic.

The recognition and the reactions to the mirror image in the mirror stage reveal the "ontological structure of the human world." 59 Lacan asserts that this recognition is "an identification" in which a transformation comes over the infans marked by:

The jubilant assumption [assomption] of his specular image by the kind of being-still trapped in his motor impotence and nursling dependence-the little man is at the infans stage thus seems to me to manifest in an exemplary situation the symbolic matrix in which the I is precipitated in a primordial form, prior to being objectified in the dialectic of identification with the other, and before language restores to it, in the universal, its function as subject.

This form would, moreover, have to be called the "ideal I."60

Identification, a complex psychological process over which the subject has no full control, signifies the separation between the " $\mathrm{I}$ " and the mirror image or "virtual complex," as Lacan calls it. ${ }^{61}$ In other words, the image and the self are separate entities. It is interesting to note that the Latin term infans literally means "without speech." With the birth of the ego in the mirror stage, the child assumes stability, unity and stature. It also assumes a split between the inside and outside, subject and object, between the self and the (mirror-image) self as other, as well as "between an illusionary stability and unity and a recognition of the power of the other in defining the self," as Grosz articulates. ${ }^{62}$

The lack of perfect correspondence between the child's mirror image or the specular self and his experienced self-with all its impotence and dependency-occurring initially in the mirror stage, reveals "in an exemplary manner the properly imaginary nature of the ego's function in the subject, along with the constitution of the ego's ideal Urbild." 63 The initial dynamic dialectic of identification of the self with his image, along with the internalization of this image and the libidinal investment in it, persists as a perpetual psychic force in the subject. The same process of identification of the self-image inaugurates the subsequent dialectical identifications with, and the libidinal investments in, other things and other persons. 
This marks the beginning of a lifelong process of identifying the self in terms of the other. Ragland-Sullivan maintains that "In fact, Lacan's mirror-stage concept is a metaphor for a mimetic process which occurs in intersocial relations with or without a mirror." ${ }^{\prime 4}$ But this identification, stresses Ragland-Sullivan, is "based on a lie-on a disjunction or asymmetry-whose later effects range from the production of a double as in the Doppelgänger phenomenon, or a bodily disintegration." ${ }^{5}$ Therefore, the self remains, in Grosz's words, "a paranoid and alienated construct." 66 The initial identification occurring in the mirror stage will remain a model for the later relationship between the actual $I$ and its image of itself, between the actual $I$ and the ideal- $I$, and between the $I$ and the other. As understood from Lacan's discussions, the narcissistic identification of the self with the mirror image and the formation of ego function around two opposite poles, affairement jubilatoire, an affirmative and joyful self-recognition anticipating the unity of the image, on the one hand, and connaissance paranoïaque, a paranoiac and frustrating knowledge of the split, alien self, on the other.

The mirror image, as well as the mental image we have of ourselveswhat Freud calls Idealich - will never fully correspond to our actual, physical and emotional being. This ever-present discrepancy between the projected specular image of oneself and what one experiences as self, or one's ideal self and the actual self, reveals the primordial nature of the human subject as psychologically split. It will perpetually disrupt one's experience of one's own existence in many different ways, spurring disappointments, frustrations, anger, or even leading to serious mental disorders.

For Lacan, the recognition of the self in the mirror stage, though essential for the formation of ego, is actually a méconnaissance, a misrecognition. Therefore, as Evans clarifies, "the mirror stage shows that the ego is the product of misunderstanding (méconnaissance) and the site where the subject becomes alienated from himself." ${ }^{\prime \prime}$ It is this process of misrecognition in the mirror stage which inaugurates the Imaginary. Hence the Imaginary constitutes Lacan's version of the ego, which is the structured conception of identity. The Real and the Imaginary are the non-linguistic aspects of the psyche before the acquisition of language and entrance into the realm of the Symbolic, where the individual can refer to himself using the first person pronoun $I$ and express his desires. By entering into the sphere of language, the individual is formed as a historical entity, that is, the child's "specular $I$ turns into the social $I .{ }^{\prime \prime 8}$ Moi declares that "In the Imaginary there is no difference and no absence, only identity and presence," implying that dif- 
ferences and absences all appear when the subject steps into language, into the Symbolic. ${ }^{69}$ Mitchell interprets the "moment of the symbolic" in genderdifferentiating terms:

the point of organization, the point where sexuality is constructed as meaning, where what was heterogeneous, what was not symbolized, becomes organized, becomes created round these two poles, masculine and not-masculine: feminine. ${ }^{70}$

It is the law of the Father which regulates this Symbolic order or the social field through its key signifier-the phallus. The difference between the imaginary phallus and the symbolic phallus should be introduced here parenthetically. The imaginary phallus is the erroneous interpretation by the child of the sight of women's genitalia-namely that a woman does not have a penis and is therefore castrated, something the boy child is afraid may happen to him if he does not obey his father's orders. Of course, other ways of conceiving of anatomical difference between the sexes, such as speculum, are possible. The symbolic phallus, on the other hand, is the signifier of sexual difference in the sense that neither man nor woman has a phallus (as a symbol of imaginary completion); both sexes are characterized by lack (what psychoanalysis calls "castration"). The Symbolic order makes them seek completion by steering sexual desire to a union with the opposite sex (heteronormativity of the symbolic). For Lacan, "phallus" is not an organ or even the symbol of it. It is a signifier-as Grosz clarifies, "the threshold signifier to the symbolic order, and the crucial signifier in representing the distinction between the sexes." 71

The process of identification with one's mirror image, based on a misrecognition, which is of course imaginary, relies on a reference to the Other, divided from the self and "other."72 Although the identification with the mirror image-exterior to the child, frozen and reversed-is necessary for the formation of our sense of self, it leaves the subject with a kind of ever-present sense of alienation or la manqué, a sense of absence or want, because the image is only a sign or a symbol, different from the signifier by which one refers to and experiences oneself. ${ }^{73}$ This sense of lack will continually mark the subject's mode of being. In Mitchell's words, the Lacanian human "subject is split and the object is lost." ${ }^{\prime 4}$ In another place, Mitchell describes this subject as "a being that can only conceptualize itself when it is mirrored back to itself from the position of another's desire." ${ }^{75}$ In other words, the identification with the specular image makes the subject a double of his own double 
and, in order to fill in this unfillable, the subject has to perpetually struggle to establish identificatory relations with others.

The mirror image is metonymic/synecdochic and metaphoric simultaneously. It is metonymic/synecdochic (a subgenre of metonymy) because the mirror image gives an external image of the body, not of the self as a whole. It is metaphoric because it stands in for the self, which is why it marks an alienation. The internal reality of the self and its feeling experience is not revealed in the mirror, although the felt reality can be incompletely approximated by that image. For men and women both, the mirror image is the first in a series of cultural images with which they identify to make sense of their identity (e.g., the different role models for boys and girls).

The act of specular recognition is an intellectual act, implying that the subject has adopted a perspective of exteriority on himself and that it is the mirror that provides for this externalization. For Lacan, the moment of the child's sudden insight in the identification experience of his own image in a mirror is analogous to what Köhler calls Aha-Erlebnis: "to express situational apperception, an essential moment in the act of intelligence."76 In the field of developmental psychology, "situational apperception" refers to the individual's ability to position the image of his physical self within the physical world and in relation to the images of other physical objects.

Before the identification of the self in the mirror stage, the child conceives of himself as corps morcelé, an aggregate; he has a "fragmented image of the body"; $; 7$ what Gallop describes as "a violently nontotalized body image, an image psychoanalysis finds accompanied by anxiety." ${ }^{78}$ With the identification with, and internalization of, the mirror image, the child can for the first time conceive of an image of his body in its Gestalt, a totality as a whole body, a complete singular entity, which Lacan calls "orthopaedic," because this provisional, fictional "I," formed in the mirror stage, functions like a brace, a crutch, a corrective instrument, supporting the subject in achieving the status of wholeness, a stable position which is imaginary and not real. ${ }^{79}$ The infant's encounter with a whole, stable and autonomous self-image presents him with an image of his ideal-I. It is partly because of this imagined coherence and the perception of the image's apparent unity, which the child was hitherto unable to perceive, that the recognition of the mirror image becomes a jubilant experience. The encounter with the noncorrespondent ideal- $I$ is a departure point for a lifelong quest for a perfect correspondence with this ideal-I. But a fear of regression into this earlier 
stage of fragmentary body, or a body-in-bits-and-pieces, may linger on in the form of an inevitable anxiety. This fear may reveal itself in dreams or fantasies of the disturbed subjects in the form of corporeal disintegration, decomposition or dismemberment.

In the very first paragraph of the article, Lacan claims that his psychoanalytical experience of the $I$ function in the mirror stage refutes the Cartesian philosophy of Cogito, and the philosophical traditions born out of it, all based on the idea of "wholism." Descartes' Cogito philosophy is based on his famous "Cogito, ergo sum," or "I think, therefore I am." He used it as a deductive proof of existence; as a method to ensure that existence is indubitable and certain (and can thus escape global scepticism). Descartes' philosophy takes for granted the unified wholeness of the human subject, as a centred autonomous "I" governed by reason. Lacan, following Freud's model of the psyche, which posits psyche as comprised of at least three divided, conflicting parts, rejects the existence of the human mind as a unified whole governed by reason, as implicit in Descartes' argument.

In the Freudian concept of ego, there is no fully self-aware ego in perfect control of itself. Self is not something knowable, and self-knowledge-and thus the perception of one's world-is to some extent an illusion. This illusory self-knowledge is shaped by the desires, fears and aggressions issued from the id on the one hand, and from the injunctions imposed by the superego, on the other. According to Lacan, the ego is not in a position to judge reality because it is developed out of the initial lack or misrecognition of the mirror stage as well as the following misrecognitions. The Lacanian $I$ comes into being through identification with the mirror image-a "captation spatiale," or a "spatial capture"-as well as through an encounter with an exterior entity; ${ }^{80}$ therefore, it cannot correspond to Descartes' inborn and self-contained unit of $I$ in his Cogito. Lacan says, "What we have here [in the mirror stage] is a first capture [captation] by the image in which the first moment of the dialectic of identifications is sketched out." ${ }^{\text {"1 }}$

Finally, Lacan argues that through "subject to subject recourse," psychoanalysis can help the patient by accompanying him to the ecstatic moment where "Tu es cela" ("Thou art that") is revealed to him. Psychoanalysis tries to make the subject become aware of the history of the imaginary images he has of his self, as well as to help him understand the way these images are supported or undermined by the Symbolic order. This is founded on the otherness of the self experience, manifested in Rimbaud's formula, "Je est un autre" ("I is an other"). It means accepting the otherness of the uncon- 
scious, where all of one's experiences that do not fit the imaginary logic of self-identification have been relegated. Psychoanalysis attempts to recover this repressed unconsciousness, which is still participating in a person's conscious discourse. This is exactly what the mirroring can often facilitate. Lacan agrees, but also adds that "it is not in our sole power as practitioners to bring him to the point where the true journey begins." ${ }^{\text {. }}$

\section{Women and the Symbolic Order}

The Symbolic order in most societies (with the exception of some archaic ones) transforms women into less able human beings. They are said to lack rationality, to be weaker in all kinds of ways, which then legitimizes their secondary status and their exclusion from the public sphere. The Symbolic order gives precedence to a "male" idea of language (in the sense of privileging control, sternness and clarity of meaning) over "female" language (chattiness, verbosity and emotional talk). All subjects have to come to terms with these gendered types of language; for both men and women, it involves the loss of a "full" command of language. Nonetheless, men's language is held in much higher esteem, and when women use "male" language (e.g., by becoming professors, doctors, professionals, politicians, etc. etc.), they are looked upon as exceptions to the rule, or regarded as having a masculinity complex.

On acquiring this male-dominated language, women experience a linguistic oppression, because they have no share in the development of the language of the Symbolic order. Women experience a constant conflict between the Symbolic order, instated by phallocentricity, and the repressed space of absence and silence which Kristeva calls "the Semiotic" - the language of the female-dominated Imaginary order. ${ }^{83}$ Jacobus paraphrases a definition of semiotic as "the pre-Oedipal phase of rhythmic, onomatopoeic babble which precedes the symbolic but remains inscribed in those pleasurable and rupturing aspects of language identified particularly with avantgarde literary practice." ${ }^{84}$ Kristeva tries to change the values of the gendered language, although she leaves the link of these different types of language to gender intact. She claims that certain writers such as Joyce were using the female language. According to Sellers, Kristeva also credits language with being potentially revolutionary in that "Only by listening to what is unspoken,.. by attending to what is repressed, new, eccentric, incomprehensible and therefore threatening to the paternal code, can women hope to disrupt its order and acquire our own voice." ${ }^{85}$ Mitchell, too, attempts to 
uncover the political implications of the phallus as a signifier. She asserts that the rule of the phallus can only be challenged by a new symbolism,

from within an alternative symbolic universe. You cannot choose the imaginary, the semiotic, the carnival as an alternative to the symbolic, as an alternative to the law. It is set up by the law precisely as its own ludic space, its own area of imaginary alternative, but not as a symbolic alternative. So that politically speaking, it is only the symbolic, a new symbolism, a new law, that can challenge the dominant law. ${ }^{86}$

Lacan defines the function of the mirror stage as, "a particular case of the function of the imagos, which is to establish a relationship between the organism and its reality-or, as they say, between the Innenwelt and the Umwelt." Innenwelt is the imaginary interior space that the "I" occupies and is to a great extent structured by the unconscious, while Umwelt is the external physical world, in which the living human subject is situated, which also could be translated as "environment." Therefore, the alienated, frozen and reversed image in the mirror serves to relate these two dialectical worlds, to bridge the subject to the world and to lay the groundwork for the formation of identity and social acculturation.

In terms of women's experience, their Umwelt is constituted by the "figurations of womanhood," by cultural images of women, systematically enforcing them into the strict definitions of womanhood..$^{88}$ Women are under constant tension, struggling to effect a compromise between these two often conflicting worlds. Since the mirror image functions as a bridge, linking the Innenwelt with Umwelt, the constant clash between these two worlds, with its cultural figurations of womanhood on the one hand and the opposing reality of women's experienced self and their inner desires on the other, manifests itself best within the mirrors of these women.

For women, the contradictions between the imaginary images they have of their selves and the images the phallocentric symbolic order systematically forces them into adopting or shedding appear conspicuously exacerbated. The incompatibility of women's experienced self and their ideal self on the one hand, and the culturally provided "feminine" self-images with its offers/demands, for instance to adopt motherhood, to acquire an education, a job and a public role on the other hand, led to a marked psychological sensitivity and a need to come up with solutions. This incompatibility of the individual self-image and the cultural presentations of femininity may lead 
to perceptual distortions, where one's experienced self does not conform to her perceived self. ${ }^{89}$

It should be noted that the "orthopaedic" body image-that totalized image of the self-is provided by the eye and the sense of sight. It is the supposed simultaneity and synchronicity of the sense of sight that can provide this totalized view. Other senses, auditory, olfactory, tactile, and gustatory, according to Lacan, can only lead to an aggregate or the body-in-bits-andpieces view of one's self. Therefore, a direct dialectical relationship between the eye and the subject, or the eye and I, is posited. Lacan's theory of the mirror stage, in complicity with his other works and also the works of Freud, is considered ocularcentric for its vision-centredness.

Feminist psychoanalytical theorists criticize these narratives as scopocentric, for constituting subjectivity through the act of seeing, as well aspolitically significant-for exercising power through the act of gazing. They attempt to reconceptualize other narratives for the formational process of identity. Cixous and Irigaray are concerned with accounting for it by undermining the idea of woman as castrated (discussed above). Cixous describes Freud's and Lacan's theory as "voyeur's theory" for its emphasis on the exteriority and on the specular. ${ }^{90}$ On the other hand, Irigaray in her doctoral thesis, Speculum of the Other Woman, proposes a speculum against that of a flat mirror. ${ }^{91} \mathrm{~A}$ speculum-a concave mirror usually used by dentists and gynecologists to examine body cavities-not only helps us to see, but also touches on what is being watched; hence, it is turned into women's "intimate mirror." 92

Ettinger joins with Irigaray in exposing the hitherto ignored significance of touch and kinaesthetic sensation in the human psyche, particularly in the process of ego formation..$^{93}$ Here it is noteworthy that from all the perceptive senses, it is only vision that marks a sense of "spatialization" and, therefore, a schism between the subject and the object, the I and the other: "Vision performs a distancing function, leaving the looker unimplicated in or uncontaminated by its subject." ${ }^{\prime 4}$ Vision can provide access by the subject to the object without necessitating any contact. ${ }^{95}$

Lacan's theory is also criticized for basing a subject's sense of self, as well as his sense of reality/environment, upon a méconnaissance, an erroneous cognitive act which denies the multiple dependencies of the self on others and on the environment. It obscures the emotional complexity of human psychological development by reducing the complex emotions into a relatively simple cognitive act, performed in relation to a visual image. As Gallop marks, the "mirror image becomes a totalizing idea that organizes 
and orients the self." ${ }^{\prime 96}$ This theory also makes alienation and the detachment of the self an unavoidable norm. That is why Irigaray calls Lacan "a master of specular profit and alienation., ${ }^{97}$ Gallop explains further:

The social self (self tainted by the world) is grounded in the specular self (assumption of the fictionally solid, cohesive body-total shape, well defined and firm). Alienation/violation cannot be avoided without calling into question the specular self, the fictional unity of the body ${ }^{98}$

Hitherto the spatial dimension of mirror and the mirroring phenomenon has been sufficiently accentuated. As demonstrated above, the Lacanian $I$ is brought into being by identification with the mirror image through its "captation spatiale," or "spatial capture." 99 Moreover, while criticizing the theories of Freud and Lacan for their inherent ocularcentricism, it was mentioned that "spatialization" remains the significant sense provided by vision. The temporal dimension of the mirror, though entailed in all the above discussions of the mirror, needs some more explicit emphasis.

\section{A Spatiotemporal Site of Psychological Interiority: Memory as a Mirror}

The mirror phenomenon contains both dimensions of space and time simultaneously. Psychological interiority also constitutes the dominant characteristic of this spatiotemporal site. ${ }^{100}$ The mirror is an ambivalent space of reality and virtuality, duality and contradiction. It is where the dyadic relationship between the real and virtual is negotiated. Relying on the spatial extension of the mirror, Foucault analyses the double function of it as the utopia and heterotopia in the following terms:

In the mirror, I see myself there where I am not, in an unreal, virtual space that opens up behind the surface; I am over there, there where I am not, a sort of a shadow that gives my own visibility to myself, that enables me to see myself there where I am absent: such is the utopia of the mirror. But it is also a heterotopia in so far as the mirror does exist in reality, where it exerts a sort of counteraction on the position I occupy. From the stand point of the mirror I discover my absence from the place where I am since I see myself over there. Starting from 
this gaze that is, as it were, directed toward me, from the ground of this virtual space that is on the other side of the glass, I come back toward myself; I begin again to direct my eyes toward myself and to constitute myself there where I am. The mirror functions as a heterotopia in this respect: it makes this place that I occupy at the moment when I look at myself in the glass at once absolutely real, connected with all the space that surrounds it, and absolutely unreal, since in order to be perceived it has to pass through this virtual point which is over there. ${ }^{101}$

Foucault also refers to utopia, and likewise the mirror, in terms of a "placeless place," "no real place" and "fundamentally unreal space," as they both share "a general relation of direct or inverted analogy with the real space." 102 He argues that utopia provides society_containing the individual-with a representation "in a perfected form" or "turned upside down," exactly in the same manner as the mirror provides the individual with his own image. ${ }^{103}$ On the other hand, Foucault calls the mirror a heterotopia, a "counter-site" and "a kind of effectively enacted utopia."104 This hetero-utopian nature of the mirror can probably account for the abundant instances in literature where someone steps into the mirror (or desires to do so) and joins with the ideal/virtual self or world over there.

In comparison with the spatial dimension, the temporal dimension of the mirror has been less studied. Though it may seem that there is simultaneity to our present stance in front of the mirror and the perceived reflected image in it, there is a time factor involved. When a subject poses in front of a mirror, first his glance is directed out of his bodily self towards the mirror in an "outbeat gesture of (usually circumscribed) ecstasis", as Casey formulates it, then the mirror reflects the image back to the viewer, allowing the subject to perceive his image in the mirror. ${ }^{105}$ The outbeat-inbeat gesture of the mirror is what Casey calls the "two-beat temporality" of the mirror. ${ }^{106}$ This move towards the mirror and back takes its own time. Therefore, what the subject perceives is not exactly what his present self is; it is his very near past. Hence any glance into the mirror accommodates a tri-temporal reality: past, present and future. Casey further elaborates:

The glance, despite its ephemerality, implicates all three phases; it arises in the present, but only as a reflection of the immediate past of interest or desire and as foreshadowing the future of current intention. Being tritemporal, the glance constitutes a genuine moment of time, as dis- 
tinct from an instant of time. The instant occurs only in the present; it is the privileged form of the present, privileged because conceived as entirely actual, and actual because occurring as a point, in particular a now-point. ${ }^{107}$

It means that when we glance at our mirror image, our present time is simultaneously and constantly accompanied by our past and our looked-for future. A glance at the mirror brings forth a wholistic temporal summary of past, present and future. Therefore, a look into the specular self grafts onto the present self both the anticipation of the future and the retroaction of the past.

It should also be noted here that there exists no pure self in the present. As a large number of philosophical and psychological studies have demonstrated, what the subject is in her ongoing present is built upon the perpetual accumulation of her past and also on her anticipation of the future. The individual remains a "subject in process" ("sujet en procès"), as Kristeva calls it in her theory of subject formation, emphasizing both meanings of the term "process":

all identities are unstable: the identity of linguistic signs, the identity of meaning and, as a result, the identity of the speaker. And in order to take account of this de-stabilization of meaning and of the subject I thought the term "subject in process" would be appropriate. "Process" in the sense of process but also in the sense of legal proceeding where the subject is committed to trial, because our identities in life are constantly called into question, brought to trial over-ruled. ${ }^{108}$

The subject is continuous and plural. It can only be defined momentarily and relationally in a process of what Deleuze calls "pure ceaseless becoming." ${ }^{109}$

There are ample cases in literature and philosophy in which the mirror serves as a metaphor for the memory. This is because there is a virtuality to the mirror image which is analogous to the reality of the bodily self, exactly in the same manner as there is a virtuality to the memory analogous to the reality of the subject's passing present. As instances of "dédoublement," both mirror and memory provide us with virtuality while our physical presence and our present state and actions remain the realities of our selves. ${ }^{110}$ It is in this sense that the French philosopher, Henri Bergson, associates memory with the mirror, locating them both within the same order: 
Our actual existence then, whilst it is unrolled in time, duplicates itself all along with a virtual existence, a mirror-image. Every moment of our life presents two aspects, it is actual and virtual, perception on the one side and memory on the other. Each moment is split up as and when it is posited. Or rather, it consists in this very splitting, for the present moment, always going forward, fleeting limit between the immediate past which is now no more and the immediate future which is not yet, would be a mere abstraction were it not the moving mirror which continually reflects perception as a memory. ${ }^{111}$

Somewhere else, Bergson explains further:

we feel vaguely that our past remains present to us. What are we, in fact, what is our character, if not the condensation of the history that we have lived from our birth-nay, even before our birth, since we bring with us prenatal dispositions? Doubtless we think with only a small part of our past, but it is with our entire past, including the original bent of our soul, that we desire, will and act. Our past, then, as a whole, is made manifest to us in its impulse; it is felt in the form of tendency, although a small part of it only is known in the form of idea. ${ }^{112}$

In this regard, the mirror image is not a reality; it is a summary of our conceptual image which associates itself with the corresponding representation perceived in the mirror, enhanced with our feelings. The present feeling is built up of the feelings of the past and feelings towards one's future; one's hopes, anxieties and fears in anticipation of the future. Mutability and change is the requisite concomitant phenomenon of temporality, that is to say, any alteration takes its own time and time leads to alterations. We turn to the mirror because we are looking for changes, the insurmountable constant changes we are experiencing at every moment. The look into the mirror helps us to foresee the future changes in our bodily self and our life ahead. Within the mirror the concept of tempus edax rerum (time, that devours all things), visualizes itself vividly. ${ }^{113}$ In an epiphanic moment, the mirror onlooker may realize that he is nothing but time, transience embodied. It should be noted here that the haunting anxiety accompanying the mirror experience is related to both the temporal and spatial dimensions of the mirror. Furthermore, the mirror and mind, both being spaces for visual perceptions, have been turned into a metaphor for each other. Shengold discusses that the mirror, in fact, "can represent a working model of the mind."114 
For the adult spectator, the look into the mirror does not function in the same manner as the primordial identification of the child in the Lacanian mirror-stage of his ego-formation, but it brings forth a reidentification, to see if he still looks like the person he last looked at and to trace the visible alterations. Moreover, the person who perceives his image in the mirror is not the same person before the act of perception. Now the self is refashioned by that perception, by his interpretation of that specular image which remains to some extent always distorted.

Though it may seem paradoxical, the mirror reflection, like memory, is psychologically internal to the subject. ${ }^{115}$ Therefore, like the mirror, memory has the potential power to facilitate the emancipation of the self: "Memory is not exactly the site of freedom, but the layering of identity and memory is the only basis for moving forward through time." 116 This is mainly because for the individual's freedom it requires all tritemporality, i.e., the present and the anticipated future which are built upon the personal past history. Many poets, including Farrokhzad and Plath, had a thorough-going familiarity with the mirror's temporal dimension and its ability to summ up past, present and future simultaneously. Farrokhzad and Plath have portrayed the temporality of the mirror figuratively in their works.

\section{Mother-Daughter: The Mutual Mirroring}

The temporality of the mirror, its capacity to depict the passage of time, is central to the theme of reflection of the mother in the mirror of the daughter in her continual process of becomings. Many female writers have expressed their astonishment, as well as their resentment, at becoming an image of their mothers. Instead of seeing their own image in their mirrors, they have encountered their mothers' reflection in it. This image dislocation implies the inevitability of taking on the mother's identity and her fate by the daughter, where the cultural forces push women into a homogeneous image of womanhood considered as the norm. Gallop writes about the female subject's "obligation to reproduce," both in terms of giving birth and in terms of reproducing the mother's story. ${ }^{117}$ This inevitability also implies the powerful hold of the mother agent on her daughter. The daughter usually views this hold with despair and resentment and struggles to free herself from it.

The daughter's ambivalent desire for the pre-oedipal relationship with her mother, as Irigaray calls the "archaic desire between the woman and the 
mother," has two dimensions: the mother who is now the rival and at the same time the object of her desire. ${ }^{118}$ De Beauvoir observes:

The daughter is for the mother at once her double and another person, the mother is at once overweeningly affectionate and hostile toward her daughter; she saddles her child with her own destiny: a way of proudly laying claim to her own femininity and also a way of revenging herself for it. ... she [The daughter] imitates her mother and identifies herself with her; frequently she even reverses their respective roles. ... the real child is also an alter ego for the mother. ${ }^{119}$

On the one hand, this desire promises an empowering union with the mother, in which they can provide each other with comfort and support. This kind of comforting support cannot be provided by anybody else, because of the mother's and daugther's exclusive access to a common knowledge and common experience. Rich claims that the mother and her daughter share "a knowledge that is subliminal, subversive, pre-verbal: the knowledge flowing between two bodies, one of which has spent nine months inside the other." 20

On the other hand, unity with the mother may lead to an effacement of the daughter, the elimination of her individuation and her total dissolution in the identity of the mother. Therefore, through unity with her mother, the daughter may risk her identity as a separate and independent entity; since, as Rubenstein observes, the "ego boundaries between daughter and mother are often merged." ${ }^{21}$ This mainly happens in women because, as Chodorow puts it, a female subject's "experience of self contains more flexible and permeable ego boundaries." 22 Chodorow continues by defining the female's sense of self against that of males in the following words: "The basic feminine sense of self is connected to the world, the basic masculine sense of self is separate." 123 Consequently, the daughter often becomes the very extension of the mother, her replica with only a lapse of time in between. La Belle remarks, "The daughter is in part a genetic replication of the mother, a biological mirroring that can be signified by the image in the glass." ${ }^{24}$ And this "very continuity of identity with the mother" is, according to Flax, "a central problematic in female development." ${ }^{25}$ It has become problematic because "the development of women's core identity is threatened and impeded by an inability to differentiate from the mother." ${ }^{126}$ It turns problematic also because this pre-Oedipal dependency on the mother functions as an encumbering dependency, preventing the daughter "from discovering 
her own body as other, different," as Kristeva argues. ${ }^{127}$ Furthermore, the situation remains ironic as long as the development of one's discrete identity from that of mother's is initiated by the reflection of the self in the mother's eyes, regarded as the infant's first mirror. Shengold argues, "Individuation develops from the situation of mirroring that starts with the first reflections of the infant in the mirror of its mother's eyes." ${ }^{28}$

The obliteration of the ego boundary and the effacement of identity will ultimately turn the daughter into "a completely petrified being," as Irigaray notes in her essay with a highly suggestive title, "And the One Doesn't Stir without the Other." 129 There, the speaker addresses her mother, pleading for a release from her paralytic engulfment. Irigaray astutely depicts the broad overlap of the daughter's selfhood with that of her mother; as well as the intertwined interaction of her narcissistic self-image and her authentic voice. The speaker not only reflects an image of her mother, but also echoes her voice-aural mirroring:

You look at yourself in the mirror. And already you see your own mother there. And soon your daughter, a mother. Between the two, what are you? What space is yours alone? In what frame must you contain yourself? And how to let your face show through, beyond all the masks? ... There's just a pause: the time for the one to become the other. ${ }^{130}$

The speaker claims that she and her mother are like "living mirrors," involved in a continuous and endless exchange of selves. ${ }^{31}$ The daughter continues by revealing her strong resentment at the mother's grip on her and at the bereavement of her image and voice: "You [the mother] put yourself in my mouth, and I suffocate."132 The losses of one's self-image and one's authentic voice remain inseparable. This is also reminiscent of what Jung, in his essay "The Psychological Aspects of the Kore" observes:

Every mother contains her daughter within herself, and every daughter her mother, and that every woman extends backwards into her mother and forwards into her daughter. This participation and intermingling give rise to that peculiar uncertainty as regards time: a woman lives earlier as mother, later as a daughter. The conscious experience of these ties produces the feeling that her life is spread out over generations. ${ }^{133}$

The temporality of the mirror is instrumental in the realization and expression of any alteration coming over a subject. When a female subject encoun- 
ters her mother's image in the mirror, this image dislocation can indicate the alteration that has already taken place in the past, or which is taking place in the present in her process of becoming, or it can even be a foreshadow of a metamorphosis which will be happening to her in the future. In this sense, the mirror is endowed with prophetic powers. It turns into a cognizant catoptromantic mirror in the hands of a female subject; a surreal omniscient surface by means of which she can traverse the limits of time and space. ${ }^{134}$

The female subject's prophetic mirror carries with it the forebodings of the coming of age, loss of youth and beauty, degeneration and death. The daughter's fear of a total loss of selfhood in that of her mother often leads to a broader fear, which Sukenick terms "matrophobia." ${ }^{135}$ Matrophobic women often feel a strong aversion to "the claims of emotion," and to whatever is regarded as feminine in their selves. ${ }^{136}$ They believe that these so-called feminine qualities force them into an utter effacement and self-nullification in their repetition of their mothers' and grandmothers' images. Rich provides a definition of matrophobia as follows:

Matrophobia can be seen as a womanly splitting of the self, in the desire to become purged once and for all of our mothers' bondage, to become individuated and free. The mother stands for the victim in ourselves, the unfree woman, the martyr. Our personalities seem dangerously to blur and overlap with our mothers'; and, in desperate attempt to know where mother ends and daughter begins, we perform radical surgery. ${ }^{137}$

Irigaray is, indeed, perceptive in her play with the mirror in its different facets. She reveals the mother's lack of selfhood by claiming, "Furtively, you [the mother] verify your own continued existence in the mirror," as if without the mirror she would have no other proof of her existence and no identity beyond that reflected image. ${ }^{138}$ This is exactly what is expected from her in society; to be a flat image which can be presented to the world in its totality. Therefore, the daughter inevitably becomes "the uninhabited region of your [her mother's] reflections." ${ }^{39}$ The mother desires a reflectiveness; a reflection of her own which she has been systematically denied in the patriarchal culture. The only outlet she can find for this reflectiveness of herself remains within her daughter, a double, a repetition of herself. In reflecting the mother's immobility, the daughter herself becomes immobile, a "statue." Irigaray unmasks the despair and at the same time the anger of the daughter at her mother's total lack of personhood and, consequently, 
her own, as an extension of her mother. At the end of her article, Irigaray expresses her wish that her mother had kept her very own subjectivity even after giving birth to her: "And what I wanted from you, Mother, was this: that in giving me life, you still remain alive."140

\section{Mirroring in Text}

Texts have traditionally been considered as mirrors for their reflecting and representing capabilities. The metaphorical image of the text as a mirror has been employed to convey paradoxical meanings. In Europe, the conceptualization of texts as mirrors of their authors was developed by Romanticism (in the second half of the 18th century), which invited the reader to identify with the author and to discover the author's superiority as a genius. Before that, literary texts were regarded as skilful variations of older texts. These texts usually carried a didactic message, with the reader recognizing that the text had implications regarding his moral life. With the advent of Realism in the 19th century, texts were regarded as mirrors of their society. The reader was asked to understand the text as a representation of the social world he lived in, and to identify with the main (positive) characters. ${ }^{141}$

In the author-centred view of the text as a mirror of the author, the text reflects the author's experiences, feelings and thoughts, leaving the reader almost out of the picture. However, in another contradictory meaning, texts have been considered as mirrors held up, not to the author, but to the reader. The author loses his prominent place in this sense and the reader becomes all significant. The early twelfth-century Persian Sufi thinker 'Ayn-ol-Qożāt Hamadānī (d. 1131) succinctly explains the meaning of the text-as-a-mirror metaphor, particularly in poetry, in the following words:

O gentleman! Consider these poems as mirrors, for you know the mirror has no face of its own, but everyone looking at it sees his own face. Likewise, there is no intrinsic meaning in a poem, but rather every reader sees his own present state of mind in it and brings into it his utmost knowledge in its interpretation; and if you say that the poem has a meaning which its poet had intended for it, and that other readers are imposing other meanings from themselves, it is as if someone says the face in the mirror is the face of its initial polisher which appeared on it for the first time. Explicating this concept is so difficult and complex that if I start it, I will digress from my main point. ${ }^{142}$ 
Insisting that the only real face in the text/mirror is the face of its initial author/polisher is indeed what is called "intentional fallacy". The metaphorical meaning of the text as a mirror held up to the reader corresponds to what Reception theory and Reader Response theory publicize and still remains one of the most controversial tenets of post-structuralism. This idea was promoted by Barthes in his 1968 essay "The Death of the Author." Barthes contends that it is not the author who is speaking in the text, but the language itself. Once the text (mirror) is in circulation, the umbilical cord connecting the text (mirror) to the author (initial polisher) is severed and the text (mirror) gains its independence, able to reflect the multiple readers (beholders). Writing, according to Barthes, is "that neutral composite, oblique space where our subject slips away, the negative where all identity is lost, starting with the very identity of the body writing." 143

This is exactly what happens in the mirror and to the Lacanian subject. In this meaning text, like the mirror, can reveal and simultaneously deceive. Furthermore, the different temporality discussed by Barthes has not escaped the perspicacious observance of the Persian Sufi thinker, Hamadānī (discussed succinctly above) in his analogy. Barthes argues:

The temporality is different. The Author, when believed in, is always conceived of as the past of his own book: book and author stand automatically on a single line divided into a before and an after. The author is thought to nourish the book, which is to say that he exists before it, thinks, suffers, lives for it, is in the same relation of antecedence to his work as a father to his child. In complete contrast, the modern scriptor is born simultaneously with the text, is in no way equipped with a being preceding or exceeding the writing, is not the subject with the book as predicate; there is no other time than that of the enunciation and every text is eternally written here and now. ${ }^{144}$

In this study, I am not concerned with this second metaphorical meaning of the text and will concentrate on the first meaning, i.e., the metaphor of text as a mirror held up to its author.

A subject's need for the objectification of his self in order to know, create and express that subjectivity through the medium of the mirror, as well as the psychologically complex interaction of one's narcissistic self and the mirror has been discussed above. There remains another medium through which this self-objectification can be enacted-a text. A subject can enter into the same dialogical reciprocity with her text as with her 
mirror. Therefore, glass and paper (or nowadays computer screen) can be interchangeably used with the same psychological function. Paper (or the screen) can provide the subject with the same medium as glass for the outpouring of the narcissistic self. This becomes particularly manifest when that writing is in the form of autobiography. Text and mirror can function as alternative means for proving and sustaining the female subject's existence. This is because, for any production such as writing, there should be a subjectivity involved and an agent active in the process of creation. Through a sustained act of creation and re-creation, the subject can reassure herself of her continual existence.

On the other hand, a look into the mirror (as discussed earlier) can facilitate a subject's crossing time-lines. Just as can happen in a text, this time-line crossing allows for dreams and fantasies. Moreover, the portrayal of mirror image in one's mirror-text can provide the author with a starting-point for considering, discussing and presenting his identity self-reflexively. Therefore, it is very true that for a woman "poetry is not a luxury"; it can become a desideratum, "a vital necessity". 145

It should be noted here that not many women write or read poetry. However, if women do think about their own identity, they must inevitably consider the social construction of femininity, for which the mirror is a central metaphor; and if they do not keep their reflections private, but make them public and wish to address women in general, then the writing of autobiographical texts may indeed become a necessary element of female discourse.

Texts and mirrors function as the two semiotic modes-the linguistic and the catoptric-for the consciousness and objectification of the self. They are both "subjective semiotic system[s]" available to be read. ${ }^{146}$ Text is indeed a mirror made up of language; it is not visual, but symbolic. Language consists of signifiers which refer to objects that are absent. Therefore, this means that the lack of completion is always already recognized. To reflect on oneself by writing about oneself means to implicitly recognize the lack of one's being and hence the necessity to give it a meaning; to (re)construct and scrutinize one's self from an external position, often retrospectively. However, it is still the self that is reflecting upon himself, making it an imaginary activity.

With the act of mirroring and writing the female subject is actually struggling "to incorporate the signifier [the mirror image/written subject] and the signified [the human observer present in front of the mirror/writing subject] within a totalizing phenomenology of self-consciousness." ${ }^{147}$ By objectifying herself either on the glass or on a piece of paper, the female 
subject can gain knowledge of her self. She relies heavily on this reflectionspecular/perceptive or mental/thought-for her sense of continual existence. This means that the subject can reflect herself both on the glass and on the paper. ${ }^{148} \mathrm{La}$ Belle emphasizes, "Texts and mirrors can perform similar psychological functions for women, particularly during periods in their lives when objectification and consciousness of self becomes necessary." ${ }^{149}$

Through the act of writing, particularly in the form of autobiography, as Olney explains, the author is "bringing to consciousness of the nature of one's own existence, transforming the mere fact of existence into a realized quality and a possible meaning." ${ }^{150}$ To acquire self-knowledge and to present that self to the world outside, the introspected, on the mirror or in text, is introjected into the introspector. By the objectification in their texts, just as in their mirrors, female writers are in fact constructing themselves. Andreas-Salomé observes, "Objectivity is mankind's glorious goal, summoning narcissism, Eros masked, from the dreams of childhood to the service of research, progress, art and culture." ${ }^{151}$ She further claims that "the compulsion toward objectification in narcissistic identification is the foundation of all creativity."152

This very act of writing, for the female subject, has often become a repudiation of patriarchal law and its rigid definition of sexual difference, which excludes women from involvement in the writing and intellectual spheres; a repudiation which sometimes leads to the stigmatization of them as mad women. ${ }^{153}$ Particularly in the twentieth century, women's autobiographies became a major medium for criticizing patriarchy, because those authors were not content with their enforced self-images or their role in society. They felt the contractions of twentieth century womanhood. Their self often became insecure, vulnerable or they may even have experienced anxiety, paranoia and so forth.

Therefore, writing an autobiographical text for a woman may turn into an inscription of the gendered history of the subject's anxiety in the process of continual becoming and the incessant adoption of identities. Butler argues that the identity, like the ego, is something to be produced and developed. Identity is a dynamic "effect," constructed during social processes and it is not universalized, "foundational" and "fixed." 154 The identity is gendered because every experience and every personal history is gendered. Mitchell argues:

I do not think that we can live as human subjects without in some sense taking on a history; for us, it is mainly the history of being men or women 
under bourgeois capitalism. In deconstructing that history, we can only construct other histories. What are we in the process of becoming? ${ }^{155}$

The female writer may go through the anxiety of reconciling the powerful and recurrent self images with which her society incessantly bombards her, and her very own authentic images. These social images position her on the side either of an angel or a monster-a binary opposition. However, a construction of one's very own genuine self, untouched by society's images and by the "cultural noise pollution," in Meyers's words, would be impossible. ${ }^{156}$ The chaste authenticity of one's self-image and the autonomy of one's writing or voice can only happen in a virtual "placeless place" - a utopia. Gilbert and Gubar discuss this in their influential work The Madwoman in the Attic:

Before the woman writer can journey through the looking glass toward literary autonomy, however, she must come to terms with the images on the surface of the glass, with, that is, those mythic masks male artists have fastened over her human face both to lessen their dread of her "inconstancy" and-by identifying her with the "eternal types" they have themselves invented-to possess her more thoroughly. ... a woman writer must examine, assimilate, and transcend the extreme images of "angel" and "monster" which male authors have generated for her. Before we women can write, declared Virginia Woolf, we must "kill" the "angel in the house." In other words, women must kill the aesthetic ideal through which they themselves have been "killed" into art. And similarly, all women writers must kill the angel's necessary opposite and double, the "monster" in the house, whose Medusa-face also kills female creativity. ${ }^{157}$

Talking about journeying through the looking-glass (in an allusion to Carroll's book Alice in Wonderland), Gilbert and Gubar imply that women must shatter their fixation on the male gaze and social constructions of femininity-not to discover an authentic self, but rather to rearrange the shards of the broken mirror to come up with a different idea of self. In fact, writing can provide women with a heterotopic space, in some sense utopian, where they can enact their marginalized position, their desires, their experiences and their bodies, which they have been forbidden to do in their real socio-cultural space. Therefore, women's existential need for writing themselves into their texts and giving voice to their own experiences is as much political as psychological. ${ }^{158}$ 
For Farrokhzad and Plath, as well as for many other women, self-realization remains in a close relationship with their self-narration. For them, productivity in the form of writing becomes a matter of survival; and nonproductivity equates with non-existence. This is also because, as Cixous explains in her famous manifesto on feminine writing, "The Laugh of the Medusa," women write from, and gain strength through, the unconscious. Cixous maintains:

To write. An act which will not only "realize" the decensored relation of woman to her sexuality, to her womanly being, giving her access to her native strength; it will give her back her goods, her pleasures, her organs, her immense bodily territories which have been kept under seal; it will tear her away from the superegoized structure in which she has always occupied the place reserved for the guilty (guilty of everything, guilty at every turn: for having desires, for not having any, for being rigid, for being "too hot"; for not being both at once; for being too motherly and not enough; for having children and for not having any; for nursing and for not nursing ...) - tear her away by means of this research, this job of analysis and illumination, this emancipation of the marvelous text of her self that she must urgently learn to speak. ${ }^{159}$

Cixous's remark grounds women's writing in culturally repressed spaces or, at the very least, minoritized as second best, or deficient compared to accepted, male-dominated modes of self-expression.

Among the different literary genres, poetry appears to be the most privileged form for the creation, recreation and also presentation of the "subjectin-becoming" or the Kistevan "subject-in-process." Melchior-Bonnet observes:

Poetry, like the mirror, restores symbolic activity, and far from turning its horn against itself, like the unicorn before the mirror or the subject of the poem, it is nourished by "the possibility of being." ${ }^{160}$

Furthermore, poetry is a fragmented piece, with separate and ostensibly irrelevant units, which makes it an ideal form for the presentation of an essentially fragmented self. Poetic language, observes Sellers, also "incorporates the unconscious and body-rhythms in a way other forms of language do not." 161 Thereby, poetry can, more than any other genre, participate in the Imaginary. Robbins explains, "Poetry, with its creative disruptions of gram- 
matical rules, syntax and vocabulary partakes of the Imaginary, even as it also functions within the Symbolic."162 In poetry, particularly in the lyrical variety, the subject can gain a powerful centrality, dominating the whole poem. Therefore, like the mirror, the poem becomes a convenient space for dealing with the subject and its complex problematic. This central "I," in lyrical poetry, can modify every other thing around it, including one's own mirror-image, as Wehinger explains in the following words:

The peculiarity of lyrical diction gives priority to the subject and allows him-as measured by the language of everyday life-the freedom to modify the second person and to speak to all people and objects as well as natural phenomena, or phantoms, not least their own mirror image. ${ }^{163}$

Schenck, stressing poetry's potential as a space, adds, "Poetry as autobiography constitutes a potential space in which a subject may be repeatedly and repeatably present to herself during the act of utterance." ${ }^{164}$ This heteroutopic space of poetry provides the female subject with an alternative means (to that of mirror) by which she can (re)construct voice, body and images of her own creation, which are often totally discordant with the images of womanhood her culture has ordained for her. It is only within this space that she is given the opportunity to reconstruct and to (re)present her own incoherent and split-at times warring-images of selfhood in the process of her becomings. Olney claims: "... by its very nature, the self is (like the autobiography that records and creates it) open-ended and incomplete: it is always in process or, more precisely, is itself a process." ${ }^{165}$ Folkenflik maintains that autobiography is itself a metaphor of the mirror stage; "one can think of autobiography itself as a mirror stage in life, an extended moment that enables one to reflect on oneself by presenting an image of the self for contemplation." ${ }^{166}$

Farrokhzad and Plath have both managed to establish a close narcissistic reciprocal relationship between their subjects and their texts. In their texts, they set down on paper a portrayal of their past experiences, their present feelings and desires, and even their anticipation of the future, often fearful but at other times peaceful. For them, text, like a mirror, is a site not only for the realization and expression of the self, but also for the creation of the self. Poetry as mirror, for both Farrokhzad and Plath, provides a space for directly engaging with their selfs by adopting the three different modes of self-inquiry, self-reflection and self-expression. Hence, the mirror metaphor turns out to be the most appropriate figure-not simply the 
figure of speech, but also the figure of thought. These female authors' need for self-affirmation and social acceptance from within their marginalized position and their struggle to move beyond that position are well reflected in their texts. They inscribe their "subject-in-process" into their texts, and establish an intimate connection between their selfs and their texts. It is pertinent to note that Farrokhzad and Plath have also both tried their hand at drawing their own self-portraits, the study of which would be beyond the scope of this book. 


\title{
Mirror Imagery in the Works of Forugh Farrokhzad
}

\author{
حسن روى تو به يك جلوه كه در آينه كرد

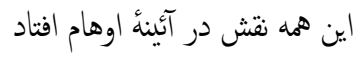 \\ With that one splendor that in the \\ mirror, the beauty of Thy face fell, \\ All these pictures into the mirror of \\ fancy fell. ${ }^{1}$ \\ Hāfez
}

\section{A Herstory of a Subject-in-Process}

In Iranian patriarchal culture, women are systematically robbed of their independent identity and their authentic voice. Like any other patriarchal culture, the Iranian manifestation socializes women to be voiceless and selfeffacing. Women are forced to present an image dictated to them, to act as obedient daughters and wives, and as self-sacrificial mothers. In this process, women have indeed become metaphorized into mirrors, into passive slates with no face or voice of their own; a specular surface reiterating an illusionary image of the other. By systematically expunging their identity, patriarchal culture has turned women into surfaces for bestowing a delusive, copacetic identity on their male associates. In this context, if a woman insists on having any voice at all, that voice must be an echo of already wellestablished patriarchal voices, further entrenching women into their dark peripheral position.

Farrokhzad had to struggle, on the one hand, with the reservoir of contradictory images of womanhood constructed by her dominantly male culture and literary tradition. These images, produced by male imagination and imposed on her, had nothing to do with the reality of women's life and their experiences. For the main part, the treatment of women, and their relationship with men, be it one of love or other, was regarded as way below 
the prestige and register of poetry. As for love, what we mainly have in Sufi literature is either celestial love for the Divine Beloved or love directed to a young (usually unbearded) boy. In Persian literature, this loving relationship between a man and a young boy is called šăhed-bāzi (literally meaning "witness-play"). ${ }^{2}$

In instances where poets start to regard the love between man and woman not as a hindrance to their acquisition of true love, i.e., that of their Ultimate Beloved, but as a step leading to that, they understandably fail to present a real image of woman and her experience in this love relationship. The image of woman presented in the mirror of male poetry remains unreal, distorted and at times reversed-what is happening in the process of presentation is called "the chiasmus of perception." In Persian literature, these images of womanhood hold woman as an ethereal virgin, self-sacrificial mother, totally obedient, face-less, voiceless wife, or hold her as a dangerous, voluptuous prostitute whose deceits should be avoided and suppressed, leaving no place in between for women qua women. ${ }^{4}$

On the other hand, Farrokhzad had to come up with an image of herself, reconciling the contradictory images of womanhood that her age was presenting to her. Farrokhzad was living in a time when Iranians were experiencing rapid modernization-which some historians would later term untimely or too rapid for their society-initiated in the Qajar era towards the end of the eighteenth century which gathered momentum exponentially under the pro-western Pahlavi regime between 1925 and the Islamic Revolution in 1979.

All these transformations had grave implications for Iranian women and the image of womanhood in Iran. ${ }^{5}$ Upper-middle-class Iranians started to know about the situation of women and their activities in the west, mainly through translations and descriptions by pro-western as well as procommunist intellectuals returning from studying abroad. The ban on the hejāb (veil), the modernization of the education system, the establishment of schools for girls and universities, and the growth in the number of available publications had an irrevocable impact on women's lives.

Farrokhzad, who grew up in such an upper middle-class family in Tehran, had to struggle painfully with all the contradictory images of womanhood in her culture. On the one hand, she had to deal with the dual images of traditional woman that her culture and literary tradition presented her with, and on the other hand she was presented with a spectrum of other possible images of womanhood which her culture was still looking at with 
ambivalence, doubt and even great fear. Farrokhzad was tackling these contradictory images, struggling assiduously to reconcile them and to adopt an image of her own.

The meagre number of female poets in the Persian literary tradition clearly indicates the forced voicelessness and invisibility of women in Iranian culture. Nevertheless, Farrokhzad was not completely bereft of any literary grandmothers, mothers or even sisters. ${ }^{6}$ But what makes Farrokhzad a phenomenal poet is her idiosyncratic candour in quest of her image and the frank presentation of her most personal and unspeakable feminine experiences. Farrokhzad not only tries to contradict the law of the Father of her patriarchal culture by having a voice and, more significantly, by voicing her feminine experiences in poetry, but she also tries to adapt the poetic form to her content, thereby stunning and angering the traditionalists in poetry, literature, the press and the prevailing cultural mores.

As Robbins observes, "the speaking subject" remains "a political and politicised subject." Farrokhzad and her poetry are indeed political and politicized. Her poetry, from the very first volume, was regarded as an immoral and dangerous form of expression which would corrupt Iranian society. This remarkable assessment of her work continued into the 1980 os, long after her death. During the reign of the last Pahlavi shah her work was seriously censored; after the Islamic revolution it was completely forbidden for a long time. Farrokhzad's work is available in Iran today, but only in heavily censored editions. Farrokhzad's complete uncensored works were published for the first time in 2002 in Essen, Germany. ${ }^{8}$

As discussed in Chapter One, Western culture has been criticized for its scopocentrism or ocularcentrism - the hegemony of eye/vision. This inherent ocularcentrism/scopocentrism characterizing patriarchal, phallocentric cultures, to which Iranian culture is no exception, reduces women's complexities into a physical appearance, presentable in toto on a flat glass. Women's identity is constructed to appease the male gaze and his desire. This reductionist view of women has either turned them into the blind disciples of codes of beauty or forced them into the veil and the harem, or even both. In such contexts, women rely on their specular image to affirm their presence, their existence and their identity. Spencer remarks that within those cultures where "the male gaze is perceived as an agent of objectification and nullification of feminine identity, then it seems natural to turn to a feminine gaze for affirmation." On the other hand, women's activity in gazing at and contemplating their mirror image becomes more "an act of self-exploration 
and discovery" than "an act of self-expression." ${ }^{10}$ Therefore, the female's gaze at her specular image can lay the foundations for constructing one's agency through one's self-image, as well as for developing one's authentic voiceone's self-image and one's voice being inseparable.

Mirror imagery plays a crucial role in the works of Forugh Farrokhzad. For her, the mirror phenomenon and the contemplation of self-image serve myriad ambivalent functions. Her use of mirror imagery is not limited to the recurrent, traditional or even clichéd images and symbolisms found in classical Persian literature. Farrokhzad manages to move beyond the traditional. She establishes herself as a feminine, modern, non-mystical and antitranscendental poet. Like many other modern female poets, she expresses, through her use of mirror imagery, the problematics of her female subjectivity, her identity crisis and the lack of a secure, stable and acknowledged subjectivity. For Farrokhzad, the mirror plays a more complex psychic function than a mere tool of solipsistic self-love and pure vanity, as it is widely held to be in Iranian culture.

Farrokhzad shifts among the three different modes of self-inquiry, selfreflection and self-expression in her mirror and in her poetry-as-mirror, particularly through the implementation of her mirror metaphors. These three modes imply different attitudes towards the self: a) through selfinquiry, the persona looks critically at her self; b) self-reflection is less emotional than self-inquiry; and c) through self-expression she presents an image of herself to others as well as to herself. By adopting a self-expressive attitude in her mirror imagery, Farrokhzad can express her desires, fears, anxieties, doubts and alienation, as well as her feelings of victorious reconciliation and emancipation. Through self-reflection, she exercises introspection and attempts to learn more about her fundamental nature, purpose and essence. Self-reflection invariably leads to inquiry into the human condition and the essence of humankind as general and into her gender-as-class in particular.

Farrokhzad's psychology of mirroring underwent radical transformations indicative of her personal and poetic development. In her poetry, the meaning and the function of the mirror were constantly changing at different stages in her life. Her poetry is extraordinarily personal: even the titles of the collections reveal much about Farrokhzad's personal life. The first and second volumes are entitled Asir (The Captive) and Dìvār (The Wall), respectively, while the third and fourth collections, published during psychologically turbulent phases of her life, are entitled 'Esyann (Rebellion) and Tavalod-i digar (Another Birth) and the fifth and final collection (published 
posthumously) was given the title she had chosen for one of the poems, İmān bìyāvarim be àgàz-e fașl-e sard ... (Let Us Believe in the Beginning of the Cold Season ...). It could be argued that there is a trend to be detected in Farrokhzad's choice of titles, reflecting how she felt at given stages in her life. Still, it would be specious (if not impossible) to draw absolute, clear-cut lines of demarcation between these phases, since she oscillated back and forth at psychologically critical times.

An overview of mirror imagery in the entirety of Farrokhzad's work reveals her feminine history of disturbed ego formation; a history of the subject-in-process, and at the same time her artistic development. ${ }^{11}$ This is because almost any psychological stance of a woman can arguably be interpreted in reference to her relationship with her specular reflection. Due to the highly ambivalent nature of the mirror, Farrokhzad elicits ambivalent, even contradictory, reactions to her mirror image. For Farrokhzad, the mirror is a powerful tool; initially for negation, rejection and creation, but ultimately for the realization and presentation of her authentic "self" in the different phases of her life. At times she utterly fails to recognize her mirror-image as that of her own reflection, indicative of the alienation and detachment of her self.

At other times of psycho-emotional crisis, when Farrokhzad finds no other proof of her subjectivity, her visibility or her true identity within her society, she turns to the mirror for an answer, hoping that the mirror will relieve her of painful inner conflicts and give her existential proof of her being and its quality. The mirror is supposed to possess knowledge by revealing the world within and the world without. Like many other modern female writers and poets, Farrokhzad demonstrates her heavy reliance on the mirror and mirroring for defining her true self, as well as for relating her subjectivity to the world around her.

A close reading of how Farrokhzad manipulates the mirror imagery in her works may provide the reader with the developmental history of her female identity within the patriarchal context of Iranian society and its multifaceted oppression of women. In this reading, I will try to understand her psychology of mirroring and the mirror's inseparable interactions with the self and the eye (particularly the male gaze), as well as with the world around her persona. The stages in the developmental process of Farrokhzad's self, as studied here through her use of mirror imagery, easily fit Farzaneh Milani's tripartite classification of the poet's life and work into those of feminine, feminist and female. ${ }^{12}$ Whether Farrokhzad was consciously engineering her mirror imageries or unconsciously resorting to them is inconsequential to this study. 


\section{Captive to the Male Gaze}

In the quest for her true self, Farrokhzad initially starts out as a captive of the male gaze. In this initial phase, she has internalized the male-defined concept of a woman as a mere object whose totality, presentable within the frame of a mirror, is to gratify male desire. As Berger observes:

men act and women appear. Men look at women. Women watch themselves being looked at. This determines not only most relations between men and women but also the relation of women to themselves. The surveyor of woman in herself is male: the surveyed female. Thus she turns herself into an object-and most particularly an object of vision: a sight. ${ }^{13}$

Berger's observation about men's cultural position on the side of seeing and women's on the side of seen, as well as women's internalization of the masculinity of the "surveyor" and the femininity of the "surveyed," should be considered in the more general picture of patriarchal cultures' hierarchical binary oppositions and their strict assignments of the gender roles on either side of the pole-active/passive, voiced/voiceless, having agency/lacking agency, authority/submission. On the other hand, one should also keep in mind the ocularcentrism or scopocentrism of these cultures which constitute subjectivity through the act of seeing and also exercise power through the act of gazing. Mulvey explains:

In a world ordered by sexual imbalance, pleasure in looking has been split between active/male and passive/female. The determining male gaze projects its fantasy onto the female figure, which is styled accordingly. In their traditional exhibitionist role women are simultaneously looked at and displayed, with their appearance coded for strong visual and erotic impact so that they can be said to connote to-be-looked-at-ness. Woman displayed as sexual object is the leitmotif of erotic spectacle: from pin-ups to strip-tease, from Ziegfeld to Busby Berkeley, she holds the look, and plays to and signifies male desire. ${ }^{14}$

The internalization of this looked-at-ness, being on the side of seen/seem rather than seeing, has generally constituted women's subjectivity, their identity and their self-image as well as the nature of their relatedness with others in their society. Unavoidably, it shapes women's relationship with their mirrors. 
Likewise, Farrokhzad has internalized the paradoxical definition of the mirror as a feminine tool for the effacement of one's true self, as well as a means of self-creation; a creation aimed to gratify the male's desire and his gaze. In this regard, her specular image gains overwhelming significance. At times her mirror functions as a replacement for an absent lover and his gaze. Farrokhzad uses the mirror primarily as an instrument to verify how she appears to men, to create her appearance in compliance with maledefined codes of beauty. Therefore, the mirror for Farrokhzad becomes a fundamentally essential tool for her consciousness of the self and for her position within her culture. For a woman who has no other self outside its confines, the mirror can determine her destiny in society, since everyone (including the woman herself) relies on that specular image for the definition and evaluation of her identity.

Although Farrokhzad is extremely disturbed and agonized by this male conceptualization of the woman as a mere object of looked-at-ness, she appears unable consciously to recognize and acknowledge it, and thereby become able to transcend it. In this initial phase, she is unable to disentangle herself from her culture's suffocating prototypes of femininity and thereby gain an independent subjectivity. It is only gradually and after passing through the painful stages of non-recognition, self-fragmentation and the rebellious act of mirror rejection that she can reach the stage of acknowledging the liberating power of the mirror in the exploration, conceptualization and construction of her female self.

In her first collection of poems, entitled Asir (The Captive), published in 1952, Farrokhzad appears to be in her initial stage of feminine imitation and internalization of patriarchal gender definitions and their cultural values. ${ }^{15}$ However, these codes and definitions fail to grant her peace or a sense of belonging to her culture. Tikku asserts that the first book is "the symbol of a psychological state in which a person finds himself imprisoned in a world of tradition and dogma with no or little hope of a fuller experimental life."16 Farrokhzad feels herself an outsider, though still manacled by these codes and definitions.

The first appearance of the mirror image in this collection is in her poem "Az yäd rafte" ("The Forgotten"), composed in the winter of 1954/55 in the city of Ahvaz. ${ }^{17}$ In this poem, Farrokhzad expresses her melancholic longing for her beloved and his gaze; the beloved who has deserted her without even sending her a letter. The poem is in quatrains, and opens with a line overtly stating the poem's ubi sunt theme: 
The memories of the past linger in my heart and alas

There is no friend to remember me

My gaze is remained fixed to the path and he

ياد بكذشته به دل ماند و دريغ نيست يارى كه مرا ياد كند ماند

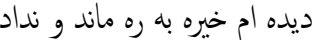
نامه اي تا دل من شاد كند روند didn't send me

A letter to brighten my heart ${ }^{18}$

In her misery, the poetic persona-who is Farrokhzad herself-obsessively seeks the reason for this desertion. In her frustration, she asks herself the pathetic question: why has he stopped watching her?

I do not know what wrong I have done

That he disentangled his rope of kindness

from me

If I had a place in his heart

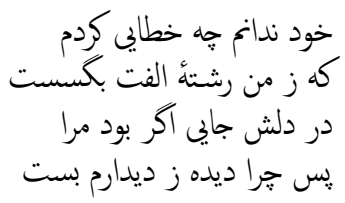

Why has he stopped watching $\mathrm{me}^{19}$

The persona openly reveals the importance of the male gaze to her and her reliance on it for her happiness. The language Farrokhzad uses indicates her need in being loved, desired and gazed upon. According to Freud's definition, the persona comes across a narcissistic woman whom "social restrictions" have trapped in an undeveloped primary narcissism, whereby she wishes to be loved and gazed upon rather than to be an active lover. The absence of the lover, who has been incorporated into the ego-ideal of the narcissistic woman, overwhelms her with melancholy and sense of self-loss. $^{20}$

It should be noted here that the last line is ambiguous. It can be rendered as "Why did he close (his) eyes to seeing me" or "Why did he close (his) eyes to my eyes," as well as "Why did he close (his) eyes to my face." This ambiguity arises due to the ambiguity of the term dìdar , which can mean "sight, vision, look," "the eye," as well as "the obvious, the apparent." ${ }^{21}$ The alternative reading, i.e., "Why did he close (his) eyes to my eyes," would rather imply equality in the relationship of the (estranged) lovers.

In the next stanza, ironically, the persona confesses that everywhere she turns she is confronted with him gazing at her. He is not literally present but in her mirror imagination she sees him everywhere gazing at her; either the memory of the past is lingering in her mind or it is her unconscious method of wish fulfillment. She is sad no longer to be the object of his gaze and therefore she feels a lack of existence: 
Everywhere I turn my eyes, it is he again

Gazing at my wet eyes

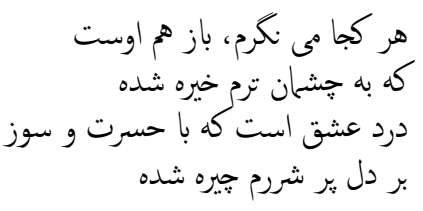

It is the agony of love that

Has conquered my fiery heart with rue and regret $^{22}$

The original is ambiguous: he (the beloved) does not look at her (the persona/lover) - as we learn in the preceding verses-but she sees him everywhere gazing at her eyes. ${ }^{23}$

In the fifth and sixth stanzas, the melancholic woman further expresses how she misses the physical intimacy of her lover. With every kiss, she misses the burning kisses of that "ill-natured" one, and with every kind embrace, she wonders what has changed, missing the "burning fire" in his breath. Therefore, in the seventh stanza, in order to compensate for this loss, she turns to poetry:

I composed poems to lift from the heart

The heavy load of grief for his love

Poetry turned out to be a manifestation of his face

To whom can I tell the tyranny of his love ${ }^{24}$

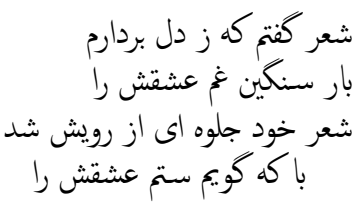

Farrokhzad composes poetry with the intention of disentangling herself mentally and emotionally from her lover and the thought of him. In fact, through composing poetry, the poet persona can create an introspective space where the other and his gaze cannot enter, and thereby she can overcome her melancholic dependency on him. The second line in Persian is ambiguous; the love could be her love for him, meaning a heavy load of grief deposited on her due to her longing for his love; on the other hand, it can be his love, meaning that his love is the cause of this load of grief. Therefore, it is love, whether his or hers, that is the cause of her grief. Through poetry, she tries to gain emotional detachment and independence; meaning that her creativity is developed out of a lost love.

But, contrary to her intention, the beloved appears reflected in her and also in her poetry. Farrokhzad's text, like her mirror, appears to be devoid of her authentic subjectivity; it rather reflects her beloved and her dependency and captivity. It is the loss of his love that has turned her into a poet. ${ }^{25}$ As Shengold observes, "Reversal of subject and object can be evoked with the mirror; active and passive can be simultaneously represented." ${ }^{26}$ The 
poet's persona is still heavily dependent on the male gender and its systems of defining a woman for her sense of self. Although she struggles to free herself by having a voice of her own, this voice turns to be an echo of her dependence. Farrokhzad composes poetry with the intention of freeing herself from this servitude, of establishing an independent voice of her own, but poetry itself turns out to be a manifestation of her captive-ness.

At one point, the persona addresses her mother, telling her to stop combing her hair, to wipe the antimony from her eyes and to take off her dress. ${ }^{27}$ She apostrophizes her mother, beseeching her to break the mirror. The effect of apostrophizing here is of a sudden emotional impetus in a rebellious act of breaking the mirror. Here, Farrokhzad plays with the concepts of male gaze, feminine make-up and the mirror, all still within their patriarchal definitions. Asking her mother to be the agent of breaking the mirror is significant. The persona is experiencing her subjectivity as the extension of her mother, the reproducer of her destiny-her kismet. Gallop explains, "The plea to the mother presumes the mother has the power to understand and fulfill the demand."28 The mother as the fellow victim is invoked because she is the one who understands. It is from her mother that she has received her "obliviousness of self." ${ }^{29}$ The mother is the perpetuator of this tradition by serving as a model and by teaching her how she should think and how she should behave. Therefore, it is the mother who should break the mirror.

As long as his eyes are not amazed by my face

What use is this beauty to me?

O Mother, break this mirror

What do I gain by adorning myself? ${ }^{30}$

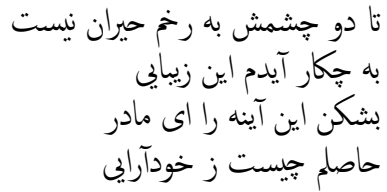

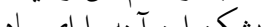
حاصلم جيست ز خودآرايى

By posing the rhetorical question as to the futility of a mirror in a context where the male gaze is absent, Farrokhzad intends to emphasize the certainty of the fact and its acknowledgement on the part of her readers. To rephrase it in the terminology of speech act theory, the illocutionary force of the rhetorical question is not to inquire after information but to assert information already acknowledged. Here, Farrokhzad presupposes that her readers will agree with her that, without the existence of the male gaze, the mirror becomes an absolutely useless thing. In other words, she is certain that her readers will be of the same mind as to the meaning of women, female mirror-image and self-adornment. 
This usage of the mirror represents Farrokhzad's initial stage of feminine imitation and internalization of patriarchal gender definitions, as well as the masculine conceptualization of a woman as pure object. Accordingly, the mirror is considered a tool for self-creation, whose purpose is to gratify the male's desire and his gaze. Although Farrokhzad finds this reliance on men and the male definition of her feminine identity far from desirable, she still seems unconscious of this structuring, and instead of rejecting this conceptualization she rejects the mirror, her image and thereby her very self through the act of breaking the mirror. Farrokhzad's experience is not unique; it is shared by all women conscious of being captive to the male gaze; as Irigaray agrees:

I, too, a captive when a man holds me in his gaze; I, too, am abducted from myself. Immobilized in the reflection he expects of me. Reduced to the face he fashions for me in which to look at himself. ${ }^{31}$

Irigaray talks about femininity as constructed by and for the male gaze. The female subject is expected to efface her authentic subjectivity and to fashion a new face according to the images of femininity her culture provides her with, in order to grant man his desired self-image. In the process, the woman is immobilized into a flat and flattering mirror of the male ego. Elsewhere, in her essay "Divine Women," Irigaray further elaborates on captivity to the male gaze:

We look at ourselves in the mirror to please someone, rarely to interrogate the state of our body or our spirit, rarely for ourselves and in search of our own becoming. The mirror almost always serves to reduce us to a pure exteriority-of a very particular kind. It functions as a possible way to constitute screens between the other and myself. ... the mirror is a frozen-and polemical-weapon to keep us apart. I give only my double up to love. I do not yield myself up as body, flesh, as immediate-and geological, genealogical-affects. The mirror signifies the constitution of a fabricated (female) other that I shall put forward as an instrument of seduction in my place. I seek to be seductive and to be content with images of which I theoretically remain in artisan, the artist. ... All too often it [the mirror] sends back superficial, flat images. ${ }^{32}$

For Farrokhzad, in these poems, the mirror is a tool for her to observe how she would appear to the male lover, as well as to create a beautiful face for 
his gaze. Now that the mirror has turned into something useless without his gaze, she wishes it to be broken. In this meaning, both the man and the mirror are closely interacting in depriving her of a sense of self, thereby constructing her destiny as a passive captive woman who is no more than an object on the side of seen/seem. In a context where a woman is defined only through the reflected image, that is to say, a context which equates a woman with her specular image, wishing to break a mirror can also be interpreted as self-destructive behaviour. This interpretation is confirmed further in the earlier stanza, where she explicitly states,

I said when I distanced him from my sight

He would certainly leave my heart faster

There is a need for death to find me

Or it is not a pain to vanish easily ${ }^{33}$

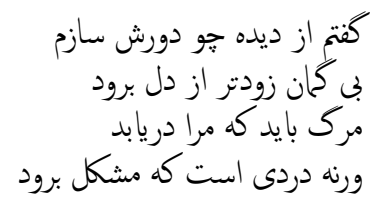

In the final two stanzas, the persona desperately seeks solitude, and for this reason she openly declares that she is in love. She rejects messengers bringing a message from anybody other than her lover. The poetic persona appears to be a captive to the male gaze and to the cultural definition of woman as well as to the definition of the mirror. She wants to break the mirror because it fails to function as defined, that is, to prepare her for the male gaze. In these early poems, Farrokhzad expresses and interrogates her condition of self-loss and emotional dependency on a man in a way that other female readers can share and interrogate: particularly the emotions of self-loss, and the confrontation with a culturally constructed image which the man desires (and which she both is and is not).

The second appearance of the mirror image in the volume Asir (The Captive) is in her 1954/55 poem "Āine-ye šekaste" ("The Broken Mirror") composed in the city of Ahvaz. The whole narrative takes place in front of a mirror. The poet persona ponders over her reflection in the mirror. In this poem, the mirror is once again a replacement for an absent lover and his gaze. The title itself tells much about the ambience of the poem, and the mood of its poetic persona-who is again the poet herself. The broken mirror in Persian (as in western) culture and literature is considered a bad omen. In the patriarchal cultural context where the destiny of a woman depends totally on her father figures-fathers, husbands and sonsbad luck for a woman means failure on the part of her male associates. She and her other female associates play very little part in building her destiny. 
In the first stanza, the persona puts on her green dress, applies make-up, arranges her hair and looks at herself carefully in the mirror, all in reminiscence of him and his love. It has again an ubi sunt theme, stated overtly in the opening line:

Yesterday in reminiscence of you and that cheering love

I clothed my body with a green dress

I stared at my face in the mirror again

Leisurely opened the band of my tress ${ }^{34}$

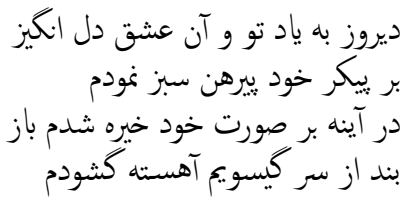

Here the mirror substitutes for the currently absent male gaze. The mirror places the persona in the positions of both subject and object-passive and active, seen and see-er-simultaneously and facilitates her oscillation between the two. In other words, with the help of a mirror she can be subject and object at the same time. In addition, the delusory essence of the mirror has induced a confusion of roles. She can gaze at herself as he would have done, had he been present. In other words, she becomes simultaneously a voyeur and an exhibitionist, thanks to the mirror.

This simultaneous adoption of subject-object position in her imagination can ease the pain of his absence and the absence of his gaze. The simultaneity of subject and object positions turns the mirror into a utopian space where the subject in pain can assimilate union with the object lover, thereby mitigating the pain of separation. The de-realizing nature of the mirror and its ability to make the reality converge with fantasy gives rise to the overflow of the subject's unbridled desires on its surface. As Melchior-Bonnet observes:

The reflection de-realizes the spectacle, and through it, desire is given the legitimacy to express itself since it no longer fears the sanction of the real. It creates a truth unburdened by the weight of its consequences. ${ }^{35}$

Moreover the green of the dress mentioned in the first stanza is associative of nature and delusion. Farrokhzad has even entitled one of her poems "vahm-e sabz" ("Green Delusion"). Her green dress here works in close association with the delusionary effects of the mirror. Putting on her green dress foreshadows the delusion to follow. The grammar of the poem and the use of the word "again" leaves no doubt that she has more than once and perhaps constantly been involved in this seducing performance in the 
mirror's theatrical stage. This delusive game has become a soothing ritual for her since delusion is the fundamental nature of the mirror, giving an ethereal, immaterial and distorted, as well as metaphoric/metonymic, image of reality.

In the second and third stanzas she is further involved in the act of self-creation, preparing herself to gratify her lover:

I fetched the perfume and spread it on my head and chest

Mincingly drew antimony on my eyes

Tousled my tress over my shoulder

Leisurely drew a beauty spot on the corner of my lip

Then I told myself with a hundred regrets that alas he is not present

To be astounded by all these charms and gracefulness

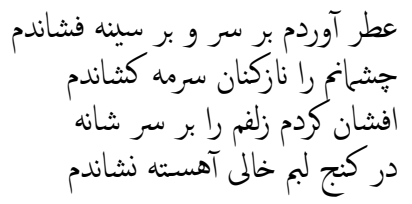

To say smilingly when he sees my green dress

You have become such a beauty again ${ }^{36}$

After this grooming ritual, set out in detail, in the fourth stanza the persona imagines that were her beloved present, he would be able to see himself in the black pupil of her eye. Indeed, she herself has turned into a mirror in which he might see himself:

He is not present to see the image of his own face

Within the black pupil of my eye the moment he gazes

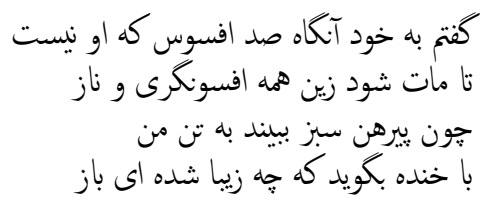

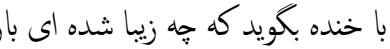

What is the use of this scattered tress

tonight

Where is his paw to settle into $i^{37}$

The first two lines contain both synecdoche and metaphor; her eyes representing herself as a whole and her whole self metaphorized into a mirror. The passive reflectivity of the mirror has been employed to metaphorize a female subject into a mirror of the male ego. Like Narcissus and like the figure of 
Gigolo in Plath's poem (which will be studied in the following chapter), the male figure turns to the reflecting surface, here the eye of his beloved, for narcissistic gratification in his self. The image the woman-as-a-mirror reiterates to the male ego is distorted and therefore delusive. As Virginia Woolf in A Room of One's Own observes:

Women have served all these centuries as looking-glasses possessing the magic and delicious power of reflecting the figure of a man at twice its natural size. ${ }^{38}$

Finally, in the last two stanzas, Farrokhzad engages in a dialogue with her mirror. She apostrophizes the mirror and the mirror listens to her and even replies. In this process, her mirror is anthropomorphized; it becomes a listening, talking and even crying mirror. ${ }^{39}$ Reciprocity is in effect: the mirror introjects her attributes as a human being as she introjects the projected mirror image back into her consciousness of self. The persona addresses the mirror, complains to it and asks it for a solution to her problem. The mirror is supposed to hold "knowledge" and thereby is invested with great power:

He is not present to inhale

voraciously the charming scent of my body

When he falls into my arms

O Mirror! I died of this regret and alas

He is not present to press my body against his chest ${ }^{40}$

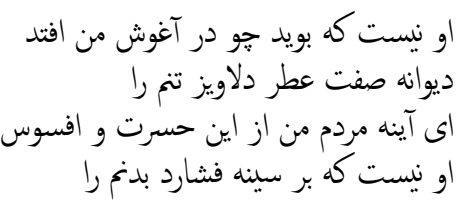

Ultimately, in the concluding stanza of the poem, the mirror breaks and cries in sorrow in response to her woeful complaints:

I was gazing at the mirror and it was listening to me

I asked: How would you solve my problem?

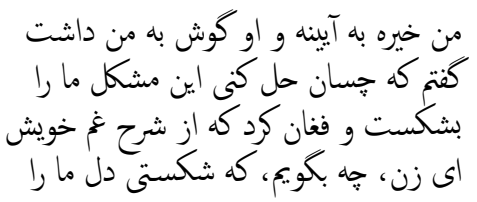

It broke and cried: By explaining your woes,

O Woman! What can I say, you have broken my heart ${ }^{41}$ 
The prosopopoeiac mirror claims to have a heart, a broken one-the projection of the heart of the woman. Whereas a woman is identified with her mirror image, a broken image equates with her sense of being fragmented. Farrokhzad projects her sorrow onto the mirror, because she feels she is nothing but that mirror image. By this projection and objectification of her sorrow she gains knowledge of her situation. This objectification onto the mirror also functions as a means of distancing her woes, thereby mitigating their effects. Farrokhzad is aware that the mirror holds answers regarding her subjectivity and its problems. In the later stages of her life again she turns to the mirror for the answer but, as will be discussed, the mirror will be able to give her a completely different kind of answer. This shift in the answers the mirror elicits reveals the poet's change of relation to her own subjectivity.

The knowledgeable mirror can also be read as an allusion to a very recurrent mirror motif in Persian literature, in which a surreal mirror reflects things beyond the present time and present space. It refers to the mythical ğàm-e ğam-Jamshid's cup or goblet, a magical omniscient or "all-knowing" mirror that provids the owner with the knowledge its owner desires. Functioning as a microcosmic space onto which a macrocosm can be reflected, this mirror grants its owner a view of the whole universe, transcending the limits of time and space. This reflecting surface was by many authors credited with the empowerment of the Persian Empire. ${ }^{42}$

Mo'in, in his study of the motif $\breve{g} \bar{a} m-e$ ğahān namā, i.e., world-revealing glass or cup, lists various interpretations of this magical glass/cup: water, astrolabe (also called speculum cosmographicum, or cosmographical mirror), mirror, the globe, geographical maps, compass, magic lantern, wine, heart, a perfect human and the world, among others. ${ }^{43}$ Due to their common qualities and functional overlappings, Persian poets have used these flat and concave reflective surfaces interchangeably, at times referring to a single entity. ${ }^{44}$ In addition, by conflating the motif of the flat mirror of the heart and other mirror imageries, Persian poets were able to express their points in a highly metaphorical, multi-layered and at times ambiguous language. ${ }^{45}$

In the poem "Šoq" ("Enthusiasm"), in the collection The Wall, the mirror is again a means through which the female speaker in the first personFarrokhzad herself-checks her appearance to see how she may appear to the world outside and particularly to her lover. Here, again, the mirror is functioning as a substitute for the male gaze. In reply to the lover's question as to what she has brought him as a souvenir from her journey, the speaker tells him to look at her face for the answer: 
Do you remember that you once asked me smiling

What souvenir I had brought you from so far away?

Look into my face so that my face answers you

A tear of enthusiasm slumbering in the eyes of desire ${ }^{46}$

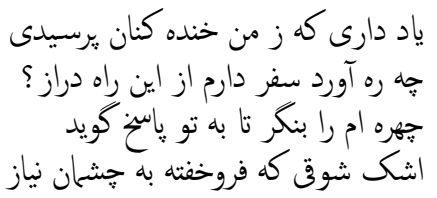

اشك شوق كه فروخفته به تهشمان نياز

In the following two stanzas, the speaker lists further the things she has brought him from this journey: a breast burnt up in the desire of an impossible love; a gaze lost in the veil of a distant dream; a body inflamed from burning appeals for union; eyes agitated by inner enthusiasm; warm lips, on which reposes a kiss filled with hope and desire, hotter than the kiss of the southern sun. In the fourth stanza, the speaker explains that after wandering many times in the streets and bazaar in search of a fitting souvenir for her beloved, she decides to present him with her body; a body blazing with the flames of inner desire. In the fifth stanza, the speaker turns to her mirror, consulting it to see if her face and her body would be a worthy present:

When I looked into the mirror, I saw, alas

That separation from you has decreased the glow of my face

I beseeched the sun to grant me

Thirst, brilliance, incandescence, and reflection ${ }^{47}$

Farrokhzad metaphorizes her face into a waning moon, whose brilliance, glow and reflectivity have decreased due to the pains of separation. Like the moon, she turns towards the sun for the source of her thirst, light, heat and brilliance. In this poem, the mirror and the image within it are associated with the moon. Moreover, the mirror turns into a temporal site. It is a slate for registering the passage of time and the deterioration associated with it. On the surface of her mirror, the speaker can observe the changes happening to her face over time by summoning up the different previous appearances and re-identifying with those previous images.

In the concluding stanza, the speaker asks the lover to open his embrace so that she can reveal what souvenir she has brought him from this distant journey, 
Now, this is me, I am this soul-burning fire

O you, the hope of a mad and woe-embracing heart

Open your embrace so that I may reveal

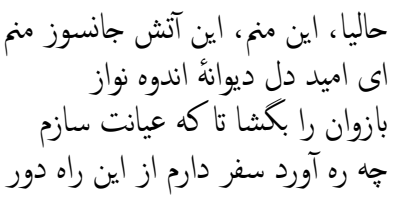
to you

What I have brought from this far-off place $^{48}$

In Farrokhzad's early poems, love for a man is a major issue and the poetic self relentlessly and almost with a singularity of commitment seeks man's desire and his gaze for a sense of happiness and fulfillment. In the three poems "The Forgotten," "The Broken Mirror" and "Enthusiasm," discussed above, Farrokhzad uses her poetry mainly for self-expression. Through her mirror imagery she seeks to express her emotional dependence on men and her sense of self-loss when confronting the culturally constructed image which the man desires; the image which she paradoxically is and is not. Expressing her dependence on a man's love and his gaze through her poetry is indeed a way of overcoming such dependence by setting her voice against the power of the male gaze and creating an introspective space into which the male gaze cannot enter.

In these early poems, the otherness of Farrokhzad's specular image is directly associated with the otherness of the male lover and his gaze. Her mirror experiences show that the mirror and the male gaze function interchangeably in the construction of the female persona's sense of self. In all these instances, the persona defines and portrays herself as being seen by the other, rather than describing the features of her lover: an instance of undeveloped female narcissism, as defined by Freud. In all these identifications, inaugurated by the initial identification at the mirror stage, Farrokhzad invariably identifies with male lovers and depends on her reflection of them to experience her subjectivity and its continuance. In this way, her poem (as she herself mentions), like her self, becomes a reflection of this other.

These mirror experiences reveal the conceptualization of womanhood and the strictly defined sex relationships promoted by her culture: woman as a mere physical appearance created to satisfy male desire and his gaze. The presentation of mirror imagery in these early poems may hint at Farrokhzad's unconscious internalization of her culture's conceptualization of womanhood. Nevertheless, by presenting and objectifying these images 
in her text, she becomes able to distance herself from them, gain consciousness over them and ultimately reject them and seek for real, more authentic images. ${ }^{49}$ Farrokhzad's descriptions of her encounter with her mirror imagery reveal the female subject's exasperating difficulty in coming in terms with her cultural images of womanhood. The presentation of these images of womanhood and female sexuality, with her unprecedented, explicit frankness in a society expecting solemnity, modesty, immobility and silence from women was revolutionary.

Through its simultaneous implementation of the "I" and "the other," subject and object, the see-er and the seen, the mirror can feed the female subject with fantasies in which she assimilates the presence of the other and his gaze and even imagines physical intimacy with him. Therefore, the persona gets involved in a continuous ritual performed in front of the mirror in order to fulfill her inner needs and bring her closer to the aim of her existence as defined by her culture. Indeed, the mirror turns into a theatrical stage where she can observe how she appears to others and to the world outside. There she often creates herself according to those images of womanhood of her social codes of beauty. The mirror is a space where the subject can act out the reality and the imaginary simultaneously, merging the exterior world and the inner psychic world, the visible realm and the invisible realm reciprocally. Therefore, for women this space of relatedness with others may remain a space of anxiety.

\section{The Mirror as an Eye}

The close reciprocity between the mirror and the eye and their reflection of one another has made the mirror a popular metaphor for the eye. As Melchoir-Bonnet argues, "Reciprocal transparency, the eye-mirror achieves both fusion and separation, identity and difference." ${ }^{50}$ In Persian literature, too, poets have recurrently identified the mirror with the eye; shining brilliance and the internalization of the image of anything within their scope of vision being their common features. Moreover, the round shape of mirrors (most popular in older times) and the ringed form of the eye make them especially similar for the classical Persian poets. ${ }^{51}$ Hence, the mirror was most often metaphorized to a wide-open, wakeful, alert and at times astonished eye. Zipoli, discussing the mirror image in some stylistic periods of Persian poetry, asserts, "Because the mirror is usually white, round and bright, it has always evoked the alert eye." 52 
As discussed in the previous section, Farrokhzad recurrently (though implicitly) turned to the mirror as an eye of the other, particularly the male gaze. In a 1957 poem composed in Munich, entitled "Dìr" ("Late"), in her collection 'Esyān (Rebellion), Farrokhzad explicitly associates the mirror with the eye through the use of a simile. The poet persona, in this poem, addresses herself in the second person "you" in a depressed, melancholic tone. In the first stanza, the day is coming to an end and darkness is invading. The day is personified in the one whose eye is invaded by the the mute and dark dream of sleep. It is time for the speaker to hasten alone towards home.

In the second stanza, Farrokhzad turns to the image of a dark shadowher double:

As long as your black shadow Is always by your side like this

Do not ever think that an eye

Will be expecting you there ${ }^{53}$

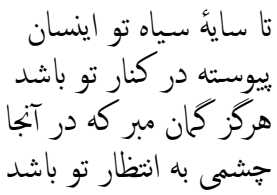

The rhetorical evasion of the first person by adopting tuism is significant here. Through tuism, the poet adopts the position of distant, objective and censuring observer, who has come out of her body and is critically watching herself, as if through a mirror. This "black shadow" appears to be the invisible, evil side of her personality - the Jungian shadow. The persona thinks that, as long as she has not got rid of this shadowy side of her personality, no one-mentioned through the synecdochic eye-will be looking forward to spending time in her company. Farrokhzad is, therefore, blaming her own "dark shadow" for her loneliness.

In the following stanzas, the persona hastens home on a late, sad and rainy night. Farrokhzad portrays the atmosphere of the house in the rain, her dark depressing room and her arrival by resorting to extravagant similes and metaphors. Even time seems stagnant; the wall clock is devoid of any chimes and refuses to strike. Then, in the seventh stanza, Farrokhzad turns to photographs; themselves mirror images frozen in a point in history:

In the worn-out frames, the images

-these ridiculous mortal faces-

Pale from the passage of time

Perhaps they once existed!54

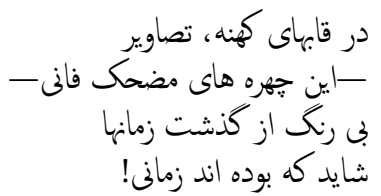


By doubting the existence of these "ridiculous," "mortal" images in the old frames, grown pale with the passage of time, Farrokhzad is actually revealing her doubt as to her own existence and its continuity-psychological projection. This psychological projection is further asserted by Farrokhzad's repositioning of her attention from the pictures to the mirror in the eighth stanza. She draws upon the close association of the mirror and the eye to compare them explicitly:

A mirror, like a big eye

Is sitting in a corner, busy watching

Upon the glass of its gaze

It has posed the rebellious spirit of the night ${ }^{55}$

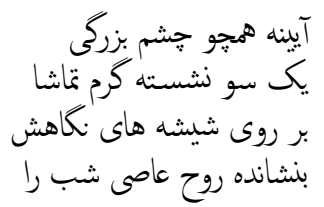

In the following stanzas, the persona, like an "old bird," turns to the warmth of her bed and with her trembling closed eyelids places her head on the "breast of a notebook." The ghosts of the dead who once slept in her bed are now crying beside her. Like effervescent bubbles on the condensed face of a swamp, these ghosts are now silently moving and moaning restlessly. The old pine tree is dense with the evil cawing of the crows and the silk scented rain dances on the windowpanes. In the concluding stanza, the speaker feels that she would regret it if she battled with her woe. Instead, she breathes her woe in, keeping it inside her, in order to compose a new poem:

You feel that it is regrettable

To fight with your own woe

You smell that blossom of woe

To compose a new poem ${ }^{56}$

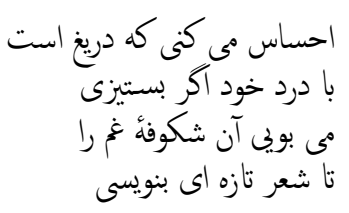

"Ta" in the last line of the quotation is ambiguous: beside "to" or "in order to" (as translated above), it could also mean "until." Therefore, the line could alternatively be translated as "Until you have composed a new poem." Both meanings are important here, since Farrokhzad describes the prerogative and at the same time the soothing effect of creativity. In order to be creative you have to feel the pain which, paradoxically, by the same act of creativity is also soothed. "Late" is a poem describing the creative process of writing poetry: creativity as a result of pain, and pain comforted by creativity. 


\section{The Mirror of the Heart}

\section{a - Non-mystical}

The metaphor of "a'ine-ye del" or "the mirror of the heart" has been used recurrently in both non-mystical and mystical classical Persian literature. In its non-mystical usage, the receptivity and the sincerity of the mirror in reflecting an image have been drawn upon to liken the heart to a mirror; the heart being a metaphor for something beyond physical existence, for human spirit. ${ }^{57}$ In experiencing worldly love, the heart should be polished like a mirror to reflect nothing but the beauty of the beloved.

In her poem "Ārezü" ("The Wish"), published in the collection The Wall, Farrokhzad employs the image of "the mirror of the heart" in its non-mystical meaning; to express her wish for her beloved's presence and for physical intimacy with him. The poem consists of nine quatrain stanzas, all of them beginning with the refrain "I wish," which signifies the concrete anticipation of the speaker. It also reveals much about the depressed mode of the persona feeling a desperate lack of companionship and love. The persona expresses her anticipation of the fulfillment of her sense of lack through kaleidoscopic similes and metaphors.

In the first four stanzas, the I-narrator-Farrokhzad herself-wishes that she could be the mysterious scent of a plant on the bank of a river, so that when the beloved passes by, she can kiss him all over. She wishes that she could sing to the tune of his "mad heart" like a shepherd's pipe; that she could pass his door while sleeping on the breeze's wavy camel-litter; that she could shine in the mornings like a "ray of the spring sun" through the "trembling silk curtain" of his window and see the colour of his eyes; that she could be the "laughter of a wine cup" in his luminous feast; or that she could be "the laxness and the drunkenness of a sleep" in his "painful midnight." 58

Here in this poem (as well as in many other poems included in her two early collections), Farrokhzad's speech is rich with extravagant metaphors, lyrical free associations, and obsessively explicit sexual references. These are all considered the classic symptoms of "love melancholy" or "love madness." A love-mad woman who originally was stable becomes insane due to being deserted by her lover. The love-mad woman employs exuberant metaphors and similes, and in order to assimilate them she displays a tendency towards self-effacement and self-annihilation-generally in the form of a death wish. ${ }^{59}$ 
In continuation of this sequence of metaphors and similes, expressing her desire for physical intimacy, Farrokhzad resorts to the mirror image in the fifth stanza, beginning with the same "I wish." But instead of being lit by the divine light, Farrokhzad wishes her heart to be illuminated by the light of an earthly love:

I wish that my heart would, like a mirror, be lit by

Your image and your smile

That each morning the warmth of your caressing hand

Would touch my body ${ }^{60}$

The poet-persona wishes her heart-mirror be lit by the image of her lover's face, an earthly creature of flesh and blood, and by his smile. In the simile she employs, the image of her beloved and his laughter is expected to be reflected like daylight upon the otherwise darkened mirror of her heart, with her heart functioning as metonymy or metaphor for her spirit or even her whole being. The lack of substance, immateriality and their supposed ethereal essence make soul and the mirror image intimate associates. Sincerity, selfless receptiveness and brilliance are considered qualities common to both the mirror and her heart-soul.

The mirror is meant to reflect the external world, but here Farrokhzad uses her poetic imagination to manipulate the mirror to depict her interiority, the internal world into which she has introjected her beloved. This is made possible because, as discussed in the previous chapter, there is a psychological interiority to the mirror. ${ }^{61}$ The mirror is not only able to reveal to its contemplating beholder the visible world, but also the otherwise invisible world, by means of "speculation." 62

In this poem (as in many of her other poems), Farrokhzad is concerned with her bodily existence. She draws upon the mirror of the heart in its mundane meaning to help her express her desire for a this-worldly love. This tendency towards the body is shared by other authentic writings of female authors. As Cixous asserts, "More so than men who are coaxed toward social success, toward sublimation, women are body."63 Farrokhzad often comes across in her poetry as anti-transcendentalist; she accepts her physicality and tends to reject the transcendentalism so much adored in classical Persian literature. To make the body-particularly the female body-and physical love holy actually becomes polemical. Indeed, 
in some of her poems, Farrokhzad explicitly glorifies what is down-toearth. ${ }^{64}$

In the sixth stanza, the persona wishes that at midnight the moon could watch her dance like "an autumn leaf"; that her sensation could raise a commotion in the heart of his house's garden. In the seventh stanza, she expresses an even more intimate wish:

I wish I could anxiously crawl into your heart

Like the cheerful memory of a woman

Suddenly I could see your eyes

Gazing on my beauty's radiance ${ }^{65}$

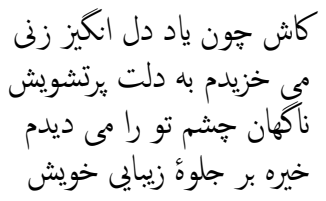

Here again, as in the poems discussed earlier in the section "Captive to the Male Gaze," the persona is seeking her lover's gaze in her concrete anticipation. In her narcissism, she appears to desire not so much to love, but to be loved and be gazed upon. The eighth stanza continues in the same spirit, expressing her melancholic desire for his physical intimacy through different exaggerated metaphors. The persona wishes her body could burn, like a "candle of sin," in the beloved's bed of loneliness, burning away the roots of his asceticism, as well as those of her desires.

I wish from the green branch of life

You would pick the flower of my woe

I wish in my poem, $\mathrm{O}$ you [my] life drive

Could see the flame of my secret ${ }^{66}$

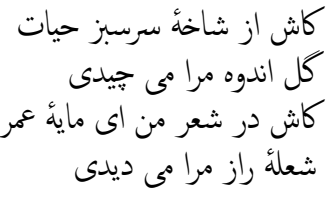

Once again Farrokhzad concludes her poem with a reference to her poetry, making the beloved, as well as the reader, aware of her presence through textualized subjectivity. The persona-Farrokhzad herself-wishes that her lover could understand the flame of her secret burning within her poems; within the text she has inscribed her innermost thoughts, feelings and wants-otherwise veiled or feigned. Therefore, as will later be shown, her poems are indeed a mirror of her self, a female subjectivity in her continual "process of becoming," as Mitchell calls it, truthfully reflecting her thoughts and feelings, as well as her lacks or deficiencies. ${ }^{67}$

In the poems studied so far, I have endeavoured to show how Farrokhzad is suffering from an ever-present sense of la manqué-a feeling of lack, deficiency or absence-which she tries to fill through a series of identifications with the other-often her male lover. In this context, she relies on 
a man's desire for her, as well as on his gaze, for her sense of self and for the fulfilment of her inner lack. In the poem "The Wish," likewise, Farrokhzad exemplifies what Freud defines as a woman's primary narcissism, whose happiness and sense of fulfilment depends on male lovers desiring her. Within this conceptualization of her self and her inner world, her mirror is metamorphosed into the male eye by means of which she can see how she appears to him, as well as to some extent quench her desire for his gaze by assimilating the presence of his view. All this is achieved through the simultaneous subject and object positioning promoted by the mirror, as well as through the mirror's ability to reveal the visible together with the invisible.

\section{b - Mystical}

The mirror of divinity, often in the form of "à'ine-ye del" or the "mirror of the heart," has been a recurring metaphor in Persian Sufi literature ever since at least the eleventh century. In this key metaphor, man's heart is depicted as a mirror reflecting God's imago(es) and his different manifestations. In Islamic Sufi thought, the culturally significant metaphor of the mirror of the heart has been used to explicate, as well as to prescribe, the relationship between man and his Ultimate Beloved. The metaphor of the mirror of divinity remains a key metaphor in Persian Sufi literature; its function transcending beyond mere description and becoming constitutive. Through appropriation of this metaphor, the Sufis configure and describe their entire Weltanschauung and mould their cognitive ethos. ${ }^{68}$

It is believed that the pure, untarnished heart can reflect the divine light of God. Through self-indulgence, however, this mirror gathers rust, hampering its ability to reflect the divine light. In order to polish the mirror and restore its reflectivity, the sālek (path seeker) has to refrain from involvement in the self and its desires. The perfect, spotless polish of this mirror is maintained only when the path seeker succeeds in attaining the state of absolute self-annihilation and self-abnegation $(\operatorname{fan} \bar{a})$. It is at this stage that the tağalli (theophany) occurs to the Sufi's heart and he revels ecstatically in the Unio Mystica, the divine receptivity upon his heart. Thereby, for the Sufi, the heart as a mirror becomes a space where microcosm and macrocosm mutually reflect each other and man becomes one with the universe and its creator. To put it in literary terms, Sufis use the vehicles of mirror and heart to convey the tenor of their love relationship. As understood in Unio Mystica, when the soul is turned into a mirror, it is not merely reflect- 
ing, but also contemplating and participating in the image and its beauty to which it is exposed. By assimilating the image, the soul-mirror undergoes metamorphosis and ultimately becomes part of that beauty.

However, before the perfect annihilation of the self in his God there is a stage in which the two presences of the man-as-a-mirror and the Truth coexist. The Sufis assert that this stage is marked by an imperfection, a deficiency, because the Sufi is still in dubious suspense between these two presences, such that his view fluctuates between them. ${ }^{69}$ This occurs because the mirror figure represents the schism between two ostensibly identical worlds or two modes of being. While it can serve as a bridge from one level of reality to the higher level of reality, from the known to the unknown, it can also become a locus of illusion and deception.

The metaphorical image of the mirror of the heart-soul originated in Neoplatonic thought, as did the twofold division of macrocosm and microcosm, as well as the division of the world into the visible and the invisible, the human soul and the Divine Being, where one reflects the other. The metaphor of the human soul as a mirror for God's reflection has been a culturally significant mirror metaphor in Western thought, and it is omnipresent in the spiritual literature of the Middle Ages..$^{70}$ Muslim mystics seem to have inherited this metaphor from the Hellenistic tradition. Descending from Plato by the way of Neoplatonic thinkers, particularly Plotinus, this metaphor can be traced in the writings of Muslim philosophers such as Avicenna (d. 1037), Abū Hāmed Gazzālī (d. 1111), his younger brother Aḥmad Gazzālī (d. 1123 or 1126) and Sohrawardī (d. 1191), who explored the idea further in their writings. ${ }^{71}$

According to this belief (subsequently embraced by Muslim mystics), the whole of creation, in particular human beings, is a mirror in which God sees himself. Burckhardt, who studied the phenomenon of mirror symbolism in Islamic mysticism, observes that the mirror has long been the most appropriate symbol for demonstrating the essential nature of mysticism, which is "purely spiritual," as well as for "the spiritual vision, the contemplatio, and more generally the knowledge, because through it the approximation of subject and object is revealed."72 This appears particularly valid when one is referring to intuitive knowledge. Burckhardt further explains:

When the heart turns into a clear mirror, on one side, the world is reflected on it as it really is, that is without any distortions caused by emotional thinking. On the other side, the heart reflects the divine 
truth to some extent immediately, that is first in the form of symbols (ǐša $\bar{r} a \bar{t}$ ), then in the form of intellectual properties (șefāt) or presences ('ayān), which are the basis of the symbols, and finally as divine realities (haqiqa)..$^{73}$

Furthermore, it is also believed that God, who is beautiful and loves beauty, has brought the universe into being in order to reflect his own beauty. Creation was necessary for God's beauty and his grandeur to be revealed and reflected. ${ }^{74}$ And man is considered potentially the most perfect created being mirroring this beauty. ${ }^{75}$ It becomes more comprehensible when read in the light of the idea that the whole world (containing beauty) originally consisted of luminous essence. It is also discussed that man can never comprehend the Truth in toto. He can only grasp incomplete representations of the Divine Truth through the ongoing reflections from pieces of the shattered mirror.

The mirror's ability to bring subject and object together, its unyielding obedience, as well as its lack of agency and its passive reflectivity were frequently drawn upon by certain Persian Neoplatonic philosophers, theologians, Sufis and poets to promote their ethico-religious doctrines. They recurrently resorted to this mirror metaphor to highlight their esoteric doctrine of supremacy of experiencing divine receptivity over reason. When they attempted to assign a more active agency to the part of the Sufi seeker, they used the term kašf (unveiling) instead. Among the Persian classical poets employing the metaphor of the mirror of the heart in its mystical meaning, evoking the semblance of God, were 'Ațtār (d. 1221?), Rūmī (d. 1273), Fah̆r ol-Dīn 'Erāqī (d. 1289), Sa'dī (d. ca. 1292), Ḥāfeẓ (d. 1389/139o), and Bīdel (d. 1720). ${ }^{76}$

In her poem "Bandegi" ("Servitude"), published in the collection 'Essyān (Rebellion), Farrokhzad draws upon the traditional, mystical and metaphorical meaning of the mirror. ${ }^{77}$ In this poem, in which she apostrophizes God, Farrokhzad depicts herself as a simulacrum to God. However, the poet uses the extended metaphor of man as a mirror of God to convey a rebellious, one might even say blasphemous, meaning. "Servitude" is a long poem of some four hundred lines, composed in quatrains, and replete with Qur'ānic allusions. It is divided into thirteen sections of unequal numbers of stanzas. The speaker complains to God and questions his grace; thereby questioning the whole Sufi tradition present in Persian literature. Somehow the poem is an open refutation of Sufism, which has had an enormous influence on Persian literature and the living culture. 
The first two stanzas open with the persona-Farrokhzad herself-announcing that there exists a shadow of a mysterious question on her lips and that today she is going to share with Him the secret of this rebellious spirit's bewilderment. ${ }^{78}$ This is despite the fact that she is well aware that $\mathrm{He}$ will reject her over and over again as long as He maintains His position as master and she hers as servant. As long as their relationship is that of master and servant, God will be involved at the beginning and the end of her dark story. In the following sections, the persona goes on to portray nihilistically dark and frightening images of human life, where man does not have the slightest control over his fate.

At one point, the persona even wonders if God is hearing her moans. She asks Him to break his glass/cup of narcissism ( $\check{g} a \bar{m}$-e hod-parastī) and sit for a while with her, with this earthly I (man-e ha $\bar{k} k \bar{\imath})$ and drink the agony of existence from the lips of her poem. ${ }^{79}$ In the fourth section, the poet persona starts recounting her story from birth, when she was conceived out of "a luscious supper" (šām-e lezatbār) and was born unwillingly. ${ }^{80}$ She was never left alone for a second to choose freely, here echoing the fatalism of religious discourses. She is born "without being an 'I'", having no agency, no subjectivity of her own. As she is roving in the illusory deserts (bìyābān-hä-ye vahm-angīz), her ears are incessantly being filled with God's voice. ${ }^{81}$ Here, Farrokhzad is referring to the constant religious echoes which mould her identity into a predesigned form-a simulacrum of God-from early childhood, depriving her of her authentic individuality. Afterwards she starts questioning the identity of her being, her origin and her end in an unfolding series of questions; but she realizes that "I am naught head to toe, I am naught, naught." 82 She realizes that God is pulling the ropes tight around men's necks "while their eyes stared at the image of the other world."

Farrokhzad employs a mirror image in the fifth section of the poem. Here, she herself is metaphorized into a mirror of God. As in the case of the mirror of the Sufis, discussed above, the persona is transformed into a mirror devoid of any agency, subjectivity or distinctive identity of its own. The speaker is utterly passive, having no will to act or any control over her fate. For her, mankind is created and doomed to life and death for no other reason than to be "a manifestation of your [God's] power" (ğelvegāh-e qodratat).$^{84}$ But in contrast to the Sufis, this passivity and lack of agency-for the speaker-is not a source of absolute serenity and consolation. Sometimes she sees the image of God's "power" (qodrat) reflected in this mirror, at other times His "tyranny" (bijdād) and even the image of His "self-worshiping eyes" (dīdegān-e hodparast). ${ }^{85}$ 
To Farrokhzad, God has created her as a mirror out of solipsism, out of sheer narcissism, just to enjoy seeing Himself in her:

I saw myself as a mirror devoid of myself

At any moment an image falls upon it by your hand

Sometimes the image of your power, sometimes your tyranny

And sometimes the image of your self-worshiping eyes ${ }^{86}$

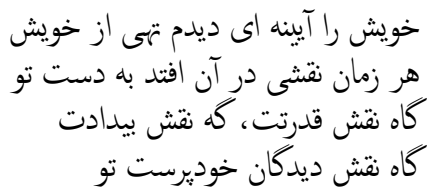

After being metaphorized into a mirror, in the following stanza Farrokhzad metaphorizes herself into a "sheep" ( $g$ üspand), wandering with no purpose among her flock (gale), while, on the other hand, metaphorizing God into a shepherd (čūpān), reposing drunk from his narcissistic game. ${ }^{87}$ Mirror and sheep are both drawn here to reveal her state of having no agency and no will.

From the last stanza of the fourth section, Satan ( his appearance in the poem. The poet starts reflecting about the identity of Satan and his function. She speaks of her many dialogues and interactions with him. ${ }^{88}$ Satan constantly transfigures himself into different shapes and forms in order to tempt human beings. At one point, he even becomes the image of a cupbearer reflected in a cup of wine:

He became a melody, circulating in the hand of a harper

He became a tremor, falling on silver breasts

He became a smile, revealing the teeth

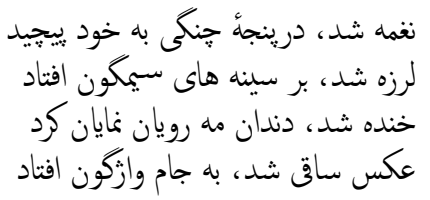
of moon-faced beauties

He became the image of the cupbearer, reflected in the inverted cup ${ }^{89}$

In this quatrain, Satan manifests himself by transfiguring into different forms and shapes, and therewith appealing to human senses; first objectifying himself, in an auditory image, in a musical melody, in the visual and kinesthetic image of a tremor, in the visual image of a smile and finally incarnating itself through the image of the $s \bar{a} q \bar{i}$, the cup-bearer. 
The term 'aks (originally from Arabic) in Persian can be played upon as a homonymic paronomasia or pun, containing the interrelated meanings of "picture," "image" and "inversion," "reversal" and "reflection." The term ğa $m$ means cup and mirror at the same time. It also figuratively refers to wine. For Sufis, $\breve{g} \bar{a} m$ recurrently refers to the mirror of the heart. ${ }^{90} S \bar{a} q \bar{i}$, literally the "water-carrier," "cup-bearer" and the "page," in Sufi terminology means the pir or moršed, that is the experienced (often aged) spiritual guide and instructor. It also connotes the images and manifestations of Divine Beauty the viewing of which makes the seeker intoxicated and drunk. Satan becomes an image or/and an inversion of the image of spiritual guide and manifests itself upon the upturned cup-a convex mirror. Sāqì-ye rühānìyan, literally the cup-bearer of the spirituals, in addition to Adam and Gabriel, may also refer to Satan in Persian literary tradition. ${ }^{91}$

The observer is beguiled by the illusory effect of the mirroring surface, reiterating a distorted, reversed image. Satan's appeal for man, often through illusions and deceptions, can best actualize itself through a deluding medium-here the mirror. Moreover, the upturned cup does not make a flat mirror; it turns into a convex mirror which not only inverts the right and left sides of the image, but also disturbs proportion and the size of the thing in front of it, thereby making the grotesque delusory effect of it stronger. Once the beholder comes very close to it, this convex mirror reiterates a larger image, hence producing an illusion of grandiosity and self-aggrandizement. On the other hand, the inverted cup makes a globe of an inverted cosmos through which Satan can traverse.

Farrokhzad's lines seem to be alluding to Hāfeẓ’s famous gazal, which opens with:

When Thy image was reflected on the mirror of cup

The 'âref from the smile of the wine

$$
\text { عارف از خندة مو حو در آينه جام افناد }
$$

fell into vain desires

With that one splendour that in the mirror, the beauty of Thy face fell,

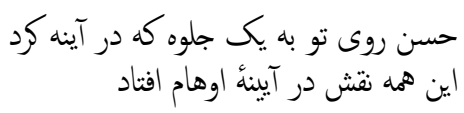

All these pictures into the mirror of fancy fell 
All these reflections of wine and varied images (of the beautiful beloved) that have appeared

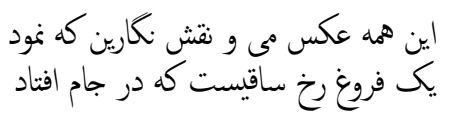

Is one splendour of the face of the sāqi

that into the cup fell..$^{22}$

Farrokhzad proceeds to list the satanic temptations appearing in a variety of forms and images, just as the manifestation of God comes forth through the diversity of its imagoes. After many dialogues with Satan, she finally decides to exonerate Satan of any blame while, on the other hand, she condemns God for her own present condition and that of humanity. ${ }^{93}$ In the sixth, seventh, eighth and ninth sections, the persona asserts that God can hold on to his position of mastery, vanity and tyranny only by frightening man with the fire of his hell. Farrokhzad then goes on to list many other proofs of God's vanity and tyranny in the ninth, tenth, eleventh and twelfth sections, while repeatedly alluding to the Qur'ān.

In the third stanza of the final section, the second mirror image makes its appearance. In this quatrain, the whole world is metaphorized into the mirror of God. In this section, the persona poses God the question: "What are you?" four times, not only so as to question his identity, but also to denigrate him. Servitude here has a twofold significance. Not only has God created her as a passive servant, but, ironically, God himself has also become subservient to his own name and to his own glory, by the very virtue of having created the world to function as a passive mirror:

What are you? A slave to your own name and majesty

[You have] seen in the mirror of the world the reflection of your own beauty

At every moment you turn this mirror around

To better gaze upon your immortal manifestations $^{94}$

For Farrokhzad, God is continually preoccupied in changing creation-essentially reflected images-as if taking delight in the game of having different perspectives of his self reflected in them. Again, this change of mirrors has its origin in the Neoplatonic and subsequently Sufi belief 
that all creation and its particles function as countless mirrors, all reflecting different aspects of one unity. ${ }^{95}$ Farrokhzad goes on to denigrate God by condemning him for: being incessantly preoccupied with moulding clay (alluding to the Qur'anic story that God moulded man from clay); being a "barrier on the path of our quest"; being "the sparkle in the eyes of a mirage"; being "the colour of deceit"; "the ooze of ominous nights"; "the darkness of a grave"; "that old bat"; "thirsty for the redness of blood"; "the enemy of light"; and ultimately the "self-worshipper." ${ }^{\prime} 6$ Then she asks, "If you are God, repose in my heart and purge me [from the dirt of my blasphemies and disgraces]. ${ }^{97}$ In the last stanza, the persona pleads with God to leave them alone just for a second, for "An opportunity, to save provisions for the journey."98

Farrokhzad uses the poem "Servitude" as a mirror in which she becomes deeply involved in self-inquiry and self-reflexivity. In her poem-as-a-mirror, she inquires about the essence of her being, the nature of her relationship with her God and her position in the world he has created for her. The mirror is known not only for revealing the visible, but also for revealing the invisible; herein lie its power and significance. The mirror becomes a bridge connecting this world to the other world. Man as a mirror of divinity has been a very popular and culturally significant metaphor. Theologians and moralists advocate the mirror when it is used in this sense-to propagate the simulacrum of God in man. On the other hand, if man's mirror fails to receive divine light, it is susceptible to reiterating an image of the devil or Satan in a panoply of delusory images.

Farrokhzad in this poem is struggling to define the identity of the human being, God and Satan for herself through their reflecting reciprocity with each other. The persona confuses the identities of God and Satan, portraying them as reciprocal, though reversed, images of each other. ${ }^{99}$ She evokes the popular metaphor of man as the mirror reflecting God, only to criticize it harshly. The mirror metaphor in this poem functions not only as a tool of revelation, but also as a constitutive medium. It reveals to her the servile nature of her relationship to her God and her desperate position in his world-as-a-mirror prison. On the other hand, being a key metaphor in Persian classic texts, it has been a constitutive and constructive metaphor, constructing the very nature of her being, her relationships and her Weltanschauung. 


\section{The Otherness of the Self-image}

Farrokhzad's use of mirror imagery contradicts the (Iranian as well as Western) culturally held view that immediately associates the woman-with-amirror image with entrapment within the self, with vanity and narcissism. At times of psycho-emotional crisis, when Farrokhzad feels no other proof of her subjectivity or authentic identity within her society, when she feels desperately alone and an outsider in her world, she consults her mirror for answers. Farrokhzad does so, hoping that the mirror will relieve her of painful inner conflicts and give her existential proof of her being and its essential quality. For her, the mirror becomes a space where her inner division, her inner fragmentation and her doubts are enacted, as well as expressed. In the examples that will be studied here, the inner division revealed in her mirror, as the direct outcome of the contradictions of her inner predicaments and the forced cultural definitions and norms of womanhood, is explicitly documented. Therefore, in these poems, rather than being a source of consolation and unity, the mirror exposes her painful experiences of anxiety, pain, shock and terror.

The poem "Ṣedā' $\bar{\imath}$ dar šab" ("A Sound at Night"), in which the mirror image appears, was composed in Tehran in 1955/1956 in her collection The Captive. In this poem, Farrokhzad inaugurates a departure from her old conceptualization of female selfhood as well as that of the mirror according to which it was a space through which she could assimilate being gazed upon by the male other. The poem "A Sound at Night" contains five cinquain stanzas, narrated in the first person. In the first stanza, the sound of footsteps in the silence of a dark and desperately lonely night provokes her to cast a look at herself in the mirror. The persona hopes that the sound in the corridor may be that of her lover's footsteps coming to visit her.

At midnight, in the heart of the silent corridor

The stroke of footsteps fell echoing

Like the heart of spring flowers, my heart

Brimmed with the trembling dews of certitude

I told [to myself] this should be he who has returned ${ }^{100}$

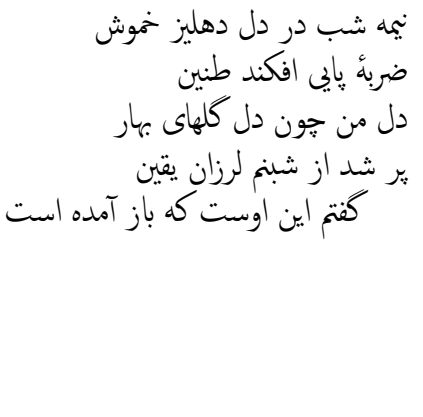


These lines portray the desperate loneliness of the poet persona-Farrokhzad herself-anticipating the return of her lover.

In hope, stimulated by this external sound stimulus, the persona rushes to the mirror to check herself, whereupon she is immediately baffled by her image. Her turn to the mirror is motivated by the other, by an exterior force: supposedly by the sound of her lover's footsteps and by the anticipation of his gaze. For Farrokhzad, confrontation with the mirror image raises doubt and a sense of bewilderment in the essence of her being-a bewilderment that she projects to the mirror. She expresses her experience of self-alienation through the quality of her countenance with her mirror imagery. La Belle observes, "when a woman feels a disunity between herself and the image in the mirror, it is often a sign of revolt or the beginning of a psychological disorientation," whereas for a man, "the split is normative." 101

At times, when Farrokhzad turns to the mirror in her existential angst, to her shock she is confronted with something unknown, unnamed-something monstrous. She expresses her wonder at the reflected image as it might be a mere illusory projection of her imagination, far from the reality of her existence. Her enthusiasm soon turns into melancholy. The mirror is obfuscated by her sigh. She feels utterly insecure:

I jumped up from my place, and in the bewildered mirror

Cast a look at myself with eagerness

Ah, my lips trembled with love

The mirror's face darkened from my sigh

Maybe $\bar{u}(\mathrm{~s} / \mathrm{he})$ was looking at an illusion? ${ }^{102}$

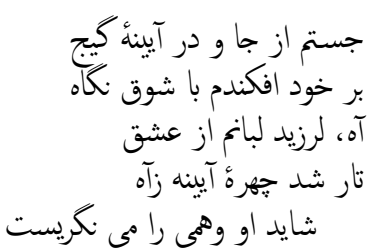

شايد او وهى را مى نكريست زاه

The whole atmosphere evoked in this poem is one of extreme loneliness; the speaker longs for companionship. The mirror is personified, and the speaker's bewilderment is projected onto it. Here the subject and the object (the poet and her mirror image) change places, and there is a shift in mood parallel to this shift in perspective, from one of enthusiasm and hope to one of disillusionment and melancholy. The mirror for the speaker becomes the agent, a powerful tool capable of changing her feelings.

Here, as in some other poems, Farrokhzad conveys her inability to recognize and acknowledge her image, partly through the grammar of the poem. 
Despite the use of the first person singular pronoun man ("I") throughout the poem, Farrokhzad, at this point, abruptly adopts the gender-free third person pronoun $\bar{u}$ ("she" or "he")—a rhetorical device called illeism. ${ }^{103}$ Illeism, the act of referring to oneself in the third person, used here serves multiple functions. Through illeism, the poet adopts the position of external, often impartial observer, as if she has come outside her body and is now watching herself from an objective distance; separating her consciousness from her physical body, the specular self from the experienced self. Furthermore, illeism illustrates a twist in the identity of the speaker who cannot reconcile herself with her own self-image.

This sudden shift of pronoun from "I" into "s/he" indicates the dominating authority of the mirror, which can change the perspective configurations on the one hand, and the exteriority of her female self-conception, selfdetachment and inner fragmentation of the self on the other. Through its process of reflection, the surface of the mirror becomes the agency of the relocation of gaze-thereby, the power. On the surface of the mirror, the observer and the observed, the gazer and the gazed upon, the see-er and the seen constantly shift their places and their power. The textual alterations in perspective configurations, occurring in confrontation with a mirror or a window, making the syntactic relationship and the ontological references ambiguous, are indeed significant.

Farrokhzad lacks a sense of "self-continuity"; she is not sure if her existence extends beyond her own experience. This doubt over her specular image reflects the insecure ambivalence she is experiencing in relation to her subjectivity. She doubts the reflection in the mirror; it is perhaps a mere illusion. The mirror becomes a vehicle of truth, an instrument of self-reflection, reminding her of her illusionary existence, of her lack of a solid subjectivity. Melchior-Bonnet argues:

Consciousness of the reflection, and reflection of the consciousness, the mirror image never ceases to be an illusion. Yet the illusion is not always deceptive. It can even provide a useful moment of psychic reality. The mirror is the place of transfer, a space of imagination in which the subject disguises his self and makes contact with his fantasies. The fiction of the mirror refuses the rigid distinction between real and imaginary and allows a more subtle dialectic of the subject. ${ }^{104}$

Farrokhzad introjects her projected image into the construction of her subjectivity, thereby becoming a "presence without substance." ${ }^{105}$ Never- 
theless, the assimilation of the immaterial, ethereal and transitory image into the structure of self remains incomplete. For Farrokhzad, it is this partial assimilation which becomes the perpetual source of division and doubt.

Another point regarding the pronouns in this poem is that the genderfree $\bar{u}$ can be taken not only as she or he; it can also refer to the poetic persona herself and/or the mirror itself personified, making the poem ambiguous and multiple interpretations possible. In all these interpretations, a sudden and unexpected shift emerges. If the pronoun is she, it means that the persona-Farrokhzad herself-wonders if she herself is looking at an "illusion" in the mirror in a moment of non-recognition. Though at first she is the acting subject (the one who jumps to see herself in the mirror in the hope of finding security in her image), soon she is disillusioned and becomes a passive object and the pronoun switches to a detached and desolate "she."

The mirror gains such overwhelming power over her that she feels a total lack in her being - a manque, to adopt Lacan's terminology. Accordingly, in her encounter with her mirror Farrokhzad experiences an utter effacement of her subjectivity. By identification with the mirror image, which provides only a distorted and metaphoric/metonymic semblance with the subject, the person develops a split and fragmentary sense of self. It is important to note that in Persian literature the mirror has been recurrently employed as a metaphor for a gaping eye. As such, the mirror has been associated with the state of shock and bewilderment, i.e., a time when the eyes are wide open and rarely blink. The bewildered eye is also unable to sleep; therefore, the mirror has also been associative of insomnia. ${ }^{106}$

In this example, looking at one's mirror image is far from vanity; it is accompanied by pain and confusion. The mirror is obfuscated by her sigh. It is her inner darkness that dims this external apparatus. The interjection $\bar{a} h$ ("Ah") and the mirror are frequently paired in classical Persian literature. Given the fact moreover that ancient mirrors were traditionally made of polished silver, steel, iron or some metal amalgam, sighing onto them caused mirrors to rust and darken with humidity. ${ }^{107}$ Zipoli observes, "Rust and sighs thus take on a simple chromatic and formal role, while their function is reduced ... to that of an obfuscating veil." 108

In the third stanza, by looking at her mirror image, the persona finds her physical appearance, corresponding to her inner state of mind, in a mess: 
My locks in disarray and my lips arid

My shoulder naked in my night-dress

But in the darkness of the silent corridor

The passer-by was momentarily adding to his haste

Suddenly my breath caught in my chest ${ }^{109}$

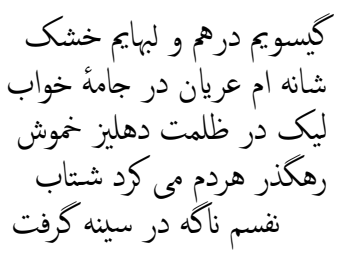

In the fourth stanza, Farrokhzad turns to the image of a window, through which she is being observed. Now it is the "spirit of the breeze" who is looking; not the persona herself and not even the image in the mirror:

As if the spirit of the breeze from the windows

Saw the grief of my lonely "I"

Poured over my confused locks

The burning scent of acacias

Hastily and restlessly I ran to the door ${ }^{110}$

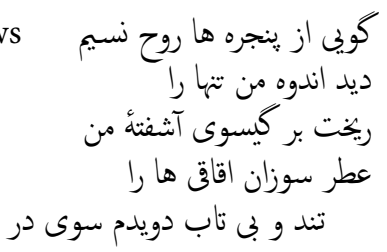

Here, her desperate loneliness is communicated unequivocally. In the concluding stanza, the stranger passes her door, leaving her lonelier and even more desperate:

The stroke of feet, in my breast

As a sound of the reed, in the breast of the plain

But in the darkness of the silent corridor The stroke of feet, slipped by and passed The wind set out a melancholy song ${ }^{111}$

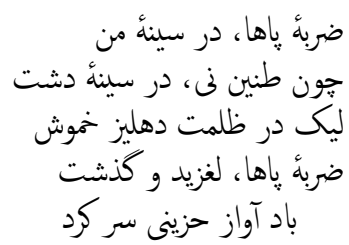

Through an analogy, the persona compares the sound of outside footsteps reverberating in her breast to the sound of a reed in the plain. Ney, the reed, used by many Persian poets, such as Neẓāmī, 'Ațtāar and Rūmī, among others, has accumulated rich meanings and symbolisms in classical Persian literature. As a wind instrument, it produces calming, meditative and often melancholic effects. It has often been played by lonely shepherds in the plains as if blowing their sighs into it. Therefore, this rustic instrument can stand for separation love poems, too. Through its plaintive sounds, the reed reveals the secrets of its separation from its origin. It can also associate knowledge, viz. reed pens and papyrus made of reed. The lean shape and yellow colour of the reed makes it a proper metaphor for the pale and 
melancholic status of the lover suffering separation from the beloved. ${ }^{112}$ In Farrokhzad's poem, too, the sound of the reed recalls the persona's heavy-heartedness as well as the melancholic song of the wind. It also hints at the moans and groans of separation.

The concluding sentence stresses the sad tone of the persona. Her interior mood becomes externalized and is projected onto her outside world. The simple sound of footsteps has given rise to the flimsy hope of companionship in the heart of this desperately lonely woman; a hope which soon turns into hopelessness as the passer-by moves away. By weaving the mirror image into the structure of her verse, Farrokhzad manages to depict the complex problematics of her female self. She can express her sense of self-distancing through the mirror mechanism, which promotes the objectsubject dialectic. According to the discussions initiated by Lacan, the subject remains an image of the image, through projecting an image onto the reflecting surface and then by introjecting that image into the structure of one's self. ${ }^{113}$ The mirror can not only breed illusion, it can also serve as a space in which the illusion can be unveiled. The whole experience she goes through in this poem functions like her mirror experience; she is disillusioned by her dreamlike anticipation of companionship, just as she is disillusioned by the image that reflects the reality of her lonely subjectivity.

The search for identity in the mirror is nowhere more explicitly expressed than in the poem "Gomšode" ("The Lost"), in the collection The Wall. The poem centres on Farrokhzad's inner conflict between her desire to compose poetry and her wish to remain silent and obedient within the walls of domesticity. The title of the poem reveals much about her confused psychological state. The poet persona-again Farrokhzad herself-is lost, oscillating between two or more psycho-emotional states. In this poem, the persona overtly declares that she does not know her real self. She turns to the mirror for an answer. Farrokhzad illustrates the duality of her subjectivity and the incompatibility of her experienced self and specular self, on the one side, and her self-image and the cultural images of womanhood, on the other, through the rhetorical device of illeism. Though the first person perspective is adopted throughout the poem, the subject dislocates itself to the gender-free third person singular pronoun $\bar{u}(\mathrm{~s} / \mathrm{he}$ ) in the first stanza, while still referring to herself. This time Farrokhzad even places it within quotation marks to stress her careful choice, as well as to emphasize its inherent otherness. 
Alas, after all those madnessess, I can't believe that I have grown sane As if the " $\vec{u}$ " $(\mathrm{s} / \mathrm{he})$ has died in me Turning me into one so exhausted, so silent and so futile ${ }^{114}$

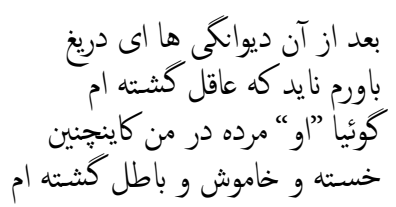

The persona claims that previously she had been behaving madly. But still she cannot bring herself to believe that she has regained her sanity. She believes that this $\bar{u}$ or her former self has died inside her, transforming her into someone exhausted, silent and futile.

In the second stanza, Farrokhzad uses the mirror image to express her lack of a settled identity and the duality of her personality. One self seems to be her genuine self, now referred to in the distanced third person $\bar{u}$, i.e., her authentic self that she has been constantly suppressing in order to comply with the cultural definitions of womanhood and in order to receive acceptance and acknowledgment as a sane woman. By referring to her authentic self by the third person pronoun, instead of the first person pronoun "I," a disparity between her experiencing self and that of her mirror image is signalled-a rift between the speaking subject and the spoken subject, between the see-er and the seen, and between the being and the seeming. Through her cunning manipulation of the pronouns, Farrokhzad conveys a disturbing sense of self-detachment, as well as the essential paradox in mirroring which encompasses both the "I" and the other. This other self-exhausted, dumb und masked - is not even a shadow of her authentic self:

Every moment I ask the mirror in despair,

What else am I, what am I in your eyes?

But in the mirror I see-alas-

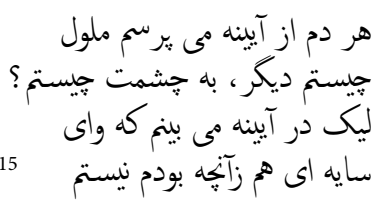

In order to know her self, the persona constantly consults her mirror, the site of introspection. Through this mirror she can observe the emergence of a dichotomy between her former self-with all its "madnesses" - and her present self. The mirror's verdict is cruel: she is not even a shadow of who she used to be. When she turns to her introspective mirror and contemplates the nature of her inner self, she is confronted by a mad woman - the image her culture provides her for the female transgressors of the spheres. Gilbert and Gubar, exploring the image of the madwoman in the nineteenth-century English literature of woman writers, observe: 
The madwoman in literature by women is not merely, as she might be in male literature, an antagonist or foil to the heroine. Rather, she is usually in some sense the author's double, an image of her own anxiety and rage. Indeed, much of the poetry and fiction written by women conjures up this mad creature so that female authors can come to terms with their own uniquely female feelings of fragmentation, their own keen sense of the discrepancies between what they are and what they are suppose to be. ${ }^{116}$

This is valid in this poem where the mad Farrokhzad appears as an embodiment of her fragmentation and duality as well as her anger towards it.

Asking the mirror can also be interpreted as questioning oneself, or a certain aspect of oneself, which again points to a split in the self in a concrete way. This kind of interrogation also signifies the temporality of the mirror, as if the mirror still maintains the images of her previous selves that once appeared on its surface; images with which she can now contrast her present self. In this way the mirror here symbolizes memory, too. The dichotomy subsists between her "false self" or "performative self" - the one formed by self-repression and social role-playings-and her authentic "real self."

Influenced by Freud's notions of self, generally divided into a central part governed by instincts and an outward part for relating to the world, Winnicott divides the self into two: the True Self and the False Self. The True Self, which remains totally or partially hidden to the subject and others, is that spontaneous, instinctive core of one's personality. It is the authentic and vital self developed by the mother's responsiveness to the infant's feeble ego. It gives the subject its sense of reality and it is the self that can truly be creative. On the other hand, the False Self is a defensive mask that the subject develops to protect the "True Self" from social threats and external rules and codes. It is developed, unconsciously, in compliant adaptation to external demands, codes and rules, and in line with the person's attempts to relate to others. The existence of the False Self disturbs the person with feelings of unreality and futility. Others, and even the person himself, at times fail to discriminate between his True Self and his False Self. ${ }^{117}$

In Farrokhzad's case, the "False Self" is developed to protect her "True Self" from exterior threats; to present to the world a picture of a silent and passive woman, settled within her assigned sphere of domesticity, a woman who complies with the forced "figurations of womanhood," or "cultural noise pollution," allowing her thereby to protect herself from being stigmatized as mad. ${ }^{118}$ Following Forugh Farrokhzad's nervous breakdown 
in early September 1955, when she was hospitalized in a psychiatric clinic for about a month, a popular magazine of the time, $H^{w} \bar{a}$ ndani $-h \bar{a}$, published an article under the title "Zan-hā yek dande kam dārand" (Women Have One Rib Too Few), in which the writer says:

Rumour has it that Ms. Forugh Farrokhzad has gone insane. This news reminded us of what the famous poet and writer Tha'ālebi had said: "Poets lack reason, and reason is no criterion of poetry. The daughters of Eve who are lacking a rib, heaven forbid the day when they become poets and beware the day they go crazy-it is truly worth seeing." In any case, we hope the rumour is not true. ${ }^{119}$

Being a woman culturally makes her an object of looked-at-ness, being on the side of gazed upon. Now being a mad woman, a woman who does not conform to society's definitions of sane womanhood, makes her even more worthy of being gazed at.

What is disturbing Farrokhzad at this point in the poem is that she has not completely assimilated her outside image, her mask, the "False Self," into the structure of her being, i.e., her defensive projected image is not internalized. Her present self is being disturbed by the consciousness of radical change. The dichotomy seems to be more between her "former self" and the present "lack of self," a lack of agency, a sort of "selflessness" which is evidently false and performative. In her continual self-effacements, Farrokhzad has struggled to suppress her real self-the active self, useful as well as voiced. This authentic female self with a voice was the one considered mad by the cultural definitions of womanhood; hence, it was forced into silence and futility. Now that her false self conforms to the ideal of the sane, virtuous, silent and passive woman, Farrokhzad feels "futile" and "exhausted" due to the continual repressions.

Finding the "real self" seems to be a disturbed process in Farrokhzad's poetry. In this regard, her "real self" is not necessarily her "former self" nor even her present "silent and futile self," but could be a foreshadowing of what she will grow into in the future, typifying Kristeva's sujet en procèsa continuously plural subject, incessantly mutable. Process of course here retains a double meaning: the subject going through a continuous series of changes, and also continuously committing the subject to trials. ${ }^{120}$ Farrokhzad depicts the experience of her "subject in process" by resorting to a mirror; an instrument which can reveal the multiplicity and fragmentation of a subject to her; the subject which can only be momentarily and 
relationally defined; a subject incessantly changing and incessantly put on trial by the very subject herself. By questioning both the former and the present self, Farrokhzad is struggling to find her "real self"; or, to draw upon Freudian interpretation, by criticizing both her former and her present self, Farrokhzad is straining to catch up with her "ideal self." Nevertheless, the ongoing debate among the antithetical warring selves undermines the notion of a true self as a fixed, established and definable entity.

The continual repression and silencing has led to the persona acquiring a split character. Though she believes that she has been mad previously and doubts whether she has become wise and normal even now, she is sure that she is no longer her true self. Farrokhzad has attempted to murder her "true self" brutally, simply in order to cast the label of "mad" aside, and this has been done with great suffering and self-denial. By echoing the language of her patriarchal society in calling herself mad, Farrokhzad's unconscious internalization of her madness is revealed; madness in the sense of a cultural stigmatizing of female non-conformism as a method of control and punishment.

In the following stanzas, Farrokhzad depicts the source of her inner conflicts and her sense of fragmentation.

Like that Hindu dancer, I am

Stamping my feet with grace, but upon my own grave

Alas, with a hundred unfulfilled wishes I have

Illumined this ruin by my own light ${ }^{121}$

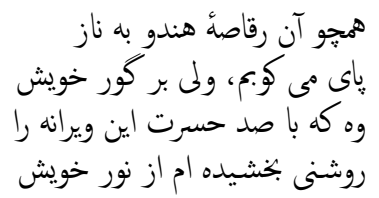

Though she seems gracefully dancing, she is dancing on her own grave. Only by murdering her real self can she stage a spectacle of graceful dance before the eyes of others. Only by rejecting a hundred wishes burning her insides can she bring light into her home, referred to as "this ruin." This is in a ruinous state because it has been built upon the debris of her wishes.

I seek no entrance to the City of Day

Undoubtedly I am slumbering in the depths of a grave

I retain a gem but out of fear

I have hidden it away in the heart of the swamps $^{122}$

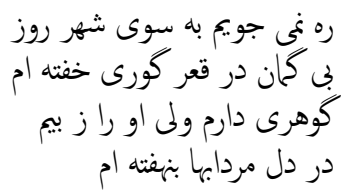


The persona claims that she owns a precious gem, but because of her fears she has hidden it in the swamps. Farrokhzad acknowledges her talent, her desire for her art, but she hides it within the swamps of imposed domesticity for fear of her society's cruel reactions. She tries to force herself to conform to the expectations of her patriarchal culture for fear of being labelled mad again. These irreconcilable conflicts between her authentic self and her desires on the one hand, and the social expectations of silent domesticity on the other, have led to Farrokhzad's painful experience of multiple selves, as well as the internalization of her madness. Hence, at this stage, Farrokhzad does not seek entrance into light, livelihood, song or creativity, but remains in the darkness of a grave.

In the next stanza, Farrokhzad acknowledges that she is being driven passively along, without aim or consciousness:

I am going, but I do not ask myself

Where is the road, where is the station, what is the destination?

I bestow kisses but I myself am unaware

Who is worshipped by this mad heart ${ }^{123}$

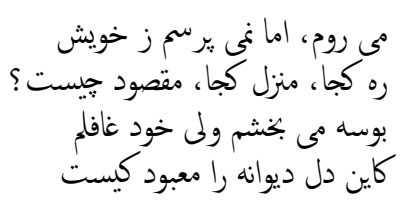

In the final two stanzas of this poem, again she overtly expresses her sense of split personality as well as her madness:

When $\bar{u}$ (s/he) died in me, suddenly whatever there was

Took on another expression in my view

As if night with his two cold hands

Cloaked in my restless soul

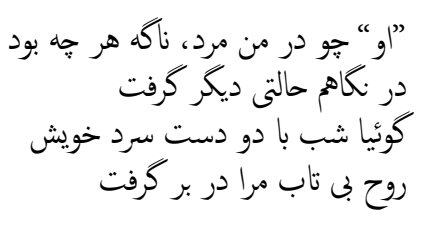

آه، آرى اين منم، اما هه سود

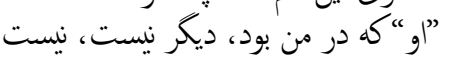

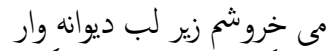
"و "كه در من بود، آخر كيست، كيست؟

Madly I roar under my breath

This $\bar{u}$ (s/he) who was in me, who is

it after all, who is it? ${ }^{124}$

Together with her "former self," Farrokhzad finds all of her old worldviews dead; she has cast off her old perspectives. Though she, like the Hindu dancer, stamps her feet, it is over her grave-death-in-life. In her quest for 
the authentic self, Farrokhzad turns to her mirror for an answer. She asks the mirror, as well as herself, to reveal the identity of that $\bar{u}$, the "former self." Here, Farrokhzad plays with the tenses: she uses a present tense question word kist (who is) for the bygone self, and a present negative for the $\bar{u}$ who nist (is no more). She asks herself "who 'is' this $\bar{u}$ who 'was' in me," a method through which she aesthetically demonstrates her split personality and her madness. The sentence also reveals that the uncanny ghost of this dead $\bar{u}$ is still lingering inside her.

In this poem again the mirror is expected to see, speak and answer her questions. The mirror is supposed to be in possession of the knowledge she seeks. Her mirror appears to be a modern descendent of the Persian omniscient mirror, the catoptromantic $\breve{g} \bar{a} m-e$ ğam. It is expected to resolve the psychological conflict of a modern woman, caught in the in-between world of tradition and modernity. The mirror, with its power to provide the onlooker with her ethereal transient images, with the otherwise invisible psychological interiority, facilitates the portrayal of Farrokhzad's "subject in process." For the female "subject in process," the surface of the mirror turns into a court where she continuously puts her subjectivity on trial. In the continual process of becomings and trials, Farrokhzad does not return to someone she was, but incessantly becomes a new person, adopting new perspectives, even though her "old self" lingers on, on the surface of her mirror. The title of the poem and the final line explicitly show the painful psychological crisis she was going through and her desperate search for her definition of self.

In this poem, Farrokhzad believes that she has been "burned," "silenced," "exhausted," "futile" and "dead," has become one who does not even seek entrance into the city of light. By inscribing a portrait of her problematic self into her text, by unveiling the irreconcilability of cultural codes with her inner desires and talent, and by objectifying them in her text, Farrokhzad gains knowledge and thereby control over them, foreshadowing a more liberated subjectivity. Farrokhzad is struggling to come to terms with the multiple images reflected in her mirror. Through this very act of voicing her madness, her forced entrapment and her silenced position, Farrokhzad steps beyond the private and becomes, in feministic terms, political. By textualizing her silence and invisibility, her very text becomes a loud clamour against the silencing and invisibility of woman forced upon her by her culture. 


\section{The Mirror of the Memory and of the Imagination}

In July 1956, Farrokhzad left Iran for the first time. She travelled for about nine months to Italy and Germany. In the same year, she published the memoirs of this journey under the title, "Dar dìyāri digar" ("In Another Land") in the influential magazine, Ferdowsī. ${ }^{125}$ This trip provided Farrokhzad with enough distance, enabling her to acquire another perspective on her society. It also provided her with respite from all the lingering rumours and the suffocating sense of confinement at being a cultural misfit.

The poem "Bāzgašt" ("The Return"), composed in September 1957, recounts Farrokhzad's melancholic experience of re-encountering her hometown Tehran and noticing the differences of ambiance after her stay in Munich. The poem, composed in thirteen quatrain stanzas, is narrated in the first person. In the first stanza, the street line comes to its end. The persona-Farrokhzad herself-arrives dusty, her eyes rushing ahead while her lips are holding "a warm greeting." In the second stanza, she recreates the atmosphere in highly metaphorical language: "in the furnace of noon," the city was boiling; the alley was burning in the "fever of the sun." Her feet, shaking uncontrollably, proceeded along the "mute cobblestones." In the third stanza, Farrokhzad depicts the differences that her eyes discerned between her hometown and the place whence she had returned, thus:

The houses were of a different hue

Dusty, dark and depressing

The faces between the veils

Were like ghosts in fettered feet ${ }^{126}$

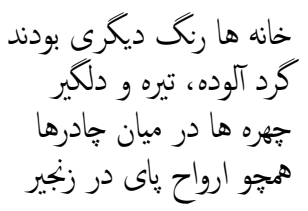

Being a female observer, the difference in women's appearances and their mood in the two countries is what catches her attention first. In Tehran, she comes across women as ghosts enchained. Within their veils and chains, they represent Coleridgian "Life-in death," represented in his "The Rime of the Ancient Mariner." ${ }^{127}$

In the following six stanzas, Farrokhzad provides an unrolling series of discrete images of what she had encountered upon her arrival through metaphors and similes: the dried-up stream like a blind eye was empty of water or any trace of it; a singing man passes by, his song filling her ears; the familiar dome of the old mosque was like a broken bowl; a believer was reciting the azān (call to prayer) in a melancholic melody from the minaret; barefoot kids holding stones were chasing dogs; a woman laughed from 
behind a veil; the wind made a shutter slam shut; the dark openings of the vestibules reeked of the damp of the grave; a blind man was walking with his stick; someone familiar was approaching. Then the persona reaches her house. Again she depicts her arrival through discrete images: a door silently opened; stretched hands invited her to an embrace; a tear dropped from the cloud of an eye; hands repelled her. Within the house, on the wall the old ivy still rippled like a trembling fountain; over the body of the ivy's luxuriant leaves was the greenness of old age and the dust of time.

In the tenth stanza, upon her entering the house, her eyes search for a sign of her son, but she finds that her room is devoid of his childish cries:

My eyes asked searchingly

"Where is a sign of him?"

But I saw that my small room

Was devoid of his childish clamour ${ }^{128}$

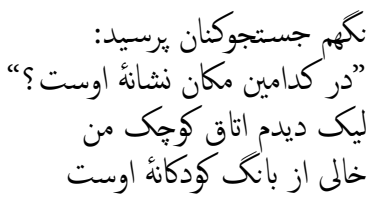

Farrokhzad is desperately looking for her son, Kāmyār, of whom she lost custody when she was divorced, even to the point of being denied the right to sporadic visits. Therefore, she indulges in her memory of him and the visual images stored in it. In her delusion she can see him in the mirror:

From the heart of the mirror's cold earth

His body, like a rose, suddenly grew;

His velvet eyes rippled,

Ah, even in [my] delusion he was seeing $\mathrm{me}^{129}$

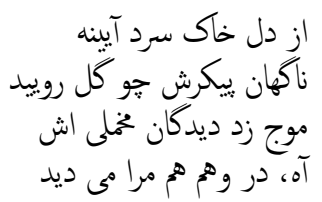

Here, Farrokhzad compares the surface of the mirror to the "cold earth," from whose core the memory of her son's body and his eyes simultaneously blossom like a flower. The mirror is cold; it is a dispassionate, objective reflector. It is indeed the graveyard of her memories. In her maternal desire to blur the boundaries between herself and her son Kāmī (shortened form of Kāmyār), Farrokhzad resorts to the mirror's delusive quality. The mirror has been traditionally associated with the imagination and consciousness, because it, like the imagination, can reiterate a picture of the visible world and its reality. Indeed the mirror has traditionally been considered "a metaphorical prism of the imagination." ${ }^{130}$ The close association of the mirror and the imagination or dream is due to their common opacity of images, their transient ethereality; being capable of surprising us by making visions suddenly appear and disappear in our psychological illusions. Farrokhzad's 
mirror in this poem has a magical quality. It can reflect things across time and space, just like the classical $\breve{g} \bar{a} m-e$ ğam. Yet Farrokhzad is well aware that this is no more than her delusion.

Farrokhzad relies on the psychological interiority of the mirror fleetingly to ease the terrible pain of loss she was experiencing; hence, for her, the mirror provides a transient utopian space where she can experience the presence of her son; a space in which not only can she see him, but he can see her also; this simultaneity of seeing and being seen can be enacted through one's mirror. As explained in Chapter One, the virtuality common to the mirror and memory has given rise to recurrent references to each in terms of the other. In both these ambivalent spaces, memory and mirror, the duality between reality and virtuality, the illusion of reality and the reality of illusion are negotiated. The mirror as a memory is transformed into the "cold earth" of a grave of dead experiences, where the spirits of bygone things grow like vegetation.

The mirror functions not only as a site of illusion and delirium; ironically, it is a site where the reality of an illusion is unveiled, often leading to a series of other painful disillusionments. In the following stanza, the mirrormemory-imagination fails in its function of producing an image; it can no longer retrieve an image, a body or a presence. It can produce nothing but a name:

I leaned against the wall's breast, Softly I said: "Is this you, Kāmī?"

But I saw that from that bitter past Naught but a name remained ${ }^{131}$

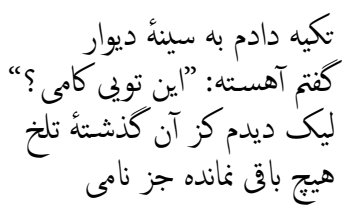

Through the mirror, as well as the imagination and memory, things lose their substance and are cast into transient ethereal existence in the form of images. Her son loses substance while being transformed into an image. Then the name and image as signifiers lose their referent, the signified, as the image disappears from her mind-mirror, leading to her disturbing disillusionment as to the presence of her desired figure.

The melancholic tone of the poem corresponds to the dark and ghostly images that Farrokhzad depicts. Farrokhzad concludes the poem with a repeat of the opening stanza, adding that her hometown is indeed the grave of her desires; a town that fetters women into veiled ghosts and murders their dreams and desires; a town that abrogates the visiting rights of a mother to her only child: 
At last the line of the road ended

I arrived dusty from the journey

The thirsty could not find a way to the

spring and alas

My town was the grave of my wish ${ }^{132}$

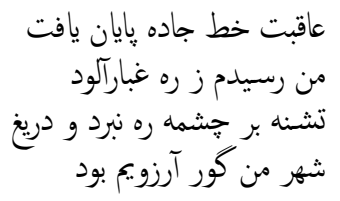

By bringing reality and imagination together, the mirror can become a site of desires. In this poem, the mirror is a utopian space where the persona imagines the presence of her son of whose company she has been cruelly deprived. In her illusion, she fulfills - at least momentarily-her desire by unearthing the images buried in her mirror-memory. Her poem serves here as a mirror for her self-expression; as a space in which she can give voice to her desires; the desires which should not be disclosed in the world outside, let alone be fulfilled.

\section{The Grotesquery of the Mirror Image}

It is generally assumed that mirrors reiterate exact replicas, reflecting the objects before them as they really are. But in fact there is a distortion to mirrors in that they give back a reversed image - a reversal of left and right, and even in some cases top to bottom. There can be an even greater distortion to the mirror than the mere reversal of right and left. Walker calls mirror's process of reversal "the chiasmus of perception." ${ }^{33}$ The perfect mirror is only a theoretical one; indeed, domestic mirrors, absorbing a significant portion of the light cast on them, are far from being perfect. This distortion and the inherent otherness of the specular image have persistently appealed to the imagination of poets and artists. Through the mirror image, the poet can perceive and represent the reality of a being, as well as the reality of an illusion. Ironically, one can also perceive and represent the illusion of a reality and being, owing to mirror's highly ambiguous nature. Therefore, the mirror has been repeatedly employed as a deceptive tool in literature. ${ }^{134}$ Farrokhzad too relies on the reversing and distorting characteristic of the mirror and the delusory otherness of its image in her portrayal of grotesque imagery. By resorting to the inherent distortion in the mirror, Farrokhzad depicts the disharmony, the grotesquery, and as well the lack of a rational relationship between the self and its image, between the self and the outside world or even between any social and cultural phenomena. ${ }^{135}$ 
Farrokhzad's apocalyptic poem "Āye-hā-ye zamīn̄" ("Earthly Verses"), published in the collection Another Birth, contains many evocations of the Old Testament and Qur'ān. The poem is prophetic, and the persona has in fact turned into a prophet. ${ }^{136} \mathrm{In}$ this poem, Farrokhzad presents a portrayal of the eschatological yawm al-qiyamat (the Day of Resurrection or the Day of Judgment), and the ähir al-zamān (the End of Time) as described in the Qur'an; the day when darkness, chaos, confusion and tyranny overwhelm the earth. On that day the sun grows cold; darkness spreads; blessings flee the earth; all vegetation dries up; the earth rejects its corpses; roads lose their continuance; nobody thinks of love, of triumph or of anything; loneliness and futility reign supreme; blood stinks of drugs; infants are born headless and cradles take refuge in the grave; they are "bitter and black days" when bread has defeated the wondrous power of prophecy. ${ }^{137}$ In the sixth stanza, Farrokhzad resorts to the mirror's distorting feature and the inherent other-ness of the specular image to present a portrait of the grotesquery of the world outside and the social disorder:

As if in the eyes of the mirrors

The motions and the colours and the images

Were reflected, inverted

And above the heads of the debased clowns

And the harlots' shameless faces

A glowing sacred halo burned

Like a parasol aflame ${ }^{138}$

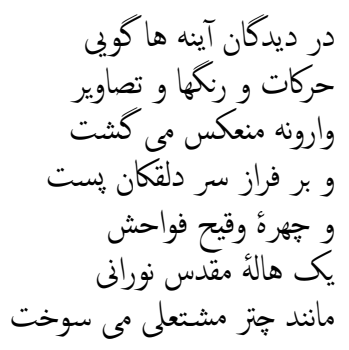

Here, once again, the close reciprocity of the mirror and the eye has been restored in the metaphorical use of "the eye of the mirror." ${ }^{39}$ Through the eye of the mirror, one can perceive and reflect naked realities, whereas the eye, without the help of the mirror, would be drawn into the illusions persistently induced by the outside world and personal inclinations.

Through this mirror, Farrokhzad acquires the artistic ability to reveal the reality of the illusionary world without. The mirror as a delusory site helps the onlooker realize the reality of illusions as well as the illusion of realities. Farrokhzad sees no rational relationship to the phenomena of her cosmos. All that she finds is uncanny grotesque imageries. Farrokhzad herself once said in an interview, "If you pay close attention you will see that we are living in a period of time when all concepts and scales are losing their meanings and are becoming, not to say valueless, but shaky." ${ }^{140}$ And elsewhere she argues, "[the world outside] is so inverted that I don't want to believe in 
it." 141 Through reflecting on the nature of the illusion, Farrokhzad uncovers the uncertainty and precariousness of the real.

Farrokhzad manipulates the delusory nature of the mirror to depict the grotesquery present within her society and its value system. In the midst of her surroundings, she perceives a lack of rationality, a disharmony in the rules governing her culture. Through her mirror image (and by extension, through her art) Farrokhzad demonstrates the distorted reality of her outside world. The world in the mirror emerges as more reliable than the source world. The distortion in the mirror is emphasized not to delude but to reveal the already existing delusion. In fact, the logical distorting function of the mirror is pushed further into the realm of illogicality, in order to reveal the illogicality of the values and relations within her world. All she can see in her world are inverted, false values. Within her society, the individuals with the lowest traits are idolatrized.

This reversal of values for the poet marks the End of Time, as described in the sacred texts on the apocalypse. Through the inherent distortive feature of the mirror Farrokhzad reveals her painful bewilderment, as well as her contemptuousness. Apocalypse (in Persian mokāšafa) literally means "unveiling" or "lifting of the veil." Also recurrently employed as a Sufi term, apocalypse is the time when the veils of all misconceptions and falsehoods, dominating the world of mankind, are lifted and the naked realities are revealed to the Sufi. The mirror as a space of misconception seems to be the most appropriate site for revealing the misconception to the beholder. The surface of the mirror not only reveals the visible world, the world of appearances; it is also a very space where the veil of appearances is lifted and the invisible is rendered visible. In this poem, Farrokhzad manipulates the mirror image in this sense to unveil the grotesquery, the misconceptions and falsehood dominating her society.

The poet continues by depicting the world in a series of discrete images: the intellectuals have drowned in swamps of alcohol; the mice have chewed the pages of the books; the sun has died and the word "tomorrow" has a confusing obscure meaning in the minds of children. It is a time when people, dead in the heart, slim and bewildered, carrying their evil corpses, keep migrating from one strange land to another, while a painful lust for crime swells in their hands. Farrokhzad continues by portraying an excessively depressing dark and violent image of man and his world. In the final stanza, the persona, addressing herself as a captive in this uncanny grotesque world, starts wondering if "voice of the prisoner," "last voice of all voices," would ever be able to dig its way from this side of spiteful night to the other side of light. ${ }^{142}$ 


\section{The Mirror and the Window}

Through constant oscillation between the mirror and the window in her poetry, Farrokhzad demonstrates the complex reciprocity of one's selfimage and one's worldview, the "I" within and the "I" without. The "alienated," "frozen" and "reversed" image in the mirror (to draw upon Lacan's terminology) serves to bridge the gap between the subject and the world. ${ }^{143}$ The function of the mirror stage, inaugurated by the child's initial selfrecognition of his mirror image, is to establish a relationship between the two dialectical worlds. Lacan holds that the initial recognition and identification of the image in the mirror, which serves as an introduction to a process of lifelong identifications, is essentially a méconnaissance (misrecognition). In Freudian terminology (which Lacan turns to), these two worlds are known as the Innenwelt, the imaginary interior space that the "I" occupies, and the Umwelt, the external physical world in which the living human subject is situated. Lacan emphasizes the essential role of the mirror image as a "virtual complex" in the development of the human psyche and the individual's entry into social and linguistic identity. In the case of Farrokhzad's poetry, Sandler observes that the window provides the speaker with "a sense of connection":

Unlike the problematic embrace of a lover, the window is a reliable haven. The window provides a sanctuary that is much more effective .... The window is a place for reflection, for writing .... The window is the place where the poet makes contact with the sum and substance of her existence. ${ }^{144}$

Like the mirror, the window provides her with relatedness, not only to her most inner self (Innenwelt), but also to the world outside (Umwelt). Farrokhzad constantly oscillates between the window and the mirror as her means of "awareness." In her poetry, the blurring of the distinction between these two dialectical worlds, the Innenwelt and the Umwelt (normally represented by the mirror and an opening such as a window) reveals the complex interaction of the self-image and worldview. For instance, in the poem "Dìdār dar šab" ("Meeting at Night"), all through the night the speaker is involved in a desperate dialogue with an "astounded face" which she spies through an opening, variously called a shutter, a window or a crack. ${ }^{145}$ What at first seems to be an apparition turns out to be the reflection of herself. The poem is a narration of her painful experience of encountering an eidetic projection of herself. 
The adjective šegoft (or šegeft), used here as an attribute of the face, in Persian denotes astounded, bewildered, strange and foreign, as well as miraculous. Thereupon, by the synecdochic phrase čehre-ye šegoft-face here referring to the person, to a subjectivity in toto-not only is the confused and astounded state of the subject conveyed, but so is its foreignness and strangeness when regarded in an objective position. In addition, by the use of "miraculous," the uncanniness (Unheimlichkeit in Freudian usage) of experiencing the fragmented duality of ego is implied. It is through this window-mirror that the invisible presence intrudes itself, making itself perceptible and visible. This unknown presence, the frightening stranger within, is what Freud calls Unheimlich, literally "unhomely" and often translated as "uncanny." Freud defines it in the following words:

Thus heimlich is a word the meaning of which develops in the direction of ambivalence, until it finally coincides with its opposite, unheimlich. Unheimlich is in some way or other a sub-species of heimlich. ${ }^{146}$

Therefore, there seems to be no clear demarcation line between the two terms of canny and uncanny and their feelings. As portrayed here in Farrokhzad's poem, there is fluidity between the two presences.

Death and a sense of nihilism overshadow the whole poem. Farrokhzad encloses the words of the other-I-the "astounded face," referred to in the gender-free third person $\bar{u}$ (s/he) - within quotation marks to make it distinct from the words of the speaker, who interrupts only to pass on her descriptive observances. The poem begins:

And the astounded face

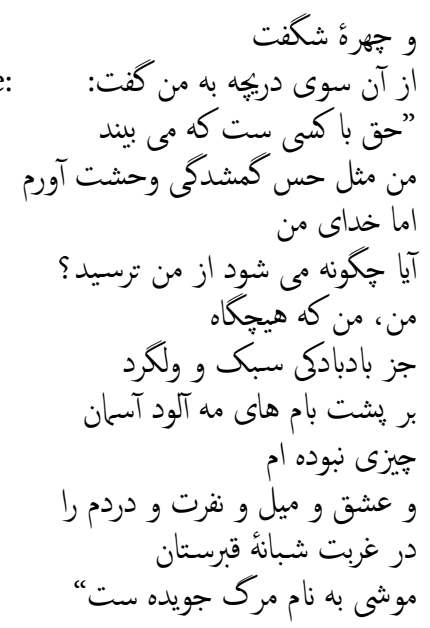

From the other side of the shutter told me:

"Whoever sees is right

I cause fear, like the feeling of being lost

But, my God,

How is it possible to be afraid of me?

Of me, me

Who has never been anything

But a light vagrant kite

Above the fog-wreathed roofs of the sky

And a mouse named death

Has gnawed my love, my desire, my hate, and my pain

In the nightly exile of a cemetery"147 
Seeing this "astounded face" - a ghostly, uncanny and haunting selfthrough a shutter fills the speaker with an overwhelming sense of horror. The nightly visitation renders this strangely familiar presence even more uncanny. It is the sense of being lost-the realization of the fragmented and detached self-that fuels her panic. The speaker is confused, unable to decide between the realities of two present entities: the self she is experiencing or the self she is visiting. In her struggle to bring the fragmentation of the self into a unity, to resolve the conflict, and to decide which one is real, the face in the opening tells her: "Whoever sees is right"; acknowledging the power on the part of the see-er over the one being seen; the gazer over the gazed upon. ${ }^{148}$ This claim to righteousness apparently fails to resolve her inner conflict. It is because in specular experience the subject assumes both positions simultaneously, that is she is both the subject and the object of the gaze.

In her horror, the speaker poses another rhetorical and ambiguous question: "How is it possible to be afraid of me?" Are others afraid of her, or is it she who is afraid of herself? In any case there exists a monstrosity, something unknown and un-named as the cause of such a horror. The persona reveals her inability to recognize and acknowledge her own image partly through the grammar of the poem. At this point, again, Farrokhzad turns to illeism; she opts for the gender-free third person singular $\bar{u}(\mathrm{~s} / \mathrm{he})$, despite having adopted the first person man ("I") elsewhere in the poem. The shift of perspective points to the disparity between the experienced self and specular self, and between self and the body, which makes the speaker (and by extension Farrokhzad) feels so lost and terrified. The second stanza continues:

And the astounded face

With those faint protracted lines

Whose fluid traces the wind, moment by moment

Was effacing and altering

While the hidden movement of the night was stealing

Its soft, long tresses

And was spreading them all over the night's reaches

Like the plants of the seabed

Flowing on the other side of the shutter

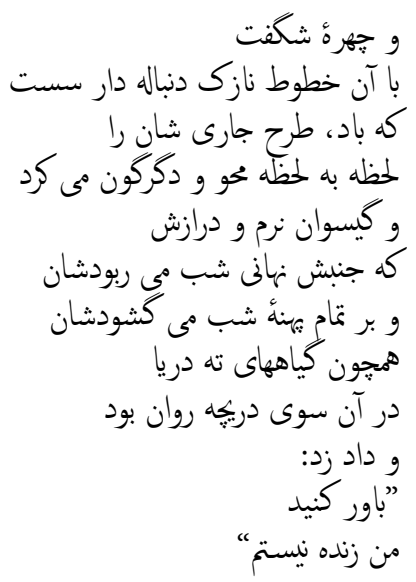


And it shouted:

"Believe me

I am not alive"149

The speaker is here expressing her horrible experience of an unstable, fragmentary and fluid self. She is indeed going through a painful crisis; unable to see her face within its borders. The shutter is functioning as a mirror for her, reflecting her face back to her. The omnipresent stranger, this unknown, alienated "I," frozen into an image, declares herself to be dead: "Believe me/ I am not alive." By the paradoxical declaration of herself to be dead, a self-contradiction in the starkest terms is revealed. As La Belle asserts. "To exist in multiplicity is, in a sense, not to exist at all because selfconception requires some conviction in the singularity of one's being." 150 What she observes through the terrifying/terrified other "I," or the $\bar{u}$ (s/he), is an accumulation of darkness. Although the speaker can discern the outside world and "the pines' silver fruits," she is all the time conscious of the presence of this stranger; this other-ness spreading itself over all inside and outside phenomena. The persona feels powerless to free herself from the overwhelming existence of this omnipresent duality:

Beyond s/he I could still see the congestion of darkness

And the pine's silver fruits

Ah, I could see, but s/he ...

Was slipping over them all

And his/her infinite heart was reaching its peak

As if s/he were the green feeling of the trees

And his/her eyes were extended into eternity ${ }^{151}$

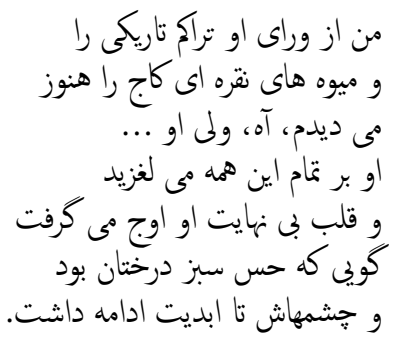

The guilt-ridden part of Farrokhzad's personality, hiding and being repressed in the mornings, is what Jung called "shadow." 152 The projection of the illusory shadow obliterates one's relation with his/her outside world and instead poses an illusory one:

As we know, it is not the conscious subject but the unconscious which does the projecting. Hence one meets with projections, one does not 
make them. The effect of projection is to isolate the subject from his environment, since instead of a real relation to it there is now only an illusory one. Projections change the world into the replica of one's unknown face. ${ }^{153}$

The speaker's inner darkness extends itself over every outside phenomenon. As mentioned earlier, the colour green, for Farrokhzad, is recurrently associated with illusion and imagination. ${ }^{154}$ The illusory sense of the "I" permeates whole the world where this "I" is positioned. The other "I" is an illusionary green image of herself-"like the plants of the seabed." It is indeed a mirror image, which by its metaphoric/metonymic representation of the self remains essentially illusive. To emphasize her terror of the self, the speaker turns to the mirror in the fourth stanza, where she can observe herself as dead:

"You're right

I have never dared to look

Into the mirror after my death

And so dead am I,

That nothing remains to prove

My death

$\mathrm{Ah}$,

Did you hear the cricket's cry

From the far end of the garden

Which under the shelter of the night, was fleeing to the moon? ${ }^{155}$

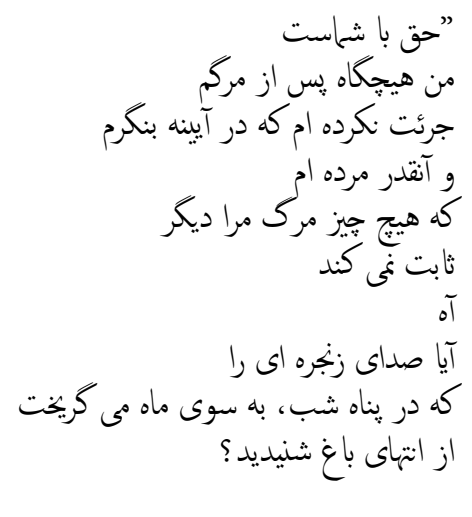

Death has wiped out her existence so thoroughly that no one can ever prove that she has even died; as if she had never lived. The speaker seems to have developed an eisoptrophobia; she fears encountering her mirror image because it is within her mirror that the multiplicity, fragmentation and the frightening otherness of the self, as well as her death, are enacted. Shengold observes that "Associations to mirrors sometimes connote denial: it's only a reflection, it doesn't count."156 In a context where the person confuses the self with its image, subject with the object, and the real with the illusory, denial of one's existence is a natural outcome. The speaker feels that she has no existence beyond that reflected image in her mirror. Through internalization of the specular image-ethereal, transient and immaterial in its essence-she feels $d e$-substantiated and $d e$-realized in the process. The 
persona seems to be trapped between the two worlds of life and death. After confessing to being "so dead," she is suddenly given a hint of life by hearing the sound of a cricket.

In the following stanza, the speaker believes that all the stars have migrated to a lost sky. Her city is a ghostly necropolis; so depressingly silent that, on her way, she meets nothing but a few pale statues, street-sweepers and sleepy patrols. Farrokhzad not only considers herself dead, she extends this lifelessness to the world outside and to others. Later in the same poem, she depicts people as corpses:

I think all the stars

Have migrated to a lost sky

And the city, how silent was the city

All along my way, I

Faced nothing

But a group of pallid statues

And the exhausted sleepy patrols

And a few street sweepers

Reeking of garbage and tobacco

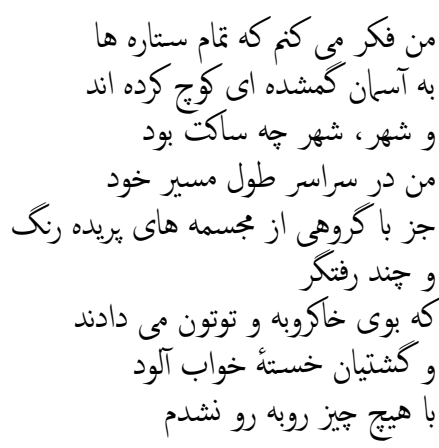

Alas

I am dead

And this night still seems to be

The extension of that same futile night"157

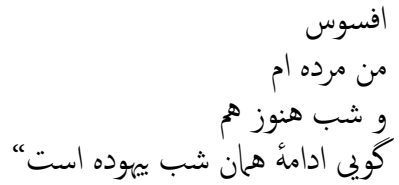

Once again, Farrokhzad reminds the reader that she-ironically the speaking persona-is dead and her outside world is the extension of the same absurd world described earlier in the poem. At this point Farrokhzad closes the quotation mark, adopts the perspective of the other "I," and inserts her observation. The "astounded face" turned silent and felt the blurring bitterness of tears in her eyes. This shift of perspective and the self-objectification are a sort of defence mechanism at a time when pain or terror becomes overwhelmingly unbearable. By watching herself in this way as an object whose eyes are filled with tears, instead of acknowledging herself to be subjectively crying, she takes the edge off the pain, making it more bearable. In the following stanza, the other "I" resumes her dramatic monologue, addressing the reader in the second person as "you": 
"O you who hide

Your face

In the shadow of life's depressing mask

Have you ever pondered

The grievous truth

That the living beings of today

Are nothing but the discarded pulps

of a living one?"158

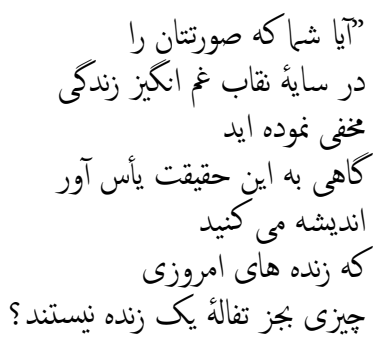

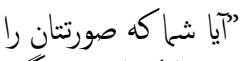
كخفى نموده ايد

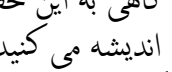

كه زنده هاى امروزى - مكيد

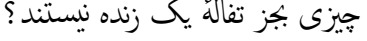

On the other hand, the persona is addressing herself whom she is visiting through the opening, the one who is hiding her true identity behind a mask, adopting images other than her own, and in the process turning to mere "discarded pulps of a living one."

In this and the following stanzas, Farrokhzad portrays the tragedy of modern man in his grotesque modern world: when the baby becomes old in his first smile; when the heart does not trust its own stony validity; when the addiction to being and to tranquilizers has abolished all the pure, humane desires; when the spirit has been exiled to an uninhabited islet; when swift-footed cavalry have turned into infantry, leaning on their spears; when the high-thinking mystics ('äref-än) have turned into lean curved opium takers; when man is no longer awaiting any Advent; and when the girls-in-love have pierced their incredulous eyes with long embroidery needles. The persona even doubts hearing the sound of the cricket, a sign from a different kind of world; perhaps it was in her dreams that she heard it. $^{159}$

In the twelfth stanza, the second mirror image of the poem appears. This time the mirror is personified; thereby granted a power beyond the power of individuals.

Now the cawing of the crows

Is felt

In the depths of morning slumber

The mirrors come to consciousness

And the isolated lonely forms

Surrender themselves

To the early trail of wakefulness

And to the secret onslaught of ominous nightmares ${ }^{160}$

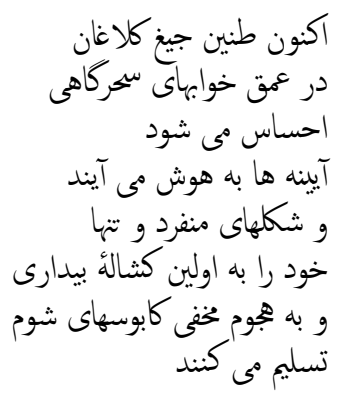


The crow, this black carrion-eating bird, is like the raven associated with imminent death. ${ }^{161}$ It is a messenger bird-an "ill-omened gossip monger." 162 The presence of a crow in a given place or its cry is considered a bad omen. In the Persian mystical cosmos, crows and ravens are also symbols of the mundane, material lower world. ${ }^{163}$ In this poem, the crows accompany the arrival of morning, but it is the mirrors that wake up, not the people.

Farrokhzad metaphorizes people to the mirrors and paradoxically an awakening to the swarming of nightmares. In this interpretation, people are reduced to their specular image, to the appearances of the lower world. They are merely what can be seen within the confines of mirrors: mere soulless, flat images, and nothing beyond. It is only their physical bodies, visible in the mirrors, which are waking up, while their true selves remain dormant or even dead, exiled on an isolated island. Here, Farrokhzad draws upon the reversing, distortive and delusive nature of the mirror to portray the state of modern man trapped in his delusions and delirium: it confuses man with his mirror-image, nightmares with wakefulness and realities with illusions. Therefore, the distortive delusionary nature of the mirror promotes the delusory and delirious man, when he is in fact an image of his image. ${ }^{164}$

In the fourteenth stanza, Farrokhzad closes the monologue, once again to insert the persona's observation of the other uncanny "I"- the "astounded face" -in the third person. Crumbling down on her both sides, she extends her begging hands towards the persona (in the first person) through the cracks:

S/he trembled

And tumbled down on her both sides

And through the cracks, her begging arms

Like extended sighs

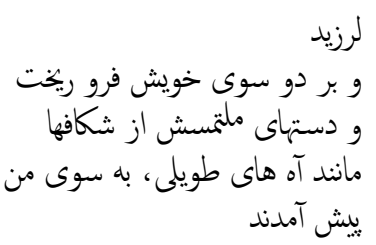

Fantasies of corporeal disintegration, decomposition and dismemberment, as expressed in this poem (as well as in other poems by Farrokhzad), bear similarities to fantasies manifested in the dreams of depressive and neurotic people. According to Lacan, before the identification of self in the mirror, the child conceives of himself as a corps morcelé, in a "fragmented image of the body," as an aggregate, or a body in bits and pieces. ${ }^{166}$ With the identification and internalization of his mirror image, the child can, for 
the first time, conceive an image of his body in its gestalt; a totality, as a whole body. Yet at times of psycho-emotional crisis, the disturbed subject fears regressing to the previous infantile state of having an "aggregate" or fragmented body; an anxiety which seems inevitable.

Farrokhzad's fantasies of disintegration, decomposition and fragmentation are further explained in an undated letter to her ex-husband, Parvīz Šāpūr. In this letter Farrokhzad expresses her bodily experiences thus:

I am very mad tonight. ... Nothing can fill the loneliness of my soul.... I wish I could, like others lose myself in the absurdity of life. ... I am very lonely. Today I was watching myself in the mirror. Now, gradually I fear my face. Am I the same Forugh? Am I the same Forugh who used to stand in front of the mirror from morning till night and make herself into a hundred faces and was contented with it? Are these sick eyes, this broken and gaunt face and these untimely lines beneath the eyes and on the forehead mine?

... My dear Parviz, it is not easy to persist. Desperation, like a termite, is turning my soul into dust .... I don't know where I will end up with these sick nerves. ... If I don't leave here I will go insane. ... I have a clear sense that I am decomposing day by day. Sometimes it is as if I collapse into myself. While walking in the street, I feel as if my body turns into dust and collapses from my sides. ... but I am well aware that I can no longer deceive myself. My soul is burning in the hell of distress and I am gazing into its ashes with desperation. ${ }^{167}$

This passage from a letter, as do her poems, bears clear testimony to the desperate loneliness and outcast position of a woman poet in Iranian patriarchal culture. In the lines cited above, Farrokhzad also refers to an earlier phase when looking into a mirror was extremely copacetic to her narcissistic vanities. Here, she overtly talks about the fundamental changes in her relationship with her mirror image. She has gradually distanced herself from these definitions. The mirror is no longer a place of solipsistic self-love, a place where she can make herself pleasant for the male gaze, or even the replacement of his gaze; it is now a place within which she fears encountering her true self, a place where her fragmentation surges into view, where she casts off her adopted mask for the world.

The mirror/window provides Farrokhzad with a space in which she can see the strange uncanniness, soullessness, confusion and absurdity of her being and that of other individuals; it is where their voicelessness and their 
immobility, otherwise invisible, are rendered visible. Individuals turn into "exterior," "alienated" and "frozen" entities, just like their mirror images. It is for this reason that Farrokhzad says it is the mirrors that wake up in the mornings, not the people. The fragmentation of the self is often translated into the fragmentation of her whole world, where she is unable to find any logical relationship among the exterior realities. As revealed in many of her poems, Farrokhzad sees a continual process of disintegration and degeneration working within any outside or inside phenomenon.

In the following stanzas, the "astounded face" continues her monologue thus:

"It is cold

And the winds slash through my [body border] lines

Is there anyone left in this abode

Who does not fear

Meeting

Her own annihilated face?

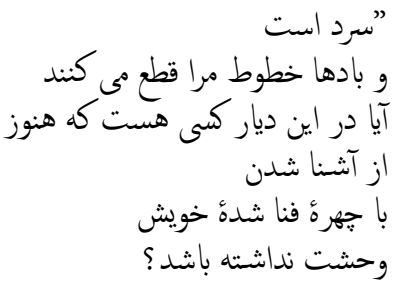

Hasn't the time yet come

To open this window wide wide wide

For the sky to rain down

And for man mournfully

To pray over his own corpse?"168

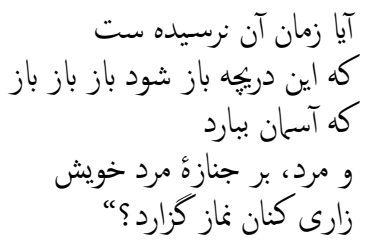

These two stanzas, in which the "astounded face" finishes her speech, foreshadow a shift. With the approach of day, the time for a change in the person approaches; time for casting off the old mask; for the death of depressing multiplicity and for the death of otherness. The "astounded face" wonders if the time has arrived for self-realization and the resolving unity of inner fragmentation.

In the last stanza, the persona reveals her confusing uncertainties and doubts. The poem is a candid portrayal of the subject's standing on trial before herself as a merciless judge all through the night-Kristeva's sujet en procès. It is a subject in a state of constant change which defies any fixed and ever-valid definition; a subject who is not only changing all the time, but is also constantly on trial, questioning and rejecting former identities, as depicted by Farrokhzad's posing many questions, as well as by her 
metaphorical, metonymic and synecdochic analogies. The window, mirror and her text turn into her courtroom, providing the heterotopic space for this trial. At the end the subject is left alone with the strong feelings of ta'asof (regret), šarm (shame) and dard (pain) before the bitterly reproaching, synecdochic, hands of the judge.

Perhaps it was the bird that moaned

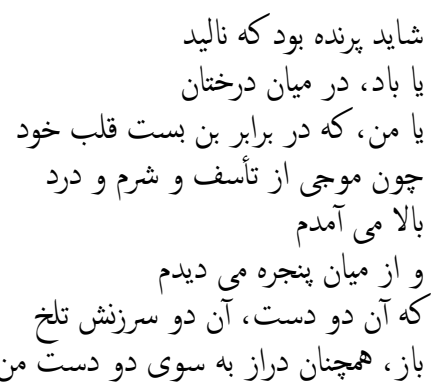

Or the wind among the trees

Or was it me myself who against my heart's impasse

Was rising

Like a tide of regret, shame and pain

And through the window I could see

Those two hands, those two bitter reproaches

Still reaching out for my two hands

Were fading

In the false dawn's light

And a voice on the cold horizon

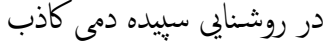

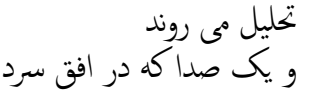

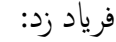

"خداحافظ" (خط"

Cried out:

"Farewell"169

In this poem, Farrokhzad employs the words dar-ī-če (small door, shutter), a'ine (mirror), šekāf (crack), and panğare (window) alternatively as the means for introspection and encountering the alter idem-the other self; therefore, they all function like a mirror by reflecting her self, or a part of it, back to her. ${ }^{170}$ The speaker's other "I" emerges on a lonely night like a ghost and starts to melt away by the "false dawn," leaving her lonely again. In this "false dawn" she evokes her "false self," the performative self shaped or imposed on her by social dictates. When women have to adopt images so distanced from their real ones, it is inevitable that they come up with such disturbing fragmentations.

For Farrokhzad, the real self, who apparently disappears in the mornings, haunts her on real nights, at the time when she is free from social masks. With the "fake dawns," paradoxically associated with evil dreams and nightmares, the ghosts of real selves abandon the city, while the mirrors, the appearances and the masks start to wake up. Apart from oscillating among the mirror, window, and other opening imagery, Farrokhzad plays with different perspectives: "I," "s/he" and even "you"-illeism and tuism—in order 
to express her tumultuous experience of an uncanny ego, fragmentation and split personality.

Farrokhzad herself explains her intention as to the meaning of this poem in the following words:

Everything was upside down. Even I myself was upside down. I hated this desperation of mine and was shocked by it. This poem is the result of such contemplations. After this poem I was able to improve myself a little bit. I manipulated the text of my thoughts and ideas and drew a red line across some of my moods. But the outside world is still like that, it is so upside down that I don't want to believe it. I worked on the language of this poem, too. In fact this was my first experiment with the language of dialogue. ${ }^{171}$

Farrokhzad inscribes an image of her self within her text. After projection and objectification of this image, with its "thoughts and ideas," she introjects the projected image, now in the form of a text, within her self. Then she gets involved in contemplation, criticism and correction of that self. Therefore, text, for her, functions like a mirror; through its medium she can engage in self-correction.

In the next poem in the same volume, entitled "Vahm-e sabz" ("Green Delusion"), the same oscillation between the mirror and window as well as the blurring of their distinction is at work. ${ }^{172}$ Like the previous poem, "Meeting at Night," this poem, too, is an expression of the speaker's specular experience. The poem begins with a mirror image in its very first line where the persona announces that she has been watching herself cry in the mirror all day:
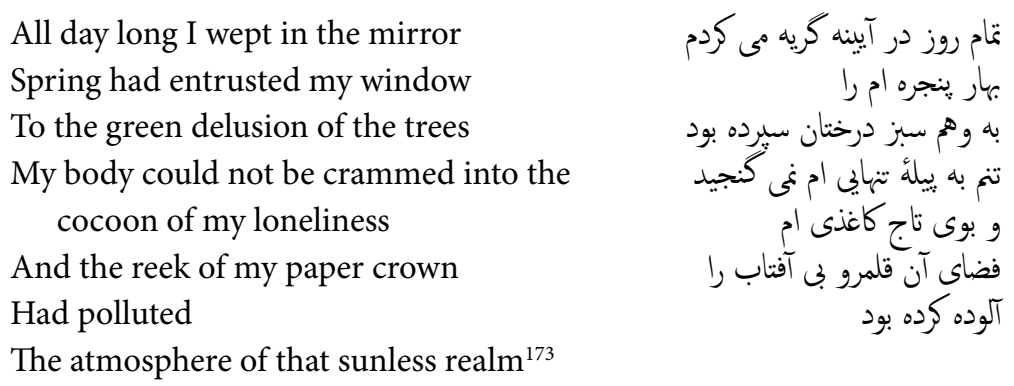

The mirror here has myriad functions for the poet persona. It provides her with a private and intimate heterotopic space for the outpouring of her 
innermost emotions. It has turned into a courtroom where she puts herself on a trial, castigating her present and older selves-Kristeva's sujet en procès. As a site of introspection and memory, it inflicts on her, as Milani expresses it, a "colossal pain":

This colossal pain stares back at her like the blinding sun, a pain so terrible that no kind mirror should ever remember it. But who said mirrors have to be kind? You look at them for too long and they open up old wounds-wounds that had closed in on themselves to alleviate the pain; wounds that, through layers upon layers of forgetfulness, had covered what was hidden underneath. That is the way it is with mirrors. ${ }^{174}$

The persona is observing herself cry in the mirror. By distancing herself from the subject in pain, through the act of objectification in a mirror, it is as if she were watching somebody else cry. Through isolating the experiencing self from the specular self by means of a mirror she can isolate herself from the thing in pain. This isolation and detachment make the pain bearable. The objectification functions as a defence mechanism for the person in excessive pain. La Belle explains it with regard to "the oxymoronic nature of the mirror":

When someone is suffering, physically or mentally, detachment comes as unbidden relief. The mind distances itself from the body because the body is making the person suffer. There is also a detachment that comes through literature, bringing a formal feeling to the moment of distress. The literary association gives the sorrow a frame, an objectified context or correlative. ${ }^{175}$

The same detaching mechanism occurring through the mirror is at work in the text. The poet objectifies and distances herself from her subjectivity by inscribing it within her text. By watching herself cry in her mirror, as well as by textualizing her pain, the persona is indeed experiencing a sort of Jungian "affect," where the suffering is not repressed or even rendered unconscious, but is seen to stand in another light. In this "different light," the problem, otherwise insoluble, seems to lose its urgency with the individual. The objectification in text/mirror allows the poet to gain a consciousness over the problem which facilitates her solving it. Studying Chinese yoga, Jung writes: 
I have often seen individuals who simply outgrow a problem which had destroyed others. This "outgrowing" revealed itself on further experience to be the raising of the level of consciousness. Some higher or wider interest arose on the person's horizon, and through this widening of his view, the insoluble problem lost its urgency. It was not solved logically on its own terms, but faded out in contrast to a new and stronger life-tendency. It was not repressed or made unconscious, but merely appeared in a different light, and so became different itself. What, on a lower level, had led to the wildest conflicts and emotions full of panic, viewed from the higher level of the personality, now seemed like a storm in the valley seen from a higher mountain top. This does not mean that the thunderstorm is robbed of its reality; it means that, instead of being in it, one is now above it. ... he is aware of a higher consciousness which prevents him from being identical with the affect, a consciousness which takes the affect objectively, and can say "I know that I suffer." ... instead of the negatively devastating thought "I am equal to suffering, My life is suffering." ${ }^{176}$

By turning herself and her desperation into signs, either in her mirror or in her text or even both (as is the case here), the observer or the author can distance herself from her subjectivity as the signifier. She becomes able to transcend the pain and see herself from a higher level of consciousness and thereby "outgrow" it. This psychological process has been the secret of many great works of art, as it is to Farrokhzad's confessional poetry.

The mirror image in the first line is immediately followed by the image of a window in the second line. The delusiveness of the mirror experience is brought to a wider context through the window. The green illusion of the trees in spring is beheld in stark contradiction to their naked reality in the winter. On the other hand, the painful reality of her experiencing self, over which she has gained consciousness through her specular self, is set in contrast to the illusory outside world. The persona expresses a desperate overwhelming loneliness, beyond the tolerance of her body; her body could not cram itself inside the cocoon of her loneliness. In this poem, the poet denigrates her rejection of the cultural image of womanhood; the conventional way of life ordained for a woman, a way of life which could have granted her the security of an insider within her culture. She reproves herself for sacrificing so much in choosing to become a poet, particularly an unconventional one. Farrokhzad mocks herself as a recognized poet carrying a stinky "paper crown." In the midst of her devastating mental 
crisis, the poet experiences a disturbing detachment between her self and her body. She expresses her inability to continue in this state:

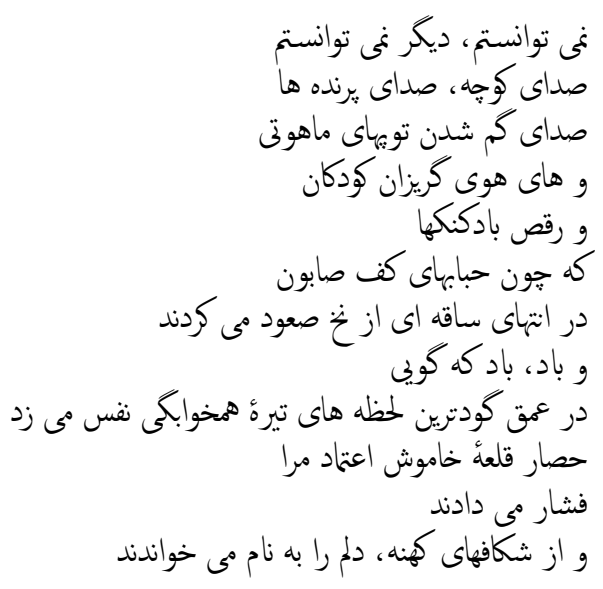

I could not, I could not any longer

The sound of the ally, the sound of the birds

The sound of tennis balls being lost

And the fleeting clamour of the children

And the dance of the balloons

Ascending like soup bubbles

At the tip of a stem of string

And the wind, the wind as if

Panting at the bottom of the deepest abyss of the dark moments of lovemaking

Were all pressing against

The walls of the silent fortress of my confidence

And calling my heart by name through the ancient cracks ${ }^{177}$

In these lines, Farrokhzad appears to have reached the nadir of her despondency. Within her mirror, a space of illusion and disillusionment, the persona doubts the reality of all the things happening around her. The mirror bridges her Innenwelt and her Umwelt. She is losing trust in the reality of her outside world, in "the sound of the alley," in "the dance of the balloons" and in "the wind," as she has lost her trust in herself. All these illusory phenomena of the outside world seem to infiltrate her innermost self through her "ancient cracks." In the third stanza, the persona continues to gaze at her self in the mirror, a site of introspection: 
All day long my gaze

Was fixed on my life's eyes

Those two anxious, fearful eyes

Fleeing my unflinching gaze

And like liars taking refuge

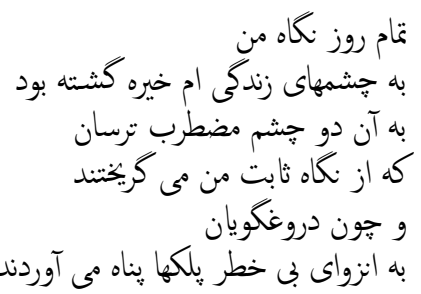

Behind the safe retreat of the eyelids ${ }^{178}$

All day, the persona has been deeply involved in introspection. On the surface of her mirror, she has been gazing into her own eyes and examining her life. She puts her older selves and their illusions to a cruel trial. The invoking of the past selves becomes possible through the temporality of the mirror. The persona is anxious and can no longer tolerate her own reproaching eyes, gazing unflinchingly at her. The older selves have been deceiving her by promising happiness and fulfillment if she can establish herself as a poet. Here mirror functions as memory, too. On this temporal surface she can revise her past life. Her feeling of self-detachment is evidently the result of her continual self-abnegation and rejection of her feminine body, as expressed in the fourth stanza. The experience is so disturbing that she closes her eyes and stops watching her image. Then she shifts from the mirror to the words, the language, rejecting both signs of the image and the words:

Which summit, which peak?

Do not all these winding roads

Converge on the finishing point

In that cold sucking mouth?

What have you given me, $\mathrm{O}$ simple words of seduction

$\mathrm{O}$ renunciations of bodies and desires?

If I had put a flower in my hair

Would it not have been more charming than this deceit,

This paper crown gone foul upon my head? ${ }^{179}$

Within this interior dialogue, Farrokhzad poses an aporia, wondering whether the words of her poems as well as her constant rejections of her body and desires have all been futile, granting her nothing in exchange. 
Farrokhzad feels that she has been betrayed by this seductive phallocentric language. For her, writing functions as an extension, a supplement and also at times a substitution for her mirroring. The visual reflection in the mirror and the mental reflection had an existential significance for her ego. In her desperation, the poet turns to her reader, asking if it would not have been better for her to adopt the cultural images of womanhood and involve herself in self-adoration than to become a poet. She continues by portraying her feelings of desperate barrenness and absurdity:

How the desert spirit took me

And how the moon's enchantment estranged me from the herd's faith

How the imperfection of my heart grew

And no other half ever perfected this half

How I stood and watched

As the ground under my own two

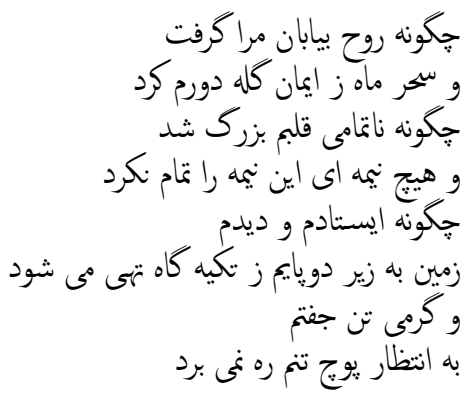
feet was depriving me of its support

And the warmth of my mate's body

Couldn't find its way to the absurd anticipation of my body ${ }^{180}$

Farrokhzad has distanced herself from the beliefs of her culture and hence senses a great alienation and loneliness; even physical intimacies do not resolve her lonely desperation. All these disillusionments are initiated and enacted within her illusory mirror. In the following three stanzas, Farrokhzad draws upon the images related to the closed sphere of feminine domesticity-unprecedented in Persian poetry for their evocation of the feminine experience and therefore traditionally beneath the dignified diction of poetry, which should deal only with transcendentalism, spirituality, divinity and culture (reserved only for men). In these lines, the persona seeks refuge in the security of women living according to the social-cultural construction of femininity; women, in Milani's words, "whose singleness of commitment saves them from the agony of ambivalence, guilt, or loneliness"; ${ }^{181}$ women bound together by virtue of the stereotypical image of womanhood that their society has constantly been imposing them: 


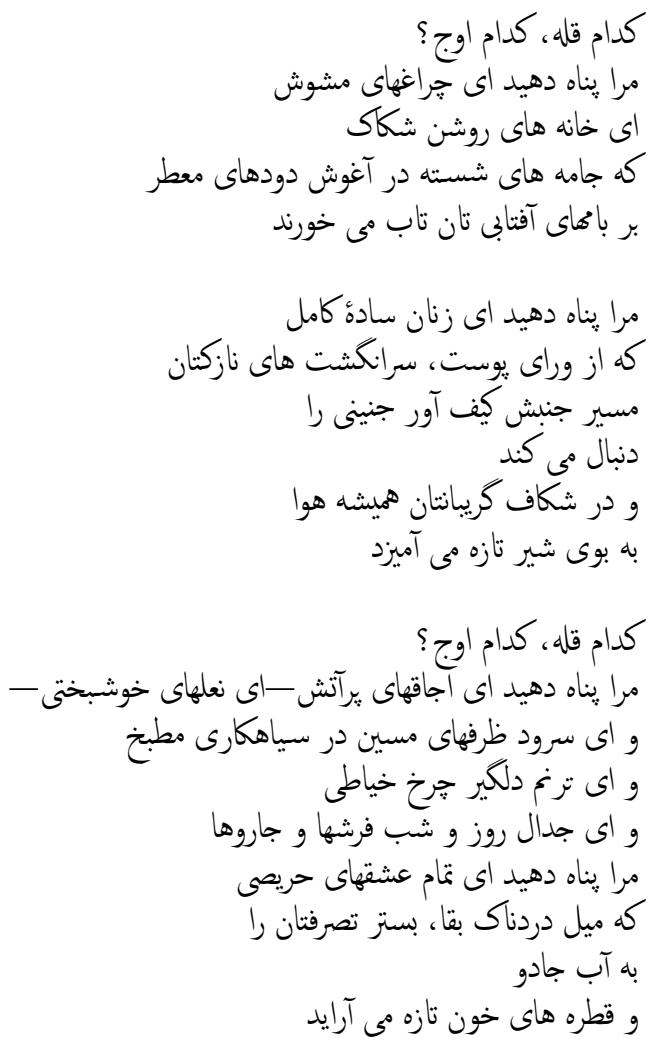

Which summit, which peak?

Shelter me O perturbing lights

O bright sceptic houses

Where upon your sunny rooftops the laundry

Is swaying in the embrace of fragrant smoke

Shelter me O simple perfect women

Whose delicate fingertips

Trace beneath the skin

The rapturous route of an embryonic motion

And in the cleavage of your collar the air

Always mingles with the scent of fresh milk

Which summit, which peak?

Shelter me O fire-filled ovens-O lucky charm horseshoes-

$\mathrm{O}$ song of the copperware in the oppression of the kitchen 
O depressing melody of the sewing machine

O night and day dispute of the carpets and brooms

Shelter me $\mathrm{O}$ all the greedy love

That the aching desire for permanence has adorned

Your bed of deflowering

With the magic water

And the drops of fresh blood ${ }^{182}$

The rhetorical question "which summit, which peak?" is repeated three times in the beginning of these stanzas, a refrain revealing the extremely disturbing effect of disillusionment for the persona. Within these lines, Farrokhzad presents a portrait of a womanhood regarded as the norm and fossilized into the structure of her culture with ambivalence. She openly reveals her feelings of envy towards the safe and accepted position of such women accredited with normal womanhood. On the other hand, the lines are marked by her undertone of contempt for their simplicity and incarceration within domesticity. The bounded sphere of domesticity held for these "simple perfect women," though providing a safe shelter, is indeed oppressive and depressing. The interminable "night and day" domestic labour, lacking creativity and unappreciated, makes the domestic activities Sisyphean.

The love within these apparently secure walls is "greedy" and the bed for lovemaking is a space for tașarrof, which, in Persian, means not only deflowering, but also alternation in one's state, deceit and trickery, capturing, taking possession of, total ascendancy and exercising power over, all signifying the power imbalance in the marital relationship. ${ }^{183}$ Though the houses of these "simple perfect women" provide them with secure shelter, much doubt and uncertainty can be found in them, as suggested in the phrase hāne-hā-ye rošan-e šakkāk, "O bright sceptic houses."184

The poet had chosen 'The Road Not Taken' by deciding to leave the security of wedlock and by becoming a poet; "And that has made all the difference." 185 She has been cruelly punished by society for her choices and now she enviously seeks shelter in the "simple perfect women" who live as their society requires them to and by choosing the well trodden road. The difference is not only the "difference between," as Johnson calls it, but also the "difference within." 186 On the one hand, the difference is between her self as a female author-a subversive force in itself-and the limiting images of womanhood her culture imposes on her: the images of "simple perfect women" limited to their forced sphere of domesticity. On the other hand, this difference is marked by the excruciating cryptic multiplicity within the 
self. In explaining the difference between the "difference within" and the "difference between," Johnson writes:

A difference between opposing forces presupposes that the entities in conflict be knowable. A difference within one of the entities in question is precisely what problematizes the very idea of an entity in the first place, rendering the "legal point of view" inapplicable. ${ }^{187}$

The last two stanzas portray the extreme desperation of the persona through moving metaphors. The illusory spring, passing through the shutter, reminds her of her illusion of having proceeded. It disillusions her to the bitter reality of her moving deeply downwards, instead of moving forward:

All day long, all day long

Abandoned, abandoned, as a corpse on the water

I was moving towards the most ghastly rocks

Towards the deepest sea caverns

And the most carnivorous fish

And the slender vertebras of my back

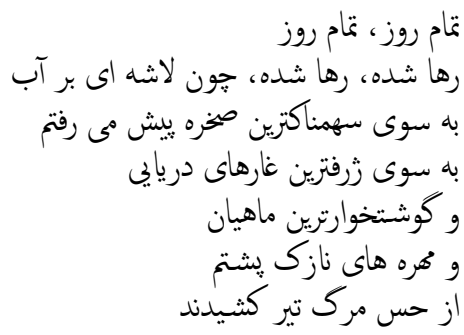

Were twanging with pain from the sensation of death

I could not, I could not any more The sound of my footsteps was rising in the denial of the road

And my desperation had outgrown the patience of my soul

And that spring, and that green delusion

Passing through the shutter, told my heart

"Behold

You have never moved forward

You have moved downward"188

The poem "Green Delusion" is an open expression of the agonies of a woman poet struggling to resolve the societal contradictions within the construc- 
tion of female subjectivity. In following her own predilections for striving to establish her own authentic subjectivity and for choosing her own words she has made great sacrifices. The poet has declined to reiterate an image her culture was constantly feeding her, the image of the "simple perfect woman" confined in the tyrannical domesticity of the kitchen, the woman whose "perfect" vocation is considered to be housewifery and motherhood and for whom the only creativity permissible is mothering. The poet paid dearly for transgressing the boundaries and now she feels dejected, lonely and an outsider. In her text-mirror, Farrokhzad portrays her realization of desperate self-loss when her self-image comes into face-to-face confrontation with the culturally constructed images of womanhood-the images which she simultaneously is and is not-in such a way that other readers can also share and interrogate it.

In this poem, Farrokhzad oscillates between the mirror and the window (and also the shutter) as her means of relating to the two dialectical and delusionary worlds: the Innenwelt and the Umwelt. The mirror entices her all day long by its invitation to introspection, to contemplate her inner world-an autoscopic mirror of self-scrutiny. The mirror becomes a space in which memories of dreams and illusions are invoked. The delusory mirror is the perfect site for disillusionment. Therefore, the mirror becomes an intimate space for the "sujet en procès," a space in which she can summon the older selves and put them on trial.

The window on the other hand is where she can relate to the outside world. It is a space through which she can see the spring's "green delusion," the "bright sceptic houses," and all the attributes of the other "simple perfect women," busy in their secure sphere of housewifery and motherhood. As Lacan observes, the mirror is a place where the Innenwelt is bridged to the Umwelt. With the primal identification with one's specular "I" in the mirror stage, the subject launches on a series of lifelong identifications. In the case of female subjectivity, women are expected and forced to identify with the images that their culture constantly sends them, with the images of "simple perfect women." In the case of Farrokhzad, she has failed to identify with these images sent by the Umwelt. For this reason she has been estranged from her "flock" and left abandoned, lonely and desperate. The mirror, for Farrokhzad, is a space where all these conflicting images, the cultural images of womanhood, sometimes contradictory in themselves, on the one hand, and the contradictory self-images, on the other hand, engage in a frontal battle. 


\section{Mother-Daughter Reciprocity in the Mirror}

Farrokhzad in her poetry was not oblivious to the temporal dimension of the mirror. After all, the mirror registers multiple changes in what appears before it with the passage of time. Here the issue is not identification or egoformation, nor even narcissistic gaze, but rather re-identification. The individual is reassured that she closely resembles the person who last glanced at herself in the mirror. The female beholder traces in her mirror the painful advance of old age, of physical degeneration. When she turns to the mirror and is confronted with her mother's image instead of her own, it signifies the ability of the mirror to map the passage of time and the onset of old age. It also gives a sense of destiny, which is usually an unhappy one; the implication is that the young woman is doomed to the same destiny as her mother and grandmother before her. In other words, the viewer is set to perpetuate the same tradition of self-effacement. As Woolf says, "We think back through our mothers if we are women."189

In her poem "Be âftāb salāmì dobāre h'wāham dād" ("I Shall Salute the Sun Once Again"), in the collection Another Birth, Farrokhzad draws upon the temporality of the mirror to show that she has attained a certain peace with her self and her world. Although she is alarmed at the approach of old age and death, she seems to have peacefully accepted it, even to the point of saluting it. The poem is in two (twelve-line and nine-line) stanzas, and is presented in the first person. In the first stanza, the speaker declares that she is going to salute a series of things. After greeting the "sun," the "stream" running through her, and the "clouds" which were her "lengthy thoughts"; after saluting the aspens in their "painful growth" which, like her, were passing through "seasons of drought"; and after saluting "the flock of crows," the speaker proceeds to salute her mother:

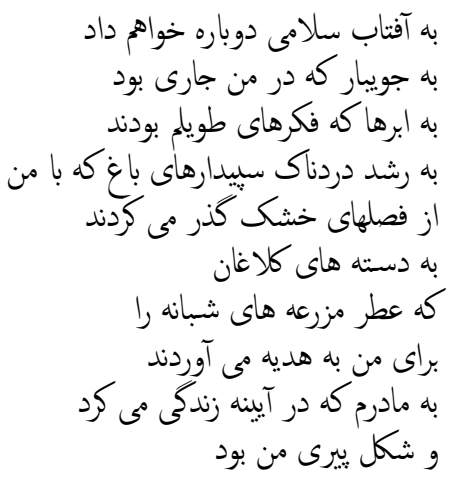




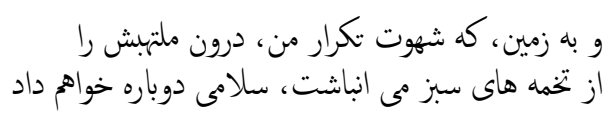

I shall salute the sun once again

The stream running through me

The clouds that were my lengthy thoughts

The painful growth of aspens in the garden which accompany me

In passing through seasons of drought

The flock of crows

Who bring me gifts of the scent of nocturnal fields

I shall salute once again

My mother who was living in the mirror

And was the image of my old age

And the earth, whose lust to repeat me,

Crammed its burning innards with green seeds ${ }^{190}$

The persona seeks to salute, to be united with her mirror image, a replication of her mother's. Irigaray in her book, Speculum of the Other Woman, declares, "I am seeking, in simplest terms, to be united with an image in a mirror." ${ }^{191}$ Immediately after saluting her mother, the speaker salutes the earth which is anticipating her return. The line "my mother who was living in the mirror" is ambiguous. One interpretation, marking an image dislocation, is that whenever the speaker turns to the mirror she confronts her mother there. In this way, as Cixous observes, the mother becomes a metaphor for the daughter, as well as the daughter for the mother. ${ }^{192}$ In this reading, the ego boundaries of the mother and the daughter merge and they attain an empowering unity which is possible due to their common experiences as well as their exclusive access to "subliminal, subversive, pre-verbal" knowledge; a knowledge flowing within and between them. ${ }^{193}$ Therefore, the mirror becomes a mantic tool; prophesying the assimilation of mother-daughter as well as their identical destiny, since the mother has always been closely associated with the implacable unformulated destiny, a destiny which the daughter, as an extension of the mother, will ultimately reproduce. Gallop asserts:

It is naivety to believe that one could ever totally separate the daughter from the mother, secure their separate identities. It is to deny that one's mother is a woman, to deny any identification with one's mother. Certainly it is a stultifying reduction to subsume femininity into the 
category of maternity. But it is an opposite and perhaps even equally defensive reduction to believe in simple separation of the two categories. The relation to the other woman only approaches its full complexity with some recognition that the "other woman" as well as oneself is and is not "Mother."194

Hence, the welcome embrace of the mother's presence in her mirror signifies the persona's inner desire to re-construct "the mother-child dyad," severed in the mirror stage and transformed into the "maternal language." 195 The persona desires to re-enter into what Kristeva calls "the voiced breath that fastens us to an undifferentiated mother" which once existed prior to the mirror stage. ${ }^{196}$

The other valid interpretation is that her mother is living within the frame of the mirror; she has no further presence, no identity outside its limits. Her mother is a woman of male-defined femininity, merely an object of outward appearance. She is a woman who needs a specular reflectiveness to verify her continual existence. In the process of the continual assimilation of the image, the mother has been petrified and frozen into an image, signifying her total lack of selfhood. The speaker believes that the image in the mirror, or the image of her mother there, resembles her in old age. In other words, the speaker believes that she is an extension of her mother and will continue in the same tradition of self-effacement. Irigaray reports, "You look at yourself in the mirror. And already you see your own mother there. And soon your daughter, a mother." 197

But there is a difference between the two. The daughter's position is at least augmented by "knowledge." Understanding the mother and reconciling with her, as well as with one's own image, means coming to terms with the eternal paradoxes within the universe and within ourselves. This reconciliation is a heroic act requiring knowledge and courage. Once reconciled, it becomes a source of empowerment for the female subject, an empowerment which frees her from her misery; it becomes the source of mutual psychological support and consolation; a power which does not exist in the patriarchal vocabulary. Birkle explains the difference in the following words:

Power, in patriarchal understanding, is always seen as power over someone, as a concept of hierarchy with superiority and inferiority. Instead of focusing on the mother's power over, it should be possible to see it as her power with others, thus changing the pattern of hierarchy to a net of 
horizontal relationships that recognize the values that lie in acceptance (instead of the destruction) of difference. ${ }^{198}$

It should be mentioned here that saluting takes place when one sees another person for the first time, or after being temporarily distanced. The speaker has been detached from her self, her mother and the world around her (at least temporarily). But now that her self and the world have been revealed to her, she can salute these two worlds. The speaker re-discovers and re-enters into the bond with her mother; into a bond, a "mother-child dyad," that has been severed, according to Kristeva, only with the daughter's entrance into the Symbolic order and identification with the father, initiated in the mirror stage. The mother, kept so far within the shadows, surges into the daughter's mirror. As Kristeva explains:

Transforming this identifying support into an Other-into the place of pure signifier-maintains the presence of a maternal, substantial, and ego-related opacity in the shadows. The mother reemerges as the archetype of the infinitely interchangeable object of the desiring quest. ${ }^{199}$

The mother who appears to have been Farrokhzad's "object of the desiring quest" reemerges, at this point of her life, from the shadow on the surface of her mirror. Farrokhzad is now mature enough conciliatingly to embrace the image by saluting it. Moreover, Kristeva adds:

To rediscover the intonations, scansions, and jubilant rhythms preceding the signifier's position as language's position is to discover the voiced breath that fastens us to an undifferentiated mother, to a mother who later, at the mirror stage, is altered into a maternal language. ${ }^{200}$

The identification with the mother in the mirror marks the indelibility of the mother-daughter bond, as well as the speaker's re-entry into this realm of "maternal language." The poet believes in a sort of reincarnation; a rebirth of subjectivity on the other side of the wall. She announces that she will come from the other side, the dark side of the wall. She will emerge with an authentic subjectivity, equipped with the knowledge of experience: 


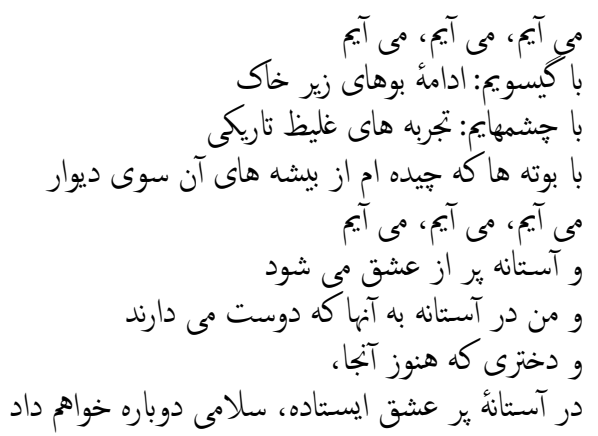

I am coming, I am coming, I am coming

With my tresses: the continuation of the underground scents

With my eyes: the dense experiences of the darkness

With the bushes I have picked from the other side of the coppice

I am coming, I am coming, I am coming

And the threshold fills with love

And at the threshold, to those who love

And to the girl still standing

In the threshold filled with love, I shall salute once again ${ }^{201}$

Farrokhzad is here asserting her symbolic rebirth, her extension beyond the death of the self. She is going to salute the girl standing at the threshold; the girl who is none other than herself. The mirror can indeed turn into a threshold leading her from "the dense experiences of the darkness" into a luminal space. Through the use of "I" and "the girl" Farrokhzad has simultaneously adopted the position of subject and object-a mirror reflection instance. The speaker has objectified herself into another (the girl standing there) to illuminate her knowledge of the girl (and herself). By saluting the girl, Farrokhzad shows her acceptance of her self, also implied by saluting her mother in her mirror. Rediscovery of the mother and the self provides Farrokhzad with consolation, authority and power; as Bennett asserts:

The acceptance of the self, whatever that self is, is the base upon which the woman poet must work, the source of her greatest authority and strength. But for her to arrive at this self-acceptance, she must possess a definition of her womanhood that is broad enough, flexible enough, to encompass all that she actually is. ${ }^{202}$ 
Expressed through the image dislocation within her mirror, in the poem "I Shall Salute the Sun Once Again," Farrokhzad acknowledges that she has taken on the identity of her mother in her incessant "process of becoming"; but, instead of rejecting it, she embraces it. ${ }^{203}$ The conscious espousal of the mother's image within the construction of her self-image renders the resentful power of the mother's hold over her subjectivity, a central problematic in the development of female subjectivity, into a consoling power with her. This reconciliation with the mother image in her mirror is part and parcel of the reconciliation of the paradoxical conflicts within her self and within the world outside her-her Innenwelt and her Umwelt.

Thereupon, the poet seems to have cast off her inner darkness, a darkness raised through the disturbing otherness, a darkness which used to spread itself over everything, inside and out. ${ }^{204}$ After all those bitter censures and harsh trials of the self, held in the courtroom of a mirror, the poet-Kristeva's sujet en procès-seems to have ultimately reached a peaceful conclusion, resolving all those conflicting images in her mirror. Now that the poet has resolved the conflicting multiplicities within and outwith her "I," and now that she has been augmented with the empowering knowledge bestowed on her by her dark experiences and disillusionments, she seems to be standing at the threshold of peace. Now the poet appears to be ready to embrace her old age, degeneration and even death.

\section{The Emancipated and Emancipating Mirror}

Farrokhzad's mirrors vividly capture the tumultuous developmental stages she passes through. Upon the glittering surface of her mirror she is confronted by grotesque uncanniness, the baffling uncertainty over the reality of her self, the unsettling multiplicity and the creepy fragmentation of her body and her self, all leading to her aversion to and rejection of the mirror. Nevertheless, in her later poems, Farrokhzad is ultimately able to value the mirror as a tool for self-realization. Now she can acknowledge the mirror's power in the reconstruction of a unified female identity.

By gradual reintegration of her fragmented self, by recalling the projected image back into the structure of the self, Farrokhzad manages to convert the mirror from a surface for registering incipient madness into a surface for prophesying liberation. Rising above the disturbing division between self and her image as well as self and the world outside, the poet aims at a more promising unity. With this fusion of multiplicity into a unity 
there emerges a sense of rebirth. The confrontation with the perturbing multiplicity, with all its fractures, decompositions and bodily fragmentations, was a precursor to a birth. As Cixous puts it in her essay "Coming to Writing," "Then, a gestation of self-in itself, atrocious. When the flesh tears, writhes, rips apart, decomposes, revives, recognizes itself as a newly born woman." 205

In this process of rebirth, the mirror turns into a primary tool for the realization and reconstruction of subjectivity. The mirror is no longer a passive surface of imitation, but an active tool of transformation. Rather than a surface that terrifies or disheartens, the mirror becomes a means of empowerment. At this point, the mirror is a liberated and liberating tool. The mirror has finally liberated itself from its culturally infused associations, and it becomes liberating by turning into a means of self-awareness. No more is it merely a feminine tool of vanity, solipsism, narcissism and of seduction and entrapment. It is within the mirror that a female subject enters into a strong relationship with her image; a space for ongoing dialectic reciprocity between self-image and the image presented to the outside world as well as an image she aspires for.

It is within this space that the subject and object, the beholder and beheld, reach out to each other and become united and the identity consolidates. Melchior-Bonnet asserts, "Instead of dooming man into immobility, the specular encounter multiples his strength by inviting him to both cast himself upon the world and study himself within it."206 Therefore, the mirror has the capacity to become a powerful tool for gynocentric perception, as an alternative to the phallocentric gaze. It is through this unification in the mirror that the female subject can resist the patriarchal system of enforcing oppositions. For a woman, her mirror can turn into a cardinal space where she can analyse, question and overcome the enforced dichotomies between the experiencing self and the reflected image on the one hand, and between the self-image and the contradictory images of womanhood her culture incessantly assaults her with on the other.

From her fourth collection, Tavallod-i dīgār (Another Birth), onward, Farrokhzad was to become a "new woman," having succeeded in constructing her authentic subjectivity, through visual and mental reflection, as an independent female will and independent female voice. ${ }^{207}$ Profound selfinvolvements and the consciousness of corporeal being are at the very heart of the feminist call, a call that appeals to the heroic act of reconstituting the psychology of the mirror experience. It appeals to the reconstruction of feminine narcissistic subjectivity within the boundaries of a self-conception 
closely associated with a woman's reflected image. And as Cooley claims, "The finest achievement of the new woman has been personal liberty. This is the foundation of civilization."208

Farrokhzad's last collection of poems, İmān bìyāvarìm be àgàzz-e fașle sard ... (Let Us Believe in the Beginning of the Cold Season ...), published posthumously in 1974, contains only seven poems. The mirror image appears in two of them: the title poem "İmān bìyāvarim be àğàz-e faṣl-e sard ..." ("Let Us Believe in the Beginning of the Cold Season ...") and "Panğare" ("Window"). The poet of "Let Us Believe in the Beginning of the Cold Season ..." inaugurates her rather long poem with the words, "And this is me," presenting herself in the first person. Milani aptly describes the poem as an "autobiographical road map." ${ }^{209}$ The poem is a portrayal of a lonely woman's melancholic musings, desperately struggling to reconcile her mutable selves with the world outside-her Innenwelt and Umwelt. These lines are presented through a series of introspections, retrospections and anticipations. The mirror image appears three times in this poem. The whole poem can be read as an open declaration of her having reached maturity; of her attaining an understanding of the world within and the world without with all their intrinsic paradoxes; an understanding of "the earth's sullied existence," and of her self; of her "impotence" as "a woman alone" at the beginning of a cold season.
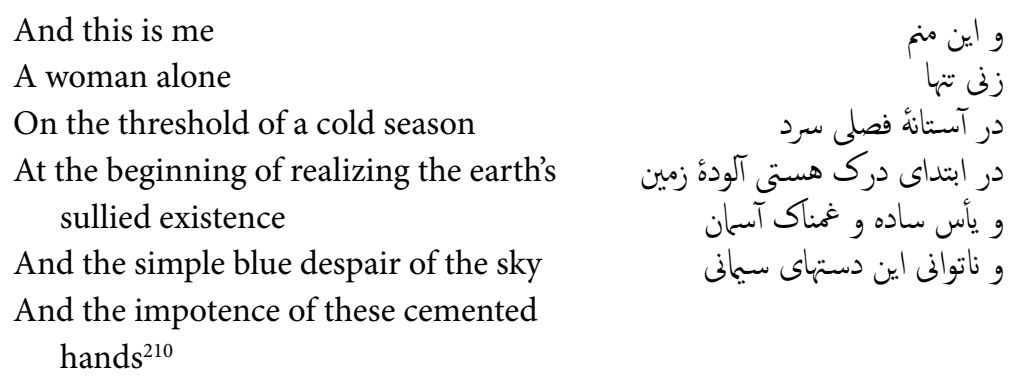

By the very first line "And this is me," Farrokhzad is assuming a subject position and an individual agency. The line is a forthright statement of a self-assertive subjectivity, of an individuality established. This unique, free-standing "I" ( $m a n$ )_Farrokhzad herself-is anchored in her historiocultural context, which, she claims, she is beginning to understand. It should be noted here in parentheses that the Persian phrase $z a n-\bar{i} \tanh \bar{a}$ is ambiguous. It can be considered as a state of being and translated as "a woman alone," emphasizing her heroic, unprecedented and unaccompanied posi- 
tion as a free and outspoken woman poet standing against the backdrop of Iranian patriarchal culture and the dominantly masculine Persian literary tradition, a woman who has found herself, her true voice and her vocation. The phrase can also be regarded as a state of mind and translated as "a lonely woman." Farrokhzad fails to bear any resemblance to Iranian society's cultural images of womanhood, and therefore is stigmatized and punished. She feels lonely, rejected and alien in her world.

The poet is reaching an understanding of herself as well as the world around her. Farrokhzad has been able to step beyond the echo-reflection of others and is now at the threshold of thought-reflection. By "on the threshold of a cold season," the speaker means that she is sensing the approach of her old age, and its accompanying degeneration, as she later in the same poem says: "This is the onset of ruination."211 Throughout the poem, the passage of time is emphasized over and over again in an obsessive manner. The sentence "time passed" (zamān gozašt) is repeated five times in the poem; though, paradoxically, time appears to be stagnant: every time the clock chimes it is four oclock. Time is exhausted and tuberculous (zamān-e haste-ye maslūl) and heavily weighed down (zamān če vazn-ī dārad). ${ }^{212}$ Now the persona knows the secret of the seasons and understands the language of the moments. The saviour (neğat-dahande), who later, in the poem "Panğare" ("Window"), is identified by the poet as the image in the mirror, is hibernating in his grave. In the second stanza, the speaker claims:

Time passed

Time passed and the clock chimed four times

It chimed four times

Today is the winter solstice

I know the secret of the seasons

And comprehend the language of the moments

The saviour is hibernating in the grave

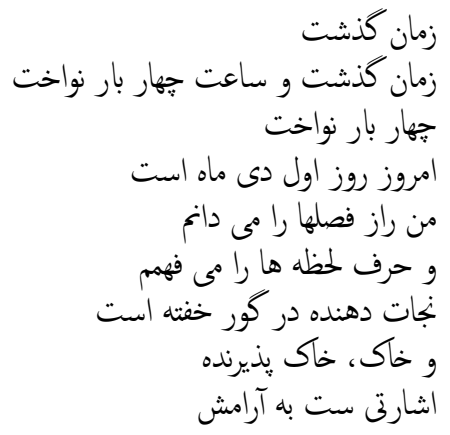

And the earth, the hospitable earth

Betokens serenity

Time passed and the clock chimed زمان كذشت و ساعت جهار بار نواخت four times ${ }^{213}$ 
In the fourth stanza, the speaker senses a change coming over her. She depicts it with the image of a wind blowing in the alley. She is reflecting on "the flowers' mating," on the feeble "buds with their slender anemic stalks," on "this exhausted tuberculous time" and on "a man passing by." In the fifth stanza, Farrokhzad turns to the mirror as a space for temporality; a surface for the registration of time and the poignant approach of old age and degeneration, as well as a site for the memory:

On the threshold of a cold season

In the mourning congregation of mirrors

And in the dirgeful assembly of pale experiences

And this sunset impregnated with the knowledge of silence ${ }^{214}$

Ageing is metaphorized into the "cold season" and the speaker is standing on its "threshold." In her sad acknowledgement of ageing and the approach of death, Farrokhzad projects, and thereby objectifies, her sadness onto the mirrors. It is not she who is sad, it is the mirrors. ' $A z \bar{a}$ in Persian means mourning ceremonies held for a dead person. The mirrors are holding mourning ceremonies for the coming of her old age and her death; thereby turning into mantic surfaces. The mirrors are mourning bygone youth and experiences. Farrokhzad has lost her illusions by experiencing life, and now those experiences have turned pale with the passage of time; these experiences are now things of the past. Through the use of a mirror, Farrokhzad objectifies herself and her despair. By this objectification she gains knowledge over both her despair and her true self. The mirror invites introspection; on its surface the invisible interiority of a subject reveals itself to her inquisitive gaze. In this sense, the metonymic mirror image is represented ironically. The mirror becomes a site of psychological interiority rather than a surface for visible appearances. Due to bitter disillusionments and the realization of degeneration it is mournful.

In the quest for the realization of her true female subjectivity Farrokhzad has been evolving patiently, solemnly and confused. Here, the speaker poses a rhetorical question, implying that no one can ever stop someone proceeding in that manner. Farrokhzad is indeed rebuking her culture, her society's continual efforts to stop her from proceeding: 


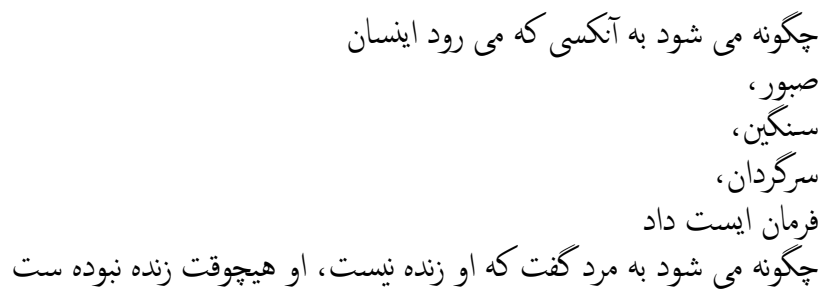

How can one command someone proceeding so

Patiently,

Solemnly,

Aimlessly,

To halt

How can one tell the man that he is not alive, that he has never been alive ${ }^{215}$

Addressing those efforts to intercept her, Farrokhzad makes clear the impossibility of her being pushed into the periphery of stagnation and passivity, often held for women. In this poem, too, Farrokhzad turns to the image of crows as the harbingers of death and degeneration. The crows are flying in circles over the "ancient gardens of boredom."

The wind blows in the alley

The lonely crows of seclusion

Whirl around in the ancient gardens of boredom

And the ladder

Was of such a low height ${ }^{216}$

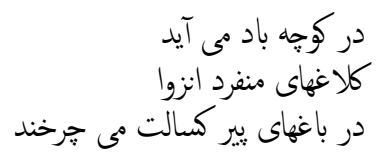

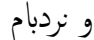

جه ارتفاع حقيرى دارد

The wind prophesyes a change-the arrival of old age. By the lines "And the ladder/Was of such a low height," Farrokhzad expresses her shocked disillusionment. Her society has taken advantage of her childish innocence and deceived her. The persona claims now that she has lost all that innocence, now that she has picked and tasted the apple, she will not crush it under her foot:

They carried off the entire credulity of a heart

To the palace of fairytales

And now

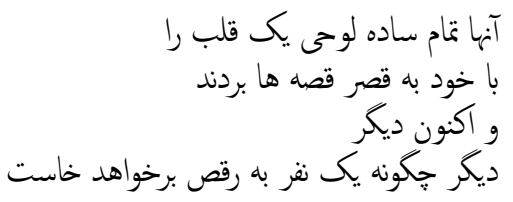


How can one rise to dance ever

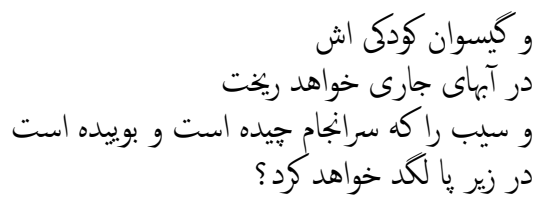
again

And pour her childhood tresses

Into the flowing streams

And trample the apple

She has eventually picked and smelled? ${ }^{217}$

Though the speaking subject and the one spoken about are ostensibly identical, referring to Farrokhzad herself, there is a gap of time and a difference. The spoken about subject who used to be a credulous, innocent child (heart is employed here as a metonymy for the person), has now grown into an experienced, and thereby disillusioned, subject. She has crossed the boundaries her culture has set for her by picking and smelling the forbidden apple. Farrokhzad is here alluding to the biblical story of Adam and Eve. She is altered by a forbidden knowledge. The questions Farrokhzad is asking here are all rhetorical; signifying that both she and the reader are well aware that she will no longer be beguiled into innocent illusions by those tales. In the following stanzas, the speaker continues prophesying dark days, disillusionments and ruination:

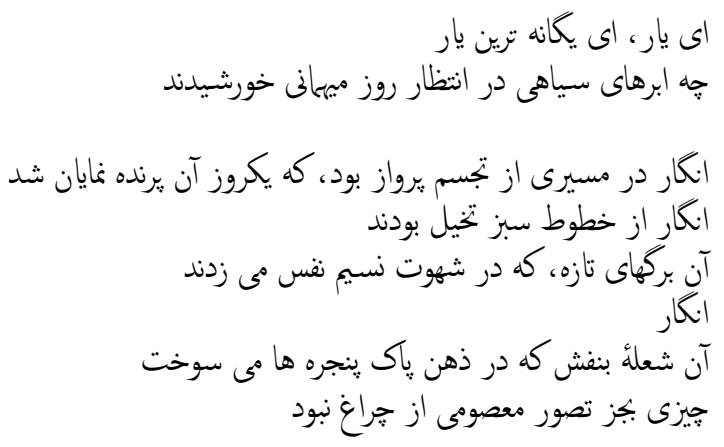

$\mathrm{O}$ friend, $\mathrm{O}$ most unique friend

Such black clouds await the sun's festival day

It was as if in the course of imagining the flight,

that one day that bird appeared

As if those fresh leaves

panting in the lust of breeze

Were of verdant lines of delusion 
As if

That violet flame burning in the chaste mind of windows

Was nothing but the innocent illusion of the lamp $p^{218}$

The window here functions like a mirror; through it reality loses its substance and becomes an illusion. As discussed earlier, the colour green for Farrokhzad evokes nature, imagination and illusion. ${ }^{219}$ The boundaries between reality and the imagination seem to have dissolved. The reality (of burning violet flame) is de-substantiated in the virtuality of delusive imagination (illusion of the lamp), and vice versa. The illusion (of the flight) seems to have gained form and substance (of a bird) on the path of imagination. This marks the poet's oscillation between the two worlds of reality and imagination and her failure to draw a clear demarcation line between them due to her psycho-emotional status.

In her journey of self-evolution, Farrokhzad as a sujet en procès has had to pass through tumultuous self-doubts and painful fragmentations of the self. She now believes that she has reached a unified understanding of her ego:

I have piloted this wandering island

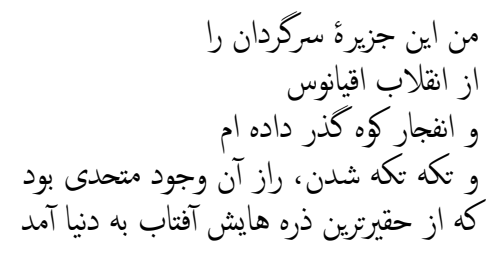

Through the tumults of the ocean,

Through the eruption of the volcano,

And disintegration was the secret of that unified existence

From whose most humble particles

a sun was born 220

All those exasperating multiplicities, fragmentations, bewilderments and eruptions were a precursor to the birth of a radiant unity. This journey towards the unity of the selves is once more emphasized a few stanzas later, where Farrokhzad rhetorically asks: "Who is this, this person on eternity's road/Moving towards the moment of unity?"221 The persona has been struggling to resolve the paradoxes of her subjectivity; the paradoxes of the "I" within and the "I" without. These lines bring to mind Lacan's theory of the mirror stage, which holds that the "orthopaedic" view of the body, the body unified and in its gestalt conceived initially in front of the mirror only follows the prior fragmentary body view, body in bits and pieces. ${ }^{22}$ 
The poem "Let Us Believe in the Beginning of the Cold Season ..." explicitly asserts the existence of incongruity between the poet's Innenwelt and her Umwelt. The speaker affirms that there is always a disturbing discontinuity-a lacuna or a gap-between the perceiving subject and the perceived object, between the self and the reflected image, as presented through the window. This irreducible gap marks the distance between the seen, the object and the specular self on the one hand, and the see-er, the subject and the experiencing self on the other: "Between the window and the seeing/There always lies a distance."223

Some stanzas later, the reader is confronted with the second mirror image. Here, the persona sketches her momentary inner sense of self-unification, a sort of return to her authentic subjectivity. She repeatedly puts her previous selves on harsh trial, blaming them for not looking. The rhetorical question "Why did I not look?" is posed three times in the poem. Then the persona claims that she can now see her real, unified self within the mirror. The mirror, which used to give rise to alienation, split multiplicity and disturbing otherness, is now paradoxically rendered into a space where fragmentations and the multiplicity of the self are merged and become united. The mirror becomes a medium of self-discovery and self-realization; a powerful tool for constructing her sense of female self. For Shengold, the mirror represents the psychic mind of the beholder:

The mirror, metaphor for the mind, is particularly suited to portray vertical splits in the mind: ego against superego; self against introject; self representation against object representation; good against bad selfand object representations.... All of these splits can appear at the mirror ... The mirror can also be used to try to repair or undo splits-to restore symbiosis or to hold together a disintegrating psyche. ${ }^{224}$

This is particularly valid due to the mirror's ambivalent and oxymoronic nature. The mirror insinuates a disturbing splitness and an ominous duality while paradoxically it is the very same site where this duality can be resolved-at least temporarily-and the person can be comforted with a sense of peaceful union.

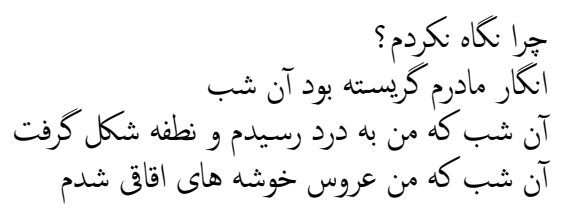




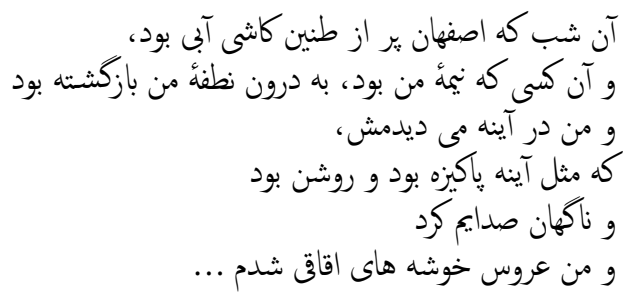

Why did I not look?

As if my mother had wept that night

The night I arrived to pain and the seed was conceived

The night I became the bride of acacia clusters

The night Isfahan abounded with the echoes of blue tiles,

And the one who was my half, had returned within my seed

And I could see her/him in the mirror,

Who was clean and bright like the mirror

And suddenly s/he called me

And I became the bride of acacia clusters ...225

The previous self is put on trial by the present self for her failure to see; for not being aware. Farrokhzad in these lines is referring to her experience of wedding, coupling and getting pregnant. The mother, as the one with whom the ego-boundaries merge, the one who has common access to the subliminal and pre-verbal knowledge, the one whose life story the daughter is going to reproduce, is invoked here. Her mother seems to have wept the night when the persona married and the seed of her child was conceived. The mother could see that her daughter, an extension of herself, was repeating the same story and destiny.

Regarding this mutual mourning in the self-effacement of the mother and daughter, Irigaray, addressing her mother, expounds, "Each of us lacks her own image; her own face, the animation of her own body is missing. And the one mourns the other. My paralysis signifying your abduction in the mirror." 226 Now the persona can see herself in the mirror: unified, pure and brilliant. Clarity, purity and brilliance are considered inherent features of the mirror. As Melchior-Bonnet mentions, "From without substance, subtle and impalpable, the mirror image manifests a diaphanous purity." 227 Farrokhzad claims that her other half is now returned into her seed, and she can see it in the mirror. The line "And the one who was my half, had returned within my seed" may also refer to the reproduction of her husband by conceiving an embryo of her son within her seed. In this sense, she is watching her son 
within the mirror of her mind/imagination. Her offspring becomes a mirror image of herself who is, like the mirror, clean and brilliant. The mother's weeping is further emphasized by repeating it in a discrete line:

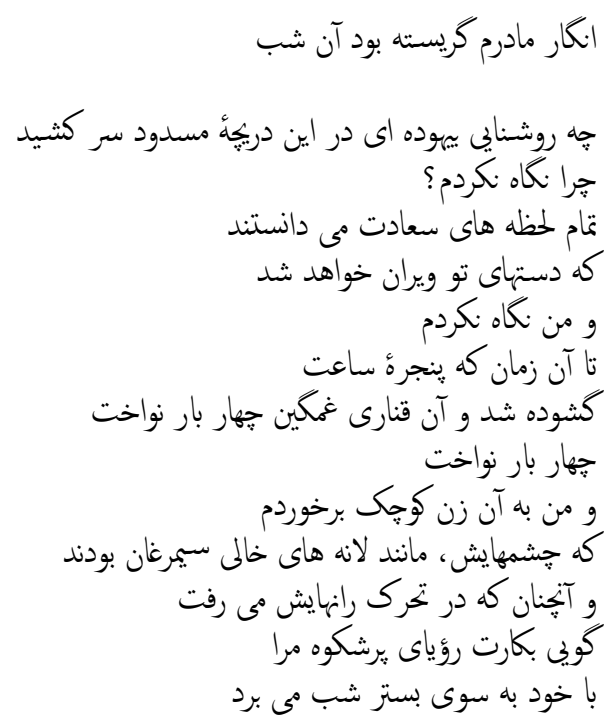

As if my mother had wept that night

What a futile brilliance glared in this blocked shutter

Why did I not look?

All the moments of bliss were aware

That your hands would be ruined

And I did not look

Not until the time when the clock's shutters flew open

And that sad canary chimed four times

Chimed four times

And I ran into that little woman

Whose eyes were like simurghs' empty nests

And walking in the motion of her thighs

As if carrying the virginity of my glorious dream

Into the bed of night ${ }^{228}$

The persona vehemently reproaches herself for not seeing on a continual basis. Here, once again Farrokhzad oscillates between the mirror and the window as the means of relatedness to the self. After seeing her mirror image, 
spotless and brilliant, in the previous stanza, now she is shocked at the futility of its brilliance gleaming through the shutter. While, in the previous stanza, the persona claimed a purity and brilliance revealed to her through the mirror, now in this stanza, she is disillusioned by the futility and fugacity of its brilliance flaring in the window. All the moments of her happiness have carried an awareness of the destruction, ruination and death awaiting her, but she has not looked. The synecdochic employment of hands, referring to herself in her totality, was Farrokhzad's favourite poetic device. Her hands frequently assume independent reality and embody her desires. ${ }^{229}$

In an epiphanic realization promoted by the clock's chiming, the persona can see the destructiveness of time. She encounters herself in a sort of mirror situation where the simultaneous convocation of subject and object, the see-er and the seen, is made possible. She defines herself by objectifying it as a small woman with empty eyes, proceeding while carrying the virginity of her glorious dream into the bed of night. In Persian mythology, the simurgh (simorg) is a fabulous, monstrous and rational bird of benevolence. It is frequently drawn upon in classic Persian poetry to convey meanings symbolically and metaphorically. The existence of this bird in the world of reality is associated with ambiguity and its nest is considered empty and unknown. ${ }^{230}$ Therefore, through this imaginative simile (tašbih $v a h m \bar{\imath})$, comparing something to an entity which does not exist in reality, Farrokhzad depicts the eyes of the woman she confronts-herself-as dark, obscure and spiritless. It is a portrayal of a female self cloaked in darkness and apprehension, a woman as a "dark continent," a "nothing to see" as Irigaray describes it: "As obscure, as black, perhaps, as the dark continent of femininity?"231

In this stanza, Farrokhzad engineers a feminine sexual metaphor through which she conveys her disillusionments brought on by destructive time. The unreality and transience of light, brilliance, purity, virginity, illusion and dream are juxtaposed with the harsh reality and longevity of darkness, night, loss of virginity and disillusionment. Farrokhzad shifts from the first person "I" to the second person "you" and then to the third person "she," in the form of "that little woman," within the same stanza, all referring to herself. This oscillation, as discussed earlier, demonstrates the radical multiplicity in her sense of self. The lines also imply the disillusionments brought upon woman by the institution of marriage; as she expresses it overtly some stanzas later: "Who is this person who wears love's crown upon her head/And has rotted amidst her wedding gown." 232 The rhetorical question refers to herself, as if she is watching herself in the mirror or 
watching an image of herself frozen into a photograph. Some stanzas later, the third mirror image appears:

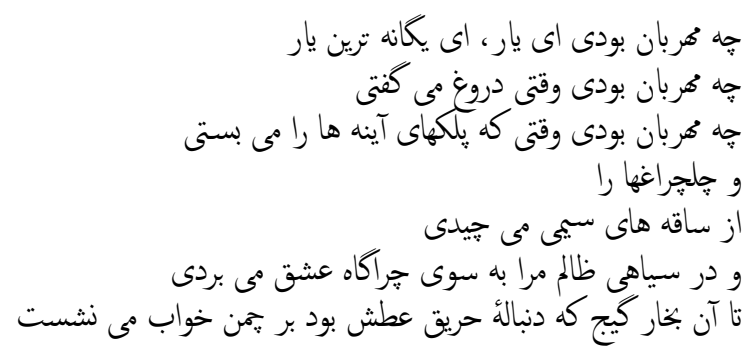

How kind you were, $\mathrm{O}$ friend, $\mathrm{O}$ most unique friend

How kind you were when you lied

How kind you were when you closed the mirror's eyelids

And plucked the lights of the chandelier

Off wire stems

And in the tyrannical darkness you took me to love's pasture

Until that giddy steam, which was the extension of thirst's fire, settles on the meadow of sleep ${ }^{233}$

The mirror image in this stanza is highly ambiguous. It can refer to the windows, to the eyes or even literally to the mirrors. By closing the eyelids of the mirrors, the poet may be referring to the lover's drawing the curtains, darkening the room and obstructing her outlet to the world outside. In preparing the scene for love-making, the lover tells lies to her, draws the curtains and turns off the lights. The persona believes that he was being so remarkably kind in doing all these; by taking her mind off the disturbing brilliance of the realities of herself and her world. Here once again Farrokhzad oscillates between the mirror and window, referring to both as the same medium for relatedness and for reality.

By mirrors the poet may also be referring to the eyes. By closing her eyes, she becomes momentarily oblivious to her turbulent state of being. The extreme kindness of the lover in stopping her from seeing and in lying to her, is paradoxically juxtaposed amid the brutality of her self-censuring for not seeing; a self-censuring which has been going on incessantly all through the poem. Moreover, it may literally refer to the mirror. The lover appears kind by stopping the merciless veracity of the mirror. Covering the mirrors may also hint at thwarting the societal gaze. The poem "Let Us Believe in the Beginning of the Cold Season ...," like her mirror-window, 
turns into a courtroom where Farrokhzad continuously puts her selves on harsh trial. The text provides her with a space for self-objectification and self-representation which gives her consciousness of the reality of her being. The mirror and the text for Farrokhzad function as a medium for self-realization, a prerequisite for the establishment of an emancipatory narcissistic relation to one's subjectivity and to one's world.

In the poem "Panğare" ("Window"), Farrokhzad maintains that a single window (and nothing more) is sufficient for her as an opening for seeing and hearing:

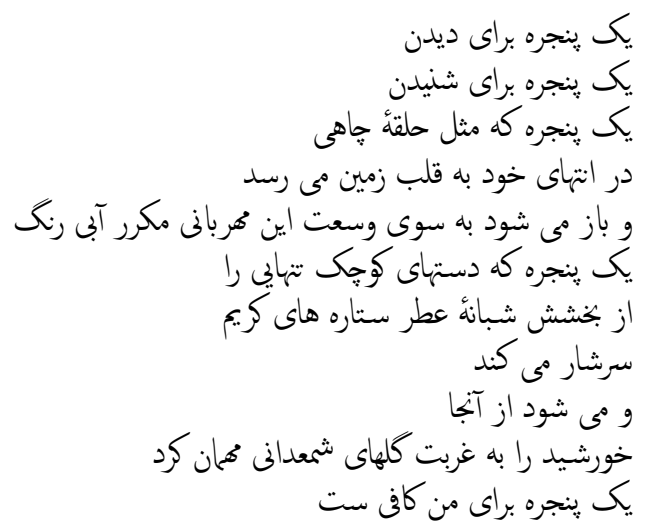

One window for seeing

One window for hearing

One window that like the shaft of a well

Reaches in its depths to the heart of the earth

And opens towards the expanse of this blue recurring kindness

One window overflowing

The little hands of solitude

With the nocturnal generosity of the bountiful stars' perfume

And thence one can invite the sun

To the exile of geraniums

One window is enough for $\mathrm{me}^{234}$

What the speaking persona needs to relate her to the world, to the earth, to the sky, to the night and to the day is a window and nothing more. In the second stanza, the persona provides the reader with her origin and background. She comes from a place where the people are no longer humans, but dolls, and where the trees are not real, but made of paper: 


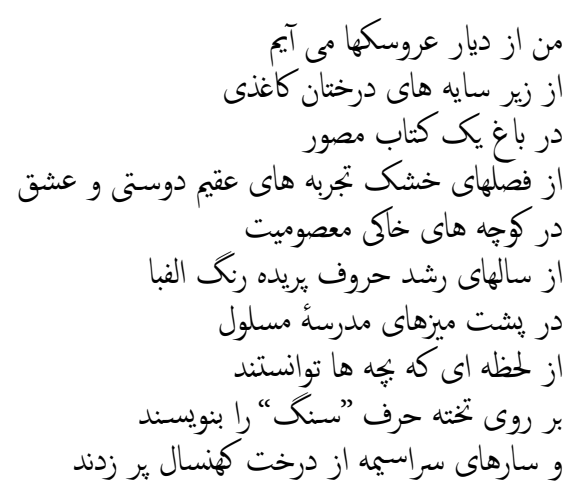

I come from the land of dolls

From beneath the shadows of paper trees

In the garden of a picture book

From the arid seasons of the barren experiences of friendship and love

In the dusty alleys of innocence

From the growing years of the pallid letters of the alphabet

Behind the desks of tubercular school

From the moment the children could write

The word "stone" on the board

And the startled starlings flew off the ancient tree ${ }^{235}$

The persona comes from a fake and artificial land with a dehumanized population. She has gone through failed attempts at friendship and love. She has left behind her childhood together with its associated innocence and naïveté. In the next two stanzas, Farrokhzad proceeds by portraying her society's tyrannical oppression towards her through graphic, dramatic and forceful images. Growing out of all those painful ordeals, when her life has turned into naught but a fleeting time, she realizes that she must "love madly."236

In the fifth stanza, Farrokhzad turns to the mirror and the window as two interchangeable entities with a similar function. Once again, she emphasizes that a single window (and nothing more) is sufficient for her as an opening to understanding and awareness:

One window is enough for me,

One window into the moment of consciousness, seeing, and silence

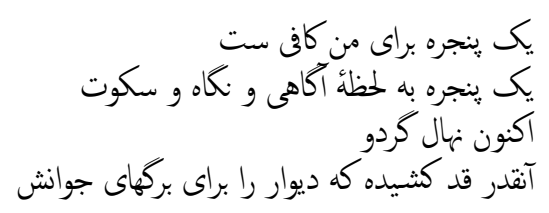


Now the walnut sapling has

grown tall enough

To define

The meaning of wall to its young leaves

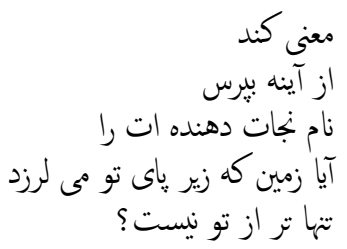

Ask the mirror

The name of your saviour

Isn't the earth trembling beneath

your feet

Lonelier than you? ${ }^{237}$

For Farrokhzad, the mirror in these lines has reversed its function from her initial conceptualization of it. It is no longer a tool of captivity or entrapment, not even a space of disturbing multiplicity. On the contrary, it becomes a means of liberation. It is now a vehicle of the truth, though not in the mystical sense. The mirror has turned into a vehicle of self-realization and self-construction, inviting the onlooker, as the Delphic principle does, to "Know Thyself." ${ }^{38}$ The mirror facilitates the formation of self. It appears to have the mantic power of divination. It is now supposed to have the knowledge and the power to reply and to direct the onlooker to salvation. The poet oscillates between the window and the mirror as the means through which consciousness, awareness and knowledge (āgāhì), seeing (negāh) and the serenity of silence (sokūt) are granted.

In these lines, Farrokhzad is making a direct appeal to the reader in general. She claims metaphorically that she has now mentally and psychologically matured enough to interpret the meaning of the wall as a symbol for suffocating confinement and oppressive entrapment for her young readers. Farrokhzad has been able to grow beyond all those imposed limitations and forced captivities and psychologically disentangle herself. Thereby, the surface of the mirror becomes the agency for the relocation of power. The power, initially located on the surface of the mirror, is relocated within the self through the process of reflection, perception and introjection of the image appearing on its surface. The mirror becomes an agency of empowerment and emancipation. Through it one can gain control of the image, and thereby, control of that power. ${ }^{239}$ Moreover, the surface of the mirror is liberating because the confrontation with the uncanny double on it, as Freud suggests, lifts the curtain: 
all the unfulfilled but possible futures to which we still like to cling in phantasy, all the strivings of the ego which adverse external circumstances have crushed, and all our suppressed acts of volitions which nourish in us the illusion of Free Will. ${ }^{240}$

By inviting the reader to turn to the mirror for an indication of one's saviour, the concept of saviour as the "other" is categorically rejected. The responsibility of self-liberation lying solely on the solitary individual is further emphasized by the rhetorical question on the loneliness of the earth. In the poem "Let Us Believe in the Beginning of the Cold Season ...," discussed earlier, Farrokhzad openly asserted that the saviour is utterly dead. ${ }^{241}$ Further on, in continuation of the same stanza, the poet thoroughly rejects the idea of religious deliverers of mankind. Contrarily, she holds the prophets and their holy books responsible for the havoc of our age:

The prophets brought with them into our century

The mission of destruction

Are these constant explosions

And poisonous clouds,

The echoes of Holy Scriptures?

$\mathrm{O}$ friend, O brother, O blood fellow

When you reach the moon

Inscribe the date of the flowers'

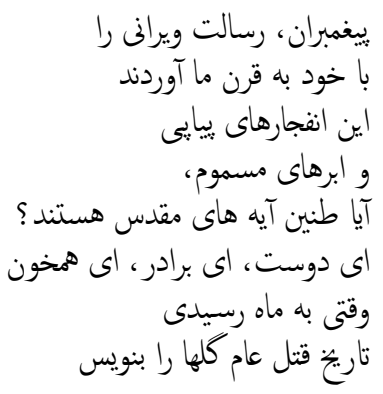

massacre $^{242}$

Farrokhzad proceeds by denigrating the doomed naïveté of dreams and illusions. Together with her youth, the old meanings are now dead for her. She feels that her time has passed. In the concluding stanzas, the persona invites the addressee to communicate with her. She is now in the shelter of the window; she can now relate to the sun:

Say something to me

I am in the window's shelter

I have relation with the $\operatorname{sun}^{243}$

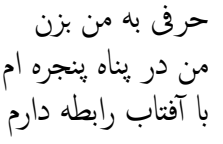

Farrokhzad begins her poem "Window" by claiming that for the comprehension of the self and the world a window would suffice her. In the very same poem, the function of the window, as a medium for the realization of 
the inner and outer worlds, is shifted to that of a mirror within which the saviour could be sought. The mirror and the window are now turned into tools of introspection and the knowledge of the "I" within and the "I" without, tools for monitoring the subject in its constant process of becomings. Through them, the subject may question her older selves, the present one or even envisage the future self. Therefore, the mirror can indeed become a source of liberation, of self-confidence and self-empowerment.

Farrokhzad has here completed her departure; a departure foreshadowed in her previous poems. Now she becomes able to acknowledge the significance of the mirror as a means of self development. This mirror is not her early mirror for seeing how she would appear to the other, mainly to a male gaze. No longer is it a space where her disturbing fragmentation and multiplicity of self surge, where it inflicts exceeding pain and angst. The mirror is now a space where the fragmentations are healed, the multiplicities are compromised and an authentic subjectivity is constructed. Now that she has reconciled (at least temporarily) the inner antithetical warring selves, her self-image with the images reiterated on her mirror, the poet exults in a sense of liberation, a sense of another birth. Squier asserts:

That rich accumulation of self-knowledge, that ability to respond to what is seen with the whole pressure of history and environment and conscious awareness which we call apperception, is the true gift of the satisfying mirror encounter. ${ }^{244}$

In her later poems, Farrokhzad introduces the mirror as a site of the individual's liberation. The specular reflection instigates mental reflection; in other words, the speculum vivifies speculation. Therefore, the mirror awakens the feeling of one's authentic selfhood. The mirror is now the place where all those disturbing feelings of uncanniness have dissolved into, turning it into a place where she feels most at home-her querencia. A convergence place of social adaptation and private introspection. It is the exact site where the person can take possession of her own face, as it is the very site the effacements or the wrong faces were continually enforced. Nevertheless, it should be kept in mind that an outright presentation of a figure of fixed, self-conscious subjectivity by means of a mirror, text or anything else would ultimately remain delusory. 


\section{Self-Mirroring in the Poetry of Forugh Farrokhzad}

Apart from the mirror, for Farrokhzad the only other alternative means of proving and sustaining her existence appears to be her writing. This is because, for any such artistic production there must be subjectivity, an agent active in the act of production. Thus, through a sustained act of creation and re-creation, the poet becomes able to reassure herself of her continual existence. For Farrokhzad, texts perform similar psychological functions to mirrors. They remain the two semiotic modes-catoptric and linguistic-for the objectification and consciousness of the self. A mirror is a semiotic medium. It is the cause of communication taking place between two entities. By objectifying herself either in the glass or on a piece of paper, Farrokhzad gains self-knowledge. She relies heavily on reflectionspecular or mental-for her sense of being. Through mirroring and writing about the self, Farrokhzad incorporates the represented (specular and written subject) as signifiers and the representing (experiencing and writing subject) as signified, within her totalizing understanding of her subjectivity.

For Farrokhzad texts and mirrors have parallel psychological functions. They provide her with objectification, thereby, the consciousness, of her subjectivity. In an interview, Farrokhzad made it clear that, for her, poetry is "a window." 245 As discussed earlier, the mirror and window at times function similarly in her poetry. She often draws upon them interchangeably. In the same interview, Farrokhzad proceeds to say that poetry is an opening to her "existence," something through which she can justify her being and discover her authentic self:

[Poetry] is a means for communicating with being, with existence in its wide sense. The advantage of it is that when one composes a poem one can claim "I exist" or "I existed." Otherwise, how can one claim one's own being? I do not search for anything in my poems. Rather, I discover "myself" in my own poems. ${ }^{246}$

Therefore, for Farrokhzad, poetry as a self-seeking space turns out to be a desideratum. In her poetry, she enters into a narcissistic dialogic relationship with her subjectivity. Poetry provides her with a heterotopic-at time utopic-space for the outpouring of her narcissistic self. Further on in the same interview, she explains her experience of composing poetry with an explicit reference to mirroring and self-reflection in a spring of water. The 
metaphorical description of her composing experience bears strikingly similarities to the story of Narcissus; wandering lost in the forest and coming upon his image in a lake:

I set off wandering, like a child lost in the forest. I went everywhere and gazed at everything. Everything attracted me till I finally arrived at a spring of water and found myself in that spring; I myself, containing me myself and all my forest experiences. But the poems of this book are in fact my steps and my searches for reaching the spring. Now poetry is something crucial for me. It is a responsibility I feel towards my existence. It is a sort of reply, which I should give to my life. I respect poetry the way a religious man respects his religion. ${ }^{247}$

Self-realization for Farrokhzad is in close reciprocity to her self-narration. It is through her perennial involvement in the discovery, recovery and definition of the self that she concocts her self-portrait and contrives her selfnarrative. Her text, like her mirror, provides her with a space-sometimes depressing, at other times utopic, sometimes captivating, at other times emancipatory-for the act of self-scrutiny both as the subject and the object; the writing subject and the written subject.

Non-productivity for the poet equates with non-existence. As Cixous explains, this close reciprocity of self-discovery with self-narration for the female poet is also because women write from where the unconscious is speaking: "because poetry involves gaining strength through the unconscious and because the unconscious, that other limitless country, is the place where the repressed manage to survive: woman, or as Hoffmann would say, fairies." ${ }^{248}$ The inscription of subjectivity into her text signifies that Farrokhzad has already recognized a lack and felt the need to give a meaning to it. She feels this need to reflect and to (re)construct her subjectivity from an external position exactly like what happens in the mirror experience. Therefore, the subjectivity textualized becomes a source of emancipating empowerment.

For Farrokhzad, producing an artistic work, especially one of a highly personal and subjective nature, becomes like seeing one's reflection in the mirror, an existential necessity-a self-affirming experience. In reply to the question "Why do you compose poetry?" raised during an interview, Farrokhzad affirms, "Because I need to. For me, poetry is a need; a need beyond the level of eating and sleeping, something like breathing." ${ }^{249}$ Within her text, she can enact her desires, fears, anxieties, her wants and her 
pleasures from her marginalized position. There, she is given a space to express the experiences of disturbed subjectivity; a subjectivity which has been systematically repressed by her society. Milani observes that Iran, as a traditionally patriarchal society, keeps women out of the realm of visibility by forcing them inside its walls, veils and silencing. In such a context, writing remains a pernicious method of subversion, a method of "encounter[ing] exclusion-spatially or verbally." ${ }^{250}$ She argues:

Writing, with its potential for public communication, for entering into the world of others, could be considered no less a transgression than unveiling. In both, a woman expresses/exposes herself publically. Through both, an absence becomes a presence. Both are means of expression and communication: one gives her voice a body, the other gives her body a voice..$^{251}$

Within Farrokhzad's text, as within her mirror, an ongoing debate is staged between her authentic self and the recurrent cultural images of womanhood, on the one hand, and among her owns multiple contradictory selves, on the other. It is only through inscribing her body and her subjectivity into the text that she can break into a presence and into visibility; to live on and feel alive. The objectified feelings on the paper become a source of knowledge and power for her.

Despite the rich cornucopia of mirror imagery in classical Persian literature, Forugh Farrokhzad proves that her grasp of the mirror phenomenon and its ambivalent functions was not confined to the model of her literary forefathers or her scant foremothers. Farrokhzad's use of mirror imagery remains mainly feminine, in that she depends on it for the realization and definition of her true self and also for that of her worldview. In her developmental journey of a "subject in process," she portrays her diverse and even contradictory personal experiences by means of the mirror. The highly ambivalent essence of the mirror elicits diverse and even paradoxical reactions from her poetic personas. In her earliest poetry, the mirror serves as a tool by which she prepares herself for the male gaze. Farrokhzad relies on this gaze and the male desire that drives it for a happy consciousness of her existence. The painful growth out of this stage is exposed by her problematic relationship with her mirror and mirroring. Ultimately, Farrokhzad comes to realize the constructive nature of the mirror at a stage where she is peacefully embracing her bygone "pale experiences" and approaching old age and death. 
For Farrokhzad poetry, like her mirror, remains a site of subject formation. Poetry becomes a mirror on which she relies for realization of her self and for relating that self to the world around her. Farrokhzad inscribes the gendered history of her subjectivity within her mirror poetry; a history of a disturbed and insecure poet in her incessant adaptation of identities. Within her mirror text, Farrokhzad gives us a vivid picture of her continual struggle with the antithetical images of womanhood in an era of Iranian history which is marked by the confusion of transition from tradition to modernity. 


\section{Mirror Imagery in the Works of Sylvia Plath}

The time will come when it will disgust

you to look in the mirror. Ovid

\section{The Mirror as the Intersection of Academic and Artistic Talent}

In her use of mirror imagery throughout her literary opus-whether poetry or prose-Sylvia Plath reveals a puissant imaginative creativity. Plath's felicitous use of mirror imagery and her aesthetic manipulation of it, rendering it a cornucopia of competent and ambivalent meanings, was not merely the fruit of her strong creative power; it was also supported by her deep academic research on the subject. Her fascination with the mirror and the shadow as forms of the human double prompted her to choose it for the subject of her undergraduate thesis at Smith College in Northampton, Massachusetts. She entitled her thesis: The Magic Mirror: A Study of the Double in Two of Dostoevsky's Novels, which she submitted in January 1955.

For this study of mirror, shadow and double in the works of Dostoevsky, Plath threw herself into a deep study of the subject from the standpoints of anthropology and psychology. She began with a close reading of the chapter on "The Perils of the Soul” in James Frazer's The Golden Bough, the chapter on "The Double as Immortal Self” in Otto Rank's Beyond Psychology and Sigmund Freud's essay "The Uncanny." In her exploration of the mirror image and the double as essential parts of man, also manifested at times in the form of shadow, Plath introduces the mirror in her thesis in these words:

The appearance of the Double is an aspect of man's eternal desire to solve the enigma of his own identity. By seeking to read the riddle of his soul in its myriad manifestations, man is brought face to face with his own 
mysterious mirror image, an image which he confronts with mingled curiosity and fear. This simultaneous attraction and repulsion arises from the inherently ambivalent nature of the Double, which may embody not only good, creative characteristics but also evil, destructive ones. ${ }^{2}$

Plath acknowledges the ambivalent constitutive share-constructive as well as destructive-the mirror image plays in the construction of one's identity. The very ambivalence of this share accounts for the simultaneity of appealing and repulsive feelings the image in the mirror evokes in the beholder. Further on in her study, Plath asserts that to achieve wholeness man should reconcile himself with its inherent duality by acknowledging the multiple insubstantial presences inhabiting his mirror:

that recognition of our various mirror images and reconciliation with them will save us from disintegration. This reconciliation does not mean a simple monolithic resolution of conflict, but rather a creative acknowledgment of the fundamental duality of man; it involves a constant courageous acceptance of the eternal paradoxes within the universe and within ourselves. $^{3}$

Plath here wittily locates man's inner paradoxes within the larger paradoxes of the universe; in other words, she relates the paradoxes of the Innenwelt to those of the Umwelt, which one should acknowledge creatively and courageously to avoid disintegration. Therefore, one's Innenwelt and Umwelt can be indeed perceived as micro-macrocosmic mirrors mutually reflecting their inherent and eternal paradoxes. How far Plath herself was able to reconcile these conflicting images appearing on her mirror through her creative art, and thereby save herself from disintegration by acknowledging their inherent paradoxes, still remains a controversial issue.

This succinct background information on Plath's scholarly involvement with mirror imagery reveals to us her deep knowledge of the theme and her conscious crafting of it in her art, aesthetically enhanced by her highly creative and imaginative mind. It also reveals to us that Plath was well aware of the ambivalent and even sometimes antithetical nature of one's multiple specular images; of how they are inherently fundamental to the structure of one's subjectivity. To this, the twenty-first-century reader can add post-Freudian and Lacanian psychoanalytical critique, not to mention the deconstructive readings of Feminism. The conflicting images of a person, projected and perceived in the mirror, and the inherently split 
subjectivity of a person constituted by an inevitable lack are particularly aggravated in the case of female subjects, having to struggle with warring images of twentieth-century womanhood. Plath's mirror and double images bear witness to the impossibility of approximating these warring images in any form other than death or in what is regarded as insanity.

Some critics have interpreted Plath's mirror imagery in general terms. For instance, Axelrod in his study of Plath's mirror and shadow imagery categorizes them as her "imagery of poetic incapacity", asserting that her mirrors portray a negative envisaging of herself as well as of her world. ${ }^{4}$ Axelrod believes that for Plath the mirror was a sort of "Baudelairean mirror of despair," functioning "as an agent of anxious narcissism," emphasizing "gross corporality" by reflecting "an ugly outer being but no inner queen." There is some undeniable truth in such assertions; however, we should be careful not to ignore the highly ambivalent, even sometimes contradictory nature of Plath's mirror images which need to be studied individually and within their textual and biographical contexts.

Plath uses her poetry for the purpose of self-inquiry. For her, art is a vessel in which she can set out in search of her true subjectivity within the stormy ocean of warring images; on the one hand, the images of monsters, sirens, witches, femmes fatales or madwomen rise to surface from the dark and obscure depths of femininity and haunt her, and on the other hand, the promising, yet contemptible flat images of "Angels in the home" stretch out temptingly on the surface. Furthermore, Plath uses her poetry, as well as her mirror to become involved in the less emotional mode of self-inquiry, and finally, through writing, she struggles to express herself. By the objectification of the self in her text and her mirror she can prove her existence as an intellectual and emotional being. In this chapter, I will address some of these attractive and repellent images of womanhood and female subjectivity and an analysis will be provided of the ambivalent confrontations of the poetic persona with these images, mostly presented through her mirror imageries.

\section{The Mirror as a Weapon of the Femme Fatale}

The deluding nature of the mirror has been recurrently drawn upon in art and literature to present it as a tool of deception and beguilement, particularly in the hands of sirens, witches, sorcerers and femmes fatales. 
These narcissistic women use their maleficent mirrors to erase or destroy the face of the other on their surfaces. Referring to the end of the nineteenth century, when the cult of the femme fatale and her sexuality was explicitly claimed a treat to masculinity, Dijkstra discusses:

Woman came to be seen as Narcissa, the true feminine incarnation of what had once been an image of masculine egotism. ... The mirror, then, came to be regarded as the central symbol of feminine narcissism. The story of Narcissus and the nymph Echo became especially popular because it permitted a convenient conjunction of the themes of woman as mirror and woman in the mirror. ${ }^{6}$

Plath draws upon the intimate association of the witch and her mirror in the poem "Vanity Fair." Composed and published in 1956 along with another poem of hers, "Spinster," in the first issue of the literary magazine Gemini, the two poems share for their central image that of a lonely spinster, a witch. ${ }^{7}$ There have been strong and inevitable cultural associations between the spinster and the witch. Both are associated with extreme malevolent female powers by dint of their non-conformity to patriarchal rules, for not being under the control of men, and particularly for their barrenness. Spinsters were frequently considered misfits, deviants and mad; as Ussher points out, they have incontrovertibly been considered "our social Nemesis." By stigmatizing spinsters as witches in the patriarchal culture, it has been sought to punish these women and harness their unchecked powers.

Plath keeps her artistic distance from these repellent figurations of womanhood by narrating their stories in the third person, in the form of "This witch" in "Vanity Fair" and "This particular girl" in "Spinster." In these two poems Plath is indeed echoing the "cultural noise pollution" surrounding these figures of womanhood, which are the fossilized images her society feeds on. ${ }^{9}$ In the first poem, the lonely woman "sets mirror enough," and in the latter, "And round her house she set/Such a barricade of barb and check," both serving as means of fortification and defence, in the case of the first "Against virgin prayer" and "To distract beauty's thought," and in the case of the latter "Against mutinous weather/As no mere insurgent man could hope to break/With curse, fist, threat/Or love, either." ${ }^{10}$

The title of the poem, "Vanity Fair," is an overt allusion to the classical nineteenth-century novel by William Makepeace Thackeray, Vanity Fair: A Novel without a Hero. In its turn, the title of the novel is an allusion to John 
Bunyan's The Pilgrim's Progress, a seventeenth-century puritan Christian allegory in which Vanity is the name of a town along the pilgrim's progress where a permanent fair is held, symbolizing man's sinful attachment to worldly things. "Vanity Fair" generally symbolizes the deluding transience of worldly life, when one loses sight of higher realities, of eternal life after death. Plath's vision of spinster, sorceress and witch, the central persona in this poem, also particularly corresponds to a major female character in Thackeray's novel, Becky Sharp. They both share the common themes of feminine wile, attachment to the world, self-love, ageing and the loss of physical beauty.

In the poem "Vanity Fair," Plath gives an alarming portrayal of ageing and corporeal deterioration, especially in the first two stanzas, through the witch's crooked fingers and her eyes which have a cold squint look and are veined like crow's feet. The continual passage of time, accompanied by the brutal consistency of ageing, positions this woman in an intermediate state between this world and the afterlife. The continual physical deterioration works as a harbinger of her death:

Through frost-thick weather

This witch sidles, fingers crooked, as if

Caught in a hazardous medium that might

Merely by its continuing

Attach her to heaven.

At eye's envious corner

Crow's-feet copy veining on a stained leaf;

Cold squint steals sky's color; while bruit

Of bells calls holy ones, her tongue

Backtalks at the raven ${ }^{11}$

This old woman "sidles," either because of her physical disabilities of old age or because of her rejected and outcast position in her society, attempting to move around furtively and inconspicuously.

Due to her nature and also because of her social position, "This witch" is envious of everything and everyone, especially of virgin, beautiful girls, ardently desiring their youth and beauty. Invidia, one of the Seven Deadly Sins in Christianity, is closely associated with looking, particularly with evil eyes. Melchior-Bonnet's description of Envy personified closely corresponds to Plath's description of the witch: "Envy is also a sin of the gaze 
(in-vidia), personified by an old, dried up, wrinkled woman with flaccid breasts and hair in disarray. ... Envy follows the virtue she denigrates everywhere: her malicious gaze corrupts what she sees." ${ }^{12}$ While the vain narcissist seems to take extreme pleasure in the assumed wholeness of his double, the envious person's sense of selfhood is dominated by "not having" and deprivation. Due to the envious witch's ardent desire, she looks at things or people askance-she squints. The witch struggles to manipulate the fates of others with her unharnessed power.

By presenting the witch's body in these grotesque terms, and also by the "eye's envious corner," Plath emphasizes her abject position. Abjection literally means in a downcast or cast-off state. The abject thing, remaining in the intermediate state, is neither subject nor object; it is something in between, something alive yet not. Kristeva defines the abject as:

the jettisoned object, [which] is radically excluded and draws me towards the place where meaning collapses. A certain "ego" that merged with its master, a superego, has flatly driven it away. It lies outside, beyond the set, and does not seem to agree to the latter's rules of the game. And yet, from its place of banishment, the abject does not cease challenging its master. $^{13}$

The witch is situated outside the symbolic. In her marginalized position, she does not abide within the rules of patriarchy, maintaining a sort of antinomian relationship to it. The attempt to bring her under the control of men and the church has somehow failed, and now she constantly challenges the symbolic Father from her peripheral outcast position.

In Christianity, the crow has been used to symbolize the Devil who plucks out the eyes of sinners. ${ }^{14}$ Likewise, the envious witch of this poem blinds the eyes of young ladies to their sins and to higher truths with the help of delusionary, de-substantiated and ephemeral images projected onto mirrors, as we will learn in the following lines. The raven, like the crow, is a "talking bird," thereby signifying prophecy. ${ }^{15}$ These birds are often considered companions to the dead. Though the sound of bells, apparently church bells, is a reminder of things holy, the witch's voice remains profane. The witch impudently disputes with the raven, the harbinger of death. She has the power to foresee what is going on in the hearts of "simple girls, church-going" and how ready they are to sin with "every amorous oaf" or "for a trinket," probably because she had once gone through the same experiences as those young girls. 
Cleaving furred air

Over her skull's midden; no knife

Rivals her whetted look, divining what conceit

Waylays simple girls, church-going,

And what heart's oven

Craves most to cook batter

Rich in strayings with every amorous oaf,

Ready, for a trinket,

To squander owl-hours on bracken bedding,

Flesh unshriven. ${ }^{16}$

The "skull's midden" and the "whetted look" of the witch are reminders of Medusa-another female abject figure with hair of hissing serpents and looks that turn the onlooker into stone. Both these abject figures share a look which immobilizes others into death, and in both stories power and control are exerted through a mirror.

Like the fair in the city of Vanity in Pilgrim's Progress, which distracts the pilgrims on their holy way, this witch owns a powerful tool by which she can distract the prayers of these simple virgin girls. It is something whose lure no young lady can withstand. This powerfully guileful weapon is nothing other than the mirror:

Against virgin prayer

This sorceress sets mirrors enough

To distract beauty's thought;

Lovesick at first fond song,

Each vain girl's driven ${ }^{17}$

Plath shifts from addressing her malevolent central figure as the "This witch" of the initial stanza to "This sorceress" in this fifth stanza. In his study of Witchcraft, Magic and Alchemy, de Givry marks "exaggerated unsociable individualism" as the main characteristic of sorcerers or sorceresses. ${ }^{18}$ These grotesque figures serve Satan as priests and priestesses in his infernal church by casting sors or evil spells. The sorcerer/sorceress is indeed the mirror image of the priest/priestess-mutually reiterating an inverted simulacrum. These demonic sorcerers/sorceresses, observes de Givry, "invoked the curse of Hell upon them as the priest called down the blessing of Heaven, and on this earth he was in complete rivalry with the ecclesiastical world." ${ }^{19}$ 
Plath here draws upon the traditionally close association of sorceresses, sirens and witches with their magical mirrors and crystal balls. These reflecting surfaces gain significant power when in the possession of devils and femmes fatales. They use this reflecting surface to create a fata morgana, to deceive and entrap men and women within their selves, distracting them from divine realities. In their hands, the mirror serves as a vestibule to the realm of the devil. A young girl, made vain by the mirror, "wills all to the black king," to the devil:

To believe beyond heart's flare

No fire is, nor in any book proof

Sun hoists soul up after lids fall shut;

So she wills all to the black king.

The worst sloven

Vies with best queen over

Right to blaze as satan's wife;

Housed in earth, those million brides shriek out.

Some burn short, some long,

Staked in pride's coven. ${ }^{20}$

The mirror traps these young girls within their vain narcissism, unable to see any other world beyond their own, a world confined within the frame of their mirrors. Deception and delusion being their predominant characteristics, Satan or the devil, as the masters of simulacra, have often been metaphorized into mirrors. Melchior-Bonnet explains:

The devil is the deceptive mirror par excellence, the speculum fallax; he is the father of lies who creates illusions, usurps resemblance, and causes man to turn away from his true model. The devil is sometimes allegorized in iconography through the image of a monkey playing with a mirror, since each one counterfeits the world, for the devil wants to rival his creator by producing simulacra. ${ }^{21}$

In this poem, Plath employs the mirror in its traditional meaning as a vehicle of vanity and pride, and hence guilt. It is a negative tool which distracts "beauty's thought," bedazzles her into the oblivion of the fire of hell, religious books and ultimately causing her downfall and eternal damnation. ${ }^{22}$ Finally, the vain girl bewitched by illusions will be housed with other vain 
girls, a "million brides" burning in the subterranean hell, a fate which the witch herself definitely shares. Vanity has long been considered a form of self-idolatry, because one rejects the image of God for the sake of one's own.

The poem "Vanity Fair" reveals Plath's growing belief in the occult and black magic. This preoccupation was to be intensified through her husband, Ted Hughes, who sank himself into celtic superstition and pagan myth for the sake of poetical inspiration. Following Alvarez, some blame black magic for Plath's ultimate suicide. ${ }^{23}$ On the other hand, the theme of the poem and its diction-words such as holy bruit of bells, flesh unshriven, virgin prayer, vanity, pride, church-going, flares, and housed in earth—make "Vanity Fair" an overt didactic poem of Christian Puritanism. Vanity was a primary concern for the Puritans, for whom the mirror was anything but divine. When the mirror ceased to be a mirror of divinity, reflecting God or his divine imagoes, it was invariably to be associated with the devil. Melchior-Bonnet observes:

With the emergence of the mirror, a fantasy world of fears and desires is born. For the preacher, mirrors were the paraphernalia of witches who lock demons inside them, but they were also dangerous objects for any Christian because they attracted "crazed stares." When the mirror was not reflecting the spotless divine model, it was the seat of lies and seductions, used by a cunning Satan to deceive men. As an instrument of both simulation and lust, the mirror fed illusions of mind and cupidity of the flesh, and thus was tied to numerous allegorical representations of $\sin { }^{24}$

This irresistible attraction of the specular image is due to its ethereal, desubstantiated and ephemeral virtuosity, which renders the reflection more attractive than the real object. Furthermore, Melchior-Bonnet asserts:

An illusionary version of the original proves more seductive than the original itself, as does variety over sameness. Reference to the unique source of all likeness is lost in the inexhaustible varieties and mutations of reflections that stimulate the mind. ${ }^{25}$

The simple virgin girl seems to lose her pure simplicity and holy virginity once she becomes enthralled in the illusory images in her mirror; thereupon, she loses sight of her religion's teachings and the divine image.

In this early poem, Plath's use of mirror imagery complies with its traditional associations. In Western art and culture, the woman-with-mirror 
figurations were invariably associated with feminine narcissism. These figurations were often accompanied by the symbols of the devil or presented in the form of a memento mori. It is only in her later poems that Plath departs from the mirror as a tool of female vanity when she becomes increasingly sceptical of institutionalized religious teachings. Plath likewise draws upon the traditionally recurrent coupling of the witch and the mirror in another early poem, "On Looking into the Eyes of a Demon Lover." In this juvenilia poem, which will be studied in more detail later, the textual I, calling herself "witch," dares to look inside her "scorching mirror" only because she believes that sirens and witches are immune to the mirror's destructiveness, which invariably "cripples," "injures" and transfigures lovely ladies. ${ }^{26}$

\section{The Childless Woman: A Narcissist}

A popular cultural belief, expounded and further reinforced by Freud, holds that as women mature their primary narcissism is intensified to the extent that their love for the other remains undeveloped. In his essay "On Narcissism," Freud announces, "Strictly speaking, it is only themselves that such women love with the intensity comparable to that of the man's love for them." ${ }^{27}$ Nevertheless, Freud allows just one outlet for women's narcissism, and that is when they bear children. It is only then that their libido can be directed to the other. Through the love of their offspring, women can for the first time experience the love of the other. However, Freud also asserts that the love of one's offspring, a biological extension and part of one's self, is "narcissism born again." ${ }^{28}$ Therefore, according to Freud, women-with or without children-are inevitably assigned to the closed circle of narcissists. For Freud, recapitulating the popular belief, the most intense female narcissism occurs in the case of barren or childless women, whose sole outlet for the love of others is thwarted.

This belief is what Plath, with the help of mirror imagery, reiterates in her poem "Childless Woman." Composed in 1962 and narrated in the first person, "Childless Woman" is an expression of the purely feminine experiences of a woman desperate to bear a child, but unable to do so. The processes of her womb and her monthly menstruations turn out to be totally futile:

The womb

Rattles its pod, the moon

Discharges itself from the tree with nowhere to go. ${ }^{29}$ 
Hers is a uroboric womb consuming itself with nothing to create. Everything seems to converge into herself, a knot in which she is trapped and from which she cannot disentangle herself. She is rewarded by nothing but a profane and ungodly love of herself. The woman, destined to reproduce, feels desperate when unable to do so; there is no future, no destiny for her. Plath portrays the despairing feelings of the barren woman through the metaphor of the palm of a hand with no lines to be read:

My landscape is a hand with no lines,

The roads bunched to a knot,

The knot myself,

Myself the rose you achieve-

This body,

This ivory ${ }^{30}$

This white-skinned barren woman fails in her obligation to reproduce: both to give birth and to reproduce her mother's and her female ancestors' story. In a simile, the speaker compares herself to a weaving spider. Instead of webs, however, she produces mirrors, reflecting nothing but herself. She is completely trapped in solipsism and self-love. The spider's web is often considered a symbol for "neglect or decay," thereby indicating that the blood, as well as the life, of the childless woman is wasted. ${ }^{31}$

Ungodly as a child's shriek.

Spiderlike, I spin mirrors,

Loyal to my image,

Uttering nothing but blood-

Taste it, dark red!

And my forest ${ }^{32}$

The mirror reiterates ethereal images without any substance or reality to them. Likewise, the body of this barren woman imitates the processes of reproduction, but ultimately fails to give birth to a substantial reality. Both the mirror and this sterile woman are as blank spaces, ready to receive the images of simulacrum. While interpreting the woman and the mirror in the famous painting by Hieronymus Bosch, Garden of Delights, ${ }^{33}$ Melchior-Bonnet asserts, "Sterile like her, the mirror imitates forms rather 
than creating them, thus taking its place among other human inventions, many of which are useless and dangerous." ${ }^{34}$ The barren woman was often regarded as useless, threatening and ungodly for not fulfilling her engendering role.

The spider also symbolizes the female in general. Woman, like a spider, spreads nets for her prey-for men. In "The Merchant of Venice," Shakespeare employs the spider in the same meaning: "Here in her hairs/The painter plays the spider; and hath woven/A golden mesh t'entrap the hearts of men/Faster than gnats in cobwebs." ${ }^{35}$ It is interesting to note that, in weaving their webs, spiders are independent of any other thing, and by spinning webs they actually create their own world. Moreover, their threads are drawn out of their abdomens. ${ }^{36}$ In his "King Henry the Eighth," Shakespeare calls a spider's web a "self-drawing web." ${ }^{37}$ The image of the spider weaving its web further emphasizes the speaker's entrapment within the solipsistic self. ${ }^{38}$ Even if the woman becomes pregnant, it is in vain; she gives birth to dead children:

My funeral,

And this hill and this

Gleaming with the mouths of corpses. ${ }^{39}$

Due to the similarity in their protruding shape, the hill, for Plath, symbolizes a pregnant woman. ${ }^{40}$

While Plath employs the mirror metaphor in her poem "Childless Woman" to portray the woman's morbid inability to move beyond the self through engendering a child, in another poem dealing with the same theme, entitled "Barren Woman," Plath employs the image of a museum as a heterotopic site, but devoid of any statue. Whereas in "Childless Woman," the mirror's facelessness with its lack of subjectivity is drawn upon to convey the woman's state of being, in "Barren Woman" the noiselessness of a historical site is invoked. The speaker of the first poem employs the image of visual doubling, while in the latter she evokes auditory doubling: "Empty, I echo to the least footfall." ${ }^{41}$ Plath aptly recognized and depicted the close alliance of the image and voice in defining subjectivity.

On another level, these two poems, "Barren Woman" and "Childless Woman," along with some other poems by Plath, such as "Stillborn" and "A Sorcerer Bids Farewell to Seem," can be read as metapoetry-poetry about poetry. On this deeper level, a more different and independent mode of 
meaning, carrying the implications of self-referential discourse, is provided. Read in this light, these poems are an allegory of the poet's wretched struggle in crafting her art, and Plath here indicates that her efforts in crafting poetry are futile. Either she fails to compose poems and stays barren, or the poems she crafts are dead, aborted, or stillborn. In the tenth book of Plato's The Republic, Socrates employs the metaphor of the mirror to define the artist's work contemptuously-Plato's theory of mimesis. Accordingly the artist is someone who spins a mirror:

turning a mirror round and round-you would soon enough make the sun and the heavens, and the earth and yourself, and other animals and plants, and all the other things of which we were just now speaking, in the mirror. ${ }^{42}$

Plato's sceptical view of art, which was to be accentuated by later Platonists, holds that the artist's creation, contriving an imitation of an imitation, like the reflection in a mirror, is at its best twice removed from the true reality of Ideas. Likewise, Plath in her struggle to concoct poetry while imagining herself "with a great public," appears to spin mirrors like a spider. $^{43}$

\section{The Gigolo: Male Narcissism}

Unlike the other instances of mirror imagery in Plath's oeuvre, mainly drawn upon to convey female anxiety, narcissism, vanity or her ruse, the mirror in the poems "Gigolo" and "Purdah" is intended to portray the male personas' obsession with narcissistic self-love and their failure to distinguish anything beyond their selves. "Gigolo" is a dramatic monologue, composed on 29 January 1963, i.e., in the final days of Plath's life. On the same day, Plath composed "Paralytic," too, apparently trying her hand at poems in which the speakers were not speaking about Plath's own personal experiences. In both these poems, the first person speakers are distinctly male figures. In "Gigolo," the male figure emerges as a direct descendent of Ovid's Narcissus, trapped in his primary narcissism. Bassnett asserts that there is a close correspondence between the persona of the gigolo "preying on women" and "an emblematic narcissist." ${ }_{4}$

"Gigolo" opens with the male speaker haughtily presenting himself in the first person through the metaphor of a watch. Here, the pocket watch 
symbolizes the mechanical and dehumanized nature of the gigolo. On the other hand, the watch ironically refers to the brevity and mortality of human life. With each tick of it, the gigolo is approaching his end. The poem proceeds with sexually charged metaphors, signifying the gigolo's sexual obsession as the dominant nature of his narcissism.

Pocket watch, I tick well.

The streets are lizardy crevices

Sheer-sided, with holes where to hide.

It is best to meet in a cul-de-sac,

A palace of velvet

With windows of mirrors.

There one is safe,

There are no family photographs, ${ }^{45}$

The misogynist I-narrator of "Gigolo" hides in holes; he is trapped within the "cul-de-sac" of his selfhood. In his solipsistic velvet palace, there are no windows, no openings to the world outside, nor is there any possibility for communication with others. All he can see is the specular reflections of himself, signifying, as Kendall notes, his "inability to range beyond the barriers of the self." ${ }^{\prime 6}$ Gigolo can see only this specular reflection; the de-realized, illusory reflection of his visibility. He invariably fails to see the whole reality of his selfhood. He is only interested in this metaphorical/metonymic projected visibility of his being. The reality of his total self, beyond the specular image, particularly those aspects of his subjectivity which are formed through relatedness with others and with the world outside, remains unknown for him, and these unknown aspects remain increasingly threatening to his sense of security.

The gigolo feels secure within the confines of his solipsistic palace, a palace of mirrors with no outlet to the world of others. He fears any relatedness with others. There is no place even for family emotion. The presence of family members through their photographs threatens his narcissistic sense of containment; he feels much safer without the family members and their memento, represented through family photographs. Family for him implies oppressive subjugation, enslavement and depressive feelings, and is expressed through associating it with "cries" and through the symbol of "rings through the nose": 
No rings through the nose, no cries.

Bright fish hooks, the smiles of women

Gulp at my bulk

And I, in my snazzy blacks,

Mill a litter of breasts like jellyfish.

To nourish

The cellos of moans I eat eggs-

Eggs and fish, the essentials,

The aphrodisiac squid.

My mouth sags,

The mouth of Christ

When my engine reaches the end of it. ${ }^{47}$

The gigolo, like the classical Narcissus, is not willing to listen to the voices of others. By the use of the word "engine" once more the dehumanized and mechanical nature of his actions is stressed. Although the female personas of Plath's poems are generally anxious about time, getting old and physical degeneration, and although the poem begins with the consciousness of the passage of time, "Pocket watch, I tick well," there is no ageing and degeneration at work for this male persona or, at least, he expresses no concerns about it. ${ }^{48}$ Even his joints are made of gold, resistant to time and its corruption:

The tattle of my

Gold joints, my way of turning

Bitches to ripples of silver

Rolls out a carpet, a hush.

And there is no end, no end of it.

I shall never grow old. ${ }^{49}$

The speaker describes his joints in terms of gold while talking about the "bitches," the female others, in terms of silver. The metal gold in literature is invariably a solar figure, whereas silver is lunar. The gigolo assumes the active role of the sun over the passive and denigrated moon. His radiation turns the women, these "bitches," into "ripples of silver." The women are assigned to the passive and objectified position of reflecting his light back 
onto him. They are turned into mirrors on whose surface this narcissusmisogynist can indulge in the joy of seeing himself. The language the gigolo employs leaves the reader with no doubt about his deep contempt for women. For him, women serve merely as mirrors reflecting back to him a magnified picture of his male ego. The same theme of the woman as a mirror to the male ego is repeated in the poem "Purdah," to be discussed in detail later.

The gigolo continues to describe women as "new oysters":

New oysters

Shriek in the sea and I

Glitter like Fontainebleau ${ }^{50}$

Under the entry "oyster," the Merriam-Webster dictionary lists such definitions as "something that is or can be readily made to serve one's personal ends" and "an extremely taciturn person," as well as "a grayish-white color." Considering Plath's meticulous choice of words, these meanings were most probably in her mind when she wrote down the word. Thereby, women are things which readily serve this male figure and his narcissistic sexual desires. Furthermore, the oyster, due to the association of bivalves with the vulva on the one hand, and with water and fertility on the other, symbolizes "female sexuality and reproduction." ${ }^{51}$ Describing women as oysters indicates that the gigolo perceives women in terms of their sexual organs rather than their whole personality.

Moreover, the oyster has often been regarded as an aphrodisiac. The colour "grayish-white" is the colour of silver and the mirror, again emphasizing women's reflecting function, their silence and passivity, as well as their subordinate peripherality to the centrality of the male figure. On the other hand, "grayish-white" can also refer to the colour of the male ejaculated semen. The adjective "new" shows the gigolo's avoidance of a prolonged sexual relationship with a woman. He constantly searches for and gratifies his desire with a new woman-mirror. The gigolo's recurrent description of women in terms of the sea and sea creatures, like "fish hooks," "jellyfish," "ripples of silver" and "oysters," leaves the reader in no doubt that the "shriek in the sea" is the shriek uttered by a woman. The gigolo glitters like Fontainebleau. The context of the lines also immediately brings a fountain to mind, implying his ejaculation.

In the concluding stanza of the poem "Gigolo," the textual I gives us a description of his acts of copulation and his orgasms: 
Gratified,

All the fall of water an eye

Over whose pool I tenderly

Lean and see me. ${ }^{52}$

Here Plath once again turns to the mirroring imagery. Now that the gigolo has been sexually gratified, benumbed to the other's feelings he leans over the pool of a watery eye to see himself, just like the mythological Narcissus. In this poem, "I" is employed six times, which shows its central significance for the speaker and his entrapment within it. Through the dehumanizing process of turning women into mirrors and objects of narcissistic gratification, the gigolo has actually dehumanized himself to an even greater degree.

On the other hand, through the pool of a watery eye the reader is assured of the human and emotional sadness of the women figures. While the gigolo ticks, we hear the female figures' cries, their "cellos of moans," shrieks and their hush. Looking into the other's eye could provide the gigolo with an opportunity for relatedness and with a passageway to the other. Nevertheless, by turning the eye into a mirror reflecting a mirage of himself, he blocks that passageway and remains entrapped within his self. The gigolo perceives nothing but the projection of his self onto the other, blocking the projection of the other's onto his. The path to bilateral mirroring reciprocity, vital for mutual love and true friendship, is blocked by the gigolo's narcissitic self-love.

\section{Woman as a Mirror of Male Ego}

The passive reflectivity of the mirror, its lack of agency and its ability to receive any image on its surface have been drawn upon in English literature in the recurrent metaphorization of women as mirrors of the male ego. This metaphorical thought has been based on the ambivalent nature of the mirror image; on its simultaneous adoption of the positions of both subject and object. In the patriarchal context, women have been forced to strive towards absolute effacement and the nullification of their own subjectivity in order to fit into the culture's procrustean definition of feminine normality. Women were generally perceived and depicted merely as the passive reflectors of men.

On the other hand, men relied on female reflectivity for the construction and sustenance of their masculine identity. As Jacques Lacan speculates, in 
the mirror stage-when the subject for the first time perceives his body in its gestalt-the ego's attempt to end desire and to attain an ideal version of itself by projecting a unified image onto an object inevitably leads to the subject's castration anxiety. Hence, for the masculine subject relying on the woman-mirror other for his self-image and for the definition of his masculine subjectivity, the withdrawal of that female reflectivity would be a great threat to his unified sense of self. In other words, without the reflecting function of femininity his sense of masculinity would be castrated.

In western medieval narratives, women were repeatedly depicted as mirrors of the knights. A courtly lady was to mirror the knightly perfection of the lover and provide him with a sense of self-importance. Nightingale in her study of the twelfth-century Chrétien de Troyes' Erec et Enide, observes that courtly ladies were often metaphorized into "idealizing mirrors" on which the knights depended for their sense of identity. The knight used to turn to this speculum "to verify his progress and ratify his very existence." ${ }^{33}$ In her discussion of the female beloved in Of Chastity and Power, Berry writes, "This figure was usually little more than an instrument in an elaborate game of masculine 'speculation' and self-determination, for the philosophical enterprise common to both Petrarchism and Renaissance Neoplatonism used women as a 'speculum' or mirror of masculine narcissism.".54

An illuminating instance would be Hutchinson's Memoirs of the Life of Colonel Hutchinson, from the seventeenth century, in which she uses the metaphor of the woman as a mirror reflecting the man within a didactic discourse that she has set down, as she informs us, for the benefit of her children. Hutchinson acts as the mouthpiece of patriarchy's limiting definition of a woman. She echoes the era's conceptualization of a woman as a passive imitator, a mirror and shade, and as a shadow of her male consort. Hutchinson herself concedes that she, as a wife, "only reflected his [her husband's] owne glories upon him: all that she was, was him, while he was here, and all that she is now at best is but his pale shade." ${ }^{55}$ Further on, she postulates that the true role of a woman is and should be that of a mirror:

a very faithfull mirror, reflecting truly, though but dimmely, his [her husband's] owne glories upon him, so long as he was present; but she, that was nothing before his inspection gave her a faire figure, when he was remoov'd was only fill'd with a darke mist, and never could againe take in any delightfull object, nor returne any shining representation. ${ }^{56}$ 
Hutchinson has undoubtedly internalized, and forcefully defends, the subordinate mirroring position of women. As she remarks elsewhere, a woman should be her husband's "shaddow." ${ }^{57}$ Moreover, it should be noted that the image women should reflect of their men should not be a realistic one, reiterating them as they are; on the contrary, this reflected image should be "dim"; it should reflect a delusive image of his "glory." What Hutchinson appears to mean by the "very faithfull mirror" is not a truthful reflection of the First Cause, the man in front of the mirror; on the contrary, what she means is that the woman should be faithful to the man by reiterating a distorted and illusory image, a glorifying image of her man.

By the incorporation of this figuration of womanhood into the structure of her self and into her self-narrative, Hutchinson has indeed turned into a mirror reflecting patriarchy, an echo mimicking its voices. Certainly this subjugation did not come easily. When she was young, Hutchinson "had a melancholly negligence both of her selfe and others, as if she neither affected to please others, nor tooke notice of anie thing before her." ${ }^{38}$ These melancholic days were most probably the effect of her going through the process of self-effacement, the forced abnegation of the self and the internalization of her subjugated position, the strict limits that her society was placing on her. Notwithstanding, it is clear that a man's love for a woman, when that woman is rendered nothing but a mirror-metaphor reflecting back his image, is the love of Narcissus deluded by his own flat image in the water.

During the era of Romanticism, the metaphorical thought of an individual as a living mirror or Seelenspiegel, reflecting the soul of the beloved or friend, became popular. It was within this context that Goethe calls his friend, Charlotte von Stein, "my dearest mirror." ${ }^{59}$ In the nineteenth century, Dijkstra discusses how the topos of woman as an imitator, as a mirror, became one of the most recurrent clichés of Western culture. Grounded on the biological-essential conceptualization of womanhood as an objective entity, the mirror itself became a symbol for woman. ${ }^{60}$ In the twentieth century, Virginia Woolf in her book, A Room of One's Own, was to confront critically the subordinate position of women, their passive reflectivity, and their morbid, culturally advocated self-effacement. Woolf evokes the woman-as-a-mirror metaphor when she points out:

Women have served all these centuries as looking-glasses possessing the magic and delicious power of reflecting the figure of a man at twice its natural size. ... Whatever may be their use in civilized societies, mirrors are essential to all violent and heroic action. That is why Napoleon and 
Mussolini both insist so emphatically upon the inferiority of women, for if they were not inferior, they would cease to enlarge. That serves to explain in part the necessity that women so often are to men.... The looking-glass vision is of supreme importance because it charges the vitality; it stimulates the nervous system. Take it away and man may die, like the drug fiend deprived of his cocaine. ${ }^{61}$

Woolf believes that this passive reflective role of women has been fuelling masculine powers for centuries, a power based not on reality, but on a magically enhanced version. ${ }^{62}$ Women have been functioning more like convex mirrors, reiterating expanded images of the male others while conceiving for themselves a diminutive self-image. Hutchinson and Woolf both play on the distorting nature of the mirror reflection, basing their arguments on the fact that the image which the mirror gives back is a reversed one. Irigaray echoes Woolf when she writes about her own mirroring function to the man and his gaze:

I, too, a captive when a man holds me in his gaze; I, too, am abducted from myself. Immobilized in the reflection he expects of me. Reduced to the face he fashions for me in which to look at himself. Traveling at the whim of his dreams and mirages. ${ }^{63}$

This is a clear manifestation of phallocentrism, where a singular model-the masculine one-is used to represent the two sexes. Analysing the psychophilosophical history of western theoretical discourse from Plato to Hegel in her Speculum of the Other Woman, Irigaray argues that the feminine is never defined in its own autonomous terms, but only through some peripheral relation to the defined centre of humanity, i.e., to the masculine model. Femininity has always been defined and represented as the complement, as the "inverted or negative alter-ego," "the reverse, the negative of the properties of sameness," "the outside, backside, other side," "an other same, or the same model" and as the mirror image of masculinity. ${ }^{64}$ Women remain the Other, the Other which, as Daly points out, "Society as we know it fears and tries to destroy." 65

Sylvia Plath evokes this traditional motif of woman-as-a-mirror in her poem entitled "Purdah." Composed in 1962, the poem is a portrayal of a woman in her dialectical struggle to release herself from the imprisoning bond of narcissistic masculinity. The woman is striving towards liberation from the stifling mental, physical, spatial and verbal captivity systematically 
enforced on her by the visible and invisible veils-the purdahs. Plath, in this poem, cites the recurrently used mirror metaphor for women, not to conform or advocate it, but rather to reject it step by step and ultimately to cast it off violently. Butscher aptly describes the poem as Plath's "most clearly feminist poem."66 The poem, Butscher elucidates, is "a distinct roar of rage over the condition of women - which she naturally related to her own special situation." ${ }^{67}$ Perloff likewise argues that the poem is "one of Plath's most forceful statements about power-the power to assume a new identity, to shed the 'veil' of harem wife and destroy her former persona as 'small jewelled/Doll"' ${ }^{\prime 8}$ The poem depicts an image of a charming and crafty femme fatale in purdah. The woman is initially a captive within the possessive boundaries of domesticity set up by patriarchy. Moreover, she is a captive within her own consciousness, marked by the internalization and echoing of the stereotypes of womanhood dehumanized into a mere object.

Purdah or veil has a literal and metaphorical significance. The word "purdah" is of Persian origin, literally meaning "curtain," "veil" or "screen."69 It also means hijab, face or head covering, and burqa, as well as the invisible world. Figuratively, it refers to the harem or haremsaray, the interior part of the house where the women and children were kept out of the sight of other men. Historically purdah refers to the sequestration tradition, separating the sexes and protecting women from the male gaze by the installation of the curtain. Furthermore, parde represents the hymen in Persian. ${ }^{70}$

In Persian, the "eye's parde" indicates the different layers of the eye's sphere that break up light rays. Conversely, a layer like dust covering the eye and preventing the person from seeing is also called parde. "In parde" suggests secretiveness, invisibility or implicitness. It may also refer to the invisible world in general. "Without parde" implies explicit, direct and deflowered or unchaste. To take parde away from something means to render its truth revealed, exposed. It should also be noted that "to go within the parde" figuratively means to pass away, to die. Moreover, in Persian musical and literary terminology, parde signifies melody, tone or note. ${ }^{71}$

In Persian poetry, the words parde and mirror are often paired. Poets used to draw on the fact that in ancient times mirrors were built from iron or other metal and were therefore susceptible to rust and a loss of reflectivity by exposure to humidity. Hence, it was a common practice to cover the mirror with a piece of soft cloth like silk-or a parde-to preserve its clarity and brilliance and also to keep it clear of dust and rust. ${ }^{72}$ Maillet observes, "To protect this fragile object and to avoid any scratches, especially on those with a vulnerable metallic surface, mirror makers would bind the mirror in 
a case lined with cloth-generally either velvet or silk." ${ }^{33}$ On the motif of veil, screen or purdah in literature Gilbert and Gubar further expound:

An image of confinement different from yet related to the imagery of enclosure that constantly threatens to stifle the heroines of women's fiction, the veil resembles a wall, but even when it is opaque it is highly impermanent, while transparency transforms it into a possible entrance or exit. Unlike a door, which is either open or shut, however, it is always potentially both-always holding out the mystery of imminent revelation, the promise or the threat that one might be able to see, hear, or even feel through the veil which separates two distinct spheres: the phenomenal and the noumenal; culture and nature; two consciousnesses; life and death; public appearance and private reality; conscious and unconscious impulses; past and present, present and future. Because it is an image of confinement that endows boundaries with a transitory and ambivalent fluidity, and because it takes on special status with respect to images of women. ${ }^{74}$

Further on, Gilbert and Gubar claim that the image of the veil, when associated with women and femininity, becomes invariably "a symbol for women of their diminishment into spectral remnants of what they might have been." 75 The patriarchal rhetoric frequently adopted for the enactment of this veiling claims that woman is like a precious gemstone for her owner. She is so precious that she should be guarded from the lascivious male eye of the stranger. Being exposed to the male eye will decrease her value and render her unchaste, as the male gaze, particularly in veiled cultures, is assumed to have phallic powers. ${ }^{76}$

The veil has been basically regarded as an Anschauungsform, a form of intuition or perception. By intercepting or reducing perception, the veil provides the observer with an unlimited space of imagination. While the view of a naked object gives it a frame and curbs the imagination, veiling grants the imagination a free rein. The veil blurs the boundary between reality and illusion. The pictorial fantasy provided by the veil invites eroticism as well as religious involvement. In eroticism, the veil plays a central role, which is exercised by the clothing and unclothing of the body. While it interposes a physical distance, the veil also holds promise of a tempting intimacy. It provides a possibility for materializing a disguised enigma. Like the mirror, which blocks the subject's experience of the true self, the veil, too, blocks knowledge of the other. The veil, and in particular the bridal veil, has been 
used to signify the hymen. Furthermore, for its function as a form of representation providing a space of imagination, the veil has been regarded as a metaphor for text, moving from the erotic experience to the aesthetic one. ${ }^{77}$

Plath was undoubtedly aware of the associations of the word "purdah." She had underlined the etymology of the word in her Webster's dictionary and also noted it in abbreviation at the top of her manuscript in these words: "Hind. \& Per. Pardah-veil curtain or screen India to seclude women." Plath opens her poem with a parodic adoption of the traditional discourse recurrently used in the prelapsarian narratives on the genesis of Adam and Eve. She provides an echo of these texts in her ironic tone. The poetic persona introduces herself in the first person pronoun as the female other. The speaker declares that she has been created from the jade green gemstone of the agonized side of freshly created Adam:

Jade-
Stone of the side,
The agonized

Side of green Adam, I

Smile, cross-legged,

Enigmatical,

Shifting my clarities.

So valuable!

How the sun polishes this shoulder! ${ }^{79}$

According to sympathetic magic, Kroll remarks, "jade-was believed to cure pain in the side. As a jade Eve made from a green Adam, she can cure the pain which may initially have been caused by carving her out of him." 80 When associated with women and femininity, jade paradoxically denotes a flirtatious, disreputable or ill-tempered woman. ${ }^{81}$ The woman is enigmatic; she shifts her clarities, again mimicking the patriarchal myth which holds woman to be the mysterious Other. Freud, in his essay "On Narcissism," represents women as the enigmatic other, because they tend to preserve the original narcissism which men denounce: "it is only themselves that such women love." 82 This, according to Freud, becomes for men the great source of fascination and at the same time anxiety. Freud goes even further and compares the female narcissist to a cat-both sharing an ambiguous nature. He observes: 
The great charm of narcissistic women has, however, its reverse side; a large part of the lover's dissatisfaction, of his doubts of the woman's love, of his complaints of her enigmatic nature, has its root in this incongruity between the types of object-choice. ${ }^{83}$

According to Freud and his followers, women, in keeping with their common tendency towards narcissism, develop an enigmatic nature unknown to their male counterparts. This enigmatic nature of women, together with its association with animals like the cat, has been recurrently exploited in literature by male and female authors alike. ${ }^{84}$ The mysterious nature of the woman, as the other, and the mystifying feature of the veil, associate the woman and the veil with each other. As Gilbert and Gubar emphasize, "the ambiguity of the veil, its essential mystery as an emblem of obscure potential, should associate it in male minds with that repository of mysterious otherness, the female." 85 The persona in Plath's poem is evidently adopting an ironical tone in repeating the old cultural cliché when she hyperbolically claims that she is "So valuable!"”

In the following stanzas, the persona adduces her close affinity with the moon by calling it her cousin. The moon is a female cousin, as Plath refers to it, in the stanza following, using the pronoun "her":

And should
The moon, my
Indefatigable cousin

Rise, with her cancerous pallors,

Dragging trees-

Little bushy polyps,

Little nets,

My visibilities hide.

I gleam like a mirror. ${ }^{86}$

Within these lines the female persona transfigures into a mirror and becomes a close relative of the moon. The mirror is indeed a lunar symbol because the moon, like a mirror, reflects the light of the sun while its nature remains totally unaffected by it. The cyclic nature of the mirror, with the presence and absence of an image within its frame, and the moon's phases of fullness (as if impregnated with an image) and its emptiness, lead to their 
being evoked, in literature, interchangeably_both symbolizing femininity. The regular twenty-eight day cycle of the moon matches the woman's cycle of menstruation. As in the poem "Childless Woman" ("The womb/Rattles its pod, the moon/Discharges itself from the tree with nowhere to go"), Plath here also uses the moon as a metaphor for menstruation and the tree for the uterus. ${ }^{87}$ The bleeding makes the woman seem to exhibit "cancerous pallors," a trick of the light of the moon. Furthermore, the moon represents the shadow side of the sun and is therefore associated with fear and mystery.

It is her femininity that makes the woman appear invisible; she gleams like a mirror. The apparent invisibility of the feminine sexual organ, especially in the flat mirror, has been interpreted in psychoanalysis as a lack, constituted by "holeness," in contrast to the male's "wholeness." Turning invisible due to one's femininity can be read in terms of the masculine economy which values male identity and unity (signified through identification with the penis or the phallus) while devaluing the other, the women identity (signified through identification with lack, dispersion, or "a nothing to see"), as Irigaray discusses at length in her work, Speculum of the Other Woman. ${ }^{88}$

As noted earlier, the passive and objective nature of the mirror and its reflecting characteristics turn it into a feminine means of granting delight. The mirror has been rendered into an emblem of women's objective position in the patriarchal context. In the poem "Purdah," the persona is transfigured into a mirror for lacking agency of her own. As Kroll observes, the speaker only "reflects her Sun-god, just as the Moon reflects the Sun." ${ }^{89}$ The adjective "indefatigable" describes the energy- and time-consuming nature of the role of reflectiveness expected from women. The idea of the woman coming into existence merely to serve as a reflector of the man is stressed in the opening stanzas when the speaker mimics the biblical narrative that Eve was created from Adam's side, not as a discrete or independent entity, but from a part of him. She should always serve him and be his companion.

By hiding her own visibilities and by turning into the mirror of masculinity, the female persona is also turned into a metaphor-imposing obscurity on clarity. The Western tradition has always linked clarity with the penis and phallic masculinity, while associating obscurity with female genitalia due to their being internal and unseen. Irigaray adds, "Woman has sex organs more or less everywhere. ... This is doubtless why she is said to be whimsical, incomprehensible, agitated, capricious." ${ }^{\prime 90}$ Thereby, the feminine subject 
has been considered incomprehensible and confusing due to the invisibility of her internalized genitals. When the woman's visibilities hide and when she is metamorphosed into a mirror, the bridegroom, the owner of the mirror, makes his haughty appearance:

At this facet the bridegroom arrives

Lord of the mirrors!

It is himself he guides

In among these silk

Screens, these rustling appurtenances.

I breathe, and the mouth

Veil stirs its curtain

My eye

Veil is

A concatenation of rainbows.

I am his. ${ }^{91}$

The figure of the virgin bride serves as the groom's ego-ideal. She reflects his lordliness; reiterating a pleasurable and often "magnified" (to draw on Woolf's word) image. Aristotle asserts, "the proportional metaphor must always apply reciprocally to either of its co-ordinate terms." ${ }^{\text {"92 }}$ Metaphorization is therefore employed here to reaffirm gynaecologized femininity in reciprocity with phallicized masculinity.

After the arrival of the bridegroom, Plath's diction becomes sexually charged. The bridegroom is narcissistically guiding himself among the "silk screens" and "rustling appurtenances." He comes to his bride at the time when she has already turned into a mirror, protected within the silk purdah and made invisible. The breathing and the movements of the mouth and the eye now become more conspicuous. It may also be recalled here that one of the meanings of the word parde in its Persian origin is hymen. Her mouth is veiled; she is not supposed to let her voice be heard. The "eye veil" or the "eye parde," referring to the refractory layers of the eye sphere, is metaphorized into nature's grandest manifestation of light refraction in the form of a rainbow. In an alternative reading, the eye veil can also refer to her eyelid, and the "concatenation of rainbows" to the excessive use of eye make-up, a common practice for brides. 
At this point, after being engaged in the sexual act, Plath once more, and this time more overtly, claims "I am his," highlighting the imbalance of power and the possessive nature of their relationship-the sexualized possessiveness. The woman is nothing more than an enigmatic and alluring commodity in the economy of psychological partnership. Her position within this structure undoubtedly confounds her authentic agency. Even in the absence of her owner, the woman is essentially impotent, incapable of doing anything. She feels frustrated by her own total lack of agency:

Even in his

Absence, I

Revolve in my

Sheath of impossibles, ${ }^{93}$

"Sheath of impossibles" is how the subject feels, helplessly entrapped, when transformed into a reflecting object. The subject experiences a frustrating state of impotence while confined within a pardah, a kind of "bell jar." "Impossibles" have been systematically imposed on the woman by the patriarchal culture. This is quite comprehensible since she was created out of the bridegroom's side and as his valuable property-as his mirror. The woman has always existed only "in and for what she mirrored," to quote Dijkstra. ${ }^{94}$ Therefore, without her lover's presence, she would be nothing and can do nothing. The female speaker claims to be silent, and voiceless. Plath draws upon the entangled interaction of the self-image and voice. When the persona was robbed of her own image, when her visibilities hid, she was definitely robbed of her own voice, too:

Priceless and quiet

Among these parakeets, macaws!

O chatterers ${ }^{95}$

After this point in the poem there occurs a shift of attitude and tone, from that of helpless desperation to that of assertive agency. The persona will no longer remain a passive and desperate sufferer of her own objectified position. She will launch herself on a violently rebellious and liberating performance. The phrase "I shall unloose" is repeated four times in this poem. The use of "I shall" in itself reveals the determination of the speaker in her process of acquiring agency. The woman is going to 
unloose first a feather, then a note, and ultimately a ferocious lioness. Her mirror- and moon-like passivity will be superseded by her ferocious activity.

Attendants of the eyelash!

I shall unloose

One feather, like the peacock.

Attendants of the lip!

I shall unloose

One note

Shattering

The chandelier

Of air that all day flies

Its crystals

A million ignorants.

Attendants!96

When sexually stimulated, the male peacock looks exceedingly proud, flaunting his colossal, colourful plumage, decorated with eye-shaped designs. Due to the eyes on his feathers, the peacock has been regarded as an ever watchful bird. In literature, it has been recurrently evoked as a byword for pride and vanity as well as for watchfulness. ${ }^{97}$ In Grecian mythology, the peacock is a symbol of goddess Hera and her ever watchfulness; thereby also symbolizing feminine power. Moreover, since the feathers of the peacock are renewed each year, it has also been evoked as a symbol of regeneration and renewal.

By unloosing a feather, the I-speaker is probably talking about setting herself free from the artificial eyelashes that are applied to the bride as an adornment, thereby rejecting her peripheral position as a decorative object in the ownership of man. The female speaker is gaining more and more confidence and voice. As mentioned earlier, in Persian literature and musicology, the word parde can mean "note." The persona's freshly acquired voice will be so piercing that it will shatter "The chandelier/Of air that all day flies." ${ }^{\text {" }}$ Her voice will mobilize "A million ignorants./Attendants!." It will mobilize those still in the inferior and subjugated position of serving. Within these lines, Plath is indeed adopting a feministic emancipatory 
voice. She employs the term "Attendants!" once more and in isolation, as if to highlight the peripheral position of women and their serving role, and to wake up her readers:

\author{
Attendants! \\ And at his next step \\ I shall unloose \\ I shall unloose- \\ From the small jeweled \\ Doll he guards like a heart- \\ The lioness, \\ The shriek in the bath, \\ The cloak of holes.99
}

In the concluding three stanzas, the ultimate cataclysmic moment of dénouement emerges. The persona, in her next move, will set herself completely free from the captivity of his ownership, from being a companion object of adornment, from ever being on the side of the gazed at and watched. The final two lines allude to the assassination of Agamemnon by his wronged wife Clytemnestra in Greek myth, dramatized in Aeschylus's Oresteia, and in which Clytemnestra is called "this two-footed lioness." 100 In Aeschylus's version of the story, Clytemnestra stabbed Agamemnon in the bath after ensnaring him within a thrown cloak. As Britzolakis observes, Clytemnestra, for Plath, constituted one of her female "apocalypticdestructive power[s]."101

After the step by step unloosings, there arrives the ultimate moment of rebellion and the destruction of the source of her oppression. The woman breaks the vicious circle of oppression and complicity by acquiring a voice and an active agency. She will cast off her passive, submissive, decorative and object position by transfiguring into a "lioness," which will kill the bridegroom and set herself free. She ultimately manages to unveil her voice and her "lioness" body-literary and literal unveiling. The lioness for Bassnett symbolizes the "female strength," and Axelrod names her "a spirit of unveiled female rebelliousness." 102 On the other hand, Uroff believes that by "lioness" Plath is alluding to the two lioness-goddesses in Egyptian mythology, namely, Sekhmet and Bast: 
One is Sekhmet, the terrible goddess of war and battle, whose name means 'The Powerful.' Claiming that her heart rejoiced in killing, she attacked men with such fury that the sun-god, fearing the extinction of the human race, appeased her with a magic potion. The other is Bast, whose origin as a lioness-goddess personified the fertilizing warmth of the sun. Goddess of pleasure, she loved music and dance. Plath's conception embraces both goddesses. ${ }^{103}$

In the poem "Purdah," the female speaker undergoes a deep metamorphosis; from the desperate angel, suffocating within the airless boundaries of her domesticity, continually guarded by a "purdah" and the phallocentric discourses, into a monstrous, powerful Medusa; into a "Lady Lazarus" who will eventually "eat men like air." 104 Strangeways hails this moment of liberation as "transcendental," for transcending the male oppression. ${ }^{105}$ The persona succeeds in liberating herself from being in captivity to the male gaze and desire by transcending her position as a reflecting agent. Without a woman as a mirror, as a metaphor, for the masculinity through whose flattering reflection the man can identify and measure himself, that masculine subjectivity would become endangered, and the power lost.

By bringing together the two ambivalent and intertwined motifs-veil and mirror-Plath conceives a poem of highly multilayered meaning. The woman-as-mirror image serves to divulge her passive numbness and her peripherality within patriarchal culture. This metaphor symbolizes woman's loss of self-image and the lack of her authentic voice. Therefore, the mirror functions oxymoronically as a veil, too, hiding the true self. The images of the veil and the mirror are so intertwined that the slightest change in the function and meaning of the one invariably affects the other's. O'Hara argues that the meaning of veil in this poem is not limited to a "piece of oriental decoration but a reference to those veils of glamorous docility." Furthermore, Sanazaro explains that women are:

Imprisoned and dehumanized by the veils of a curtain devised for the subjugation of women in Oriental societies. Not only does the veil separate her from the world at large; it also confines the dynamic, active self and effects a division of her personality. Ultimately the "purdah" is the system of male domination, and the poem is the process of the speaker's emergence from that system. ${ }^{107}$ 
The outside, visible segregation sneaks its way inside, inserting an invisible, yet more sinister, schism within the female subjectivity. O'Hara speaks of another sort of unveiling, within the wider context of the poem, the unveiling of "simpering clichés" enacted by Plath's "murderous irony."108

A second reading of the poem leaves the reader with no doubt about the speaker's ironic language; as if she is mocking the phallocentrism of religious texts and patriarchal cultures. By shedding her mirroring/metaphorical self, the woman is casting off her fake self and acquiring a true self with an authentic voice, a self that has been kept latent within the literal and metaphorical purdahs. According to Winnicott, the true self, the authentic and vital self, which often remains totally or partially hidden, is that spontaneous, instinctive core of one's personality; the one that can be creative. On the other hand, the false self is a mask used to defend the true self from environmental and social threats. This false self is developed in compliant adaptation to external demands, codes and rules and in line with the person's attempts to relate to others. The existence of the false self continually disturbs the person with feelings of unreality and futility. ${ }^{109}$ At the end of the poem, the persona accumulates enough power to murder the false self-the self burdened with the image of a decorative object, an angel, a doll incarcerated within the purdah.

Now that the woman kills her oppressive husband, and together with it her false self, she can overthrow patriarchy's hierarchical system and its enforcement of the mirroring function on women. Not only has the female persona liberated herself from her subdued position by achieving self-awareness and a consciousness of the source of injurious oppression, but she has also done so by violently asserting that self; by acting out what Butler calls "theatrical rage": "theatrical rage reiterates those injuries precisely through an 'acting out,' one that does not merely repeat or recite those injuries, but that also deploys a hyperbolic display of death and injuries." 110

At the beginning of the poem, Plath merely recites and repeats the injuries induced by the historical specular/metaphorical function imposed upon her female subjectivity. Thereafter, she portrays her gradual selfempowerment by the very rejection of that role and ultimately by a hyperbolic display of death, inflicted upon the bridegroom - the source of her oppression and her metaphorization. The metaphorization of the woman into the mirror, enacted by the phallocentric rhetoric of the patriarchal system, in the realm of the imaginary, eventually keeps both masculine and feminine subjects alienated from the Real-the authentic truth of the self. ${ }^{111}$ In the poem "Purdah," Plath is narrating a story of voicelessness 
and voiced eloquence, invisibility and stark visibility, oppression and rebellion and ultimaltely death and killing. By inscribing her personal story and desires within her text, Plath's voice indeed becomes an emancipatory voice of Feminism.

\section{Mother in the Mirror}

In her poem "All the Dead Dears," Plath evokes the motif of the mother and female ancestors appearing in one's own mirror. This image transposition can occur when the female subject is dealing with her anxiety over the passage of time and its accompanying degeneration. It may also occur in dealing with her anxious obsession in forging an independent subjectivity, one which is discrete from the mother's. The mother-daughter image dislocation in the mirror is an overt manifestation of the female subject's mental and emotional struggle in tearing herself away from the mighty hold of her mother (and female ancestors). "All the Dead Dears" was written in 1957 when Plath was an undergraduate student in England. The poem is considered by Butscher as "one of the few genuine masterpieces from the late stages of her relentless apprenticeship," and a prime example of Plath's technical craftsmanship in dealing with a serious theme of personal obsession. ${ }^{112}$ In a letter to her mother, dated 8 April 1957 Plath writes, "I just yesterday finished one of my best, about 56 lines, called 'All the Dead Dears." 113 The poem was inspired by Plath's visit to a fourth-century A.D. stone coffin on public display in the Archaeological Museum in Cambridge. Plath begins the poem with this explanatory note:

In the Archaeological Museum in Cambridge is a stone coffin of the fourth century A.D. containing the skeletons of a woman, a mouse and a shrew. The ankle-bone of the woman has been slightly gnawn. ${ }^{114}$

The first stanza contains a picturesque description of the contents of the coffin in the museum - a heterotopic site of time dislocation. And time, together with its devouring ruination, remains the controlling theme all through the poem:

Rigged poker-stiff on her back

With a granite grin

This antique museum-cased lady 
Lies, companioned by the gimcrack

Relics of a mouse and a shrew

That battened for a day on her ankle-bone.

These three, unmasked now, bear

Dry witness

To the gross eating game

We'd wink at if we didn't hear

Stars grinding, crumb by crumb,

Our own grist down to its bony face. ${ }^{115}$

Only now that, within the space of a museum, the veil of life and its absurdity are stripped from these three pathetic skeletons, we can observe the denuded, bitter reality, the ongoing devouring and "grinding" destruction of time. These three skeletons now bear naked witness to the reality of an illusion, the illusion of life. The skeletons in themselves function as a mirror through which the persona confronts the reality of her mortality. Once the veil of illusion is cast off in the form of these skeletons, the narrator is confronted with the excruciating reality of the brutal universality of death, depicted thus:

How they grip us through thin and thick,

These barnacle dead!

This lady here's no kin

Of mine, yet kin she is: she'll suck

Blood and whistle my marrow clean

To prove it. As I think now of her head,

From the mercury-backed glass

Mother, grandmother, greatgrandmother

Reach hag hands to haul me in, ${ }^{116}$

Although there is no affinity between the I-speaker of the poem and the dead lady lying in her coffin, paradoxically, she discovers a kinship between herself and the lady, who is going to pass her death onto her. At this point in the poem, Plath bridges the glass behind which the skeleton is kept to the glass of her own private mirror, both functioning as spatiotemporal heterotopian sites. The speaker oscillates between these two kinds of glass-the museum glass case and her mirror-to summon up the connection. On the 
surface of her private mirror an image dislocation takes place. Her mirror, as Foucault demonstrated, is both a utopian space, "fundamentally unreal," and a heterotopian one. ${ }^{117}$ The persona visualizes herself drawn into a virtual space with the help of a mirror; a space where she is currently absent, a space that constitutes the realm of her dead ancestors; therefore, it becomes utopian. Like a sanctuary, a cemetery or a museum, the mirror is a heterotopic site. All these places are real places; they are "counter-sites," pertinent to her present spatiotemporal position where the "outlaws" abide. ${ }^{118}$ It is interesting to note that necromancers use a black mirror or Claude glass for conjuring up, visualizing and communicating with dead souls. ${ }^{119}$

Bridging the real with the imaginary, the mirror maintains a hybrid site of the exterior world and the inner psychic one-the Umwelt and the Innenwelt. The kinship that the persona (and by extension the poet) senses with the dead lady in the coffin, as well as the witch-like appearance of the images of her mother, grandmother and great-grandmother on the surface of her mirror, point to the homogenous identity she is forced to reproduce by society's narrow definition of womanhood. The apparition of one's mother within the mirror marks the unformulated implacable destiny awaiting the daughter. With their hag hands, these female ancestors resemble witches. They hover as Medusa figures which Christodoulides terms "abject."120

In psychology it has been suggested time and again that the daughter is unceasingly involved in a fight against the mother figure-the figure held to be an adversary in the Symbolic. The daughter vehemently resents her engulfment by the mother and her paralysing hold on her. She struggles to reject any identification with the mother whatsoever. ${ }^{121}$ In the poem "All the Dead Dears," the persona reveals her "matrophobic fears" through mirror imagery-the fear of a continual merging of the ego boundaries between herself and her mother, as well as between herself and other women sharing the same inevitable fate and forced to reproduce the same life story. Christodoulides asserts, "the speaking persona, the phobic girl, is afraid of all mother figures; she is afraid of sharing the same fate as her female ancestors, and feels that she is unable to do anything to change such a fate." 122

The mirror in the process turns into a tool of personal apocalyptic prophesies; now it is the witch's crystal ball inviting the onlooker to communal homogeneity. Due to the mirror's essence as a temporal palimpsest which can remind us of the passage of time by revealing the incessant alterations on its surface, it has been regarded by many women as the site for this fearful ageing process. For them, mirrors function as "terrible rooms," as Plath says 
in her poem "The Courage of Shutting-Up." Within these mirroring rooms, "a torture goes on one can only watch./ The face that lived in this mirror is the face of a dead man." 123 In fact, mirrors themselves have been considered by many female authors to be the very cause of ageing and its concomitant degeneration: "Mirrors can kill and talk," Plath notes in the aforementioned poem. ${ }^{124}$ Or the mirror becomes a place where tenacious old age and death lurk. While in her forties, de Beauvoir wrote, "Deep in that looking glass, old age is watching and waiting for me; and it's inevitable, one day she'll get me." 125

As the poem "All the Dead Dears" proceeds in the next lines, the persona once again annexes the glass surface of her mirror to another reflecting surface; that is, to the surface of the water. Turning away from the mother and the female ancestors in the glass case, this time the speaker identifies with the distorted and indistinct image of her father in the depths of the water:

And an image looms under the fishpond surface

Where the daft father went down

With orange duck-feet winnowing his hair- ${ }^{126}$

Plath's anxious relationship with both her mother and her father is explicitly presented in this poem, the poem which Lane aptly describes as "Freudean Gothic." ${ }^{27}$ In the Jungian reading of the lines, water symbolizes her subconsciousness/unconsciousness, in the depths of which she is haunted by the image of her father. Plath considered her father's death "a 'deliberate' act of betrayal," because he had not sought medical treatment for his diabetes until it was too late, and because he had failed to provide for his family financially after his death. ${ }^{128}$ In an effort to save his life, the father's leg had to be amputated but he died a few months later. In this poem, and in the poem "Mirror," Plath demonstrates that she was influenced to a large extent by Jung's passage where he explains:

Whoever looks into the water sees his own image, but behind it living creatures soon loom up; fishes, presumably, harmless dwellers of the deep-harmless, if only the lake were not haunted. They are water-beings of a peculiar sort. Sometimes a nixie gets into the fisherman's net, a female, half-human fish. Nixies are entrancing creatures .... The nixie is an even more instinctive version of a magical feminine being whom I call the anima. ${ }^{129}$ 
The following stanza further reveals the persona's obsession with death and how it will take hold of living beings in unanticipated moments:

All the long gone darlings: they

Get back, though, soon,

Soon: be it by wakes, weddings,

Childbirths or a family barbecue:

Any touch, taste, tang's

Fit for those outlaws to ride home on, ${ }^{130}$

Finally, in the concluding stanza, Plath explicitly articulates the central theme of her poem: the time that devours everything; the Ovidian Tempus edax rerum (time, devourer of all things), or the Shakespearean "Devouring Time."131 Like the lady's skeleton in the museum, each one of us, easily fooled into the absurdity of life while alive, will be summoned and seized by death at any moment, just when life's cycle has set off somewhere else:

And to sanctuary: usurping the armchair

Between tick

And tack of the clock, until we go,

Each skulled-and-crossboned Gulliver

Riddled with ghosts, to lie

Deadlocked with them, taking root as cradles rock. ${ }^{132}$

"All the Dead Dears" portrays the persona's (and the poet's by extension) ambivalent feelings towards the mother-daughter bond: her post-infantile anxiety as well as her inner desire to return to the realm of the imaginary and identification with the mother. On the one hand, the female subject fears merging her identity with that of her mother/foremothers and losing her very own authentic image and voice. On the other hand, the lines of the poem hint at the persona's inner desire to reconstruct "the mother-child dyad" which once existed prior to the mirror stage and which Kristeva describes as "the voiced breath that fastens us to an undifferentiated mother." ${ }^{133}$ Schwartz and Bollas interpret the desire underlying Plath's self-destructive behaviour and her many suicide attempts as her desire for:

turning back to a maternal space to find the father when the sources of fatherhood in the outside world seem depleted. That is, the search for 
merger with the dead father who, in fantasy, resides inside mother's body is the last alternative. ${ }^{134}$

Plath chose the same title, "All the Dead Dears," for one of her short stories, which is based on her first visit in 1956 to her parents-in-law at their house, The Beacon. At the time, Ted Hughes's father, Billie Hughes, and his mother, Edith Farrar, provided Plath with the initial sketches for her characters, Clifford and Nellie Meehan. ${ }^{135}$ The story shares with the eponymous poem the theme of a dead woman taking another woman with her to the abode of the dead. One evening in the house of Mr. and Mrs. Meehan, accompanied by their two guests, they become involved in a roll call of their dead relatives and acquaintances. The story begins with Mrs. Meehan's claim that she has seen her dead sister. She admits to having sensed and seen other dead people, too, whom she calls "presences," at times coming back and waiting for them. ${ }^{136}$ At the end of the evening, when everybody else has left, Mrs. Meehan recognizes the apparition of a dead woman, the previous owner of the house, informing her that her time has arrived.

In both the verse and prose versions of "All the Dead Dears," the central female persona comes into contact, and gets involved in an ambivalent dialogue, with her female precursors. The dialogue of the female author with the ghosts of her female ancestors carries immense literary significance. Based on Harold Bloom's theory of "The Anxiety of Influence," Gilbert and Gubar have developed their own gender-differentiated theory of "The Anxiety of Authorship." Gilbert and Gubar discuss that Bloom's theory is based on the male-dominated and male-oriented literary tradition. Therefore, for the anxious female author, the immediate question is not that of the direct or indirect influence of literary "forefathers," but how she can gain enough selfconfidence to write and to contemplate her position as an author within this male-dominated literary tradition. Whereas in Bloom's model, male authors are involved in competition and aggression with other literary figures for being self-consciously influenced as well as for desiring to be influential, the woman author feels a "secret sisterhood" with her female literary role models for showing her that she can write. In Plath's works, too, the female persona's coming into contact with her "fore-mothers" may indicate the author's "Anxiety of Authorship." Plath reaches back for her literary foremothers to establish a literary identification, a sort of "secret sisterhood." 137 


\section{The Monstrous Degeneration Lurking in the Mirror}

The mantic power of the mirror evokes an unheimlisch or uncanny otherness on its surface which appalls the female onlooker. The mirror can give the keen observer an inkling of her future, her ageing and the ineluctable destiny she will share with her female ancestors through the image of the mother emerging in the daughter's mirror. Apart from the mother-daughter image dislocation, female authors have resorted to other exaggerated grotesqueries and animal imageries in depicting their apprehension of ageing and its accompanying physical and mental degeneration. One of the most extensively discussed poems by Sylvia Plath depicting the complex reciprocity of female subject and her specular image is the 1961 poem entitled "Mirror." As suggested by its title, the mirror is of nexus significance for the narrating persona, the textual "I," and for its poet. The mirror in this poem speaks; it has a distinct voice and exerts an excessive controlling power over the female persona, while the woman, on the other hand, is rendered mute and voiceless. The whole poem, containing only two stanzas, is presented through the perspective of the mirror in the first person pronoun I. The pronoun I is repeated ten times in this rather short poem, thereby emphasizing the narrator's deep involvement with her subjectivity. This I begins the poem in an assertive mode, indicating the cardinal centrality of the mirror as a subject-speaker and its independent identity. This poem is a proof of Plath's dramatic ability; she is able to project herself into any persona-even an inanimate one. The vigorous and imposing agency of Plath's mirror stands in harsh contradiction to the passive and silent objectivity of mirrors in general. On the other hand, the mirror's obsessive concern with itself echoes its author's almost Narcissus-like concerns with herself.

The language and the tone of the mirror persona is that of self-defence; as if the mirror is arguing to prove its own innocence against the ambiguous feelings of the woman towards it. The mirror claims to be veracious, exact and sans preconception in contrast to the woman, who seems to be encumbered with preconceptions. The mirror seems to claim tacitly, it is not me the mirror, but the woman, who is posing. Being utterly devoid of preconceptions also means that the mirror has, in Kroll's words, "a pure and enlightened mind," a mind which the woman undoubtedly lacks. ${ }^{138}$ Likewise, the language the mirror persona adopts is clear and precise. 
I am silver and exact. I have no preconceptions.

Whatever I see I swallow immediately

Just as it is, unmisted by love or dislike. ${ }^{139}$

In the metapoetic interpretation of her poem as a mirror, Plath is struggling to achieve an exact language free of any preconceptions. The mirror claims to be omnivorous, feeding on everything that comes within its domain. All the while it remains unjudgemental, cool and untouched by any sort of feeling. Through anthropomorphization, the mirror gains immense power over the objectified woman. It has the ability to swallow, to meditate, to look, to think, to see and, above all, to speak. Yet, despite the mirror's enormous power, particularly over the woman, it claims not to have abused this power, as if exonerating itself from the woman's censure of cruelty: "I am not cruel, only truthful-/The eye of a little god, four-cornered."140

While the woman's ability to practise a veracious and objective selfanalysis is to a large extent hampered by her preconceptions, the mirror, on the other hand, is equipped with what Axelrod calls, the "Freudian means of objective self-analysis." ${ }^{141}$ The mirror's impersonal dispassion and aloof objectivity give it titanic power and the opportunity for cruelty. The mirror can devour everything and see everything. For the female beholder, the mirror holds infinite knowledge within its frame; the knowledge that raises the mirror to the status of a god in her eyes. The mirror-god knows everything about her and can tell her all. This mirror is a descendant of the magical omniscient mirrors that recur in literature, whose infinite knowledge transcends the borders of time and space. It is reminiscent of the villainous stepmother's mirror in the story of Snow White or the mantic crystal balls of witches. Unlike the woman who depends so much on her mirror for the image it reiterates, the mirror, like the god, does not need any mirror image. On the god-like status of the mirror for women, La Belle observes:

The radical exactness and objectivity of the mirror generate its value as a corrective for the subjectivity that women bring to the glass. It is indeed a "god" elevated above the mortal world, its serene silence broken only by utterances of absolute truth and enormous rhetorical potency. ${ }^{142}$

Plath evokes the topos of the omniscient mirror in a similar sense once again in her 1962 poem "Berck-Plage," this time ironically. In the third part of this poem, the persona introduces a partially knowledgeable surgeon in these terms: 
$\ldots$ and this is the surgeon:

One mirrory eye-

A facet of knowledge. ${ }^{143}$

Folsom argues that the surgeon's impersonal, mirrory eye is only "a facet of knowledge," because he is "capable of mending broken bodies, but by implication incapable of mending broken souls." 144

In the poem "Mirror," the mirror persona proceeds by reflecting upon itself in the following words:

Most of the time I meditate on the opposite wall.

It is pink, with speckles. I have looked at it so long

I think it is a part of my heart. But it flickers.

Faces and darkness separate us over and over. ${ }^{145}$

In these lines, the wall opposite the mirror has also been anthropomorphized. It has the colour of a human face-pink with freckles, apparently the attributes of the woman. The mirror and the woman constantly trade places: where the mirror has been anthropomorphized, the woman has been dehumanized, depersonalized and defined in terms of a wall. This also marks the shift in power, implying how the mirror is controlling the woman and her life.

The lifelong dialogue and interaction between this woman-wall and her mirror-god have made them exceptionally intimate and loving. Internalizing whatever exists in the outside world, the mirror introjects the wall and the face of the woman into itself, as the woman introjects the images on the mirror into her own subjectivity. By seeing and internalizing everything outside itself, the mirror incorporates them into its heart. Therefore, it turns from silver into pink with freckles. In Western culture, Speculum sine macula, a mirror without spots, invariably epitomizes the Virgin Mary, her Immaculate Conception and her perpetual virginity. Thereupon, one might infer that the woman in Plath's poem is a normal, fallible woman, tarnished with her sins and faults.

Claiming to have a heart is another emphasis on the mirror's anthropomorphized identity. The image in the mirror is not fixed; it is marked by the cycles of presence and absence, a quality that makes it a lunar symbol. While the sun has always been considered golden, the moon, like the mirror, is invariably regarded as silver. ${ }^{146}$ Plath herself draws upon this mirror-moon 
association in her other poems. In "Lorelei," the full moon is called "bland mirror-sheen," and in "Purdah," the mirror-woman claims the moon to be her cousin. ${ }^{147}$

In the second stanza of the poem "Mirror," the mirror metamorphoses into a lake, still maintaining its reflecting feature. Here the woman intrudes for the first time: "Now I am a lake. A woman bends over me,/Searching my reaches for what she really is." ${ }^{48}$ The reflecting power of the water has made it a mirror symbol. In her 1959 poem "Dark Wood, Dark Water," Plath employs the phrase "mirror of water." ${ }^{149}$ In psychology, lakes and waters have been interpreted as symbolizing the unconscious. It is pertinent to note that the lake has often been associated with silver in literature. ${ }^{150}$ The mirror-lake is, for the woman, not only a means of introjection but one of introspection over which she leans for self-contemplation as well as for a chance at revelation. The woman peers into this lake-mirror, searching for her real identity and true self. She fixes her gaze on these reflecting surfaces not only for an observation of her exterior or her visible appearance, but also for the revelation of her innermost invisibilities. Indeed, the mirror's interiority can reveal the psychic inner states to its sentient beholders.

To her disillusionment, the woman faces the cruelty of a truth which she cannot bear. She therefore turns to mendacious reflectors-the candles and the moon: "Then she turns to those liars, the candles or the moon./I see her back, and reflect it faithfully" 151 Candles and the moon, like the mirror and the lake, reflect light, but they do not reflect things and the cruelty of their truth as they are. Therefore, they are called liars by the mirror-lake-persona. The pale quality of their light and their inability to shed full light on objects cause the candle and the moon to be associated with fancy and imagination. They are indeed delusory by virtue of giving a false sense of brilliance not belonging to the original object. As Kroll argues, the moon's "light softens and romanticizes what it illuminates." ${ }^{152}$ Plath herself explicitly mentions this delusive nature of the moon in her juvenile poem, "Moonsong at Morning" in these terms: "O moon of illusion,/enchanting men." 153

The woman turns her back on the visible and invisible inner reality of her self emerging on the surface of her mirror. The mirror, unaffected by the woman's faithless move, continues to reflect her back faithfully. In response to her reflected image, the hands of the woman become agitated, probably in an effort to wipe away her tears, to hide her facial blemishes (by applying make-up) or to smooth out the facial wrinkles and the other signs of ageing. 
The mirror is capable of exerting extreme power over the woman all through her life. It can make her anxious or cry:

She rewards me with tears and an agitation of hands.

I am important to her. She comes and goes.

Each morning it is her face that replaces the darkness. ${ }^{154}$

Significantly, the mirror of this poem elicits only negative feelings from the woman: tears or agitation. There is no trace of joyous feelings; or perhaps they are so superficial, short-lived and trivial that they do not deserve to be reported by the mirror. Therefore, it is impossible to infer from the lines that the woman turns to her mirror for the gratification of her vanity, in a way in which female characters of the male-authored, emblematic traditional texts have been constantly and exclusively depicted; far from it. The mirror-lake is well aware of how essential the specular reflection is for the woman's sense of selfhood. Furthermore, the mirror knows that it plays a crucial role in her ineluctable destiny, in the context where she is judged and evaluated only on the basis of her visible appearance, presentable in toto in the mirror. The woman begins her days by looking at herself in this mirror. A young woman has been drowned/swallowed in this mirror-lake and an old woman, "a terrible fish," springs into existence: "In me she has drowned a young girl, and in me an old woman/Rises toward her day after day, like a terrible fish." 155

The mirror remains the only truthful and faithful life-long companion of the woman, from the time she was a young girl until her old age. The poem reveals a profoundly intimate and symbiotic relationship that exists between the woman and her mirror. The mirror exercises an overwhelming power over the woman. It controls her feelings and her fate. It is within the mirror's frame that the woman attempts to gain selfawareness and self-definition. The shift of agency and power from the woman to her mirror is depicted through a shift in attributes. The mirror is anthropomorphized while the woman is dehumanized. It enjoys an assertive individuality and voice while the woman suffers from depersonalization and muteness. The woman introjects the projected image on the mirror in the same way as the mirror claims to introject everything within its domain. The mirror truthfully reveals to the woman her invisible interiority and her visible alterations; the signs of her caducity and the irreversible degeneration, portrayed through the abject image of "a terrible fish." 
The theme of "a young girl" turning into "an old woman," as well as the phrases like "comes and goes" and "day after day" convey a crushing sense of time, dominant in the poem. Forebodings of her growing old, degeneration and death force the woman to turn her back faithlessly on the mirror. In the concluding stanza of Plath's 1961 poem "Face Lift," the female narrator, recovering from cosmetic surgery, expresses her extreme aversion to the physical degeneration, capturable within her mirror, in these words:

Now she's done for, the dewlapped lady

I watched settle, line by line, in my mirror-

Old sock-face, sagged on a darning egg.

They've trapped her in some laboratory jar.

Let her die there, or wither incessantly for the next fifty years, ${ }^{156}$

The uncanny grotesquery of the woman, her abjectness, the consequence of her growing old and her physical degeneration are removed from the surface of her looking glass and relocated in another glass object-the laboratory jar.

More than being a heterotopic space, where a young girl is replaced with an agitated, crying woman and ultimately with an old woman, "a terrible fish," the mirror is indeed a temporal space, governed by Zeitlichkeit. The mirror promotes the summoning of the past, present and future simultaneously within a single act of looking. Furthermore, the anthropomorphization of the mirror facilitates the relocation of the blatant human attribute, that is its Zeitlichkeit, within its luminous surface. The mirror is in fact a slate for the registration of time and its enforced alterations. Like the devouring time of Plath's poem, "All the Dead Dears," the temporal mirror of "Face Lift" becomes devouring, too; sharing the recurrent topos of Tempus edax rerum. This mirror likewise "swallows" and "drowns" everything. Any time the woman turns to her mirror, it is an attempt at re-identification. She tries to trace the alterations from her last consultation of the mirror, while at the same time attempting to foresee coming alterations. Though her previous self is dead, swallowed/drowned in the mirror-lake or incarcerated in a laboratory jar, its apprehensive memory lingers on in her mind and in her mirror's reflecting surface. The woman's confrontation with the mirror is, therefore, laden with her past memories, her present status and her anticipated future, capturing the Zeitlichkeit of her human essence. Having in mind past images while observing her present state, the woman conceives in her imagination her future face. Therefore, the mirror, like the witch's 
globe, is for her prophetic. By revealing things that are not literally present, things that transcend her present physical appearance, the mirror becomes for her a very important site on which she depends for its divine god-like knowledge. For a sense of self-hood and self-continuance, the woman lives on the mirror's prophesies.

In Freudian psychology, the lake is identified as a symbol of unconsciousness, while fish are regarded as the "live' material from the depths of the personality, relating to fertility and the life-giving powers of the 'maternal' realms within us." 157 In a Jungian reading of the poem "Mirror," Timmerman maintains that the woman's confrontation with the fish within the mirror-water is actually her confrontation with the "unconscious self" and "the reality of her true nature." 158 Furthermore, Timmerman asserts Jung's invariable association of fish with femininity, "the mythic variations employed by Jung associate the fish with feminine nature, which Jung names in his quaternity as the anima, the unconscious, feminine self." ${ }^{159}$ Thus, in the Jungian approach, the "terrible fish" stands for one's anima, shadow, or his demonic self; indeed a Hydean alter ego that rises to the surface of consciousness from the depths of the subconsciousness/unconsciousness. Timmerman draws attention to the "forceful parallelism" between Plath's poem and Jung's analysis of the reality of the shadow in his The Archetypes and the Collective Unconscious. ${ }^{160}$

Through her image of the "terrible fish," Plath depicts a monstrosity within the mirror by resorting to the inherent otherness of the mirror image. Reader and writer share this knowledge that the mirror image cannot be equated with the entity in front of it. Plath uses her artistic imagination to push this otherness to an extreme. This otherness is also confirmed with the reversing quality of the mirror. As Cooper observes, the mirror is "the gateway to the realm of inversion." ${ }^{61}$ The woman is further dehumanized in terms of a "terrible fish," having neither the body nor the soul of a human. For Freedman, on the other hand, the woman's monstrosity is a picture of her autonomy and "assertive selfhood" in her struggle to define and to express herself. ${ }^{162}$ In defiance of patriarchal dictates, the womanmirror tries to develop a voice of her own to tell her own story. Freedman argues:

To tell one's own story, even if it is, as it must be, the story of absence and effacement is to establish a presence and to display, perhaps for the first time, the face behind the angelic silver mask. ${ }^{163}$ 
Plath's frightening image of the "terrible fish," a Medusan figure, has been linked to her desire not to comply with the image of the silent woman, just as the abhorrence of Medusa has been linked, by some critics, to Medusa's being voiced. ${ }^{164}$

Many female authors have reported their horrible confrontation with an uncanny otherness or a monster within their mirrors. The artistic productivity of the female writer, where silent mothering is regarded as the only acceptable and advocated creative outlet for a woman, transfigures the Angel in the House into a monstrous creature. Having a voice and not reiterating the homogeneous images of womanhood forced on them results in these women being cast as grotesque monsters, feared and repelled by their culture. Time and again this grotesquery relocates itself in the women's private mirror, inciting immense terror and desperation. Johnson, in her $A$ World of Difference, argues, "It is as though male writing were by nature procreative while female writing is somehow by nature infanticidal," that is, the most horrible crime one can commit. ${ }^{165}$ Ultimately, the symmetrical, mirror-like structure of the poem "Mirror" has been considered "catoptric" for its simultaneous description of the mirror's properties and for its exemplifying it in the poem's structure. ${ }^{166}$

\section{The Promising Mirror}

In the poems studied above, the mirror is a surface into which the female onlooker introspectively peers to gain a consciousness of self, but time and again she comes up with bitter disillusionment. The mirror has not only been the location of these negative transfigurations, but it was actually endowed with a power to initiate these transfigurations. This was enforced mainly by the mirror's temporal and spatial dislocating feature. By its overwhelming power over the woman, the mirror repeatedly terrified or upset her.

The only poem of Plath's in which the mirror's inimical feature is reversed and the persona ultimately comes up with an appealing, solacing image is her juvenilia poem "On Looking into the Eyes of a Demon Lover." In this poem the mirror is metaphorized into the eyes of a demon lover and his black scorching pupils. This mirror-eye, like Medusa's eye, damages the onlooker, turning "each lovely lady" into a cripple, making her a disabled passive creature: 


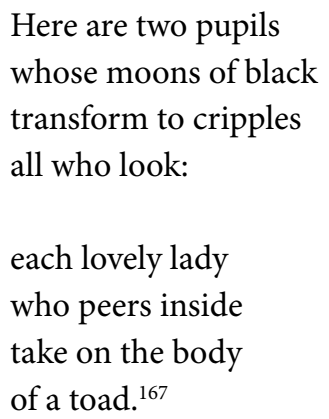

The mirror and the moon, the passive reflectors, are paired here once again. The moon-mirror cripples and transforms every female onlooker into a toad, a creature traditionally viewed as demonic. The woman turned into a toad in her mirror is a precedent for the woman transfigured into "a terrible fish" in the water-mirror of the poem "Mirror." Pupils resembling "moons of black", "scorching glass" and "furnace" are employed here as a different metaphor for the mirror. The eye-mirror transfigures the bodies of the lovely ladies into the bodies of toads and into cripples.

The eye-mirror inverts the world, turning back the lover's burning gaze "to injure/the thrusting hand." It "inflames to danger/the scarlet wound"; it scorches, and finally chars the exquisite features of the female onlookers. The inverting feature of the mirror, its deceptive metonymic/metaphoric feature, and the inherent otherness of the specular image threaten to trap the lovely ladies within their vanity and solipsistic self-love, ultimately leading to their downfall and total destruction:
Within these mirrors
the world inverts:
the fond admirer's
burning darts
turn back to injure
the thrusting hand
and inflame to danger
the scarlet wound. ${ }^{168}$

In traditional Christian culture, once the mirror fails to be a space for the manifestation of God or his divine truth, it invariably becomes a medium for the devil. The mirror draws the person into the vertigo of his flesh 
and into the physical world of appearances. By supplying the imagination with illusions, mirages and thus desires, the mirror turns into the most convenient tool in the hands of the guileful Satan and his servant witches and sorceresses. Melchior-Bonnet discusses the association of the woman at her mirror with demonic forces in these terms: "Woman thus personified the disorders of the soul, and by looking at herself in the mirror, she always played the devil's game: either she gave in to his temptations or, possessed, she sheltered a demon in her heart." ${ }^{69}$ Therefore, the tight association of the woman's mirror and the demon remains inextricable.

The witch's mirror has the power to invert; it is not only the reversal of the left and right sides, but also the inversion of the whole world. As Maillet explains, "The great satanic principle so well understood by witches consists in inverting, reverting, overturning everything invested by the sacred world." 170 One of the etymological meanings of the word "reflect" is "to turn back to." Hence, the specular reflection would be injuring, endangering for the "lovely lady" who indulges in self-admiration within the mirror. Women's visible beauty and their narcissistic loving obsessions with their specular images within the demonic eyes of their mirrors have been recounted as the root of their downfall. Nevertheless, the textual "I" claims, in the poem, that she is not afraid of looking into the mirror, because she is not a "lovely lady." She is a "witch"; and, therefore, immune to her own tools; the mirror cannot damage her:

\section{I sought my image \\ in the scorching glass, \\ for what fire could damage \\ a witch's face? ${ }^{171}$}

Witches have frequently been known to use curved mirrors or mirror balls as their tool for seeing the otherwise invisible and forbidden spirits or forbidden worlds. These curved mirrors have traditionally been associated with devils and demonic forces. Maillet reports:

Mirrors, which are supposed to celebrate the epiphany of vision, are used against nature-that is, against settled expectations-according to diabolical principles that make of them the devil's dark and illusory traps. Witches, always a subversive force, recuperate convex mirrors, whose dim reflections lend themselves to all sorts of troubling 
phantasmagoria, for their éclat bewitches and blinds anyone who looks at them. ${ }^{172}$

The disorder or subversiveness in the persona's nature makes her consider herself a witch, as all subversive women have been culturally stigmatized. The concave side of the spherical mirror can concentrate the rays of the sun. When intensified sufficiently, these rays can set fire to anything inflammable. Therefore, they are also called "burning mirrors." This mirror, as well as the curved pupil, can burn her face; or it can "afflict painfully with censure or sarcasm," as the other meaning of "scorch" denotes. ${ }^{173}$

The question the speaker poses here is a rhetorical one; not inquiring after any information, but rather acknowledging it on the part of the speaker as well as the reader. It is taken for granted that the speaker and reader jointly agree that no fire can ever damage a witch's face. The belief that witches cannot be burned is further corroborated by the two concluding lines of the poem, where the female persona is confronted by an exquisite image in her mirror. Contrary to her forebodings, however, the speaker encounters in her mirror an image which is a symbol of love and beauty - the Roman goddess, Venus, whose beauty was believed to surpass that of all other goddesses and who used to move in "radiant" beauty.

\section{So I stared in that furnace \\ where beauties char \\ but found radiant Venus \\ reflected there. ${ }^{174}$}

The persona dauntlessly stares at her image in the burning mirror, the site where beauties are burned. This is the only case in Plath's poems where a female subject turns to her mirror without having any doubt, apprehension or anxiety. Dictionaries provide us with another meaning for "char" beside that of "to burn," and that is "to work as a cleaning woman." ${ }^{175}$ While expecting to come up, within her mirror, with a demonic reflection of herself, an image of a witch as the female arch-subversive figure, probably due to her aspirations to move beyond the char-work of domesticity or probably due to her involvement in writing, the speaker comes up instead with the figure of Venus, known for her radiant beauty. Jinghua provides us with an intertextual reading of the poem: 
The projection of this dauntless self in poetry can be read as a visual representation of her famous "I am I" and "the girl who wanted to be God" declaration of adolescent independence in her 1949 diary, which subsequently presents her altering perceptions of both the beautiful and the flawed image she sees when looking into the mirror. ${ }^{176}$

Through her juxtaposition of abject figures of spinsters, sorceresses, witches, hags, as well as terrible fish and toads on the one hand, and simple girls, virgins, young girls, lovely ladies and Venus on the other, Plath presents a conspectus of her culture's stereotyping of womanhood into the dichotomy of the angel and the monster, leaving no space in between. Through her use of mirror imagery, Plath not only portrays this binary opposition, the conflict between knowable entities-what Johnson calls the "difference between"but also unveils the "difference within," the cryptic duality within the self as one entity, the idea of this oneness problematized by this very difference. ${ }^{177}$ In Plath's portrayal of "difference within," the reader as well as the poet is confronted with an unknown presence, a frightening stranger, something indefinable, unnamed, and thereby monstrous. This is exactly what Freud calls the Unheimlich, the uncanny, while arguing that the fluidity between the two counter-terms, canny and uncanny, is the core of their meaning. The monstrous other, the stranger, the witch, mother, fish, and toad, as well as Venus, that the female subject encounters within her mirror-and that encounter shocks her because she finds it unfamiliar and incomprehensible -represents nothing less than the uncanny version of herself. Freud elucidates:

It may be true that the uncanny [unheimlich] is something which is secretly familiar [heimlich-heimlisch], which has undergone repression and then returned from it, and that everything that is uncanny fulfils this condition. ${ }^{178}$

Plath's persona of the witch in this poem is a Medusan figure; a frightening, repressed and oppressed figure whose dark continent-the selfhood knowable through the mirror-should remain unexplored. Plath, just like Cixous in "The Laugh of the Medusa," dares to look into her self in her introspective eye-mirror in defiance of the warnings and, contrary to her expectations, she comes across an exquisite image. Cixous writes, "You only have to look at the Medusa straight on to see her. And she's not deadly. She's beautiful and she's laughing." ${ }^{179}$ The woman's power and voice once-and still—feared as 
threatening and thereby repressed in the ossified and ossifying figures of Medusa and witches should no longer remain unexplored. Women should dare to look into their own images within their mirrors. These mirrors are maps that will guide them through their fears and through the depths of their frozen rage into the sources of their power.

\section{Child as a Mirror}

Plath associates one's offspring with a reflecting surface-water or the mirror-in her poems "You're," "Morning Song," "For a Fatherless Son," "Brasilia" and "Child," two of which will be studied in this work. ${ }^{180}$ In her poem "Morning Song," composed in 1961, Plath provides a detailed narration of her giving birth and the ensuing maternity experience from a first person perspective. Apostrophizing her daughter, Frieda Rebecca Hughes, born on 1 April 1960, Plath draws a clear analogy between the child and the mirror. The poem was written when Frieda was about ten months old. It begins with the word "love" as the initiating force of the baby's life. Nevertheless, this life is itself described in mechanical terms, encumbered with time, and proceeding within antithetical elements:

Love set you going like a fat gold watch.

The midwife slapped your footsoles, and your bald cry

Took its place among the elements. ${ }^{181}$

The baby's heartbeat is described in terms of the tick-tock of a fat gold watch; an extremely precious premium for the mother. The midwife guides the baby, by slapping the soles of her feet, through the threshold of life among the ever-warring elements-mainly constitutive and atmospheric. ${ }^{182}$ The baby assertively claims her place among these elements by an elaborate "bald cry." Though the life of this new-born infant is set in motion by the force of love, the stanzas that follow reveal that her coming into existence is enmeshed in angst and foreboding, not only for herself but for her parents as well; it poses a threat to their safety and peacefulness. The parents are overwhelmed by her birth. They are transformed into baffled, speechless, inactive walls. The simile also marks the parents' anxious feelings of alienated detachment towards this new creation as well as their "emotional frigidity and dread," to quote Middlebrook's terms. ${ }^{183}$ 
Our voices echo, magnifying your arrival. New statue.

In a drafty museum, your nakedness

Shadows our safety. We stand round blankly as walls. ${ }^{184}$

The parents' voices echo, aurally mirroring and magnifying the cry of their baby. The baby is a new creation; a "new statue" in the desolate museum exposed to a hostile atmospheric element-the wind. Her nakedness is regarded as frightening to the parents, since it directly exposes the baby to the elements-unmediated and unshielded. Through an extended metaphor, the mother compares her new-born child to a mirror, and herself to a cloud. The mother-cloud distills itself forming a puddle-the childmirror-on whose surface the mother's effacement is reflected.

I'm no more your mother

Than the cloud that distills a mirror to reflect its own slow

Effacement at the wind's hand. ${ }^{185}$

Now that the baby has been born, the mother persona claims that she is "no more" her mother; the placenta, their biological link, has been severed and she is discrete and separate. In this extended metaphor, running through the entire stanza, Plath returns to the atmospheric elements mentioned in the first stanza to depict the nature of her child-mother interaction. The mother-cloud precipitates itself in the form of drops, extracting her essence into that of her child-puddle as mirror, obliterating her own existence in the process. The synecdochic metaphor, "the wind's hand" signifies the passage of time and its forced alterations, particularly in their daughter-mother relationship; their gradual separation as well as degeneration and the ultimate abolition of the self.

Through the process of distillation a kind of detachment is at work; the detachment of the child from the mother's body, marking a deprivation in the sense of wholeness the mother used to feel when they were united during pregnancy. On the other hand, Wisker explains that Plath is here creating "liberating, celebratory images," because through these images the mother speaker can show the reader that the new-born baby is gaining her unique and independent individuality, differentiated from that of her mother, just by being born and leaving her mother's body. ${ }^{186}$

The infant, having an imaginary identity with the mother and with no concept of self or the boundaries separating it from the (m)other, is initially living in the Real (in the Lacanian sense). Facilitated particularly 
by the mirror in the mirror stage, he will soon be able to differentiate and thereby detach himself from the mother. It leaves the mother with a sense of detachment from her own part and self-a sort of effacement. Nevertheless, the Real will continue to remain, after the mirror stage and even after the acquisition of language (foreshadowed in the poem by the baby's playing of her notes and vowels), as the irreducible perceptual surplus of outside world that resists being turned into language and entering into the realm of the Symbolic.

The Real exists more conspicuously in the mother-daughter bond where the daughter remains her mother's visual and aural double-mirroring her image and echoing her voice. To this bond the daughter is going to respond with a display of strong ambivalent feelings. Moreover, by turning into a mirror of the mother, reiterating her effacement, the daughter will undergo the same process of effacement. The mirror employed in the poem "Morning Song" is not an introspective medium, nor an instrument of delusory vanity; it is an imitative mirror reflecting the mutual effacement at work.

In the fourth stanza, the mother recounts how she wakes through the night and listens to the soft feeble breaths of the baby amid the pink roses, reassuring herself that the baby is alive:

All night your moth-breath

Flickers among the flat pink roses. I wake to listen:

A far sea moves in my ear. ${ }^{187}$

The baby's moth-breath flickering reveals the frailty of her life. By the pink roses Plath is probably referring to the patterns of her quit or the wallpaper which also hints at the baby's gender. In deprecatory language, the mother describes her attending to the baby devotedly and almost self-effacingly; a single cry from the baby involuntarily activates the mother's endocrine system, releasing milk. "Cow-heavy" due to carrying the extra weight she gained during her pregnancy and/or because of the milk produced in her breasts:

One cry, and I stumble from bed, cow-heavy and floral In my Victorian nightgown.

Your mouth opens clean as a cat's. The window square ${ }^{188}$

Moreover, as Bayley observes, cow, for Plath, is often associated with confinement in domestic life. ${ }^{189}$ The dawn breaks. It is perceived only within 
the limits of "the window square"-a metonymy for the dawn, whose brilliance will swallow all the "dull stars." The baby is fully awake, babbling and making the first "morning song":

Whitens and swallows its dull stars. And now you try

Your handful of notes;

The clear vowels rise like balloons. ${ }^{190}$

The poem can arguably be classed within the genre of aubade; a song greeting the dawn. The mother persona links the first day of her baby's life to the morning of her own. A new life has begun both for the mother and for the daughter; a life of ambivalent emotions: love and fear, a new creation and effacement in that creation.

Plath returns to the child-as-mirror metaphor in her 1962 poem "Brasilia." This time, she adopts the mirror as a metaphor for her baby son, Nicholas, who was born on 17 January 1962. At the time of the poem's composition, Nicholas was barely eleven months old. Two months later Plath took her own life. The poem embeds some ostensibly classical Nietzschean themes. This is corroborated by our knowledge of the fact that Nietzsche exerted an extreme influence on Plath. To reiterate her own words, Plath "devoured" Nietzsche's Thus Spoke Zarathustra and in a paper called it "our bible of individualism at present."191 She also incorporated ideas from Nietzsche into her other poems.

In the first two stanzas of "Brasilia," Plath talks about expressionless people; people who have steel torsos with "Winged elbows and eyeholes." She talks ironically of these potentially "super-people," the Nietzschean Übermensch or superman-the this-worldly antithesis to God. ${ }^{192}$ The winged man contains a multiple allusion. It may allude to the best-known iconic symbol of Zoroastrianism: Faravahar, the Achaemenid winged man, the symbol of Ahūrā Mazdā, which is generally taken to represent the human soul. It also represents the "Divine Royal Glory" (khvarenah), or the fravaši of the king. ${ }^{193}$ On another level, Plath may be alluding to the famous Nazi iconic figure of the winged man with a swastika. Moreover, the winged man may be an allusion to the statue of Christ the Redeemer, now the symbol of Rio de Janeiro, Brazil, with its loose sleeves hanging down its sides, resembling wings.

Will they occur,

These people with torsos of steel

Winged elbows and eyeholes 
Awaiting masses

Of cloud to give them expression,

These super-people!-_ ${ }^{194}$

Plath talks about these supermen waiting for the time to be given expression, thereby implying not only the past winged men, the former super-people, the Zoroastrian faravahar, Christ or the Nazis, but also pointing to yet to come super-people, signifying the eternal recurrence in history-another Nietzschean theme. In the following lines Plath introduces her baby son, Nicholas, in terms of a plump baby shrieking:

And my baby a nail

Driven, driven in.

He shrieks in his grease

Bones nosing for distances

And I, nearly extinct,

His three teeth cutting

Themselves on my thumb-

And the star,

The old story. ${ }^{195}$

Her baby would be only a nail in the steel torsos of these super people. The depersonalization of these expressionless "super-people" is juxtaposed in sharp contrast to the vulnerable humanity of her baby who has a greasy human body, eloquent expressions and is experiencing pain. He is crying apparently because his bones are growing rapidly, causing him some pain, and because he is also teething and bites on his mother's thumb in an attempt to soothe this irritation. Here, as in the poem "Morning Song," the mother persona claims to be experiencing the process of effacement, the annihilation of her own self: "I, nearly extinct." Then once again the persona returns to the theme of eternal recurrence through her image of "the star,/The old story."

In the next stanza, the mother persona is confronted with two contradictory elements: sheep and wagons; similar to what she has already depicted in the figure of her baby and the depersonalized super-people. Plath associates the image of sacrificial, innocent sheep with her innocent baby son and wagons with expressionless, steel super-people: 
In the lane I meet sheep and wagons,

Red earth, motherly blood.

O You who eat

People like light rays, leave

This one

Mirror safe, unredeemed

By the dove's annihilation,

The glory

The power, the glory. ${ }^{196}$

Apostrophizing the powerful, glorious and voracious deity in the form of "O You," the mother speaker pleads with him to spare her baby, to leave him unredeemed. This pleading occurs in a context where the imploring mother has herself already been devoured: "And I, nearly extinct." The ravenous, devouring God of this poem with his insatiable hunger, desiring perpetual sacrifice, conforms to Plath's general image of God, depicted in her other poems. Plath here portrays "the brutality of the Christian universe" with its "intense callousness." 197

The poet's depiction of herself as a mother corresponds to the mater dolorosa, lamenting herself into extinction for the coming sacrifice of her son in a future historical cycle, turning the earth red with her "motherly blood." 198 The dove is a symbol surrounded by only positive connotations. It stands for love, spring, simplicity, innocence and the Holy Spirit. It is also a widespread symbol for peace. ${ }^{199}$ Hence, the "dove's annihilation" implies the time when innocence is lost, when the Spirit of God is dead and when love and peace are only a distant memory.

Plath employs the metaphor of the mirror now and again to represent her baby. The brilliant clarity of the mirror, its vacuity and its receptivity have been recurrently drawn in literature and theology to represent the original soul and the innocent self untarnished by sin and unmarked by the illusory images provided by demons. This recalls the fact that speculum sine macula is one of the popular attributes of the Virgin Mary and her divine child, signifying their immaculate purity. Accordingly, the Virgin Mary gave birth to God's imago and his reflection, Jesus Christ, while she remained untransformed in the process. The mother of the poem "Brasilia" begs the voracious God to spare her baby-already free from sin-from redemption. The mother-child mirroring depicted in Plath's poetry-the mirror being 
a metaphor for the poet's offspring or a surface upon which her mother's image is reflected-has destruction, degeneration and self-effacement at its heart.

\section{The Mirror Image Being Identical with the Self}

The ambivalent self-substantiating reliance of a woman on her mirror is nowhere more explicitly and aesthetically portrayed than in Sylvia Plath's semi-autobiographical novel The Bell Jar, first published in January 1963 in London under the pseudonym Victoria Lucas. The novel is a chronicle of Plath's struggle with madness and her escape from it at the end of the novel. The protagonist of the novel, Esther Greenwood, corresponding to Sylvia Plath herself, wins a writing contest sponsored by a fashion magazine at the age of nineteen. For her prize she is given a job for a month as a guest editor in New York, where she is psychologically disturbed by the huge amount of obsessive emphasis given to how she and other girls in the company look and should look. How she thinks or how she writes seems to have far less importance than her outward appearance. These girls are systematically reduced to their mere outward appearance, a phenomenon that can be captured in toto within the constraints of a mirror.

This cultural structuring of women reduced to their looking glass image is "epitomized," as La Belle observes, in the various gifts given to these young female writers while they are actually there as apprentices for their later careers and lives. ${ }^{200}$ Quite early in the novel, among many other gifts of the same sort, Plath meticulously describes the contents of a make-up kit Esther had received from the magazine:

I still have the make-up kit they gave me, fitted out for a person with brown eyes and brown hair: an oblong of brown mascara with a tiny brush, and a round basin of blue eye-shadow just big enough to dab the tip of your fingers in, and three lipsticks ranging from red to pink, all cased in the same little gilt box with a mirror on one side. ${ }^{201}$

On another occasion, at the Ladies' Day banquet, the place-cards in the restaurant to which the magazine girls were invited are actually pocket mirrors. Esther's friend, Doreen, is absent that day and Esther saves her place-card for her. Her place-card is "a pocket mirror with 'Doreen' painted 
along the top of it in lacy script and a wreath of frosted daisies around the edge, framing the silver hole where her face would show." ${ }^{202}$ This "silver hole" with her name on top is supposed to be a reminder of who she really is in her totality each time she looks into it. "Hole" is employed here as a metaphor for the mirror; it functions as a window, a threshold to the world outside.

The image on the mirror is what the girl would be presenting to the world outside. The feminine being is reduced to an exteriority, to an image on the mirror's surface; and, therefore, it constitutes a hole in the structure of her being. It is also interesting to note that the mirror is a gift chosen for the Ladies' Day. These gifts disturb Esther so much that she cannot bear the sight of them; she hides them away for a long time, until such time as she will feel "all right again." ${ }^{203}$ Such gifts indicate one of the patriarchal culture's structured methods of reducing female subjectivity into a mere outer image, an object of male gaze and desire. The quality and quantity of these "free gifts showering" the girls-lipstick, sunglasses, mascara, eye-shadow and mirror-all suggest that the outward appearance of these girls, presentable through specular reflection, is actually the only thing that counts. ${ }^{204}$ What remains insignificant and inconsequential is their mental reflection.

Esther is unable to bear the sight of these gifts because she cannot cram her total self within the limited and limiting frame of the mirror. She cannot submit herself to the act of continual self-creation through make-up in order to satisfy the demands of her patriarchal culture. Esther can bring these gifts out only when she thinks she feels well or, to rephrase it, when she feels that she is ready to conform to her society's categorization of a sane woman who has accepted and follows the normative roles it has thrust upon her. When Esther feels sane and "all right," she brings out these tools of feminine self-definition and self-creation and puts them to use, but while insane she hides them away. An interpretation in the opposite direction can also be valid. When Esther gets "a kick out of those free gifts" and, as we shall see, when she becomes recurrently unable to identify with her mirror image, culminating in her highly problematic reaction to her self-image on one occasion in the asylum that results in her being denied access to a mirror, she is considered mad. ${ }^{205}$

A minor character in the novel that best fits into the patriarchal culture's definition of femininity is Hilda. Hilda is one of the girls residing at the same hotel with Esther in New York. Hilda not only obsessively and slavishly follows fashion, but she is actually "half a year ahead of time."206 She 
makes fashionable hats for herself and always moves "like a mannequin."207 Bundtzen describes Hilda as:

a mindless mannequin for the stylish hats and other accessories she creates in accord with shifts in fashion (another example of female creative energy channeled into a socially acceptable, and absurdly insignificant, activity). ${ }^{208}$

During Esther's long walk with her, Hilda "stared at her reflection in the glossed shop windows as if to make sure, moment by moment, that she continued to exist." ${ }^{209}$ Hilda represents a woman who has completely internalized her culture's masculine conception of woman as an object of gaze, presentable and creatable within the mirror. She has no independent authentic identity of herself; therefore, for her, existence is all that is visible within the mirror. For Hilda, the only way to be reassured of the continuum of her existence is by ceaselessly checking her specular image. The mirror, for her, is anything but introspective or a site for exploration of the self. It is merely a site of exteroception; a utopian site of hallucinated completeness, where she can present this completeness to herself and to the world outside. Like schizophrenic women, as noted by Showalter, Hilda relies on the continual observation of her mirror image as a representation of her "unoccupied bod[y]," and for confirmation of her existence. ${ }^{210}$ MelchiorBonnet argues, "The world represented in the mirror is curiously neutral in that its image depicts only the appearance of an appearance, a dream existing only as a pale and colorless reality that is uncertain of its existence."211

Hilda is representative of all female subjects trapped within their mirrors, in the world of visible appearances, vanity and solipsism. She lives in the terrain of mere visibilities. She represents the patriarchal images of feminine vanity and sheer appearance. Hilda's self conception and her sense of social presence are all defined by her mirror. Therefore, she invests the mirror with great power because her appearance is what determines her social destiny. The image reflected in the mirror determines how others and especially men will react to her. Therefore, as La Belle observes, "The reflection goes beyond sign or metaphor and becomes the self itself; the reflection becomes the predicate of existence." 212

For Hilda, having no specular reflection means having no existence. Bundtzen comments on Hilda in these words, "Her narcissistic habit of gazing at herself in shop windows is compensation for nonentity: ... Behind 
her 'vacant, Slavic expression' is a 'blind cave.' She does not, in fact, exist."213 The vacuity of Hilda's subjectivity corresponds to the mirror's vacuity and its receptivity-the mirror as a "silver hole," which is also hinged on the inherent gap between the self and the image, the sign and the signifier. The continuum of Hilda's existence is conceptualized through her specular reflection, and not through mental reflection. Hilda is herself an imitative mirror, introjecting and projecting her society's images and echoing its voices. Hilda reiterates the images of womanhood and the voices that her culture has recurrently and abundantly fashioned for her; the reiteration of what is called "cultural noise pollution" by Mayers. ${ }^{214}$

Moreover, Hilda evidently becomes Esther's mirror image, her double and reverse replica. While Hilda is completely trapped within the mirror, Esther is unable to cram herself into its confines. Coming to terms with the conceptualization of woman as a mere object, presentable in its totality by her specular reflection, remains an excruciating experience for Esther all through the novel. Being in Hilda's company is, for Esther, such a disturbing experience that she believes it to be her "penalty." ${ }^{15}$ Esther hears Hilda's voice as the voice of a terrifying creature and curses "the luck that had timed my arrival in the hotel cafeteria to coincide with Hilda's."216 They fail to communicate: "The silence between us was so profound I thought part of it must be my fault."217

At the very beginning of the novel, Esther recounts how the execution by electrocution of the Rosenbergs continually disturbed her. Julius and Ethel Rosenberg were the American communist couple who were executed in 1953 on dubious charges of espionage. Esther empathizes with them. She is disturbed by the atrocious violence exerted on human beings in the name of law:

The idea of being electrocuted makes me sick .... It had nothing to do with me, but I couldn't help wondering what it would be like, being burned all along your nerves. I thought it must be the worst thing in the world. ${ }^{218}$

Hilda, on the other hand, detached from human pain, advocates their being executed: "It's awful such people should be alive .... I'm so glad they're going to die." ${ }^{219}$ At this point, Esther likens her voice to a voice of the dybbuk she had seen in a play the night before. Dybbuk is derived from a Hebrew word meaning "attachment," "hanging on," "cleaving" or "clinging." In Kabbalah and European Jewish folklore, a dybbuk is a demon or a 
malicious possessing soul of a dead person that attaches itself to the body of a living person and inhabits it until it fulfils the function that it had failed to perform in its lifetime. ${ }^{220}$

Through this ventriloquism not only does Hilda put on a face which the gaze of her society expects her to, but she also echoes whatever noise her society feeds her without being involved in genuine mental reflection. It is not a voice of her own, but the callous voice of the ferocious society which has attached itself to her. Like the mythological figure Echo, Hilda's voice is unauthentic or, as Spivak calls, "non-originary."221 And as with the figure Narcissus, the mirror has paradoxically blocked her way to an authentic selfknowledge by reiterating an illusory and delusive image. Hilda is deprived of her own voice and is petrified into the image her culture fashions for her.

Later on in the novel, when all the girls are expected to pose for the magazine photographer "with props to show what we wanted to be," Hilda's identity is epitomized by her holding a "bold, faceless head of a hatmaker's dummy to show she wanted to design hats." 222 On the other hand, Esther, the last one to be photographed, is reluctant to pose for a photo. She has been hiding in the powder-room, but they find her. When asked what she wants to be, at first she says she does not know and then she says she wants to be a poet. When the photographer asks her, "Show us how happy it makes you to write a poem," Esther bursts into tears. The photographer asks her to smile and "at last, obediently, like the mouth of a ventriloquist's dummy, my own mouth started to quirk up."223

Esther tries, with extreme difficulty, to pose, to reflect the face that society has fashioned for her. For Esther, striking a pose becomes as excruciating as confronting her own mirror image-both frozen and immobilized. Posing for the photographer and the others means presenting herself to the gaze of the other, already as a picture. Owens describes Lacan's "mechanism of pose" in the following terms:

to strike a pose is to present oneself to the gaze of the other as if one were already frozen, immobilized-that is, already a picture. For Lacan, then, pose has a strategic value: mimicking the immobility induced by the gaze, reflecting its power back on itself, pose forces it to surrender. Confronted with a pose, the gaze itself is immobilized, brought to a standstill..$^{224}$

Owens labels the idea "rhetoric of the pose."225 Striking a pose functions similarly to the look at one's specular self, as they are anchored with the gaze 
of the others as well as with the cultural images of selfhood. In her study of the self-portrait in convex mirror, Haselstein argues that:

the view of one's own mirror image is charged with the imaginary gaze of others; the strange-appearing face and the observer form a split whole. Face, like speech, appears as a zone of mediation between the private selfreservation and public self-alienation, that is as a space of a double-coded script, referring to the sedimentation of the self as and in the mirror of the other. ${ }^{226}$

Therefore, viewing one's image in the mirror, like posing for the photographer, remains psychologically demanding for the female subject, in that she has to deal with all the intransigent images appearing on her private mirror and in the mirrors of others. Posing for the gaze of the other becomes an excruciating experience for Esther since she has to negotiate her "private self-reservation" with that of her "public self-alienation." Esther has to arbitrate between these two worlds in order to strike a pose. That makes Esther feel:

limp and betrayed, like the skin shed by a terrible animal. It was a relief to be free of the animal, but it seemed to have taken my spirit with it, and everything else it could lay its paws on.

I fumbled in my pocketbook for the gilt compact with the mascara and the mascara brush and the eyeshadow and the three lipsticks and the side mirror. The face that peered back at me seemed to be peering from the grating of a prison cell after a prolonged beating. It looked bruised and puffy and all the wrong colors. It was a face that needed soap and water and Christian tolerance.

I started to paint it with small heart. ${ }^{227}$

Esther's effort in painting her face is indicative of her creating a new face and positing a different self to appease the outside world. Unlike the other female characters in the novel, such as Hilda, who are drawn into this self creation and appear content with it, for Esther it remains an excessively difficult task. While Hilda has managed her own total self-effacement, it becomes increasingly disturbing for Esther to represent herself, or even a part of herself, in the mere realm of visibilities.

Hilda symbolically represents herself to the world through the faceless head of a dummy. She is as faceless and as voiceless as her dummy, just 
as the world around her wants her to be-a dumb object of vision easily refashioned by her patriarchal culture. Esther, on the other hand, is reluctant to be presented to the world of visibilities, as well as to herself, as an entity the world incessantly and cruelly insists upon. Finally, when she succumbs to be photographed, she feels herself "betrayed" like a "ventriloquist's dummy," like a "terrible animal." Esther describes her self in terms of skin, "an unwanted envelope," as Biven suggests. ${ }^{228}$ She feels that her spirit and her everything else have been taken away. Then she tries to create herself afresh for the world by creating a new appearance. La Belle explains Esther's reaction in these words:

Esther reacts so emotionally to the photographer because his request tears something essential from her being-her ambition to be other than an object completely capturable in a photograph, the mirror with a memory. Even the concept of being a writer has been reduced to a visual image, to looking like a "happy" poet (perhaps a contradiction in terms for Plath). Esther responds to this double trauma, both to herself and to her ambition, by testing her sense of self-identity. But the single means for doing so immediately available to her is the glass, an instrument that demonstrates the way Esther is trapped in visual objectification not only by others but also by herself. The external incident with the photographer dramatizes an unresolved conflict between competing semiotic modes of self-realization: writing and mirroring. ${ }^{229}$

Esther does not succeed in escaping from posing as the images her culture systematically imposes on her, frozen and immobilized for the gaze of the others, and that is what makes her feel so terribly betrayed. She has extreme difficulty in reconciling her two dialectical worlds, her Innenwelt driven by her authentic self and its predilections on the one hand, and her Umwelt assailing her with contradictory figurations of twentieth-century womanhood on the other. Therefore, she becomes immensely insecure, anxious and vulnerable. Looking into her mirror-image as well as posing for a picture-an image with a memory-both immobilized and frozen and somehow exterior to her real self, brings Esther back into the front line of her battlefield. Moreover, presenting mental reflection in the form of a frozen picture is indeed paradoxical and betraying.

In a context in which a person's specular self is equated with his being in its totality, destroying the mirror signifies destroying one's self, as is purported in Plath's juvenilia poem, "Epitaph in Three Parts." The poem is 
one of Plath's early poems where she deals with suicide. It reveals, as the title suggests, Plath's early mental obsession with death. The first person perspective is adopted in the poem. The persona receives a similar message three times: "There is more than one good way to drown," which forms the refrain at the end of each part.

In the first part of the poem, the persona receives the message through a telegramme addressed to her in a bottle, that is, a human message; in the second part, she receives the message from a lonely gull flying above, that is, a message from the world above; and finally, in the third part, waving grass engraves the message on a stone, as if speaking to her from the world below, and as if she is being beckoned by her very own grave.

In the first part of the epitaph, the persona watches the message arrive by sea:

Rocking across the lapis lazuli sea

comes a flock of bottle battleships

each with a telegram addressed to me.

'Destroy your mirror and avoid mishaps',

chirps the first; 'live on a silent island

where the water blots out all footsteps.'230

Contrary to the culturally held belief that breaking a mirror brings bad luck, here the message asserts that, to avoid mishaps, she should destroy her mirror. Though the popular belief and the message in the bottle seem contradictory on the surface, they are both built on the same underlying a priori: that a person's mirror image is equal to one's selfhood and whole being, and therefore the determinant of one's destiny. The mirror here bridges her inner self to the world outside. It marks the passage from the self to the other, as the message continues by advising her to lead an isolated life with no human presence or memory of others. Moreover, the mirror, being the tool of demons, witches and sorcerers, entraps young girls within its frame of vanity and narcissism.

The second sings: 'Receive no roving gallant who seeks to dally in the port till dawn, for your fate involves a dark assailant.' 
The third cries out as all the ships go down:

'There is more than one good way to drown.'231

In the second part of the epitaph, the message "There is more than one good way to drown" is put into the mouth of a bird flying above, after other birds have devoured the eyes of a drowned sailor:

In the air above my island flies

a crowd of shining gulls that plunge to launch

an accurate assault upon the eyes

of the bold sailor falling under drench and hunger of the surf that plucks the land, devouring green gardens inch by inch.

Blood runs in a glissando from the hand that lifts to consecrate the sunken man. Aloft, a lone gull halts upon the wind, announcing after glutted birds have flown: 'There is more than one good way to drown.232

In the first two parts, the persona appears to be on the shore of her island watching horrible incidents taking place: the ship sinking and the drowned sailor being devoured, all the while receiving constant warnings and invitations to death. In the third part, the scene is going to change; she is entering her room at night:

Grasshopper goblins with green pointed ears caper on leafstalk legs across my doorsill, and mock the jangling rain of splintered stars.

My room is a twittering gray box with a wall there and there and there again, and then a window which proves the sky sheer rigmarole

that happens to conceal the lid of one enormous box of gray where god has gone and hidden all the bright angelic men. 
A wave of grass engraves upon the stone:

'There is more than one good way to drown. ${ }^{233}$

The speaker's room appears as a suffocating and depressing box. The room's only window opens on to the threatening confusion of the celestial world. The sky disguises the lid of another grey box where god detains "all the bright angelic men" from her view. Both these grey boxes-her room and the one in the sky-are in fact graves which she and the bright angelic men inhabit or will soon inhabit. By entering into this grey box, the persona enters her own grave, marked by a tombstone bearing the message, repeated for the last time in the poem, "There is more than one good way to drown."

\section{The Appalling Otherness of the Specular Self}

In the portrayal of her self through a mirror, Plath relies, more than any other feature of the mirror, upon the inherent otherness of its reflected image. In the realization of the self and in the presentation of it, Plath pushes the inherent otherness of the reflected image, often taken for granted in the usual daily use, to an extreme. In doing so, Plath either totally rejects her reflected image as an absolutely foreign entity or depicts a complete otherness present within the mirror's frame. Through this rejection, as well as through her presentation of the otherness, Plath becomes capable of aesthetically conveying to her readers her difficulties in relating to her subjectivity and to the world around her.

The horror induced by the uncanny otherness in the mirror is because one of the very first and fundamental means of self-knowledge is often acquired by the objectification of the self on the mirror, and then by identification with the reflected image. In other words, the consciousness of the self is attained first by the projection of one's image on a reflecting surface and then by introjecting that reflected image within the structure of consciousness. This act, according to Lacan, is an intellectual act through which one gains a perspective and thereby a knowledge of one's self. Therefore, one remains an image of one's image. When the identification with one's specular image fails, one abruptly comes across a menacing vacuity. The subject loses his grasp of that fundamental base of self-knowledge and of the knowledge of the world. All the means of relation with one's self and with one's world are severed. When the onlooker unexpectedly confronts something 
other than the familiar projected image in a mirror, something grotesque, monstrous, unknown or uncanny, it fills him with extreme bewilderment, horror and despair.

The disturbing otherness of the image can be more than apprehension of the soon-to-arrive debacles, as discussed in the previous parts. The mirror's reversing, $d e$-realizing and $d e$-materializing nature opens up to further transmogrifications in the mirror of the mind. In other words, the logical conversions transpiring on the mirror's surface-reversion, de-realization and de-materialization-prompt boundless illogical conversions in the subject's psyche. The delusive nature of the mirror can turn it into a threshold of a utopian otherworld, where the lack is fulfilled; a theatrical stage where the desire is performed or the anger is released. On the other hand, the mirror can turn into a courtroom where ruthless trials of the selves are staged, the "terrible rooms" where the ongoing torture in the psyche of an alienated and split subject is enacted. ${ }^{234}$

One of the occasions in Plath's poems on which the poet persona openly rejects the reflected image as that of herself occurs in the poem "The Burntout Spa," penned in November 1959 in Yaddo, the artists' colony in Saratoga Springs, New York. While there, Plath visited an ancient abandoned spa, which became the inspiration for this poem. In her journal entry dated 11 November, Plath writes, "I wrote a good poem this week on our walk Sunday to the burnt-out spa. A second book poem."235 In her elaborate description of the place, Plath draws on fantastic imageries of beasts and monsters. She imagines that "An old beast," "A monster of wood and rusty teeth" had died on the spot and had thereafter been transformed into that spa. The first four stanzas are the poet's imaginative portrayal of this monster and the description of its transformation into the spa:

An old beast ended in this place:

A monster of wood and rusty teeth.

Fire smelted his eyes to lumps

Of pale blue vitreous stuff, opaque

As resin drops oozed from pine bark.

The rafters and struts of his body wear

Their char of karakul still. I can't tell

How long his carcass has foundered under

The rubbish of summers, the black-leaved falls. 
Now little weeds insinuate

Soft suede tongues between his bones.

His armorplate, his toppled stones

Are an esplanade for crickets. ${ }^{236}$

In the fifth stanza, the poet-persona introduces herself for the first time into the poem by adopting the first person perspective. Through a simile, the poet-persona draws an analogy between what she is doing in her study of the interior parts of this monster-spa and what doctors as well as archaeologists regularly do in their study of the interior parts of the body/psyche or an archaeological site:

I pick and pry like a doctor or

Archaeologist among

Iron entrails, enamel bowls,

The coils and pipes that made him run. ${ }^{237}$

The close affinity between her work and that of a doctor/archaeologist can be traced back to the example of Freud who had a passion for both. According to Pankejeff, "Freud himself explained his love for archaeology in that the psychoanalyst, like the archaeologist in his excavations, must uncover layer after layer of the patient's psyche, before coming to the deepest, most valuable treasures."238 Kuspit believes that the psychoanalyst-archaeologist metaphor, which Freud originally draws upon and Plath revives in this poem, is "a mighty metaphor." ${ }^{239}$ Both disciplines are involved with the study of surface-depth dyads and different strata developments.

In the sixth stanza, Plath continues portraying the spa in terms of natural elements:

The small dell eats what ate it once.

And yet the ichor of the spring

Proceeds clear as it ever did

From the broken throat, the marshy lip. ${ }^{240}$

The lines provide a depiction of how nature overpowers the monster, transforming it into its own landscape. The shift of power is conveyed through how the valley is now eating away at or eroding this monster, whereas in the past the monster used to feed on it. In fact, the monster has not stopped bleeding through its broken throat and marshy lip ever since. Plath once 
again stresses the fantastic element in her description by employing the term ichor, which in Greek mythology refers to the ethereal fluid running through the veins of the Greek gods, corresponding to human blood.

From the seventh stanza onwards, the persona engages in talking about herself; initially she does so by adopting the first person pronoun " $\mathrm{I}$ " in the seventh and eight stanzas, and then, upon encountering her reflected image in the water below, she suddenly shifts her perspective to that of the third person ("it" or "her") and finally, in the ninth stanza, she adopts the plural "we" and "us." After the encounter with the image reiterated in the water, the poet-persona, as a doctor and archaeologist, shifts her attention from picking at and prying into the monster-spa and focuses on this new object, prying into her "entrails":

It flows off below the green and white

Balustrade of a sag-backed bridge.

Leaning over, I encounter one

Blue and improbable person

Framed in the basketwork of cat-tails.

$\mathrm{O}$ she is gracious and austere,

Seated beneath the toneless water!

It is not I, it is not I. ${ }^{241}$

The reflected image of the persona in the water below is blue, depressed and melancholic. Moreover, the Merriam-Webster Dictionary inserts under the entry "blue": "of a woman: learned, intellectual."242 The reflected image is improbable, signifying the improbability of her dreams and artistic aspirations in the form of her desired self-image-the Idealich or ideal ego. The basketwork in which her reflection is framed is in fact the reflection of the above "Balustrade of a sag-backed bridge" over which the persona is standing. The mirror-like surface of the water objectifies her in the form of the reflected image. Now the subject "I" comes across the objectified and estranged image who seems gracious and austere. Her description of the image reveals the dichotomy of her experienced self and the specular self, induced by the ethereal essence of the mirror image.

This dichotomy and the experienced duality of the personality are expressed through shifts of pronouns. The persona refers to her reflected image as "she," not as "I," signifying the otherness of the image and the exteriority of her self-experience. The inherent alienation and division, enforced 
by the initial misrecognition of one's specular image, according to Lacan, in the mirror stage, haunts the subject throughout her life and surges to the level of consciousness, particularly in times of crisis and when one comes across the otherness in her reflected image. The objectified and alienated image takes on a passive position. She has not sat there under the water by her own will, but is being seated. At the end of the stanza, the persona twice overtly and vehemently rejects her reflected image as hers: "It is not I, it is not I."

The uncanniness of the persona's experience of the self as the other is situated within the uncanniness of the place she describes. The persona observes the world around her, her Umwelt, in its monstrous features and then she encounters the monstrosity of her inner subject, her Innenwelt through the medium of a reflecting surface. The spring, the monster's ichor, is the mirror in which she comes across the otherness of her inner self. It is this mirror that bridges her two dialectical worlds. The uncanniness and the monstrosity of these two worlds are described in abject terms. Abjectness not only finds meaning in physical grotesquery, such as in the form of a monster and his ichor, deadly to mortals, but it can also mark a psychological deviance, as manifested in her aberrant encounter with her specular image. Christodoulides links the abjectness of the persona's self image in this poem to the image of the feminine arch-abject, Medusa, by calling the reflected image an "abject medusan figure." ${ }^{43}$ She reads Plath's poem in the light of Kristevan theory, observing that rejection and negation of this "blue" and "improbable" other is a process prerequisite to adopting an identity as a subject and entering into symbolicity. ${ }^{244}$

In the concluding two stanzas, the persona reveals her fear of degeneration and death, brought home to her by the erosion and putrefaction continually going on in nature:

No animal spoils on her green doorstep.

And we shall never enter there

Where the durable ones keep house.

The stream that hustles us

Neither nourishes nor heals. ${ }^{245}$

On another level, the lines are an expression of the poet's fears of barenness, of artistic impotency, tonelessness, silence and stillness, envisaging herself "Seated beneath the toneless water!" These fears continually haunted Plath 
and she recurrently expressed them in many of her poems as well as in her novel. Plath's conception of her self-image has been closely linked to her linguistic creativity, since both mirror and the language function as subjective semiotic modes. The persona fears that she will not be able to find her way into the realm of art-the world of immortal imagination and dream.

Butscher, on the other hand, reads the poem "The Burnt-out Spa" in the biographical light of the death of Plath's father and her obsession with it. He interprets the monster and its ruins in terms of Plath's "fallen idol of her father," observing that the poet-persona meets "her double in the magic mirror of a father-shadowed past." ${ }^{246}$ For him, the "other self" seated under the water is "the real artist in her and the offspring of the myth of the father." ${ }^{247}$ By adopting the pronouns "we" and "us," after the pronoun "it" joined the pronoun "I" in referring to the same self, the multiplicity of self-experience is emphasized once more. Moreover, it may hint at the universality of the feeling of impotence and artistic aridity, particularly for the female author who seeks entry into the male-dominated literary canon.

In her 1956 poem "Tale of a Tub," Plath gives aesthetic expression to her anxieties over the otherness of her self-experience, the irritating feelings of the antithetical inner duality, the discrepancy between her private and public selves, between her mask and nakedness; all raised into consciousness and presented through the depiction of her mirror encounter in a lavatory room. For the title of the poem Plath borrowed the title of Jonathan Swift's first major satirical work, A Tale of a Tub. Therefore, the title of the poem is indeed a satire of a satire.

Plath's poem launches with a portrayal of the eye of the poet-persona gazing, like the "photographic chamber" or a camera obscura, recording the "bare painted walls" of her lavatory room. The homophonic eye/I, where the "chamber of the eye" can be understood as the chamber of I, especially when read aloud, posits a pun. Through recording the "bare painted walls," the persona is actually introjecting them-incorporating their bareness and repressing delimitation into the structure of her subjectivity. The recording chamber of the eye/I immediately renders any exterior phenomenon into something interior through its process of internalization. This internalization, combined with the blurring of the distinction between exterior and interior, is further exposed by metaphorizing the room's plumbing into raw nerves, rendered visible by means of an "electric light" which flays these nerves. As well as denoting stripping off the skin or surface, to flay has the figurative meaning of to criticize harshly. The persona is stripping her 
self of its surface layers and its masks, exploring her innermost self while continually censuring herself scathingly, evoking the Kristevan "subject in process":

The photographic chamber of the eye records bare painted walls, while an electric light

flays the chromium nerves of plumbing raw;

such poverty assaults the ego; caught

naked in the merely actual room,

the stranger in the lavatory mirror

puts on a public grin, repeats our name

but scrupulously reflects the usual terror. ${ }^{248}$

The persona is naked in her lavatory room. She feels threatened by the poverty and vulnerability of this very nakedness, which is assaulting her ego; just as the poet feels threatened by the nakedness of her newborn infant in the poem "Morning Song," which casts a shadow on her safety.

The persona calls the mirror "the merely actual room," juxtaposing the actuality of this site to all those other places where she is not naked and is wearing a public mask. It is paradoxical in the sense that the reflected specular image is in fact virtual to the reality of things held within its scope. The mirror is a heterotopic site where the subject can meet her true self, while it is also a place where she can pose for public presentation, examining her false self. Therefore, the mirror here functions simultaneously as introspective and imitative/mimetic. The actuality of this site is also juxtaposed to the "photographic chamber" of her "I." Whatever is devoured and internalized by the camera of her eye no longer remains actual; it is tainted by her imagination and by her subjectivity, distancing it from reality.

The persona, unable to bring her experience of the self (introception) and her mirror image (extroception) together, encounters a total stranger, the other in her mirror. She fails to experience a cenesthetic subjectivity; i.e., she fails to recognize her specular image, the image directly projected from bodily zones as her own. Therefore, she experiences the feelings of an uninhabited body. The otherness she encounters in her mirror is due to the inherent otherness of the specular image. It is this otherness that renders the mirror an illusory and delusory tool. Paradoxically, it is within its frame that illusions are disclosed in epiphanic moments.

In this actual and most private place-the mirror-the persona casts off all her public masks and veils and engages in self-scrutiny and self-criticism. 
It is through such nakedness that she feels her ego is exposed to assault. The existence of a discrepancy between her public mask and private nakedness is overtly presented. Despite the persona's excruciating feelings of duality and monstrous otherness, the stranger "puts on a public grin" in her mirror, as if mechanically putting on make-up, veil or a mask. The phrasal verb "to put on" also means to tease or to "mislead deliberately especially for amusement." ${ }^{249}$ Though this private self feels desperate, also confirmed by the tone of the entire poem, her public self manages to put on a grin.

This stranger, i.e., the public self, repeats "our name," indicating the subject's anxious efforts to retain the relatedness of her private self to her public self. She struggles to keep conscious about the position of her self in the public site, a virtual place for her, through a pretentious imitative act. Now naked in the actual room of the mirror, released from her masks and clothes, the persona "scrupulously reflects the usual terror" of her unknown and anonymous self, the monstrous self, the abject inside. This mirror is the same actual "terrible room[s]," in Plath's other poem "The Courage of Shutting-Up," "In which a torture goes on one can only watch./ The face that lived in this mirror is the face of a dead man."250

In the second stanza, the first person plural pronoun "we" is adopted, which the poet maintains throughout the rest of the poem. Employing this plural pronoun, despite the stark loneliness of the persona in the most private room while describing her most private experience, indicates the multiplicity of her self-experiencing, as well as her awareness of the universality of her experience. The speaker anticipates her readers' sympathy or even their empathy:

Just how guilty are we when the ceiling reveals no cracks that can be decoded? when washbowl maintains it has no more holy calling than physical ablution, and the towel dryly disclaims that fierce troll faces lurk in its explicit folds? or when the window, blind with the steam, will not admit the dark which shrouds our prospects in ambiguous shadow?251

When there exists nothing to bemuse her imagination or to distract her mind, when things are stripped of their visionary or sacrosanct associations, and when the world outside is shut out of her mind by the steam on her window, she cannot refrain from plunging into desperate meditations over 
the reality of her subjectivity, her ego, while also becoming aware of her tangible corporeal landscape. Nakedness and the unmasking assault her ego, leaving her guilt-ridden.

In the third stanza, the persona expresses how she has cast off all her beliefs in things metaphysical. She has lost all her illusions over the last twenty years. Now her "authentic sea" rejects those beliefs, plucking away their veil of flesh and revealing their innermost depths of "honest bone":

Twenty years ago, the familiar tub bred an ample batch of omens; but now water faucets spawn no danger; each crab and octopus-scrabbling just beyond the view, waiting for some accidental break in ritual, to strike-is definitely gone; the authentic sea denies them and will pluck fantastic flesh down to the honest bone. ${ }^{252}$

In the fourth stanza, the persona draws a portrait of her corporeal experience. She expresses how her limbs waver in the water of the tub and how they shudder "away from the genuine color of skin," which is "faintly green." She has a problematic sense of her body's borders. The "lines which draw/the shape that shuts" her in are "intransigent." The persona wishes to get rid of these uncompromising lines within her imagination. The problematic sense of body borders is indicative of her critical psychological problem. But even in her dream the persona cannot ignore "absolute fact":

We take the plunge; under water our limbs waver, faintly green, shuddering away from the genuine color of skin; can our dreams ever blur the intransigent lines which draw the shape that shuts us in? absolute fact intrudes even when the revolted eye is closed; the tub exists behind our back: its glittering surfaces are blank and true. ${ }^{253}$

Plath's poetry and prose reveal her obsession with skin. She frequently portrays her disturbed consciousness of her skin as both a "highly cathected organ" and a psychological construct. ${ }^{254}$ The present eye/I is no longer the passive entity that it was at the beginning of the poem, mechanically and 
passively recording and internalizing any outside phenomena. The eye, very much like her "I," has revolted. But even when closed, the "blank," "true," naked and "absolute" facts forcefully thrust themselves upon her.

The necessity of putting on a mask for the public self and disguising the inner horror is brought up more elaborately in the fifth stanza:
Yet always the ridiculous nude flanks urge
the fabrication of some cloth to cover
such starkness; accuracy must not stalk at large:
each day demands we create our whole world over,
disguising the constant horror in a coat
of many-colored fictions; we mask our past
in the green of eden, pretend future's shining fruit
can sprout from the navel of this present waste. ${ }^{255}$

Societal public life will not tolerate the presentation of one's true self without any sort of covering or mask. The interaction of the individual with society forces the disguise of the true self. The use of masks is more emphasized in women. Female non-conformists are punished severely. For any individual, Birkle observes, "Sameness and difference on several levels necessarily lead to tension and can create various manifestations of self, such as the 'true' and 'false' or 'private' and 'public' selves." 256

The female persona's consciousness of the unreality of what she is experiencing as self and whatever is related to her being finds itself emphasized once again in the concluding stanza. For her, life is all imagination and madness. It is only through death that things can be rendered real:
In this particular tub, two knees jut up
like icebergs, while minute brown hairs rise
on arms and legs in a fringe of kelp; green soap
navigates the tidal slosh of seas
breaking on legendary beaches; in faith
we shall board our imagined ship and wildly sail
among sacred islands of the mad till death
shatters the fabulous stars and makes us real. ${ }^{257}$

In the poem "Tale of a Tub," as well as in some of Plath's other poems, the catoptric experience is accompanied by fear, terror and anguish. The mirror becomes a site where the repellent poverty and vulnerability of her female 
ego are revealed to her. La Bella observes, the mirror for the female poet is not fallacious, as it would be for the male poet, but "perilous," associated with anxiety and terror. ${ }^{258}$ The poem "Tale of a Tub" is a register of Plath's reflection over her dialectical multiple selves and their excruciating incompatibility with both her inner and outer worlds. The mirror reveals, or even inserts, the duality of the subject's dialectical worlds, inside and out, private and public, together with their threatening nakedness and shielding masks, respectively. While a person can adopt different public masks to reduce or block the others' knowledge of the self and thereby, protect the self, her nakedness remains unflinching, because, as Bloom affirms, "nakedness is not a fiction"; it "is precisely what cannot change."259 This immutability of nakedness makes it even more threatening to its subject.

The journey within and without is initiated by the subject's reflection over her reflected image in the lavatory mirror. The specular image nourishes her meditations not only over what appears visible within her mirror but also all that remains invisible to it. Therefore, by emphasizing the oxymoronic nature of the mirror, which gives it psychological interiority as well, the poet makes it a model of divine reflection. Nevertheless, the persona fails to delve into the fantastical and transcendental illusions initiated by her mirror, which Plath uses in some other poems. The subject remains conscious of the naked, unmasked and terrifying reality of her self.

Plath's 1962 poem "The Other" is highly ambiguous. In it, the mirror is vehemently denounced as the source of the excruciating radical split within her subjectivity. The mirror is also regarded as the source of her problematic relationships with others. All thorough the poem, the other functions ambiguously. The other can be referred to as an exterior entity, such as another person. Some critics believe that the other in this poem refers to a rival, somehow identifiable when the poem is read in the light of biographical information. Some mention that the other is none other than Assia Wevill, a married woman at the time with whom Ted Hughes had an affair "despite all marriages," as Hughes himself puts it, and for whom he eventually left Plath. ${ }^{260}$ This reading is strengthened by the fact that the poem was composed within a few weeks of Assia and her husband David Wevill's visit to their house. ${ }^{261}$ On the other hand, Butscher believes that the other, as Plath's rival, refers to Olwyn or Olga-both of whom were mistresses of Ted. Butscher also suggests that the other may even refer to both of these women. ${ }^{262}$ Axelrod detects the source of Plath's rage in her references to her "flirtatious husband" and to the "three young women in a park." ${ }^{263}$ 
On the other hand, Christodoulides identifies the other with Plath's mother. This speculation is supported by some elements in the poem itself as well as by the fact that at the time of the poem's composition, Aurelia Plath was visiting them in their house in Devon, England. ${ }^{264}$ Other readings hold the other not to be an exterior entity but an integral part of the persona's self; that is, her double, her shadow or her alter idem. In this reading, the other marks a "difference within," as Johnson categorizes, emphasizing the presence of duality and chasm, particularly in the psychologically turbulent moments of the poet's life. ${ }^{265}$ Wood, affirming such reading, observes, "the other is more a projected reflection (a 'cold glass' image) of a potential facet within the speaker's personality than any character from the real life."266

All these interpretations seem simultaneously valid enough, revealing Plath's artistic dexterity in composing a multi-layered and ambivalent poem. In this poem, the demarking boundaries between the interior other and the exterior one seem so evanescent that these two entities merge into one meaning. As the reference of the textual "I" oscillates between the outside and inside "you," the tone of the poem alters from one of frustration, rage and hatred to one of contempt and ultimately victory. There exists no clear distinction between the psychological otherness of the inner I and the others, exterior and alien to the self. As Lacan's theory reveals, with the misrecognition of the specular I, and the identification with the specular image as a metaphoric/metonymic other in the mirror stage, the subject sets out on a lifelong series of identifications with outside others. Therefore, the identification with the specular image and the realization of its inherent otherness inextricably controls one's relation with any outside other. As manifested in this poem by Plath, the insurmountable otherness of the inner self overshadows the relationship of the subject to the outside others.

Although the gender of the person to whom the poem "The Other" is addressed remains ambiguous throughout, reading further leaves us in no doubt as to its gender. The persona is certainly apostrophizing a feminine subject/object. In the first half of the poem the addressee comes home late, wiping her lips as if wiping away lipstick. She is a white Nike, the Greek goddess of victory, the Roman equivalent of Victoria, who is intruding on her private territory, exasperating her victoriously. Furthermore, as Jinghua argues, "White Nike" as an "emblematic icon" may also allude to a particular visual art motif: "These emblems not only contain meaning in themselves as minimized representations but also enrich the meaning of the poems through intertexuality."267 The addressee's handbag stinks; inside, she carries her knitting and her sticky candies: 
You come in late, wiping your lips.

What did I leave untouched on the doorstep-

White Nike,

Streaming between my walls?

Smiling, blue lightening

Assumes, like a meathook, the burden of his parts.

The police love you, you confess everything.

Bright hair, shoe-black, old plastic,

Is my life so intriguing?

Is it for this you widen your eye-rings?

Is it for this air motes depart?

They are not air motes, they are corpuscles.

Open your handbag. What is that bad smell?

Is it your knitting, busily

Hooking itself to itself

It is your sticky candies. ${ }^{268}$

The intruding other's smile seizes her. This other is presented as a Medusan figure, with a threatening smile. All through the poem the other is described in terms of its abjectness. The persona remains the target of her overpowering gaze. The other's presence leaves her with a fragmentary body view; she feels her body shattering into its component cells.

The second half of the poem starts by mentioning that the persona cannot get rid of the overwhelming presence of this abject other, because she has her head on her wall. One interpretation can be that the persona has on her wall a picture of this other-most probably her mother. Through the poet's evocation of "Navel cords," Christodoulides's identification of the other with Plath's mother becomes more evident. This identification is made even more valid by the description of a "Shriek" from her belly in the line immediately following. Moreover, in both her poetry and her prose Plath has recurrently portrayed her mother as an abject figure, vehemently rejecting her mother's powerful grip over her. 
On the other hand, the second interpretation is that the persona sees herself in a mirror on the wall. In this meaning, experiencing the otherness of her specular image and her alienation from it becomes so gravely painful that she not only rejects that image as hers, but also rejects the mirror. Furthermore, Plath often associates the moon with the mirror. The mirror is definitely a lunar symbol since the moon, like a mirror, reflects the light of the sun while its nature remains totally unaffected by it.

I have your head on my wall.

Navel cords, blue-red and lucent,

Shriek from my belly like arrows, and these I ride.

O moon-glow, o sick one, ${ }^{269}$

In the following couplet, the persona metaphorically talks about the adultery of this other or her desire for it, although the adultery fails to lead to any pregnancy because this other has "a womb of marble"; the female other is depicted as totally barren. Britzolakis asserts that by referring to this other in terms of a Greek statue with a "womb of marble," Plath "turns the female body, which conventionally signifies life and fertility, into a trope of imprisonment and petrifaction."270

The stolen horses, the fornications

Circle a womb of marble.

Where are you going

That you suck breath like mileage?

Sulfurous adulteries grieve in a dream.

Cold glass, how you insert yourself

Between myself and myself.

I scratch like a cat. ${ }^{271}$

The mirror inserts a rupture and a multiplicity in the speaking persona's sense of self. As the experiencing self and the specular self will never fully correspond, the person is left with an ever-present sense of splitness and alienation. By initially projecting an image of the self onto the mirror and then by introjecting that image, i.e., by incorporating it into the structure 
of one's subjectivity, the subject remains an image of one's own image. Therefore, the mirror leads to a connaissance paranoïaque, to evoke Lacan's terminology; a paranoiac and frustrating knowledge of a split and alien self, which also forms the foundation on which the knowledge of the other or the outside world is laid. ${ }^{272}$

The mirror's ultimate purpose is indeed reversed. It prevents the person's gaining knowledge over her subjectivity by returning a metaphoric/ metonymic image. Meanwhile the mirror, as the cause of frustrating and paranoiac duality and alienation, like the mirror of the poem "Mirror," remains unsympathetic, undisturbed and cold. It faithfully and coldheartedly reflects her and her pains. In this poem, the mirror functions more as a kind of veil, rather than a means of revelation. It is a mask disguising her from herself by giving back an image of otherness. The mirror traps her in a virtual space between the real and the imaginary. Butscher comments on these lines in the following words:

The mirror is again installed, and the poem doubles back on itself as a dialogue between two Sylvias, another confirmation of the fact that she was growing more aware that Ted's betrayal had led to the emergence of the bitch goddess. ${ }^{273}$

In reaction to this disturbing situation, the speaker, like a cat, scratches. She scratches either herself or the surface of that cold glass, probably in an attempt to erase her image, or at least to alter her visible exteriority or its reflected image in the mirror. It is the very same knowledge of this uncompromisability of the duality of the self into a unity which ultimately proves destructive for Narcissus as he realizes, "But now we two-one soul—one death will die."274 The reflected image is indeed a representation of contrast rather than similarity. In her essay "Divine Women," Irigaray observes that the mirror:

functions as a possible way to constitute screens between the other and myself. ... the mirror is a frozen-and polemical-weapon to keep us apart. ... The mirror signifies the constitution of a fabricated (female) other that I shall put forward as an instrument of seduction in my place.

... Though necessary at times as a separating tool, the mirror-and the gaze when it acts as a mirror-ought to remain a means and not an end that enforces my obedience. ... The mirror freezes our becoming breath, our becoming space. Our becoming bird, perhaps? Though it may 
at times help us to emerge, to move out of the water, the mirror blocks our energies, freezes us in our tracks, clips our wings. What protects me from the other and allows me to move toward him or her is more often the settling of a space, an enclave of air rather than the interposition of mirrors and glasses whose cutting edge all too often threatens to turn against me. ${ }^{275}$

The mirror does not respect the subject's boundaries; it forces itself in between. The mirror features the Kristevan abject, as described in her Powers of Horror: "What does not respect borders, positions, rules. The inbetween, the ambiguous, the composite." ${ }^{276}$ In this poem, the mirror functions as an abject in that it exactly becomes what "simultaneously beseeches and pulverizes the subject." 277 The next couplet describes the persona's blood again in terms of abject, marking her intermediary, in between state of being-between being and non-being, life and death. Her blood running, i.e., her being alive, is, like her mirror image, merely a physical appearance, used to distract the onlooker as well as herself with a false impression: "The blood that runs is dark fruit-/An effect, a cosmetic." ${ }^{278}$ Finally, in the concluding couplet, the other's smile, which was previously regarded with extreme foreboding, "like a meathook" and metaphorized into a "blue lightning," turns out not to be fatal. Plath seems to be able to overcome the crisis of this intruding otherness once again: "You smile./No, it is not fatal." 279

Plath in her poem "The Other" draws upon the otherness of her spectral self-image and the terrifying rift it inflicts. Through her mirror, an uncanny version of the self emerges from the dark realm of repression. Furthermore, the inner otherness and multiplicity, enforced by the mirror, are inextricably concatenated with the others outside, brutally and coldheartedly intruding on her territory; just as the projection of the self into the other is connected with the introjection of the other into the self. This inner otherness, marking the "difference within," as well as the "difference between," to adopt Johnson's terms, is particularly aggravated by the position of the women amid the contradictory and irreconcilable images of female selfhood. ${ }^{280}$ Like the witch-Venus of the poem "On Looking into the Eyes of a Demon Lover," the persona of the poem "The Other" ultimately survives victoriously the devastating smile of this overwhelming and omnipresent Medusan other; just as Cixous describes it, "You only have to look at the Medusa straight on to see her. And she's not deadly. She's beautiful and she's laughing."281 
The pattern of shocking monstrosity of the specular image and the nonrecognition of it are interwoven in Plath's semi-autobiographical story of her madness in The Bell Jar. During the periods of turbulent emotional crisis, Esther (corresponding to Sylvia Plath herself) comes across a grotesquery in her reflected image, which she rejects as the other. This failure to bring together her introception and extroception, the experiential self and her projected image, culminates in her extension of that otherness to the mirror itself; she rejects the mirror being a mirror. Esther is acknowledged as sane and ready to be released into society only when she can re-establish the normative relationship with her mirror image.

To represent her sense of utter alienation and detachment, Esther sees herself initially as a Chinese and then as an Indian woman. At the time of her psycho-emotional crisis in New York, just before her total mental collapse and hospitalization in an asylum, Esther fails to identify with her reflected image. In the mirror of the hotel elevator she confronts "a big, smudgy-eyed Chinese woman staring idiotically into my face. It was only me, of course. I was appalled to see how wrinkled and used-up I looked."282 Back in her hotel room, lonely and depressed, she thinks the cause of her depression is her silence: “The silence depressed me. It wasn't the silence of silence. It was my own silence."283 She regards her telephone as her only means of communicating to other people, relating her to the world outside, but it remains "dumb as a death's head."284 That night Esther returns to her mirror once again before trying to sleep. On its surface she comes across a grotesquery of her image, corresponding to her psychological grotesquery: "The mirror over my bureau seemed slightly warped and much too silver. The face in it looked like the reflection in a ball of dentist's mercury."285

One night after having experienced some devastating events, Esther creeps onto the hotel's parapet and from the top she throws away all her clothing, saving not a thing:

Piece by piece, I fed my wardrobe to the night wind, and flutteringly, like a loved one's ashes, the grey scraps were ferried off, to settle here, there, exactly where I would never know, in the dark heart of New York. ${ }^{286}$

By casting all her clothes into the city's streets Esther is symbolically rejecting all her public masks, her false selves, and together with them all the codes of femininity, feeding them back to her society. The next day, in the train heading home, Esther looks into her mirror and encounters an uncanny otherness: 
The face in the mirror looked like a sick Indian. I dropped the compact into my pocket-book and stared out of the train window. Like a colossal junkyard, the swamps and back lots of Connecticut flashed past, one broken-down fragment bearing no relation to another.

What a hotch-potch the world was!

... A wan reflection of myself, white wings, brown ponytail and all, ghosted over the landscape. ${ }^{287}$

Esther fails to identify with the ocular reflection in her mirror. The projected self resists being introjected completely. Then she turns away from her mirror to the window as if in an effort to detach herself from this appalling grotesquery projected onto her mirror. This psychologically significant shift reveals her struggle to take her mind off her inner splitness and its frustrating grotesquery and to relocate it in the outer world, but this shift proves of no avail. The reflection of her face on the window interpolates itself on the entire outside world. The psychological fragmentation of her inner self is translated into the fragmentation of landscape in the world without; proving the intertwined reciprocity of these dialectical worlds. The chaotic disarray of her innermost subjectivity casts itself onto the world outside.

In constructing her text as a mirror house, Sylvia Plath synthesizes her ingenious aesthetic imagination with her academic erudition on the subject. She installs different mirrors-flat or curved, transparent or opaque, mimetic or introspective-at different angles to present her ambivalent multiple selves from varied perspectives. Her mirrors, installed within a broader text-mirror, provide us with kaleidoscopic insight into her tumultuous inner and outer worlds, dominated by the intransigent images of twentieth-century womanhood. These mirror images reveal the exasperating "difference between" as well as the "difference within." 288 By employing the mirror imagery in its plethora of meanings, Plath reveals her extensive understanding of the highly ambivalent nature of the mirror.

Plath draws upon the mirror's delusory nature, which provides an alluring simulacrum by reiterating a de-realized, ethereal and inverted version of reality, to make it a powerful and irresistible tool in the hands of witches, sorceresses and demons ("Vanity Fair" and "On Looking into the Eyes of a Demon Lover"). The mirror is installed in her poetry to portray the dehumanized narcissism of the male figures who, like the mythological Narcissus, are trapped within their solipsism, failing to relate to others ("Gigolo" and "Purdah"). Furthermore, Plath echoes the cultural views surrounding a barren woman in her portrayal of a female Narcissa whose only way to 
experience the love of the other-i.e., through having a child—is blocked (“Childless Woman").

In her depiction of woman as a mirror/metaphor for the male ego, traditionally forged to describe and prescribe the nature of gender reciprocity, Plath does not advocate it but rather mimics it in order to reject it vehemently ("Purdah"). Plath demonstrates her most contradictory feelings to the mother-child relation through wielding the dialectics of mother-child mirroring ("All the Death Dears," "Morning Song" and "Brasilia"). There are also instances in her works in which the visible specular image is equated with the self in its totality. Thereby, the existence or non-existence of the specular image signifies the individual's life or death (for example, through the characterization of Hilda in her The Bell Jar and the poem "Epitaph in Three Parts").

The confrontation with the inner otherness and the multiplicity of the subjectivity as well as the grotesquery forced on one's image by the hand of devouring time make mirrors terrible rooms of torture for women ("The Burnt-out Spa," "Tale of a Tub," "The Other," "Mirror," "Face Lift," "The Courage of Shutting-Up" and the example of Esther, the protagonist of The Bell Jar). Despite all the appalling otherness and monstrosity of the specular reflection, the mirror can be liberating and the image beautiful and victorious when peered at straight on ("On Looking into the Eyes of a Demon Lover" and "The Other").

The present study of Plath's mirror imagery is by no means exhaustive. Plath's dexterity in manipulating the diversity of mirror images and the mirror's capacities to elicit different interpretations are not limited to the instances studied in this chapter. The present study only provides a reading of some of her poems and some cases in her prose. For instance, the mirror is also depicted by her as both a utopian space through which the person desires to pass (the speaker in the short story "Ocean 1212-W") and a dystopia where the subject is continuously inflicted with desperation over the division and degeneration ("The Other" and "The Courage of ShuttingUp"). ${ }^{289}$ Mirrors have also been adopted to present the mind, consciousness and imagination as well as memory ("Insomniac"). Moreover, it has also been metapoetically used to liken her poem to a mirror ("A Sorcerer Bids Farewell to Seem"). 



\section{Conclusion}

A study of the mirror imagery and psychology of specular reflection in the works of Forugh Farrokhzad and Sylvia Plath, as two contemporary paradigms from two different cultures, reveals much about the universality of the female subject's psycho-emotional problematics in relating to her own subjectivity as well as to the world around her. The study attempts to delineate universal traits of the feminine struggle for self-realization and self-expression across cultural borders and language barriers. The disturbance in relating to self and the other is caused mainly by the patriarchal culture's strict and suffocating definitions of womanhood, emblematized in literature as in life by the mirror imageries that burden women with oppressive values.

At times, the mirrors of these women fail to reiterate the images assigned to them by their culture, leaving them with desperate feelings of lack and the loneliness of an outsider. They themselves often fail in their function as mirrors to, and metaphors of, the male ego, and are therefore confronted with monstrous, unknown and unnamed others in their mirrors. The mere study of the mirror imagery in the works of these female authors helps us to understand their turbulent life story, a "her-story" of a subject in process, incessantly in flux and continually on trial. This is made possible because any psychological stance influences the female subject's mirror encounter. As their female identities stubbornly refuse to fit into the procrustean bed of fixed definitions (assigned by their cultures), women's mirrors, too, resist functioning homogenously. Their mirrors are highly ambivalent and at times even prove extremely paradoxical. Therefore, the mirror encounter leaves them with disparate feelings.

Farrokhzad and Plath both draw upon the repertoire of the most popular mirror imageries in their literary cultures, but then turn against those traditional readings in their depictions; and therefore become emancipatory, in that they refuse to reduce or adapt their art to the cultural mores which reverbrate in their societies. One such traditional mirror is the tran- 
scendental mirror of divinity. This oxymoronic mirror reflects the invisible God or his reverse image, Satan or the demon. In her poetry, Farrokhzad invokes the metaphor of man as the mirror of God only to reflect her own desperate passivity, lack of agency and voicelessness as well as to denounce God's paralysing sovereignty. In this same mirror, Farrokhzad encounters Satan in whom she can confide as a fellow sufferer. Plath, on the other hand, invokes the recurrent image of the mirror as the tool of demons, sorcerers and witches. Through the mirror's de-realizing nature, providing the onlooker with a fata morgana, an alluring version of reality, the witch invites the onlooker into the sin of vanity and self-idolatry, whereas the only image permitted in the mirror is that of God. Farrokhzad and Plath also borrow the traditional mirror-eye metaphor, a metaphor based on the transparent reciprocity of the reflective surface and the organ of sight.

Both Farrokhzad and Plath, in their poems, refer to the mirror of the male gaze, where the woman is equated with her mirror image and regarded as a mere outward manifestation. The woman has to re-create her image constantly in accordance with the images of womanhood and female beauty with which her culture incessantly assails her in order to satisfy the male gaze and his voyeuristic desire. Farrokhzad's early poetry reveals her disturbed initial internalization of this concept, where her subjectivity is reified by male gaze. At times, her mirror becomes a substitute for the male gaze and his desire, essential for her narcissistic sense of existence and sense of self-continuity. The mirror is not merely an imitative site, where she can make herself appealing to the male gaze, but it also becomes a theatrical stage where she can rehearse her desires and imagination; a utopian space where her narcissism is satisfied. Though it seems excruciating for her, yet seeing no other utility for the mirror at this stage, she rejects it. Soon Farrokhzad becomes psychologically mature enough to outgrow this captivating mirror.

Plath, in her poetry, aesthetically portrays this mirror of the male gaze through the metaphorization of her own subjectivity into a mirror of the male ego and his desire, only to reject it vehemently. Plath also refers narcissism to its original male gender. For these male Narcissi, woman merely functions as a mirror/metaphor, on whose surface they can quench their narcissistic desire for the self. Plath manages to unveil and reject this hierarchical gender reciprocity which systematically deprives women of their own authentic images and confounds their agency, turning them into mere Echoes. In her novel, Plath portrays an example of such women turned into nothing more than mirror images through a minor character. There she 
also chronicles her own extreme disturbance caused by society's constant imposition of such figurations of womanhood and its strict expectation placed on women to reiterate the exact images.

The temporality of the mirror and the Zeitlichkeit of the specular reflection have not escaped the attention of these poets. Within their mirrors, both Farrokhzad and Plath encounter not only their present selves but also their previous selves, the selves that they constantly put on brutal trial within their mirror courts, criticizing them harshly and at times rejecting them vehemently. The mirror, for both these poets, proves to be a virtual heterotopic site of memory. The same mirror can become mantic, too, prophesying their future images within its frame. It is within these mirrors that the female poets confront the grotesquery, the monstrosity of the future self devoured by degenerating time and death.

The same temporality of the mirror causes a shocking image dislocation when the mother appears in the daughter's mirror. Farrokhzad's and Plath's ambivalent feelings towards their mothers are portrayed through this image dislocation, taking place within their private mirrors. They both encounter the image of their mothers within their own mirrors, indicating the daughter's adaptation of the mother's, as well as her foremothers', identity and destiny. While Plath recurrently demonstrates her ambivalent feelings of fear, disdain and contempt towards this identity-merging, i.e., the pre-oedipal desire to return to the "undifferentiated mother," and to adopt the face and the fate of the mother, Farrokhzad, on the other hand, appears to become able to grow out of her ambivalent feelings towards her mother. ${ }^{1}$ At one point, Farrokhzad embraces this merging with the mother peacefully by saluting her mother who was living within her mirror.

While Farrokhzad confronts the desired image of her son within the illusory-imaginary space of her mirror, Plath traces her own self and the effacement of that self reflected within the mirror of her children. Moreover, through mirror imagery, Plath can express her ambivalent feelings towards motherhood. On the one hand, her poetry discloses that she is well aware of the cultural images surrounding a childless woman - a Narcissa spinning spider-like webs round herself-while, on the other hand, she reveals how overwhelmed, perplexed, insecure and threatened she feels towards this motherhood and her new-born mirrors.

Moreover, the mirror provides Farrokhzad and Plath with an introspective space, a space where they come to the realization, as well as the presentation, of the exasperating fragmentation and multiplicity of their inner selves, and ultimately their madness. Within their mirrors, they come across 
the uncanny, the grotesque and monstrous otherness of their inner selves. The uncanniness which leaves them with the terrifying sense of abjectness, of the sense of being in between, of a suspension between life and death. All these frightening images reveal much about the anxious difficulty of these poets in bringing together their own authentic and desired image of self, on the one hand, and the images of womanhood imposed on them by their cultures, on the other. Through their mirror imageries, Farrokhzad and Plath can disclose their desperate entrapment within the paradoxical situation their culture has created for them. On the one hand, they long for the security of feeling a sense of belonging to their society with its images of womanhood, while on the other, they desire to step out of the stifling images of womanhood by realizing their own authentic images and adopting their own voices.

While Farrokhzad and Plath have both portrayed instances of the captivating mirror for the female subjectivity, they have also provided their readers with an emancipatory mirror. Acknowledging the desperate loneliness of the quest for the authentic female self, Farrokhzad openly invites her readers to consult their mirrors for redemption. She appears to have become capable of rejecting the established images of womanhood; the images her narcissistic patriarchal culture incessantly forces on her mirror; the images she once used to envy. Farrokhzad saw enough of life to realize the emancipatory nature of the mirror in giving her self-awareness and reflecting back her desired image of selfhood. Plath, envisaging herself as a witch as well as a terrifying other, an abject Medusan figure, ultimately survives, daring to look victoriously at her mirror-the demon's eyes and a cold inserting glass-fashioned to intimidate and control female nonconformists.

Finally, text, for Farrokhzad and for Plath, has the same psychological function as their mirror. Text, like their mirror, remains a heterotopic oblique space where they can encounter their antithetical multiple selvesfluid and ever-changing. Onto their text-mirrors they can continually reflect and objectify their subjects in their constant becomings, and thereby be assured of their existence. Therefore, the text for them turns into a desideratum, not a luxury. The mirror-text is a space they seek for their true subjectivity and their authentic voice. In their existential angst, Farrokhzad and Plath project their selves onto its surface and then introject the projected self into their structure of consciousness. Indeed, this is what makes their life stories and their art merge, making it impossible to draw a demarcation line between the two. 
It is within this space (mirror and text) that these female authors are engaged in an ongoing debate, on the one hand, between their own selves and the recurrent self-images their culture impose on them and, on the other hand, among the multiple contradictory selves within. Through writing Farrokhzad and Plath can inscribe the gendered history of their subjects within their texts. In the simulacrum the mirror provides, far more than similiarites, the contrasts-representational, epistemological, ontological as well as political-are divulged. Therefore, text-mirror, for them, becomes a space, and a window, where the visible and the invisible, the being and the seeming, the interior and the exterior, the private and the public, introspection and the mimesis and finally the imaginary and the real converge. 



\section{Appendix: Farrokhzad's Poems Discussed in the Text with Their English Translation}

\section{The Forgotten}

The memories of the past linger in my heart and alas

There is no friend to remember me

My gaze remained fixed on the path and he didn't send me

A letter to brighten my heart

I do not know what wrong I have done

That he disentangled his rope of kindness from me

If I had a place in his heart

Why has he stopped watching me

Everywhere I turn my eyes, it is he again

Gazing at my wet eyes

It is the agony of love that

Has conquered my fiery heart with rue and regret

I said when I distanced him from my sight He would certainly leave my heart faster There is a need for death to find me Or it is not a pain to vanish easily

$$
\text { از ياد رفته }
$$

ياد بكذشته به دل ماند و دريغ

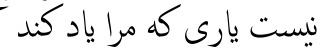
ديده ام خيره به ره ماند و نداد كاد كاد نامه اى تا دل من شاد كند اند

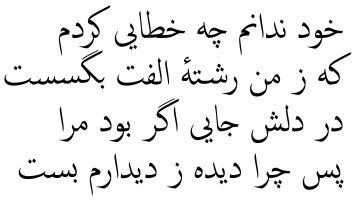

هر كجا مى نكرم، باز هم اوست

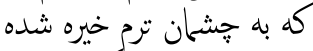
درد عشق است كه با حسرت و و سوز بر دل بر شررم تيره شده

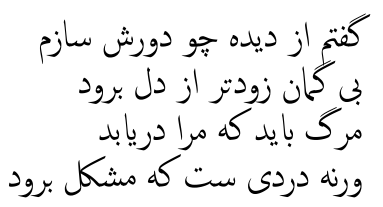


When lips glide over my lips

I sigh wishing that this was him

I wish the lips kissing me

Were the burning lips of that ill-tempered one

When they embrace me affectionately I ask myself what happened to his embrace What happened to that burning fire Aflame in his silent breath

I composed poems to lift from the heart The heavy load of grief for his love

Poetry turned out to be a manifestation of his face

To whom can I tell the tyranny of his love

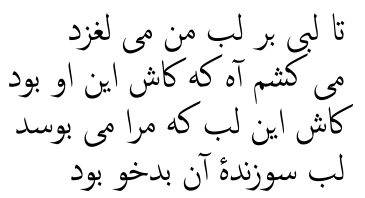

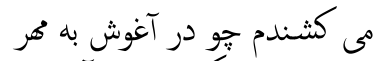

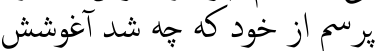

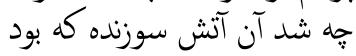
شعله ور در نفس خاموشش آنش

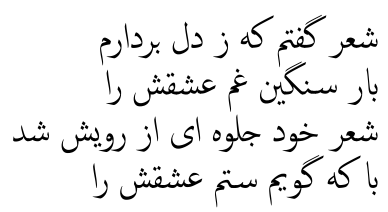

O Mother, take this comb from my hair

Wipe the antimony off my eyes

Take this dress of mine off my body

What else is life but my prison

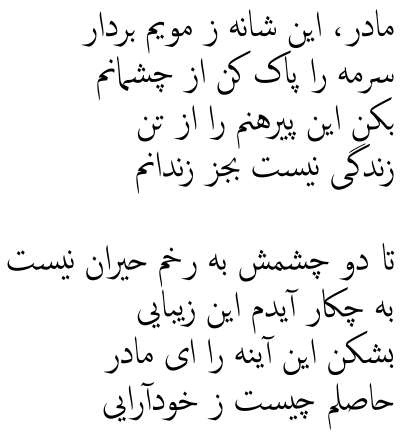

O Mother, break this mirror
What do I gain by adorning myself?

Shut the doors and say that

I have torn myself away from everybody but him

If somebody asks why? I am not afraid

Divulge that I am in love

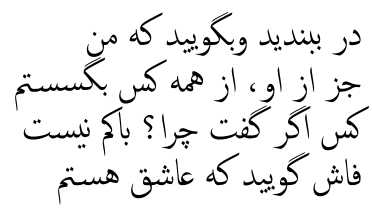


If a messenger arrives from a distant place Ask him instantly from whom the message comes

If not from him, tell him

That woman has left this house a long time ago

Ahvaz-winter 1954-1955

\section{Enthusiasm}

Do you remember that you once asked me smiling

What souvenir I had brought you from so far away?

Look into my face so that my face answers you

A tear of enthusiasm slumbering in the eyes of desire

What souvenir have I brought you, $\mathrm{O}$ my life fountain?

A breast burned in the rue of an impossible love

A look lost in the veils of a distant dream A body inflamed with the burning hunger for unification

What souvenir have I brought you, O my life fountain?

Eyes tumultuous from inner desire

Warm lips slumbering on them with hope and desire

A kiss hotter than the kiss of the southern sun

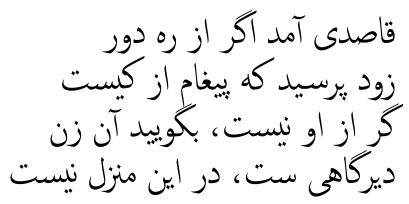

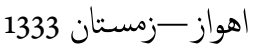

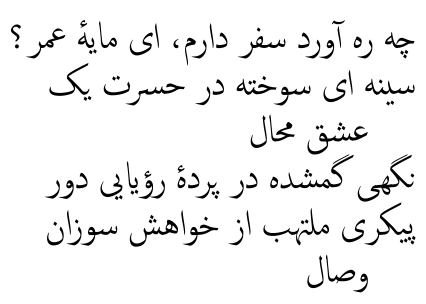

هو ره ره آورد سفر دارم، اى مائٌ عمر؟

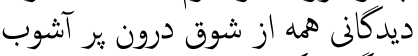

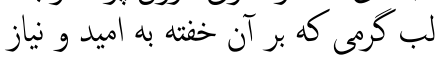

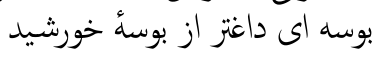
جنوب اب دابر

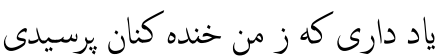

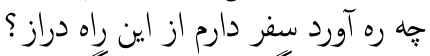

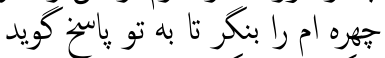
اشك شوق كه فروخفته به تجشمان نياز 
How often in the search for a proper present for you

Have I wandered in the heart of the streets and bazaars

Finally I decided to present to you

A body within which a hidden desire blazes

When I looked into the mirror, I saw, alas

That separation from you has decreased the glow of my face

I beseeched the sun to grant me

Thirst, brilliance, incandescence, and reflection

Now, this is me, I am this soul-burning fire

$O$ you, the hope of a mad and woe-embracing heart

Open your embrace so that I may reveal to you

what I have brought from this far-off place

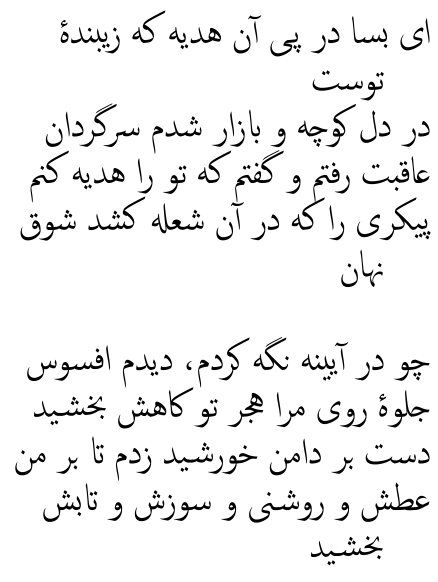

حاليا، اين منم، اين آتش جانسوز منم دواز

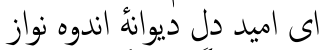

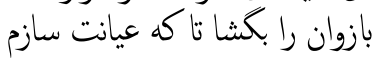
جه ره آورد سفر دارم از اين راه عان دراز

\section{Late}

Into the eye of the exhausted day has crawled

The mute and dark dream of a sleep

Now, again, on this path

You have to hasten alone towards home

As long as your black shadow Is always by your side like this

Do not ever think that an eye

Will be expecting you there

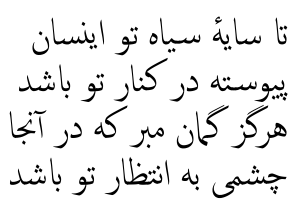


Your house, like a grave, is sitting In the midst a cloud of the dust of trees Crowned like yesterday

A crown of rain's silver strands

From the dark and calm corners

As the door is opened to your face

Hundreds of silent and mysterious salutes

Wearily fly towards you

As if the heart of the darkness is beating In that small sad room

Night, like a black snake crawls

Onto the fine colourful curtains

The clock was on the breast of the wall Devoid of any strike, any chime In a body of silence and muteness It was itself a piece of the space

In the worn-out frames, the images

-these ridiculous mortal faces-

Pale from the passage of time

Perhaps they once existed!

A mirror, like a big eye

Is sitting in a corner, busy watching

Upon the glass of its gaze

It has posed the rebellious spirit of the night

You, weary as an old bird

Head to the warmth of bed

With closed fluttering eyelids

You lay your head on the chest of the notebook
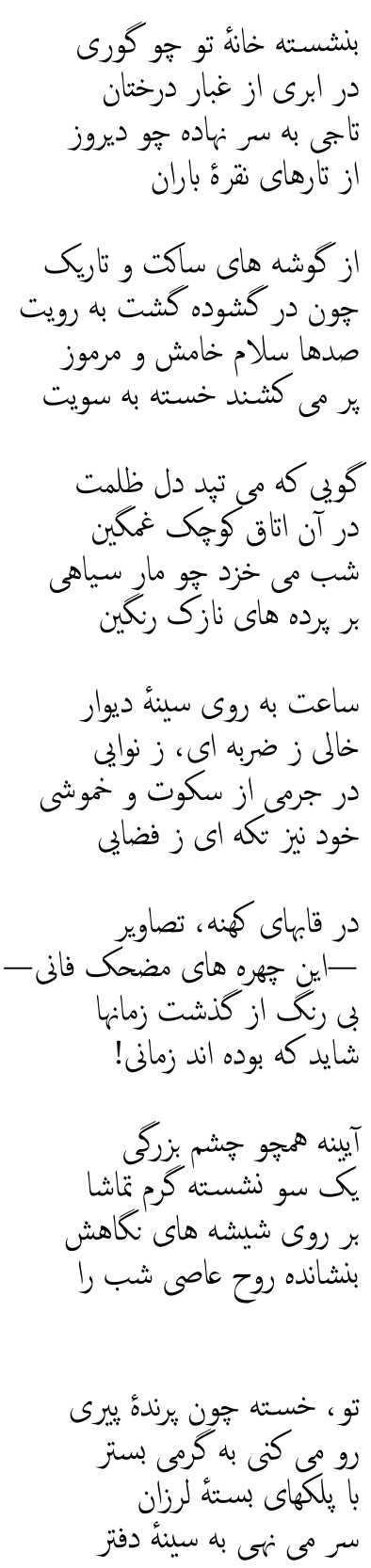
As if the ghosts of the past dead Are crying beside you

Those who have slept on this bed

Before, in past time

A thousand silent motions from them

A thousand restless moans from them

Like fugacious bubbles

On the contracted face of the swamp

The ancient pine tree is dense with The ominous cawing of the crows There dances on the windows again The redolent silk of the rain

You feel that it is regrettable To fight with your own woe You smell that blossom of woe

To compose a new poem

June, the 1oth, 1957-Munich

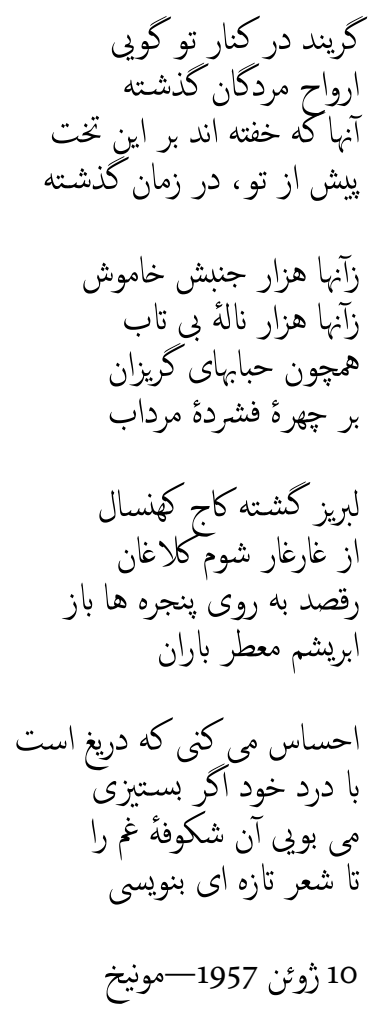

The Wish

(To Pūrān Mīnū)

I wish I was the cryptic scent of a plant

On the beach of a still river

When you happen to pass that place

I could caress you head to toe with my lips

$$
\text { (آرزو }
$$

I wish I could sing like the reed of the shepherd

To the tune of your mad heart

Slumbering on the swaying camel-litter of the breeze

I could pass your door

$$
\begin{aligned}
& \text { كاش بر ساحل رودى خاموش }
\end{aligned}
$$

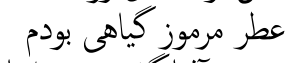

$$
\begin{aligned}
& \text { جو بر آنجا كذرت مي افتياد } \\
& \text { به سراياى تو لب مى سودم } \\
& \text { كاش :جون ناى شبان مى خواندم } \\
& \text { به نواى دل ديوانهُ تو نو نوان }
\end{aligned}
$$

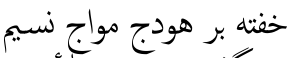

$$
\begin{aligned}
& \text { مى كذشتم ز در خانهُ تو نو }
\end{aligned}
$$


I wish in the mornings I could shine through your window

Like a ray of the spring sun

I could see the hue of your eyes

Through the trembling silk curtain

I wish in your luminous feast

I was the laughter of a wine cup

I wish in a painful midnight

I was the laxness and drunkenness of a sleep

I wish that my heart would, like a mirror, be lit by

Your image and your smile

That each morning the warmth of your caressing hand

Would touch my body

I wish in the midnight the moon could watch my dance

Like an autumn leaf

In the heart of the garden of your house

My rapture could cause a tumult

I wish I could anxiously crawl into your heart

Like the cheerful memory of a woman

Suddenly I could see your eyes

Gazing on my beauty's radiance

I wish my body could shine like the candle of $\sin$

In your bed of loneliness

So that the root of your asceticism and that of my longing

Would burn from this sweet sinning
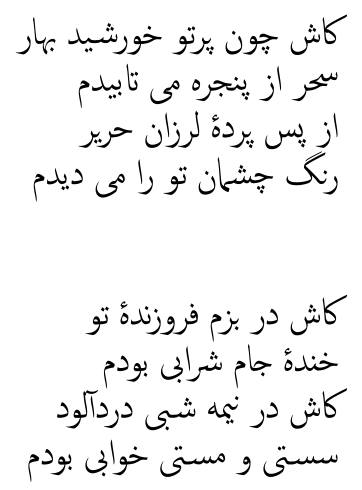

كاش جون آينه روشن مى شى تد

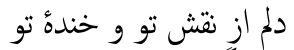

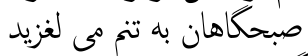
كرمى دست نوازندة تو نو

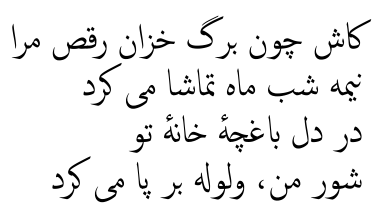

كاش جون ياد دل انكيز زنى

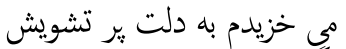

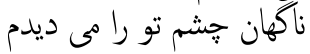
خيره بر جلوهُ زيباني خويش

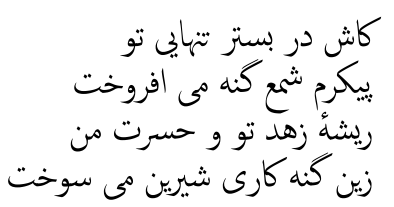


I wish from the green branch of life You would pick the flower of my woe I wish in my poem, $\mathrm{O}$ you [my] life drive Could see the flame of my secret
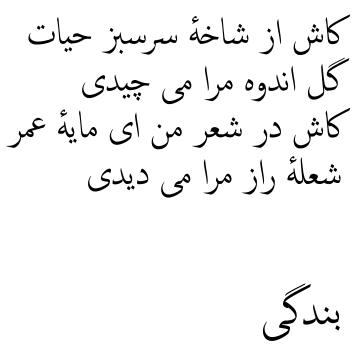

On my lips a shadow of a cryptic question In my heart a restless life-burning pain Today I am going to put forth This rebellious soul's secret of bewilderment

Though you banish me from your threshold,

As long as I be a servant here and you God there

My dark life story won't be a story

From whose beginning and whose end you are absent

At midnight the cradles rock peacefully Unaware of the man's painful immigration Like a quivering boat, a mysterious hand

Draws me rowing into the mouth of storms

Faces gravely foreign in my eyes

Over houses the tears of the stars

The terror of prison and the glitter of the chain's link

Tales of the unique God's mercy

The cold breast of earth and the stains of the grave

Every greeting a dark shadow of a farewell Hands empty and in a distant sky

The sick and fevered yellowness of the sun
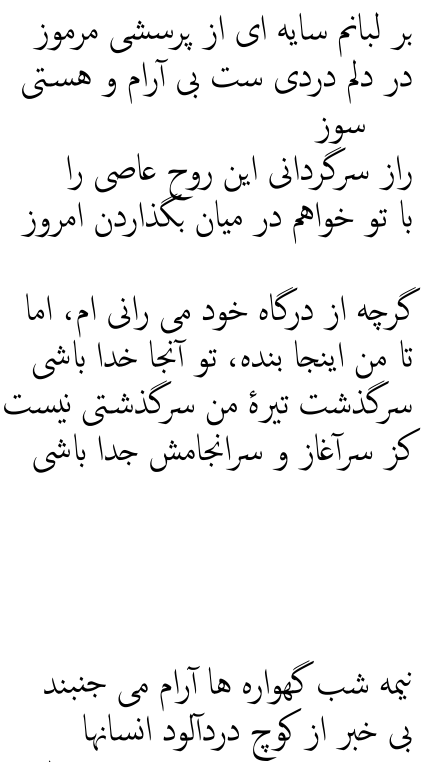

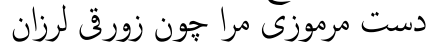
مى كثد پياروزنان در كام توفانها

جهره هاني در نكاهم سخت بيكانه خانه هايى بر فرازش اشكى اخت اخترها وحشت زندان و برق حلقة زئه زنجير داستانهاين ز لطف زئن ايزد يكتا

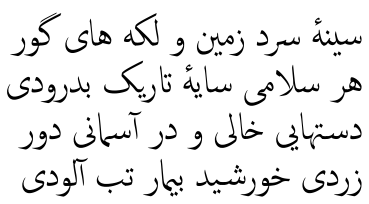


An endless search and a vain struggle A dark road and the feet weary of the way No sign of fire on the summits of Tür No answer from behind this closed door

Ah, does my moan find its way to you? So that you smash your mirror/cup of vanity upon the stone

So that you sit with me, me the earthen, for a while

And drink from the lips of my poem the pain of being

For years I suffered within me, but today Like a flame, I flare to burn your stack Either you render my restless clamour silent

Or I shall teach you another way

Though I know you banish me from your threshold,

As long as I be a servant here and you God there

My dark life story won't be a story

From whose beginning and whose end you are absent

What am I? Offspring of a luscious supper A stranger thrusts me on this way of mine Once a body entwined around another body

And I was born into the world unwillingly
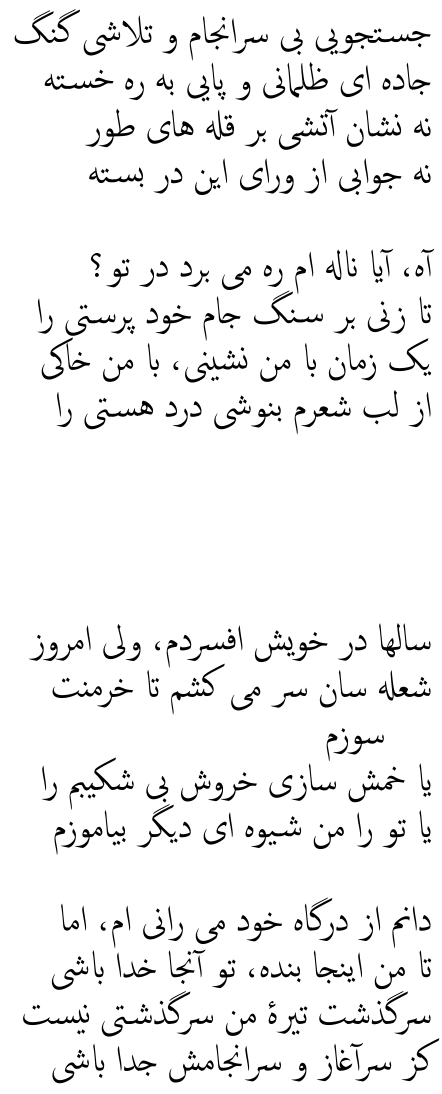

جيستم من ج زادة يك شام لذنتبار

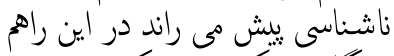

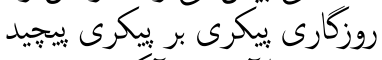
من به دنيا آمدم بي آنكة خود خواهي يدي 
When have you left me alone so that with two open eyes

I could choose a form for myself?

So that I might name as mother whomever I choose

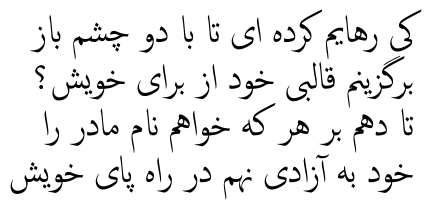

So that I might freely set my foot on the path

I was born into the world so that in your world

I should be the fruit of two fiery bodies' union

When had we known each other ere that?

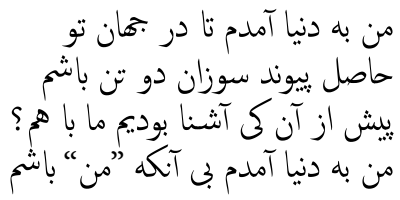

I was born into the world without being "I"

Days passed by and into my eyes blackness was poured

The darkness of your blind lingering nights

Days passed by and the song of that lullaby died

And my ears filled with your voice

"Childhood" like the swallows with colourful wings

Flew off towards other skies

In my brain the seed of thought bestirred itself

An unannounced guest knocked at the door

I would run in the illusory deserts

Sit besides the springs drunken

Break the branches of mystery, yet

Each moment a new branch grew from the body of this shrub
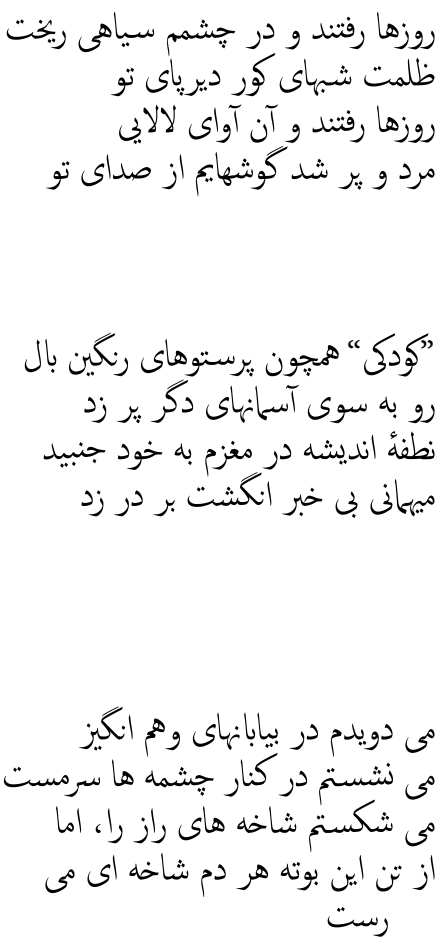
My path led to distant plains

Floating on the tide of my thoughts

I crept into the heart of the wandering waves

Untying from my feet the chain of darkness

Finally one day I asked myself silently

What am I? From what beginning do I come?

If I am the warm light of life from head to toe

From which sky of mystery do I radiate?

Why do I silently think in this manner night and day?

Who has sown in me the seed of thought

Is the harp in my hand and am I the proud harpist

Or has someone placed this harp on my lap?

If I were not or were I in another world Would I still have my power of thinking? Could I still find my way Into the riddles of this mysterious world?

Fearfully in search of that enigmatic answer I headed down a dark labyrinthine road You cast a shadow on that "end" and I knew that

I am naught head to toe, I am naught, naught
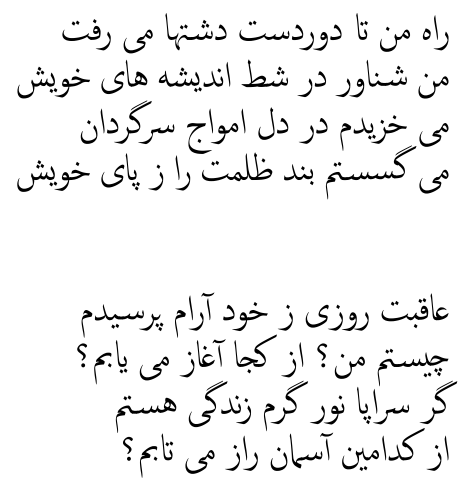

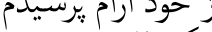

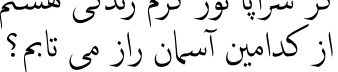
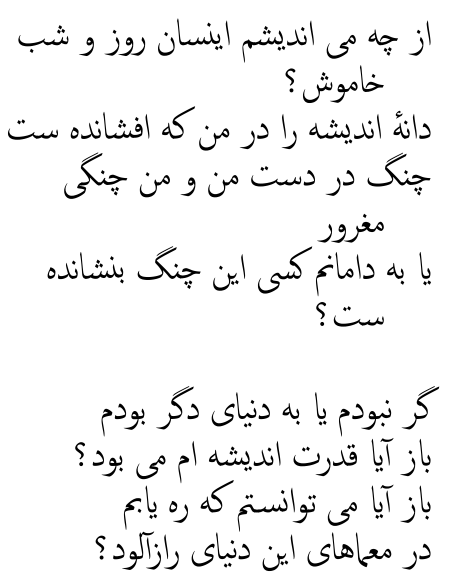

ترس ترسان در يى آن پاسخخ مرموز

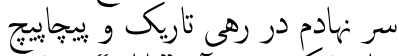

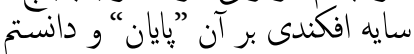
ضاى تا سر هيج هستم، هيج هستم، هيج 
You cast a shadow on that "end" and in your hand

There was a rope tied round necks at its other end

You were dragging people along life's winding road

While their eyes stared at the image of the other world

You were dragging people along the path and singing:

May the fire of hell be the infidel's toll

Who chooses Satan in place of me

May the fire of hell be gravely burning to his soul

I saw myself as a mirror devoid of myself

At any moment an image falls upon it by your hand

Sometimes the image of your power, sometimes your tyranny

And sometimes the image of your self-worshiping eyes

A sheep lost in the midst of the herd

The shepherd has opened the way to the wolf

The shepherd, drunk from this game

Crocked is resting peacefully in a corner

You were dragging people along the path and singing

"May the fire of hell be the infidel's toll

Who chooses Satan in place of me

May the fire of hell be gravely burning to his soul."
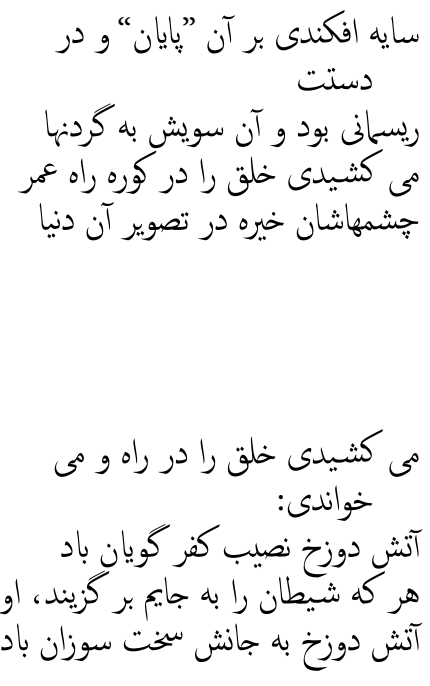

خويش را آينها اى ديدم تهى از خويش

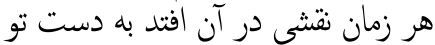
كاه نقش قدرتت، كه نقش بيدادت

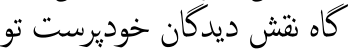
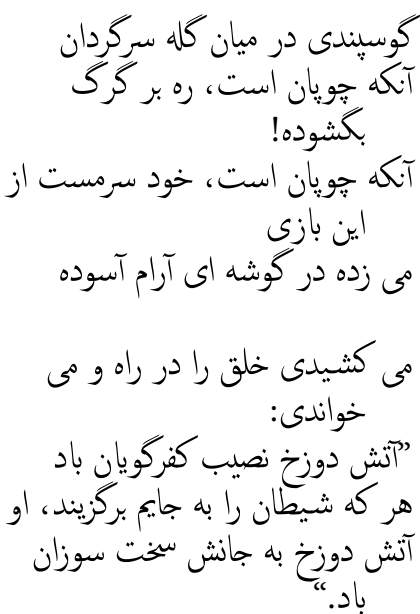
You yourself created this accursed Satan

Turned him rebel and banished him toward us

It was you, it was you who created from a flame

Such a demon and set him on the road

You gave him an opportunity that as long as there is a world

He would set fire with his evil fingertips ${ }^{1}$

He would turn into a wild joy in a still bed

He would turn into a kiss on lips burning with thirst

Whatever was glamorous, you ruthlessly condoned

It became a poem, a cry, love and youth

It became the scent of flowers, sprinkled on the plains

It became the colour of the world, the deceit of life

It became a wave on the wavy skirt of the dancers

It became the fire of wine, boiling in the wine-vault

It set such a commotion in the soul of wine drinkers

That from every ruin was heard the sound of cheers and more cheers
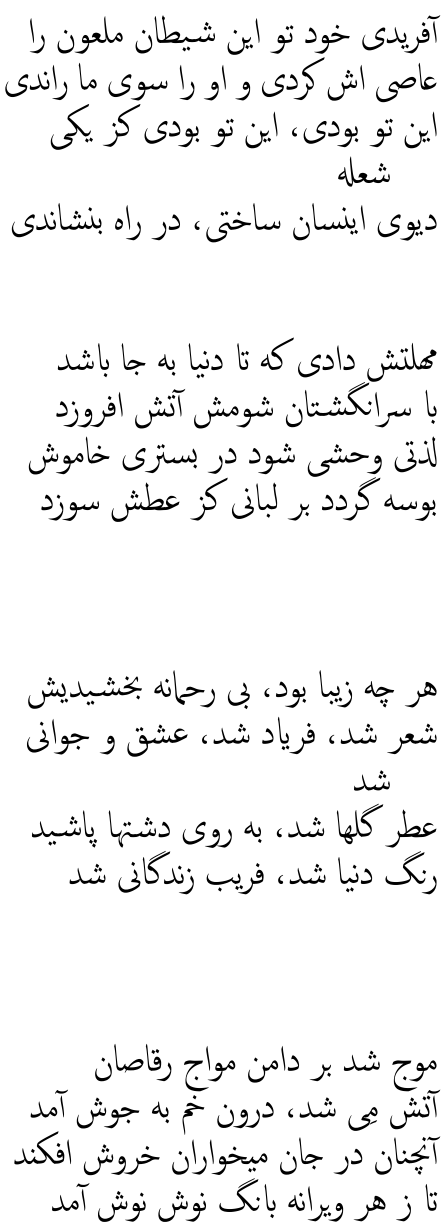
He became a melody, circulating in the hand of a harper

He became a tremor, falling on silver breasts

He became a smile, revealing the teeth of moon-faced beauties

He became the image of the cupbearer, reflected in the inverted cup

In these dark nights the charm of his song Became the guide of the lost in the deserts The sound of his steps danced in the heart of the altars

The glitter of his eyes became the light of wayfarers

Whatever was glamorous, you ruthlessly condoned

Dismissing them on the path of beauty-worshippers

Then with your cries of wrath and fury

You filled our blue glass dome with clamour

Our eyes brimming with that alluring image

We prostrate ourselves in our submission Any moment the dark story of your

\section{"Śamūd" tribe ${ }^{2}$}

In our eyes takes on the hue of blood

You sat till he [Satan] subordinated them, then

Like a plant you dried them up with a storm

The whirlwind of your rage came over the "Lūṭ" tribe

You burned them, with scorching lightning

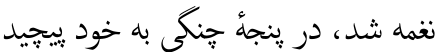
لرزه شد، بر سينه هاى سيمكون افتئاد خنده شد، دندان مه رويان نغايان كرد عكس ساق شد، به جام وازثون افنتاد

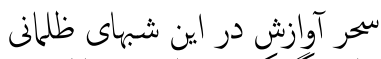
هادى كم كرده راهان در بيابان شد شيد

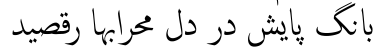

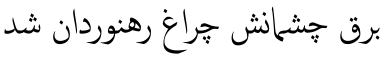

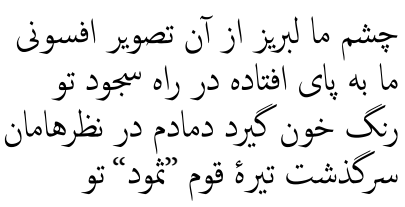

خود نشستى تا بر آنها جيره شد آنكاه

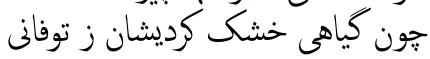

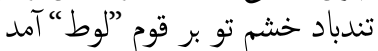
سوختيشان، سوختى با برق سوزانى تلوطي 
Woe to this game, this painful game

Why do you turn us into toys thus?

We are a thread of rosary whirling in your hand

You whirl us zealously and assail us in vain

As soon as our eyes met the two eyes of life We were introduced to "sin," this ambiguous word

You created sin, it stirred within itself

It rushed upon us, to the very same sin we finally turned

Were you and your mercy with us

Could Satan ever convey his way and love to us?

Was there ever any sign or sound of his steps

In this raging rebellious soul?

You successively drag me and us into the grave

So you can say that you can be thus

So that I and we may be a manifestation of your power

So that you be the cold iron sledge on our head

What is this Satan banished from the thresholds?

Staying as a guest in our still mansion A hand has sprinkled on the fire of his burning body

The redolence of the world's pleasures

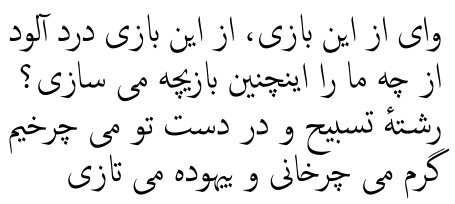

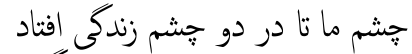
با "خطا"، اين لفظ مبهم، آثنا كثنتيه تو خطا را آفريدى، او به خون خود جنبيد تاخت بر ما، عاقبت نفس خط آنطا كشتيم

$$
\begin{aligned}
& \text { كر تو با ما بودى و لطف تو با ما بود } \\
& \text { هيج شيطان را به ما هرى و وراهى با با بود } \\
& \text { بود؟ هيط }
\end{aligned}
$$

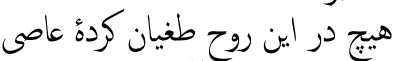

$$
\begin{aligned}
& \text { زو نثنانى بود، يآ آواى بائى بود؟ كودة }
\end{aligned}
$$

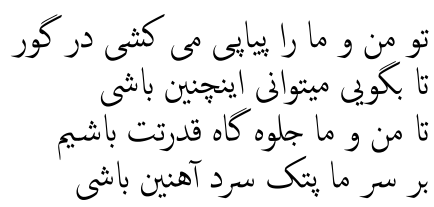

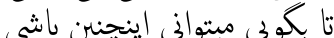

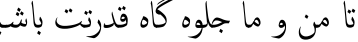

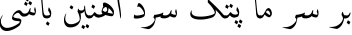

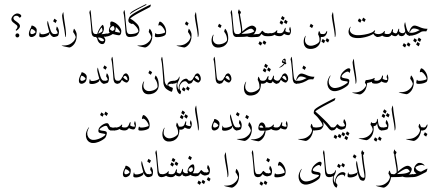


What is he but what you wanted him to be? A dark spirit, a dark soul, a dark basis A dark smile on those smileless lips A dark beginning, $\mathrm{O}$ God, a dark end

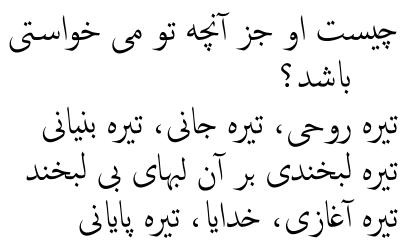

When has his tendency been the origin of this bitter being?

When have you asked his opinion on an issue?

If you had left him alone to himself

Never in the world could you have seen an image of him

Many a night did he come into my dream His eyes were streams of tears and blood Whinging bitterly, and I could see that on his lips

His moans had no hue or charm

Ashamed of his disgraceful and ignominious name

He searched for a niche to get rid of his self His body was of the hue of foulness

Weeping, he desired a power to detach himself from himself

Many a night did we converse

My ears still seem to be brimming with cries

Satan says: Spit on this existence, on this painful existence

Spit on this existence which is so disgusting

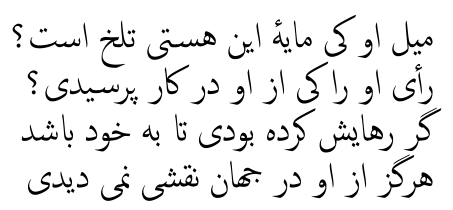

اي بسا شبها كه در خواب من آمد او

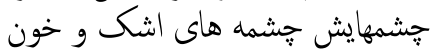

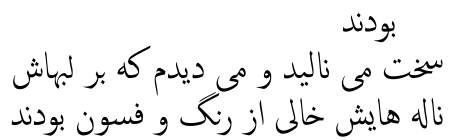
شرمكين زين نام ننك آلودهُ رسوا

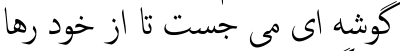
كردد يسكرش رنك يليدى بود و او كريان

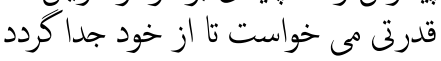

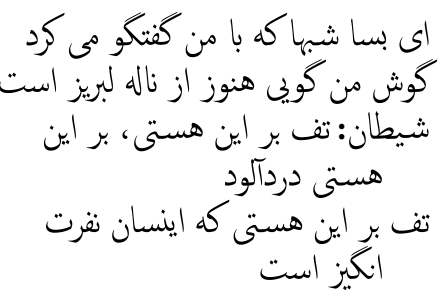


He is my creator, then why does he whisper every second

In people's ears that I was like that, I am like this?

If I am a guileful Satan, what is my sin?

He doesn't want me to be something else

His hell was burning with hunger for prey

He put a hunter's snare in my hand and tamed me

To trap thousands of prey in my snare, all of a sudden

He turned a world tumultuous with the clamour of my name

His hell was burning with hunger for prey His realms of punishment erected, awaiting Fiery spears and the tents of smoke

Thirsty for his infinite sacrifices

The bitter fruit of the wild "zaqqūm" tree Still hanging futilely on the branches That wine mixed with the hell's hot water ${ }^{3}$ Hasn't inflicted anybody's heart with a new spark

His hell was empty of the moans and cries of pain

His hell was shining and burning uselessly To cast its absurdity in a different hue He taught me the ways of deceiving people

What am I? One afflicted whose feet are tangled

In the ropes of a dark destiny

$\mathrm{O}$ my disciples, $\mathrm{O}$ wanderers on the way

He has chosen our path, considered it well
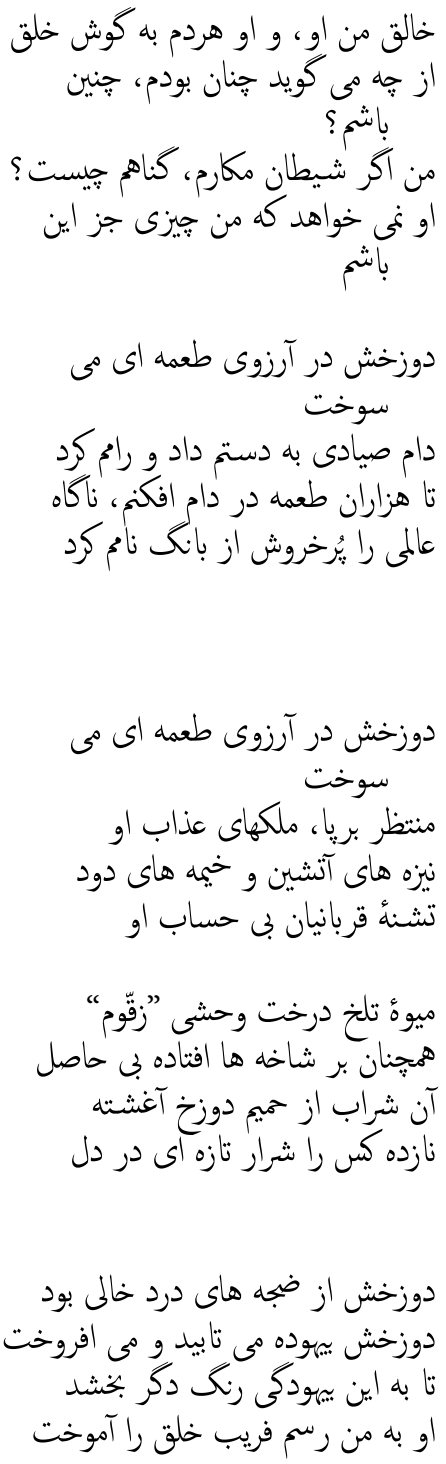

من جهه هستم ؟ خود سيه روزى كه بر بايش

بندهاى سرنوشتى تيرِ بيجنيده

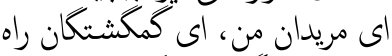
راه ما را او كزيده، نيك سنجيده 
O my disciples, $\mathrm{O}$ wanderers on the way

The path is not one we can find a way to him

Until when will you search for the path? The path is invisible and we are travelling to him

$\mathrm{O}$ my disciples, $\mathrm{O}$ his curse on us

$\mathrm{O}$ my disciples, $\mathrm{O}$ our cries from him

$\mathrm{O}$ the one who is all tyranny, his tyranny is on us

All our merry laughter from him

We are no sea to turn into our own wave

We are no storm to be our own wrath

Since we have lost his favour in vain

Why are we struggling to become our own eyes?

Neither are we an embrace to be burnt from ourselves

Neither are we a song to shiver from ourselves

Neither are we "we" to have sinned

Neither are we "he" to fear ourselves

If we chanced proceeding not to be entrapped

He would spread his trap with fresh guile

For his feverishly burning hell

He would foster any moment fresh baits

O my disciples, $\mathrm{O}$ wanderers on the way

I am fed up with this ignominious name

Though he tried to put me to sleep,

"I am the Satan, alas I am wide awake"

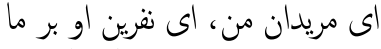

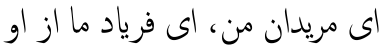

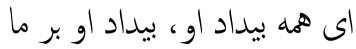

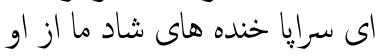

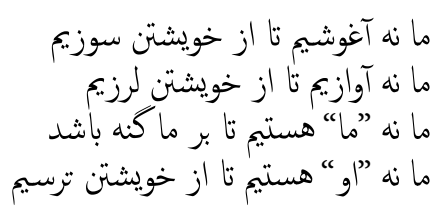

ما اكر در دام نافتناده مى رفتيم

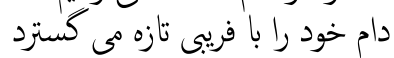

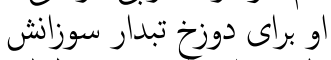

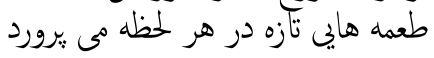

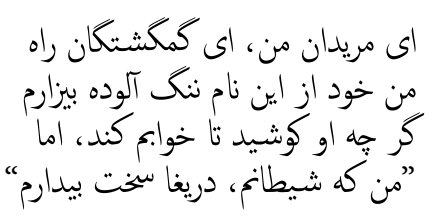


Many a night he and I in that darkness

Rained tears, rained tears incessantly

Many a night I gently kissed Satan's lips

When they ceased talking

Many a night my hands caressed

That wrinkled face

Many a night when his voice was raised

My knees prostrated without hesitation

Many a night he wished just for a second

To be out of that scarlet cloak

Wished to turn to the very spirit of purity

Not to be the lord of half of the inferior world

O God, of what avail is this self-love?

"We are ourselves the miserable and wretched fallen"

In any deed and any thought we see no trace of a hand,

Or magic role, except for your own image

You created the earthen world, and are aware

That from its head to its toe it is naught but a mirage, a deception

We are puppets, and your hands are busy playing

Our rebellion, our blasphemy is not something foreign

You asked us to thank you, we thanked you But for how long should we thank you?

You block the way and laugh at the wayfarers

Where are you, where, so that we can find our way to you?
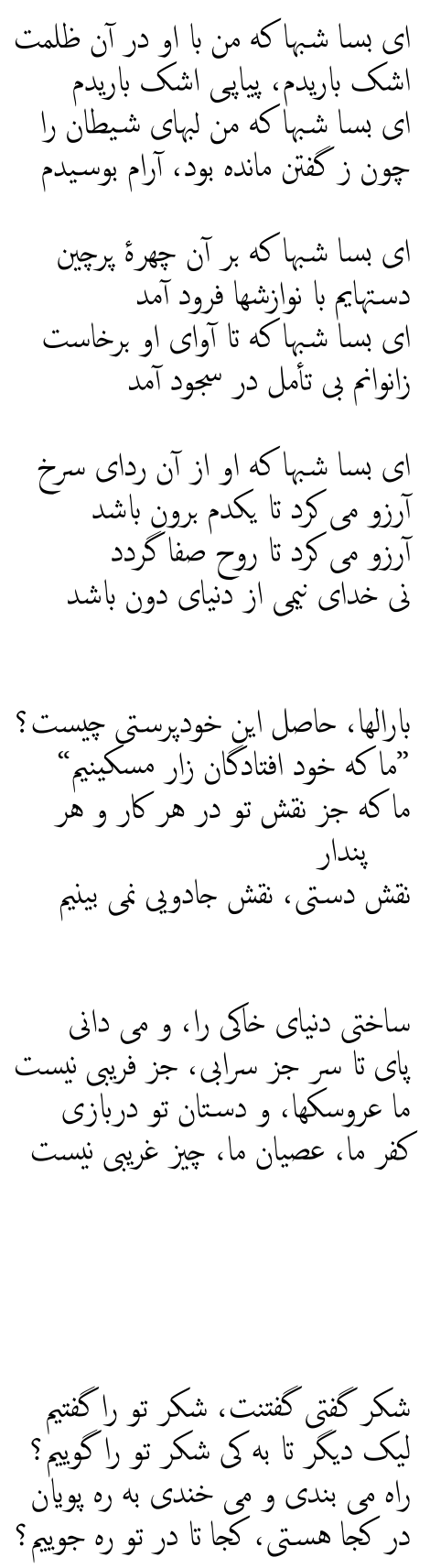
Like wax, we take our shape in your hand Then what is the myth of doomsday?

Why then are we burning so hard in the mouth of hell?

What is this bitter punishment and this pain of remorse?

This world itself has turned into such a fervent hell

Fire all over, excruciating misery everywhere

Many a yoke and chain twisted at the feet

From the dust of bodies rises cold smoke

The good and the bad are together burning among the flames

The robe-clad ascetic and tavern-going libertine

The heartless wine seller and the intoxicated wine drinker

The enlightening cup bearer and the heavenly saint

This world itself has turned into a hell so burning

Still there is a hell awaiting us there

We are defenceless and hell's gatekeeper is hard-hearted

All the time he says that he is with us in whatever we do!

Forget not that illustrious blithesome master

Whose name due to his ill fate was "Satan"

The one who was amazed at your work and your justice

Whatever he said, I realized, was very true
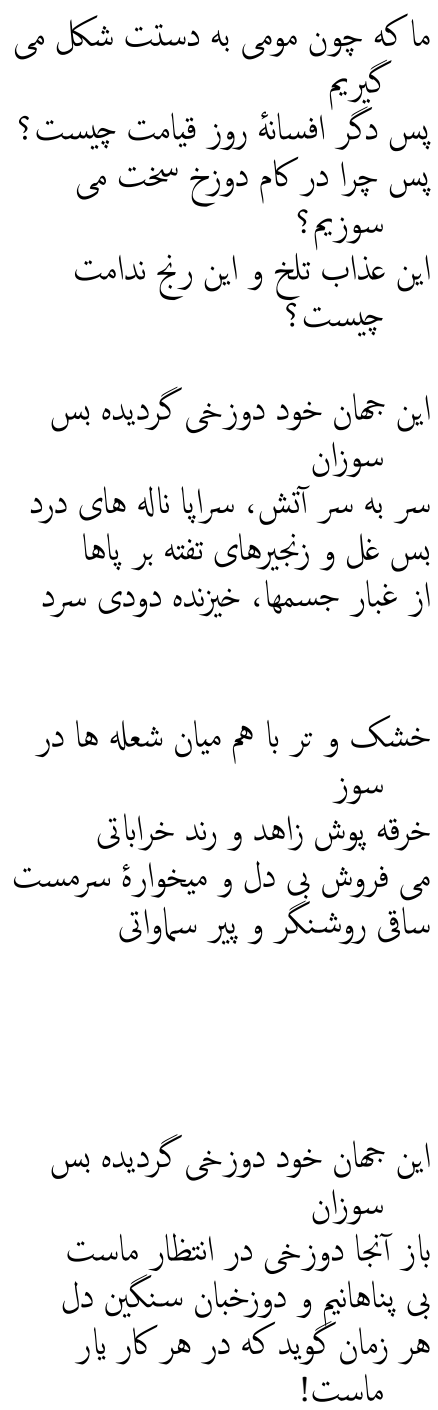

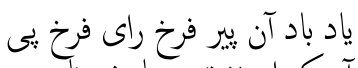
آن كه از بخت سبياهش نآ نيخ

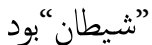

آن كه در كار تو و عدل تود تو حيران بود هر جه او مى كفت، دانستي، نه جز آن آن بود 
This is me the rebellious servant whose name

Your hand adored with the ornaments of these words

Woe to me, woe on my revolt and my mutiny

Whether I say it or not my place is there

On doomsday again you'll carp at this insignificant me

Accusing me of once having spoken blasphemy

You'll weigh my load of sin on the scale

To say that I was rebellious and of dark disposition

One tray of the scale brimming with the load of my sins

The other what? I beseech O God

What is your basis for this mysterious weighing?

The heart's desire or the dark stones of the

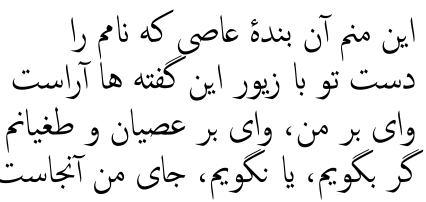
desert?

How easy it is to talk about the "self"

Face to face on that dreadful day

Amazed to search on your scale

For people's honour which you continuously disgrace

In a book, or in a dream, I do not know

I envisaged an image of the Great God's court

You were busy judging and alas, a hundred times

On your scale I saw hypocrisy, I saw
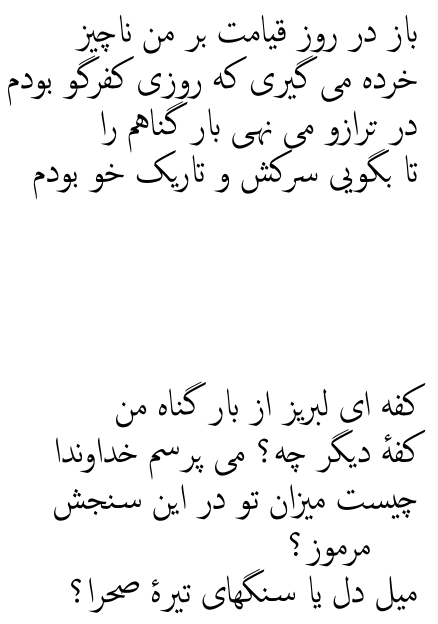

خود جه آسان است در آن روز هول انكيز روى در روى تو ، از "خود“" كفتكو

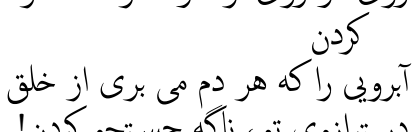
در ترازوى تو ، ناكه جستجو كردن!

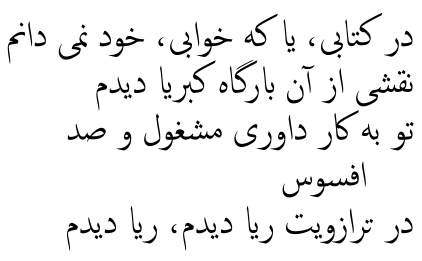
hypocrisy 
You rage, but don't ask me to abstain from my tomorrow

I who will be dust tomorrow, what is the use in abstaining

I am well aware of my end

You ravenous and, I, O God, a meagre prey

You ravenous, your hell has opened its mouth over there

With its venomous serpents, the breath of the hell's discrete trees has turned

The air dark and poisonous ${ }^{4}$

Foul water is the hell's bitter, burning wine ${ }^{5}$

Beyond the colossally firm walls

"Inferno," that last pit of fires ${ }^{6}$

Has spread itself to suddenly embrace

Our earthen and absurd bodies

I wish you had never bestowed on us existence

Or if you had, our existence was ours

We would taste this purple wine

Then nonexistence would be the veil of our drunkenness

For years, we, your servile puppets

Have danced to thousands of your instrument's tunes

Finally we will still burn from the fire of your wrath

We understood well the meaning of your justice!
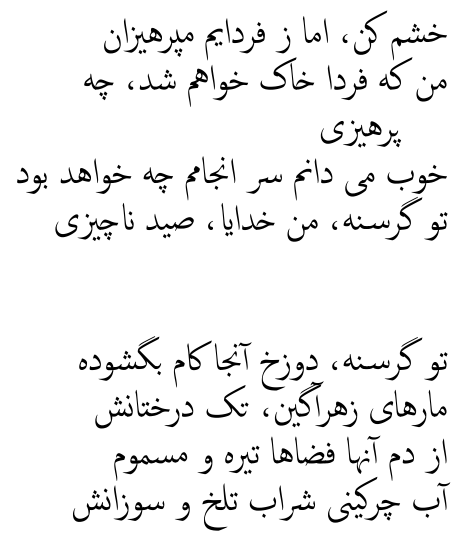

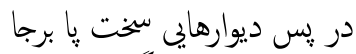

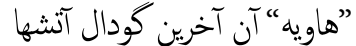
خويش راكسترده نا ناكه فراكيرد

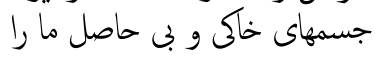

كاش هستى را به ما هركز نمى دادى دادي

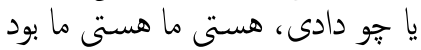
مى تشيديم اين شراب ارغوانى را ها ها نيستى آنكه خحار مستى ما بود ارغان را

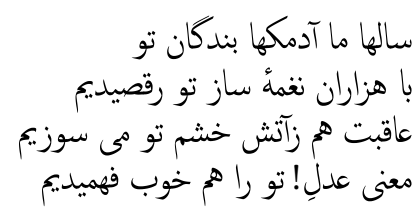


As soon as we, the hapless, called you just You veiled your face in the silk of mercy

You made a mysterious myth out of a paradise

You gave to us on credit, but took the ready cash of people's lives

Glowing with existence, they refrained from existences

For years they rubbed their faces on the prayer carpet

Your name on their lips and in their dreams

A cup of wine pressed to their lips while they looked on the faces of those houris

You both smashed their cup of "todays" And mocked with vengeance their "tomorrows"

They turned into their own graves and, $\mathrm{O}$ rain of mercy

Centuries passed by and you never rained on them

Why do you declare this rubicund wine forbidden?

In your paradise, the streams are flowing with wine ${ }^{7}$

The prize of the virtuous would be

Finally one of your heavenly houris there ${ }^{8}$

In our every breath you deceive us with a spell

Every time you drag us into a sea

In the blackness of this dungeon, you sometimes light

A dream candle from the garden of paradise

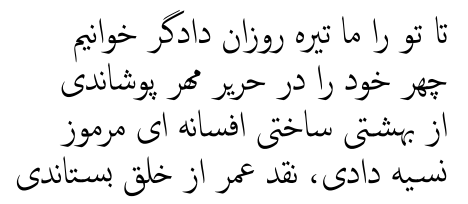

تا تو را ما تيره روزان دادكر خوانيم

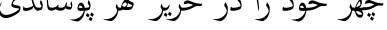
نسيه دادى، نقد عمر از خلق بستاندى مردي
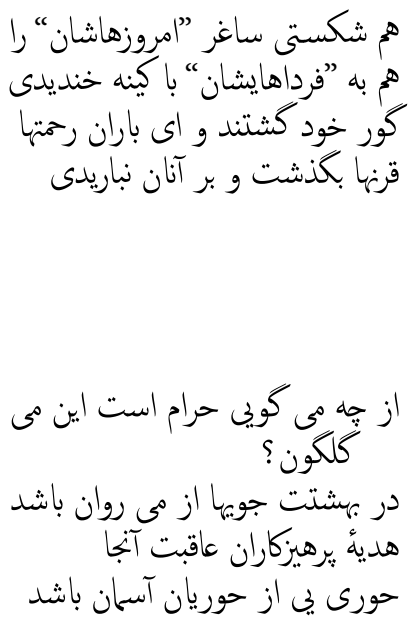

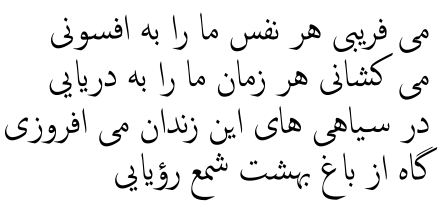


In this ruined world

If we have let ourselves go in a burning cup of wine

O Lord, again it's your hand at work

Why do you declare our deed inadmissible?

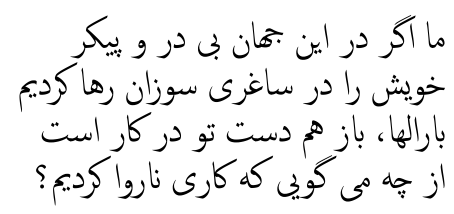

We do not desire that golden repose

At your fountains of Salsabi $l^{9}$

Let the well-behaved have the shades of lotus and Tiū $b \bar{a}^{10}$

We remit this divine mercy to yourself

Hāfez, that pīr who was the sea and the world himself,

Sold this Edenic garden in exchange for a grain of barley ${ }^{11}$

Who am I not to spare it for a goblet of wine?

You brand my ominous name with wickedness

What is this colourful scented myth?

What is this magical enchanting dream?

Who are these Houris, these grapes of light?

Whose garments are made from the gaunt silk of austerity?

Pitchers in their hands and on those delicate forelegs

The illusory trembling wavelets of skirts They strut softly from a door to a threshold Their breasts slumbering in the embrace of corals

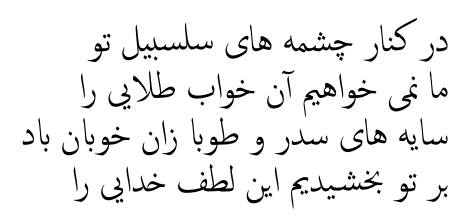

حافظ آن ييرى كه دريا بود و دنيا بود

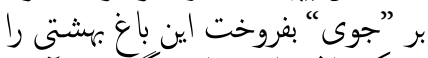

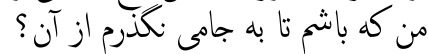

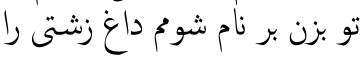

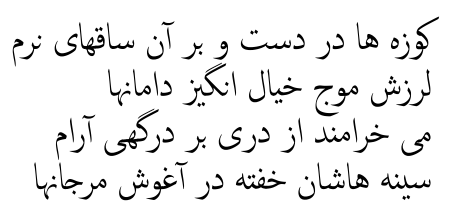


Waters purer than teardrops

Streams slipping over the fresh grasses

Fruits like bright beads of ruby

Sometimes picked, sometimes unpicked on each branch

Boys with grace and beauty head to toe ${ }^{12}$

Cup bearers of the feast and robbers of the hearts' treasures

Their beauties eternal and the eyes of heaven's tenants

Sometimes desire them and sometimes houris

Palaces, their walls billowy marble Thrones, at their feet beads of diamond Curtains, like wings of green silk

From the air exudes the thick fragrance of jasmine

Here, we are dust at the feet of wine and beloved

We are called non grata and disgraced drunkards

There, in that world, you bestow on

Your pious, sinless believers wine and beloved

That bitter and burning "sin" on its path With which our souls had a hastening desire for reunion

Suddenly took on another name in your paradise

In your paradise, O Lord! It was a good deed itself
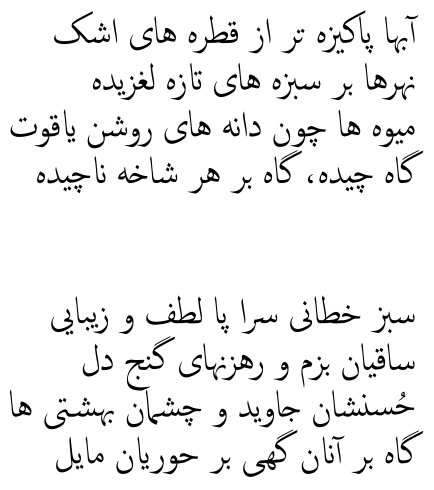

سبز خطانى سرا يا لطف و زيباني

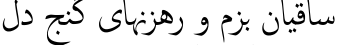
كاه بر آنان كهى بر حوريد جُيان مايل
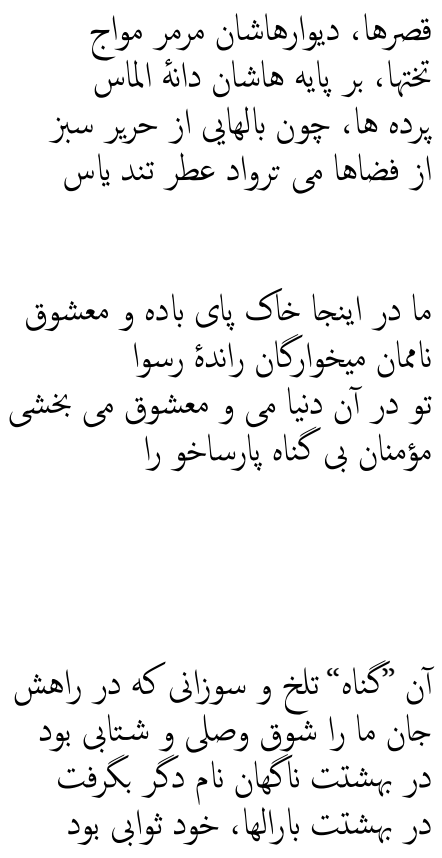
Whatever we have, we have it from you, you yourself said:

"My grace is sea and my wrath is like a storm

Whomever I will, I will make malignant ${ }^{13}$

Whomever I choose will be chaste."

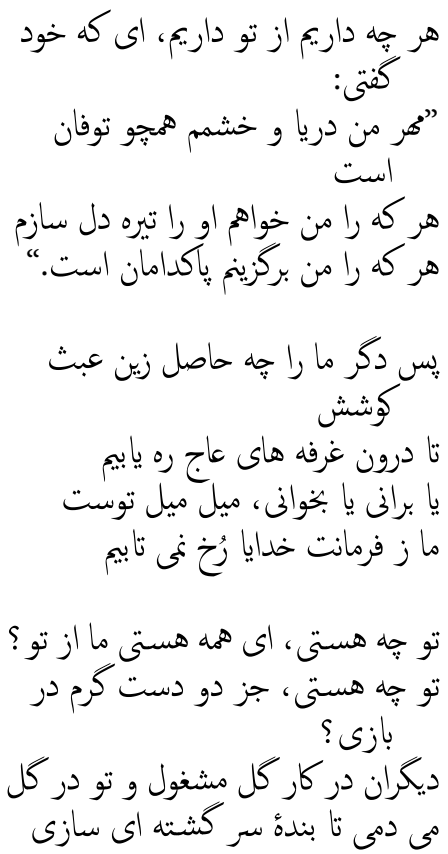

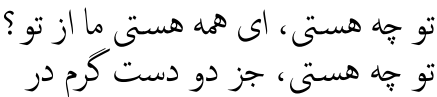

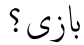
ديكران در كار كل مشغول و تو دركل مى دمى تا بندة سر كشته اى سازى

O Lord, we won't disoblige your command

What are you, $\mathrm{O}$ source of our entire existence?

What are you, but two hands busy at a game?

Others are busy at the work of flowers

And you blow at mud to make a bewildered servant

What are you, $\mathrm{O}$ source of our entire existence?

But a barrier on the path of our quest

Sometimes you squeeze us in your claws of

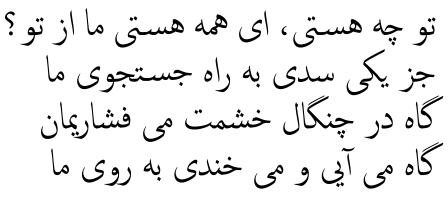
wrath

Sometimes you come and mock us to our faces

What are you? A slave to your own name

تو קه هستى ؟بندة نام و جلال خويش

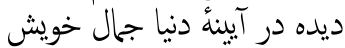
and majesty

[You have] seen in the mirror of the world هر دم اين آيينه راكردانده تا بهنت the reflection of your own beauty

At every moment you turn this mirror around

To better gaze upon your immortal manifestations 
You are the sparkle in the eyes of a mirage, the colour of deceit

You are the ooze of ominous nights, the darkness of a grave

Maybe you are that old bat slumbering out

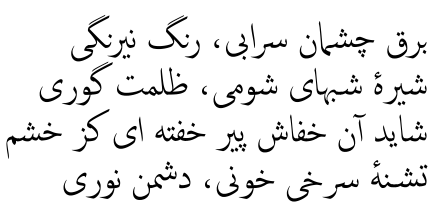
of his fury

Thirsty for the redness of blood, enemy of light

You are a self-worshipper, O God, you are a self-worshipper

If I talk blasphemy, turn me into a thorn, into dust ${ }^{14}$

You defiled me with thousands of

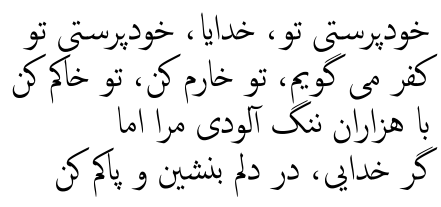
disgraces, but

If you are God, repose in my heart and purge me

Spare us for a moment, let us be ourselves Then burn us so that we burn due to "ourselves"

Thereafter either a tear, or a smile, or a cry

An opportunity, to save provisions for the journey

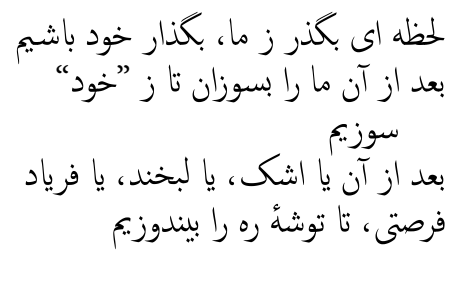

\section{The Return}

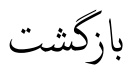

At last the line of the road ended

I arrived dusty from the journey

My eyes galloping ahead of me

My lips carrying a warm greeting

The city boiling in the furnace of noon

The street burning in the fever of the sun

My feet trembling hard

Advancing on the mute cobblestones
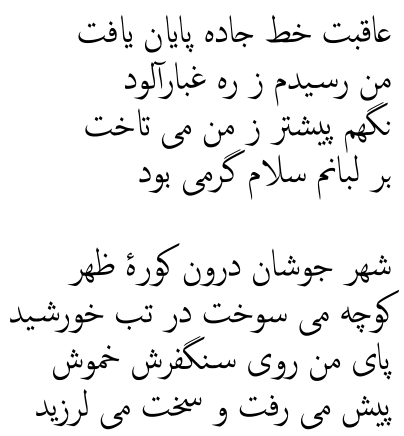
The houses were of a different hue

Dusty, dark and depressing

The faces between the veils

Were like ghosts in fettered feet

The dried-up stream, like a blind eye

Devoid of water or any sign of it

A singing man passed by

Filling my ears to the brim with his song

The familiar dome of the ancient mosque Looked like the broken bowls

A believer atop its minaret

Was singing the call to prayer with a melancholic tune

Children, barefoot, stones in hand Were chasing dogs

A woman laughed behind a veil Abruptly the wind slammed a door

From the black mouth of the vestibules The damp stench of the grave was coming A blind man passed by tapping his cane Someone familiar was approaching from afar

There a door opened silently

Hands drew me in

A tear fell from the cloud of eyes

Hands pushed me away

On the wall the old ivy

Still rippled like a trembling fountain

Over the body of the ivy's luxuriant leaves

The greenness of the old age and the dust of time
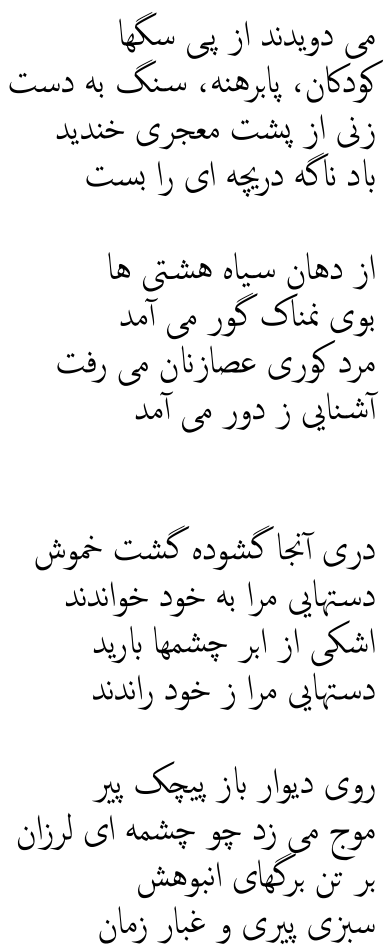
My eyes asked searchingly

"Where is a sign of him?"

But I saw that my small room

Was devoid of his childish clamour

From the heart of the mirror's cold earth His body, like a rose, suddenly grew;

His velvet eyes rippled,

Ah, even in [my] delusion he was seeing me

I leaned against the wall's breast, Softly I said: "Is this you, Kāmī?" But I saw that from that bitter past Naught but a name remained

At last the line of the road ended I arrived dusty from the journey The thirsty could not find a way to the spring and alas

My town was the grave of my wish

September, the 16 th, 1957 -Tehran

\section{Upon the Earth}

Never have I wished

To become a star in the sky's mirage

Nor like the souls of the chosen

To be the silent companion of angels

Never have I been separated from the earth

Nor acquainted with a star

I have been standing upon the earth

With my body like the stem of a plant

Sucking in wind, sun and water

To survive
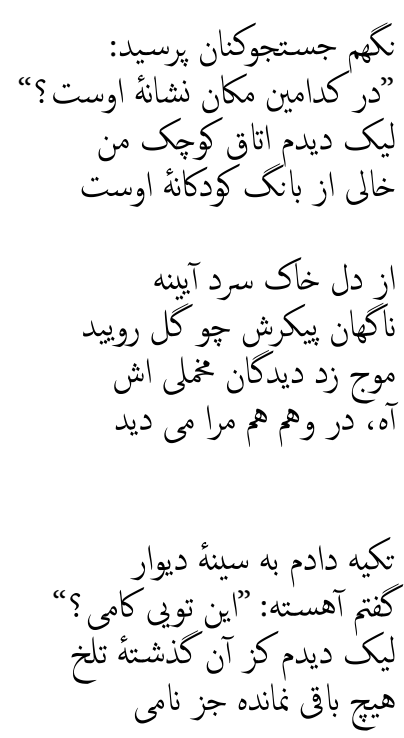

عاقبت خط جاده بِايان يافت

من رسيدم ز ره غبارآلود

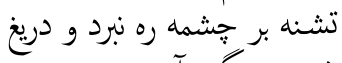

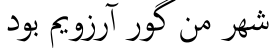

25 شهريور 1336- تهران

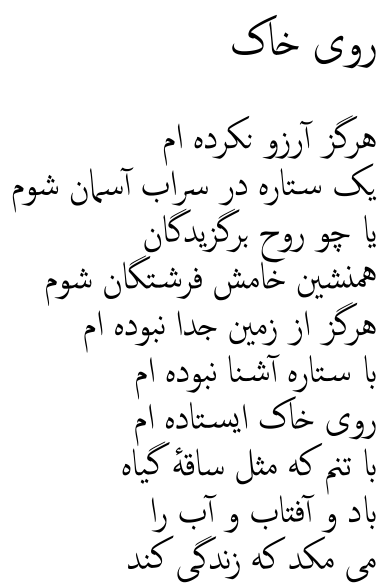


Pregnant with desire

Pregnant with pain

I have been standing upon the earth

For the stars to worship me

For the breezes to caress me

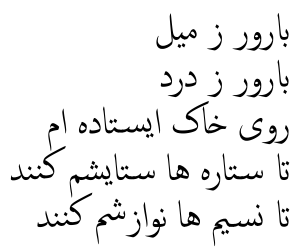

Looking out of my peephole

I am naught but the echo of a song

I am not eternal

Naught I seek but the echo of a song

In the cry of delight which is purer

Than the simple silence of a woe

I seek no nest

In a body which is dew

Upon the lily of my body

On the wall of my cottage which is life

With the black line of love

Passers-by

Have drawn mementos:

An arrow-pierced heart

Overturned candle

Pallid silent dots

On the tangled letters of madness

Every lip that touched upon my lip

A star was conceived

In my night that was settling down

Upon the river of mementos

Why should I wish for a star?

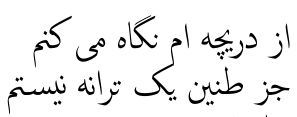

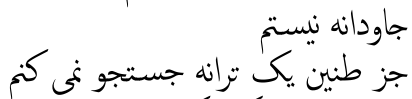

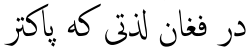

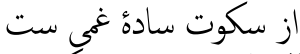

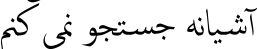

در تنى كه شبنى ستى ستى

روى زبنق تنم

بر جدار كلبه ام كه زندكى ست عن عن

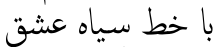

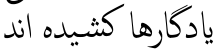

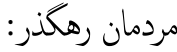
ق ق قلب تيرخورده شمع وازگكون

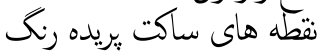
بر حروف درهم جنون ينائ

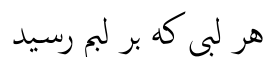

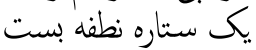

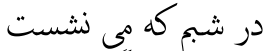
روى رود يادكارها

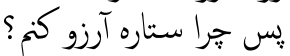

This is my song

- amiable and soothing

Heretofore it has not been more than this
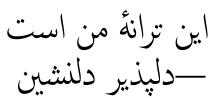

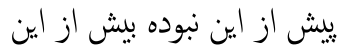


Earthly Verses $^{15}$

Then

The sun grew cold

And the bounty fled the lands

And the grasses withered in the deserts

And the fish withered in the seas

And no longer did the earth

Receive its corpses

Night, like a queer imagining,

Was continually rising and swelling

In all the pallid windows

And the roads abandoned their continuance

Into the dark

No one dreamt of love any more

No one dreamt of victory any more

And no one

Dreamt of anything any more

In the caves of loneliness

Futility was born

Blood reeked of bhang and opium

Pregnant women

Gave birth to headless infants

And cradles, in shame

Took refuge in the graves

What bitter and black days

Bread defeated the miraculous power

Of prophecy

The starving and destitute prophets

Fled the promised holy land

And the strayed lambs of Jesus
آيه هاى زمينى

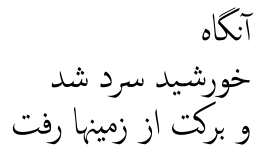

و سبزه ها به صحراها خشكيدند

و وماهيان به درياها خشكيدا خهند

و خاك مردكانش را دران

زان هي به خود نيذيرفت
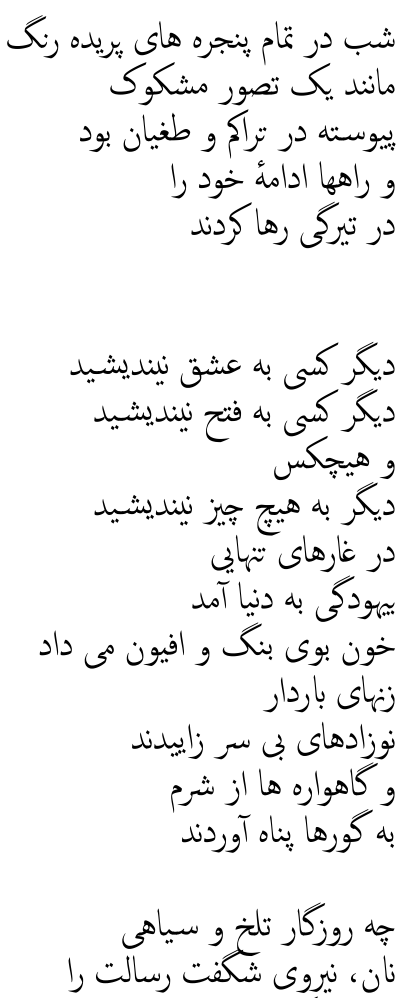

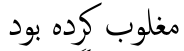

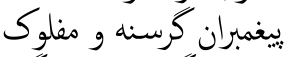

از وعده كاههاى الهي كريختيند

و بره هاى كمشدة عيسى العى 
No longer heard the voice of a shepherd calling hey-hey

In the bewilderment of the plains

As if in the eyes of the mirrors

The motions and the colours and the images

Were reflected, inverted

And above the heads of the debased clowns

And the harlots' shameless faces

A glowing sacred halo burned

Like a parasol aflame

The swamps of alcohol

With their acrid poisonous fumes

Drowned in their abyss

The mass of motionless intellectuals

And sly rats

Gnawed the gilded leaves of books

In old cupboards

The sun was dead

The sun was dead, and tomorrow

In the minds of children

Had a lost, obscure meaning

In their writings

They depicted

The bizarreness of this overused word

With a large black blot
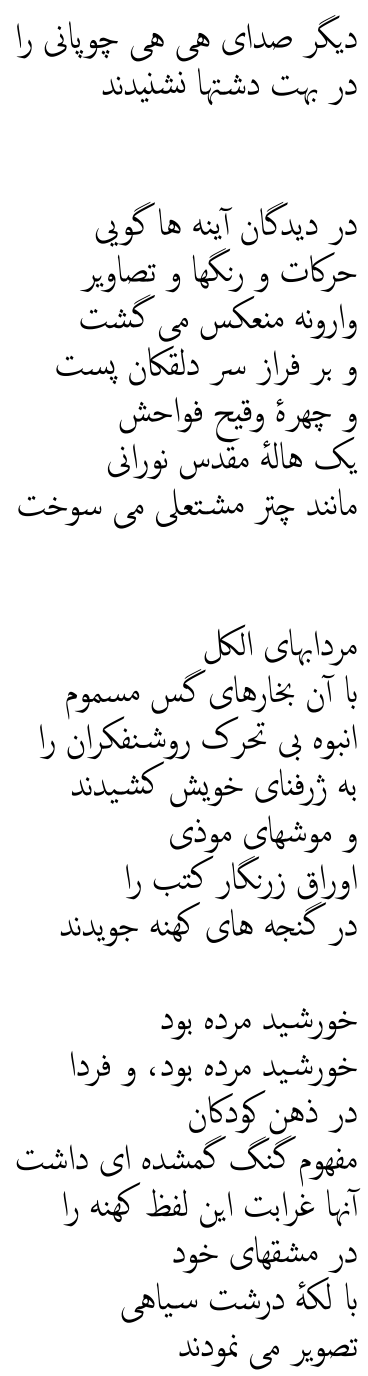

People

A fallen mass of people

Dead-hearted, gaunt and bewildered

Beneath the sinister burden of their corpses

Wandered from exile to exile

And an aching lust for crime

Swelling in their hands

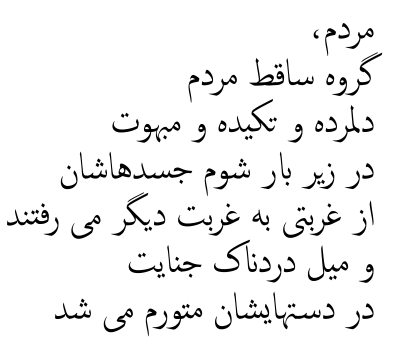


Sometimes a spark, a trifling spark

Suddenly exploded from within

This silent lifeless gathering

They would assult each other

Men slitting each other's throats

With knives

And sleeping

In beds of blood

With pre-pubescent girls

They were drowned in their own horror And the dreadful sense of sinning

Paralysed

Their blind and witless souls

Always in the rites of execution

When the rope of the gallows

Would pop from their sockets

The convulsing eyes of a condemned man

They would sulk in themselves

And from voluptuous imagining

Their old and exhausted nerves would twinge with pain

But always round the plazas

You could see these petty criminals

Standing

And staring at

The ceaseless flow of the fountains

Perhaps

Behind the crushed eyes, in the depths of congelation

Something half alive and confused

Had still remained

Which with its lifeless struggle

Wished to bring faith in the purity of the song of the waters
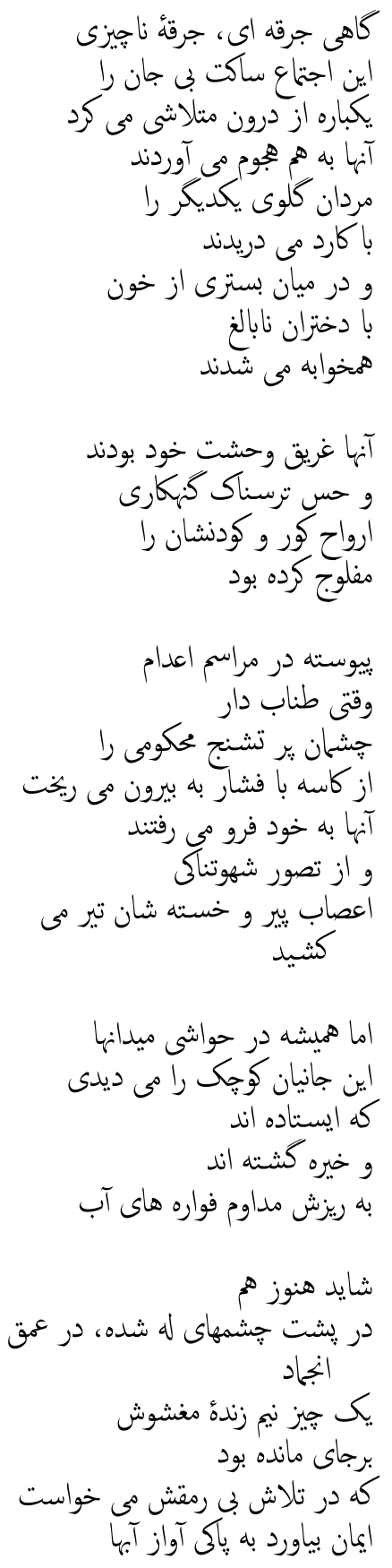
Perhaps, but what an infinite emptiness

The sun was dead

And no one knew

That faith was the name of that aggrieved dove

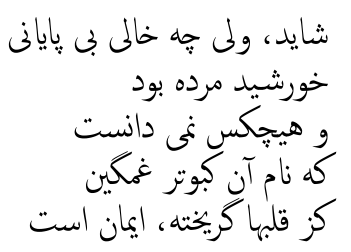

Which had fled from the hearts

Ah, $\mathrm{O}$ voice of the prisoner

Will your whining of desperation

Ever burrow through any side of this

detested night

To the side of light?

$\mathrm{Ah}, \mathrm{O}$ voice of the prisoner

$\mathrm{O}$ last voice of all voices ...

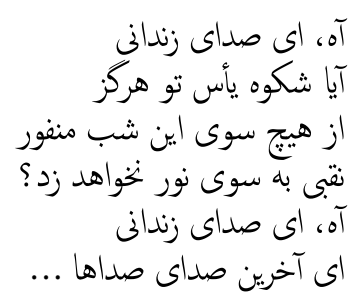

\section{Meeting at Night}

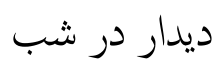

And the astounded face

From the other side of the shutter told me:

"Whoever sees is right

I cause fear, like the feeling of being lost

But, my God,

How is it possible to be afraid of me?

Of me, me

Who has never been anything

But a light vagrant kite

Above the fog-wreathed roofs of the sky

And a mouse named death

Has gnawed my love, my desire, my hate, and my pain

In the nightly exile of a cemetery"

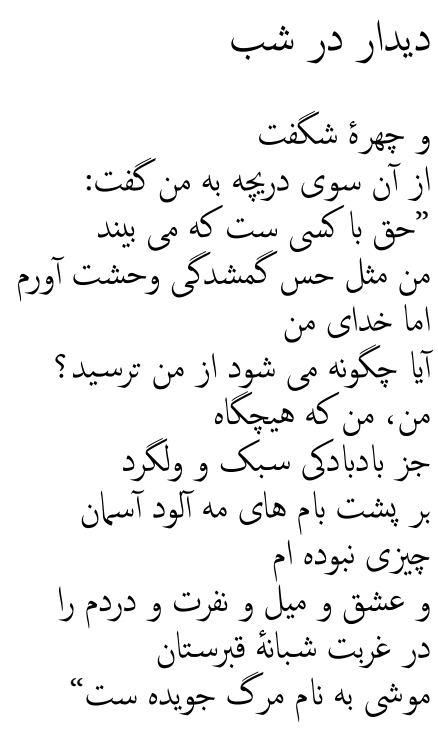

And the astounded face

With those faint protracted lines

Whose fluid traces the wind, moment by moment

Was effacing and altering

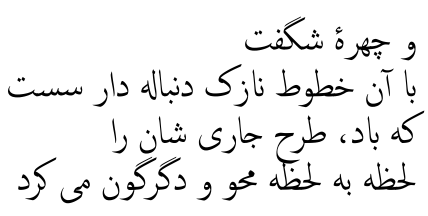


While the hidden movement of the night was stealing

Its soft, long tresses

And was spreading them all over the night's reaches

Like the plants of the seabed

Flowing on the other side of the shutter

And it shouted:

"Believe me

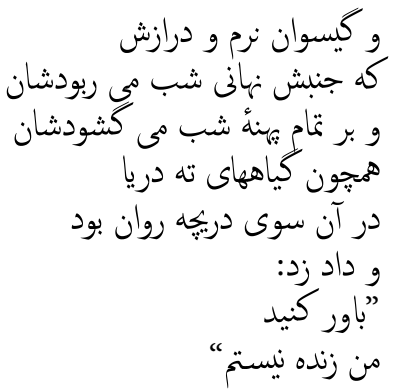

I am not alive"

Beyond s/he I could still see the congestion of darkness

And the pine's silver fruits

Ah, I could see, but s/he ...

Was slipping over them all

And his/her infinite heart was reaching its peak

As if s/he were the green feeling of the trees

And his/her eyes were extended into eternity

"You're right

I have never dared to look

Into the mirror after my death

And so dead am I,

That nothing remains to prove

My death

$\mathrm{Ah}$,

Did you hear the cricket's cry

From the far end of the garden

Which under the shelter of the night, was fleeing to the moon?

I think all the stars

Have migrated to a lost sky

And the city, how silent was the city

All along my way, I
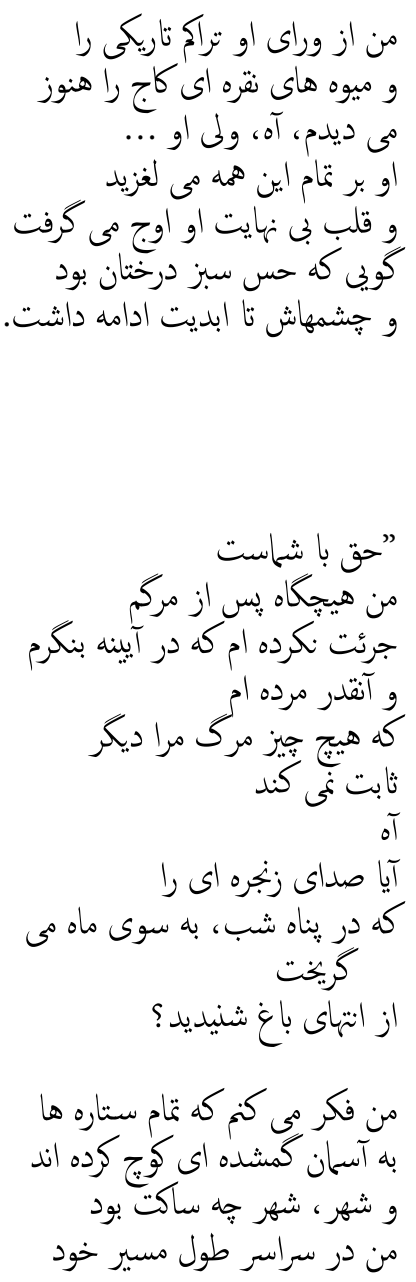
Faced nothing

But a group of pallid statues

And the exhausted sleepy patrols

And a few street sweepers

Reeking of garbage and tobacco

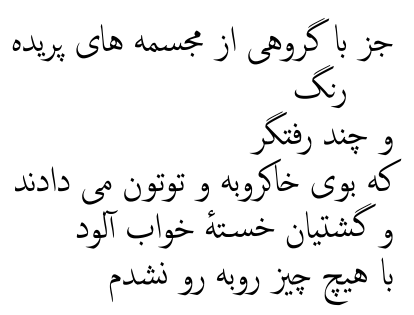

Alas

I am dead

And this night still seems to be

The extension of that same futile night"

S/he grew silent

And the vast expanse of her two eyes

Turned bitter and blurred with the sensation of tears

"O you who hide

Your face

In the shadow of life's depressing mask

Have you ever pondered

The grievous truth

That the living beings of today

Are nothing but the discarded pulps of a living one?

As if a child

In his first smile, has grown aged

And as if the heart-this damaged slate

Whose main lines have been manipulated-

Would never again trust

Its own stony validity

Perhaps addiction to existence

And the constant consumption of sedatives

Have dragged the pure and simple and human desires
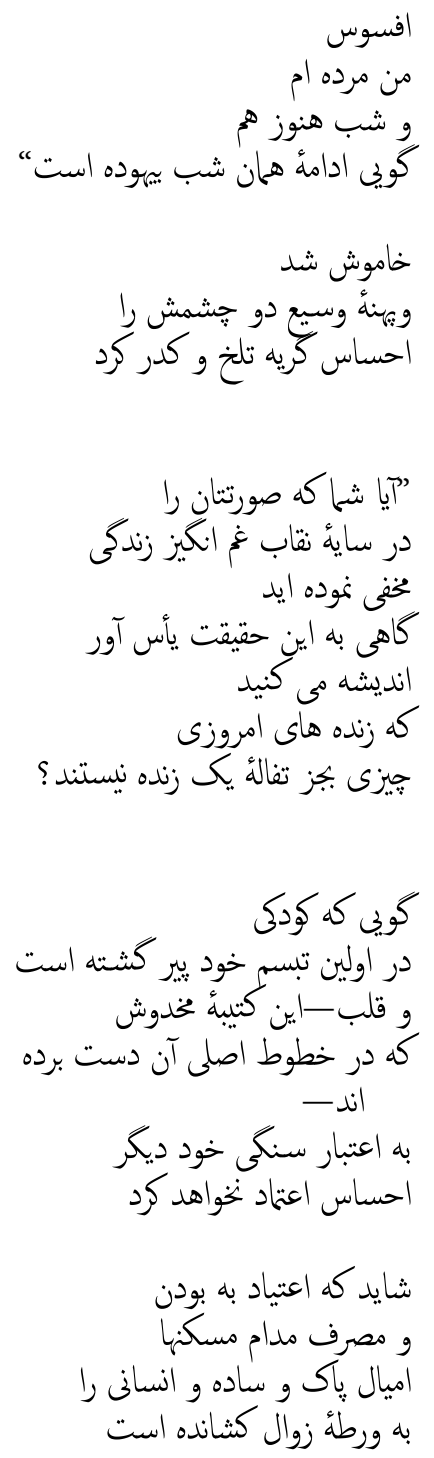
Into the abyss of decadence

Perhaps they have exiled

The soul to

The seclusion of an uninhabited islet

Perhaps I dreamt the cricket's cry

Then these infantry

Patiently leaning on their wooden spears

Are those fleet-footed cavalry?

And are these stooped, lean opium takers

Those innocent high-thinking mystics?

Then is it true, true that mankind

No longer awaits any Advent

And the girls in love

Gouged their own incredulous eyes out

With their long embroidery needles?

Now the cawing of the crows

Is felt

In the depths of morning slumber

The mirrors come to consciousness

And the isolated lonely forms

Surrender themselves

To the early trail of wakefulness

And to the secret onslaught of ominous nightmares

Alas

I, with all my memories

Of blood, which sang nothing but the blood epics

And the pride, the pride which

Never has lived such a despised life

I am standing at the edge of opportunity

And I listen: no sound

And I look: no leaf stirs

And my name which was once innocence itself
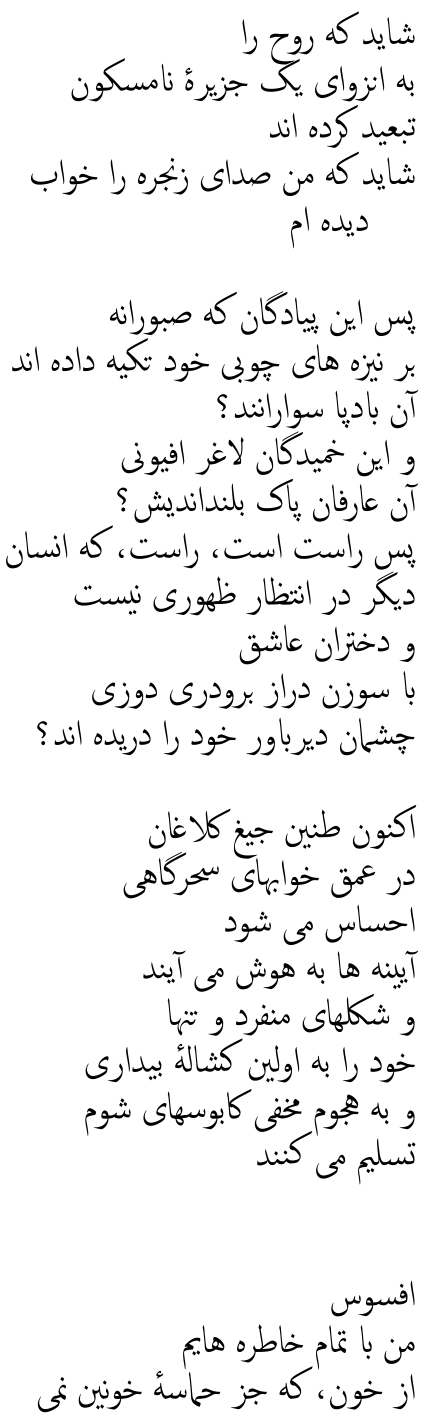

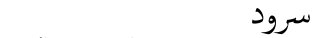
و از غرور، غرورى كه هيجگ

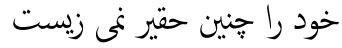

در انتهاى فرصت خود ايستاده امن إيست

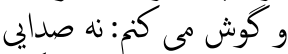

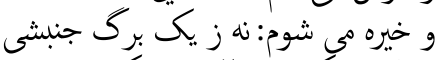
و نام من كه نفس آن همه ياكلى بود 
Now does not even stir

The dust of the graves"

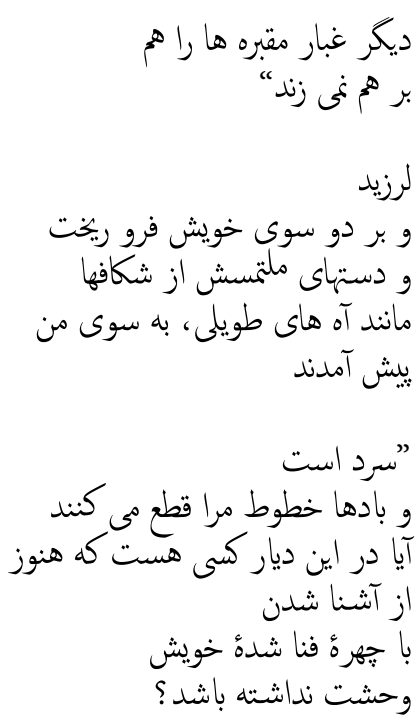

S/he trembled

And tumbled down on her both sides

And through the cracks, her begging arms

Like extended sighs

Reached out to me

"It is cold

And the winds slash through my [body border] lines

Is there anyone left in this abode

Who does not fear

Meeting

Her own annihilated face?

Hasn't the time yet come

To open this window wide wide wide

For the sky to rain down

And for man mournfully

To pray over his own corpse?"

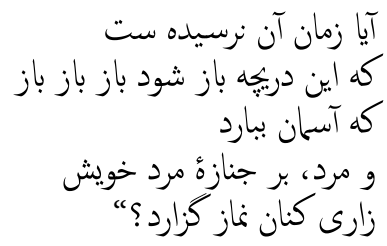

Perhaps it was the bird that moaned

Or the wind among the trees

Or was it me myself who against my heart's impasse

Was rising

Like a tide of regret, shame and pain

And through the window I could see

Those two hands, those two bitter reproaches

Still reaching out for my two hands

Were fading

In the false dawn's light

And a voice on the cold horizon

Cried out:

شايد يرنده بود كه ناليد

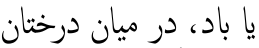

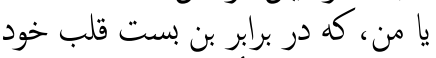

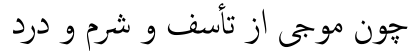

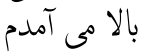

و از ميان ينجره مي ديدم آندم

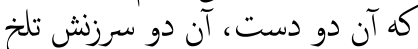

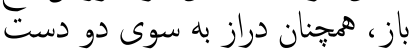
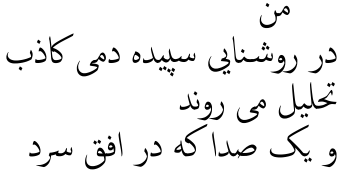

فرياد زد:

"خداحفظ"

"Farewell" 
Let Us Believe in the Beginning of the Cold Season ...

And this is me

A woman alone

On the threshold of a cold season

At the beginning of realizing the earth's sullied existence

And the simple blue despair of the sky And the impotence of these cemented hands

Time passed

Time passed and the clock chimed four times

It chimed four times

Today is the winter solstice

I know the secret of the seasons

And comprehend the language of the moments

The saviour is hibernating in the grave And the earth, the hospitable earth

Betokens serenity

Time passed and the clock chimed four times

The wind blows in the alley

The wind blows in the alley

And I think of the flowers' mating

And the buds with their slender anemic stalks

And this exhausted tuberculous time And a man passing by the soaked trees;

A man whose blue ropes of veins

Like dead snakes, have crawled up

The two sides of his throat
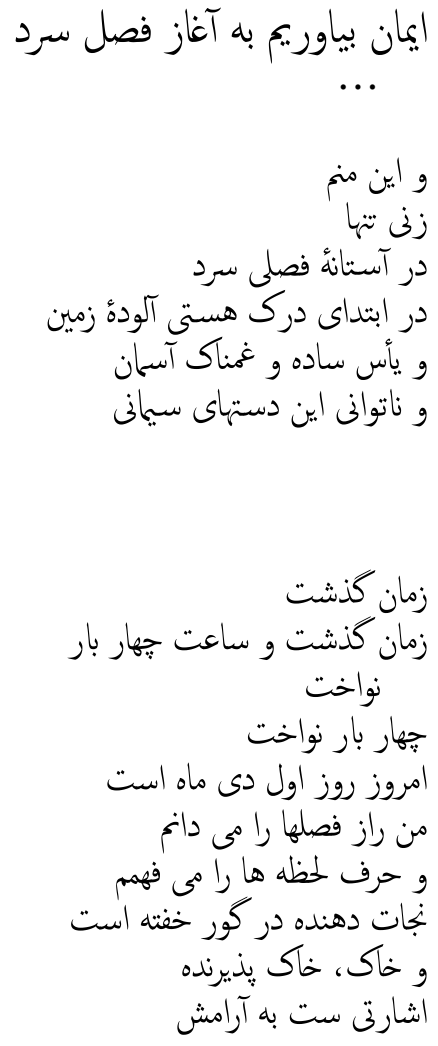

زمان كذشت و ساعت جهار بار نواخت

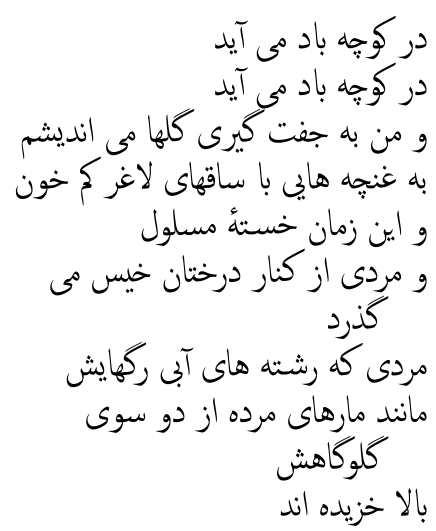


Reiterating in his throbbing temples

Those bloody syllables

-Hello

-Hello

And I think of the flowers' mating

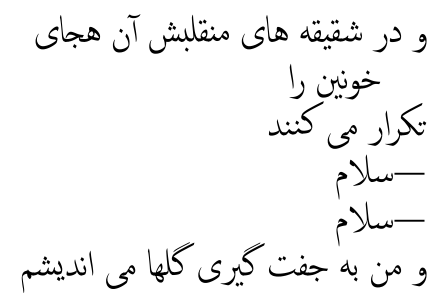

On the threshold of a cold season

In the mourning congregation of mirrors

And in the dirgeful assembly of pale experiences

And this sunset impregnated with the knowledge of silence

How can one command someone proceeding so

Patiently,

Solemnly,

Aimlessly,

To halt

How can one tell the man that he is not alive, that he has never been alive

The wind blows in the alley

The lonely crows of seclusion

Whirl around in the ancient gardens of boredom

And the ladder

Was of such a low height

They carried off the entire credulity of a heart

To the palace of fairytales

And now

How can one rise to dance ever again

And pour her childhood tresses

Into the flowing streams
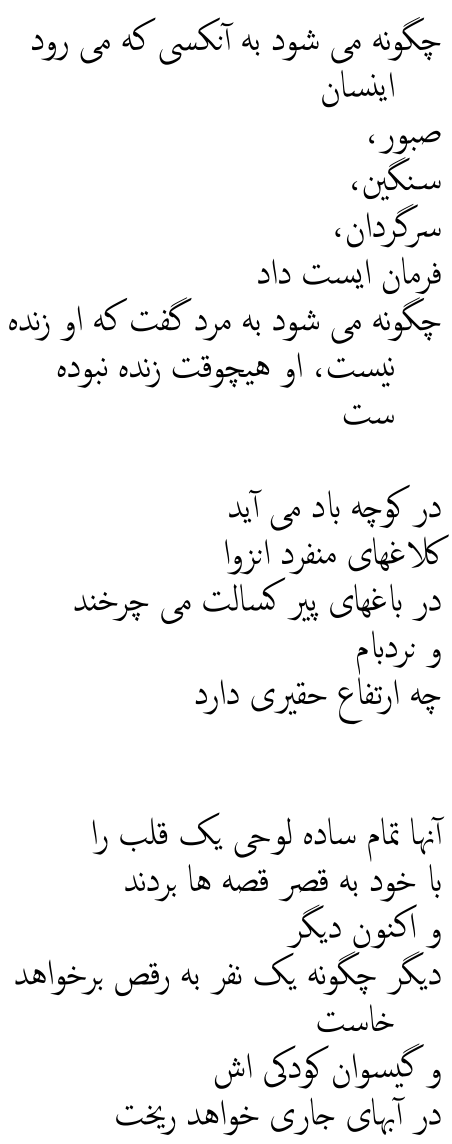
And trample the apple

She has eventually picked and smelled?

$\mathrm{O}$ friend, $\mathrm{O}$ most unique friend

Such black clouds await the sun's festival day

It was as if in the course of imagining the flight, that one day that bird appeared

As if those fresh leaves panting in the lust of breeze

Were of verdant lines of delusion

As if

That violet flame burning in the chaste mind of windows

Was nothing but the innocent illusion of the lamp

The wind blows in the alley

This is the onset of ruination

That day, too, when your hands were ruined the wind was blowing

Dear stars

Dear cardboard stars

When lies begin blowing in the sky

How can one take refuge any more in the verses of the abashed prophets?

We will meet each other like the dead of thousands and thousands years and then

The sun will judge the putrescence of our corpses

I am cold

I am so cold as never to be warm again

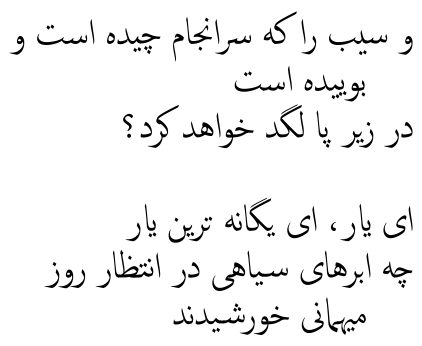

$$
\begin{aligned}
& \text { انكار در مسيرى از تجسم يرواز بود، } \\
& \text { كه يكروز آن يرنده نمايان شيد شئد }
\end{aligned}
$$

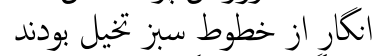

$$
\begin{aligned}
& \text { آن بركهاى تازه، كه در شهوت نسيم بندي } \\
& \text { نفس مى زدند }
\end{aligned}
$$

آن شعلةُ بنفش كه در ذهن هاك هِ ينجره

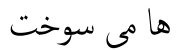

جيزى بجز تصور معصومى از جراغ نبود
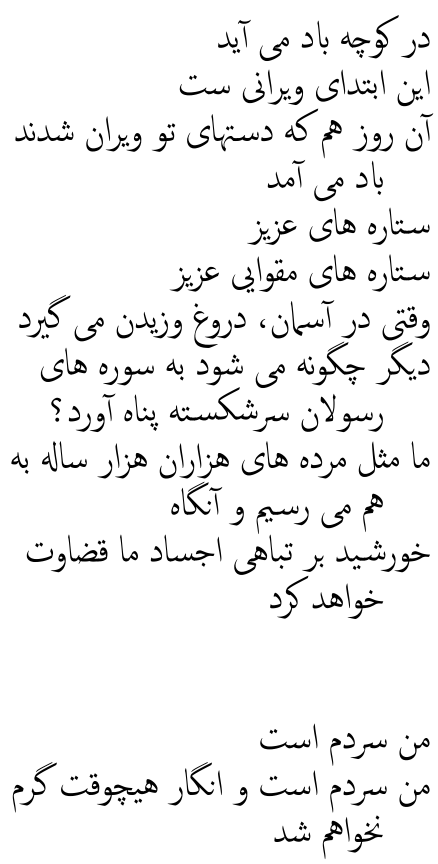
O friend, O most unique friend "How old was that wine anyway?"

Look what a weight

Time has here

And how the fish gnaw my flesh

Why do you always keep me at the bottom of the sea?

I am cold and I despise shell earrings

I am cold and I know

That nothing will remain

From all the red delusions of wild poppy

But a few drops of blood

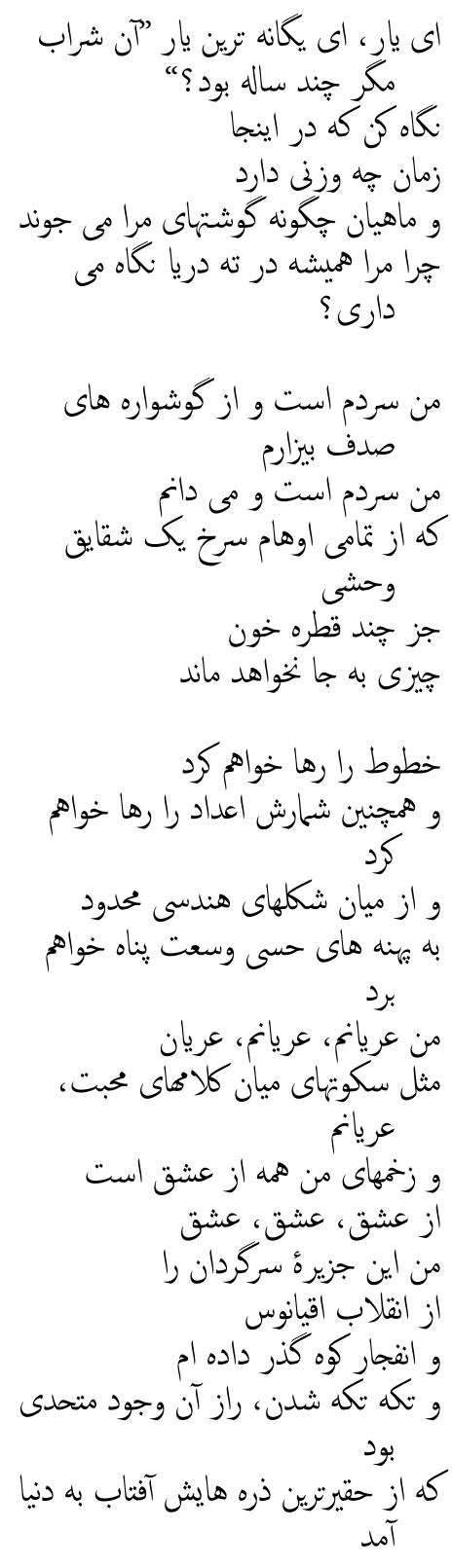

I will let go of the lines

I will let go of the counting of numbers likewise

And from the midst of limited geometric shapes

I shall seek refuge in the tangible spaces of vastness

I am naked, naked, naked

Naked as the silences between the words of love

And my wounds are all from love

From love, love, love

I have piloted this wandering island

Through the tumults of the ocean,

Through the eruption of the volcano,

And disintegration was the secret of that unified existence

From whose most humble particles a sun was born

Greetings $\mathrm{O}$ innocent night!

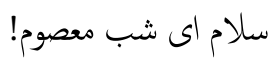


Greetings $\mathrm{O}$ night that changes the eyes of desert wolves

Into bony sockets of faith and trust

And by the side of your streams, the ghosts of willows

Scent the kind ghosts of the axes

I come from a world of apathetic thoughts, words and voices

And this world resembles a snake's lair

And this world resounds with the footsteps of people

Who, while they kiss you,

In their minds they weave your gallows' rope

Greetings $\mathrm{O}$ innocent night!

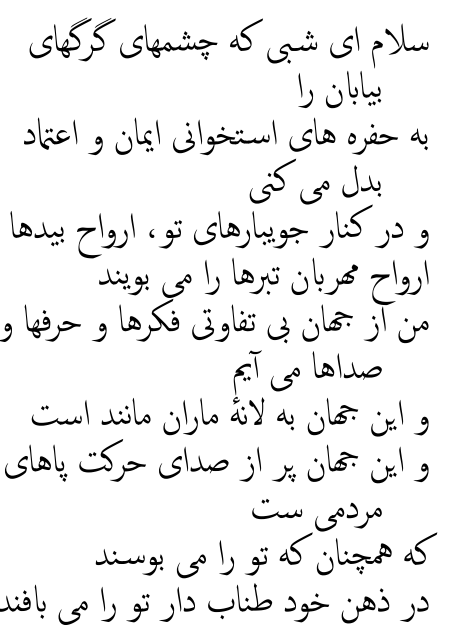

Between the window and the seeing

There always lies a distance

Why did I not look?

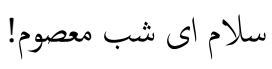

Like the time a man passed by the soaked trees ...

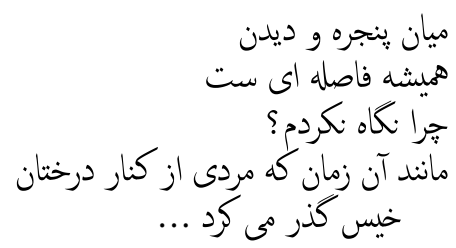

Why did I not look?

As if my mother had wept that night

The night I arrived to pain and the seed was conceived

The night I became the bride of acacia clusters

The night Isfahan abounded with the echoes of blue tiles,

And the one who was my half, had returned within my seed

And I could see her/him in the mirror,

Who was clean and bright like the mirror And suddenly s/he called me

And I became the bride of acacia clusters

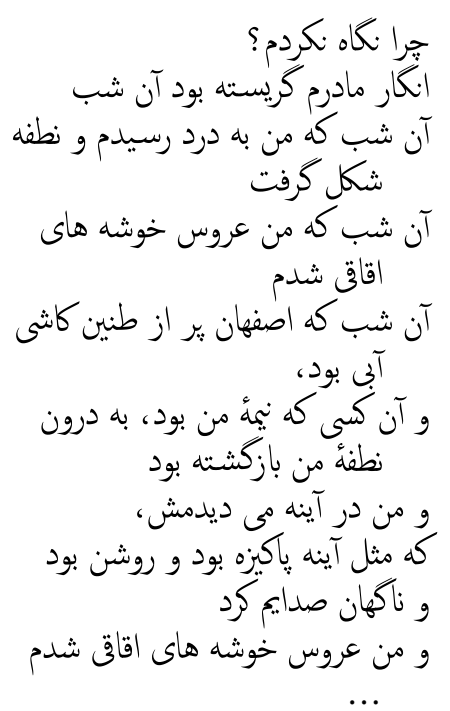


As if my mother had wept that night

$$
\text { انكار مادرم كريسته بود آن شب }
$$

What a futile brilliance glared in this

blocked shutter

Why did I not look?

All the moments of bliss were aware

That your hands would be ruined

And I did not look

Not until the time when the clock's shutters flew open

And that sad canary chimed four times

Chimed four times

And I ran into that little woman

Whose eyes were like simurghs' empty nests

And walking in the motion of her thighs

As if carrying the virginity of my glorious dream

Into the bed of night

Will I ever again comb

My tresses in the wind?

Will I ever again plant violets in the gardens?

And set geraniums

Under the sky behind the window?

Will I ever again dance on the glasses?

Will the doorbell ever again carry me towards the anticipation of voice?

I told my mother: "It is all over now"

I said: "It always happens before you think

We should send the newspaper an obituary"

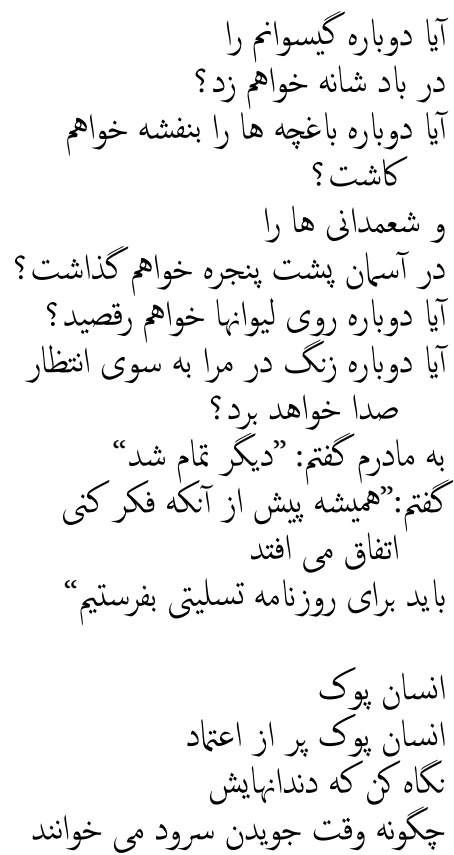

Hollow man

Hollow man full of vanity

Look how his teeth sing a song

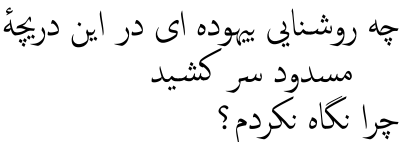

تمام لحظه هاى سعادت مي دانستيند

كه دستهاى تو ويران خواهد شئ داند

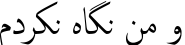

كا آن زمان كه ينجره: ساعت

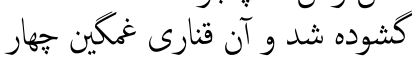

بار نواخت

جهار بار نواخت

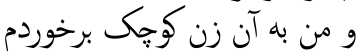

كه جشمهايش، مانند لانه هاى خآ خلى

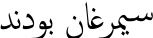

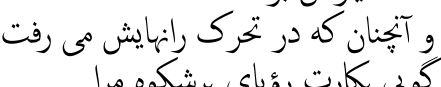

با خود به سوى بستر شب مى برد برد

While chewing 
And his eyes devour

While staring

And how he is passing by the soaked trees:

Patiently,

Solemnly,

Aimlessly

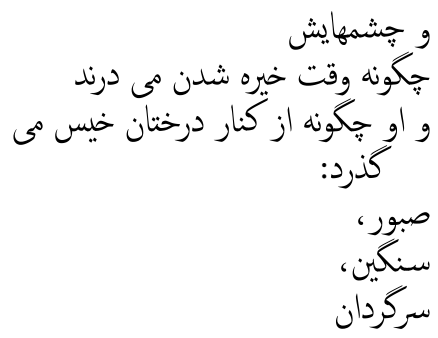

At the hour of four

At the moment when his blue ropes of veins

Like dead snakes, have crawled up

Both sides of his throat

Reiterating in his throbbing temples

Those bloody syllables

-Hello

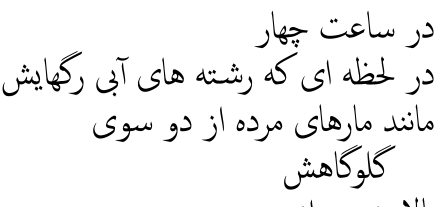

بالا خزيده اند

و در شقيقه هاى منقلبش آن هجاى ناى

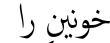

تكرار مى كنين

-Hello

Have you

Ever smelled

Those four water lilies? ...

Time passed

Time passed and night fell upon the bare acacia branches

Night was sliding behind the window panes

And with its cold tongue

Was sucking in the dregs of the past day

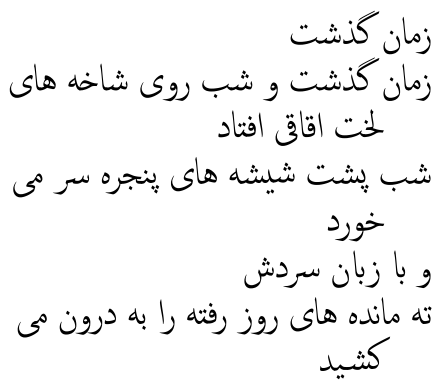

Where do I come from?

Where do I come from?

So fused with the night's scent?

The earth of his grave is still fresh

I speak of those two young green hands ...

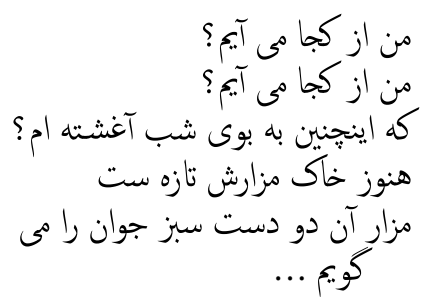


How kind you were, $\mathrm{O}$ friend, $\mathrm{O}$ most unique friend

How kind you were when you lied

How kind you were when you closed the mirror's eyelids

And plucked the lights of the chandelier

Off wire stems

And in the tyrannical darkness you took me to love's pasture

Until that giddy steam, which was the extension of thirst's fire, settles on the meadow of sleep

And those cardboard stars

Orbiting round the infinity

Why did they voice the words?

Why did they invite looks into the house of the eye?

Why did they take the caressing

To the coyness of virginity's tresses?

Look how here

The soul of the one who spoke in words And caressed with looks

And was tamed from stampeding with caresses

Has been crucified

On the poles of illusion

And the imprint of the five branches of your fingers

Which were like the five letters of truth

Remains upon his/her cheek

What is silence, what is it, what is it, $\mathrm{O}$ most unique friend?

What is silence but unspoken words

I turn speechless, but the sparrow's language
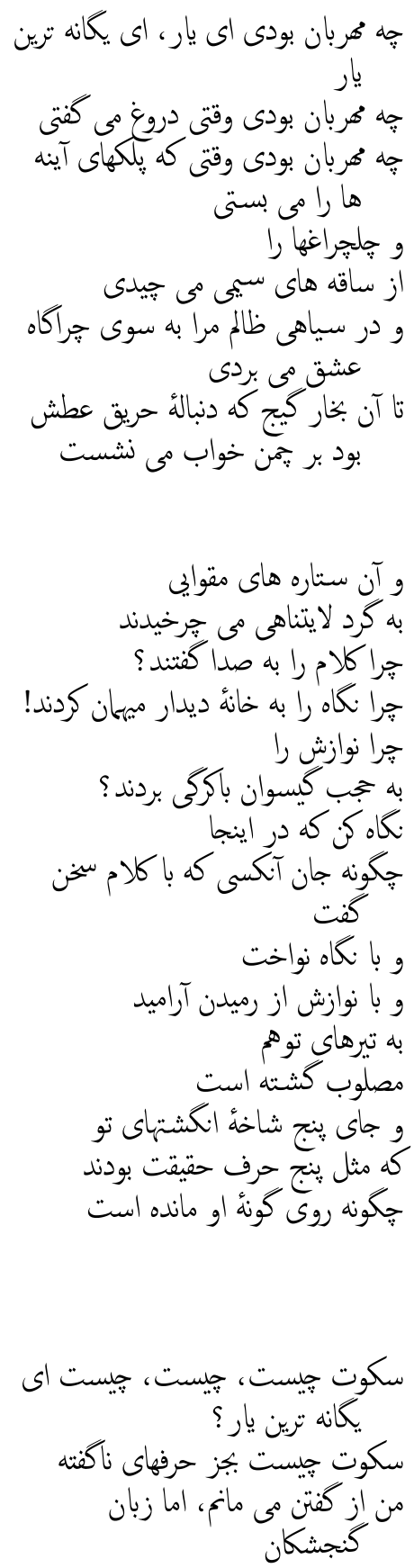
Is the language of life in the flowing sentences of nature's feast

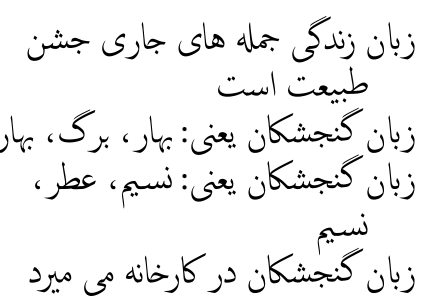

The sparrow's language means: spring, leaf, spring

The sparrow's language means: breeze, fragrance, breeze

The sparrow's language dies in factories

Who is this, this person on eternity's road

Moving towards the moment of unity

And winding her eternal watch

With the mathematical logic of subtractions and dissipations

Who is this person who does not regard the rooster's crowing

To be the start of the day's heart

But rather the beginning of breakfast's smell

Who is this person who wears love's crown upon her head

And has rotted amidst her wedding gown

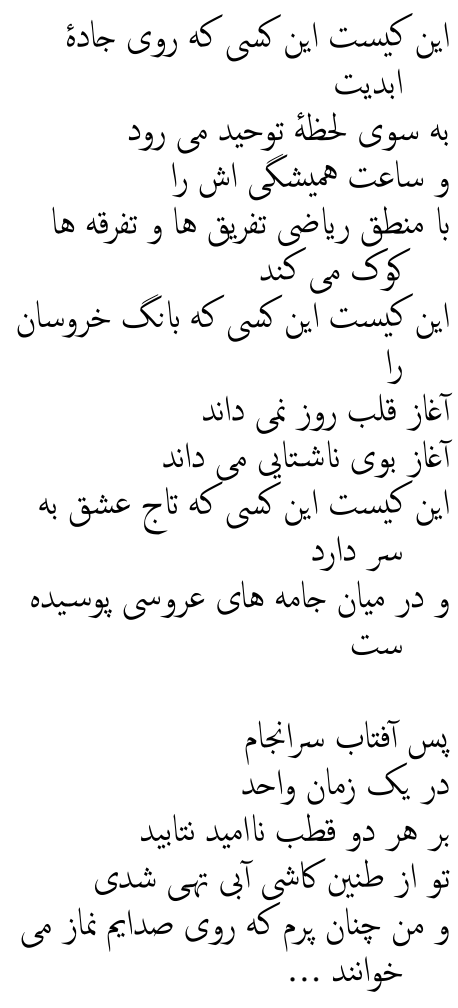

So in the end the sun did not shine

On both hopeless poles

In one single instant

And you were emptied of the blue tile's echo

And I am so full of it that they recite prayers over my voice...

Happy corpses

Weary corpses

Silent pensive corpses

Well-mannered, well-dressed and well-fed corpses

In the stations of scheduled times

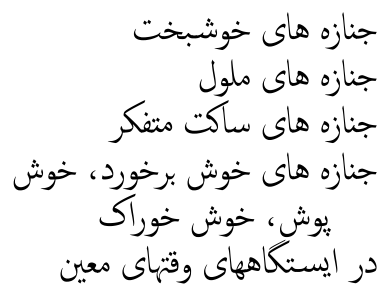


And in the dubious backdrop of temporary lights

And the lust for buying futility's rotten fruits ...

Ah,

How many people at intersections worry about accidents

And this sound of whistles to stop at the very instant when

A man must, must, must

Be crushed beneath the wheels of time

A man passing by the soaked trees ...

Where do I come from?

I told my mother: "It is all over now"

I said: "It always happens before you think

We should send the newspaper an obituary"

Greetings $\mathrm{O}$ queerness of loneliness

I surrender the room to you

For the dark clouds are always

The prophets of fresh verses (signs) of purification

And in a candle's martyrdom

There lies an incandescent secret

Which the last and the tallest flame knows well

Let us believe

Let us believe in the beginning of the cold season

Let us believe in the ruins of imagination's gardens

In the idle overturned scythes

And the incarcerated seeds
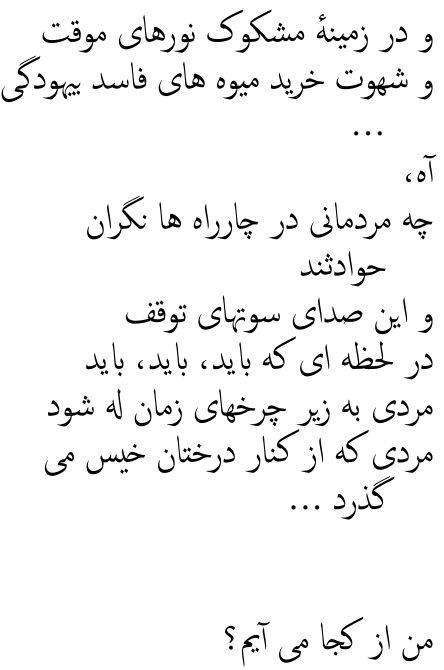

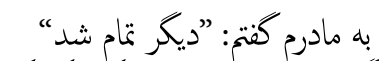

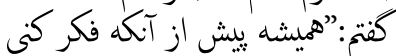
اتفاق مي افتد بايد براى روزنامه تسليتى بفرستيم." افند

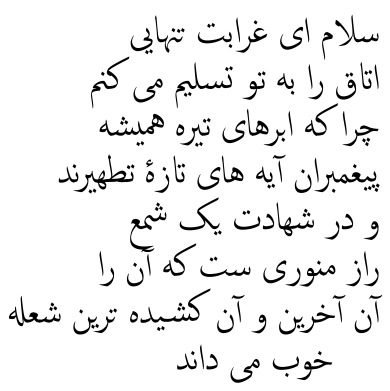

Look how it is snowing ... 
Perhaps the truth was those two young hands, those two young hands

Buried beneath the incessant falling of snow

And the next year, when spring

Mates with the sky behind the window

And within its body burst forth

Green fountains of lightweight stems

They will blossom $\mathrm{O}$ friend, $\mathrm{O}$ most unique friend

Let us believe in the beginning of the cold season ...

\section{Window}

One window for seeing

One window for hearing

One window that like the shaft of a well

Reaches in its depths to the heart of the earth

And opens towards the expanse of this blue recurring kindness

One window overflowing

The little hands of solitude

With the nocturnal generosity of the bountiful stars' perfume

And thence one can invite the sun

To the exile of geraniums

One window is enough for me

I come from the land of dolls

From beneath the shadows of paper trees

In the garden of a picture book

From the arid seasons of the barren experiences of friendship and love

In the dusty alleys of innocence

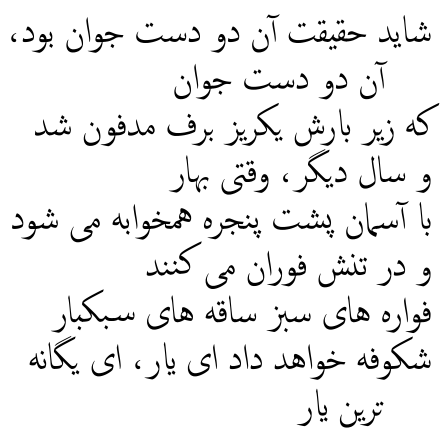

ايمان بياوريم به آغاز فصل سرد ... - م
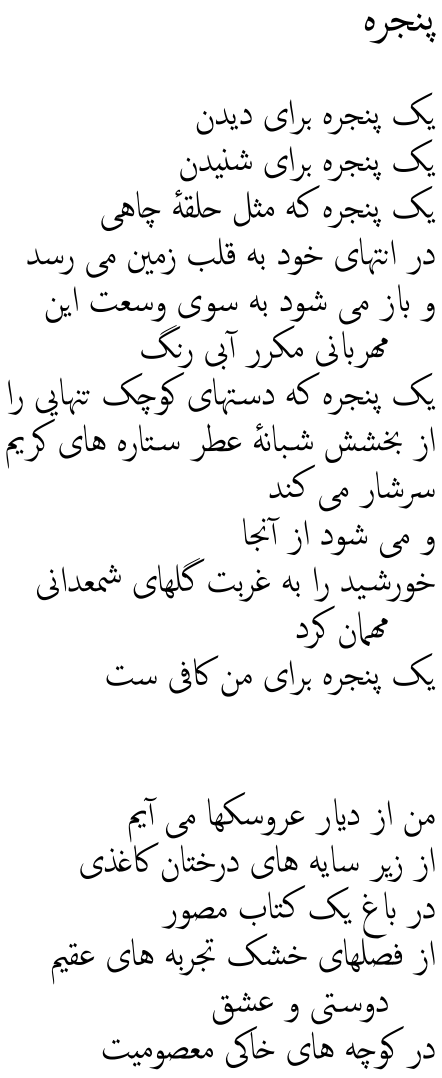
From the growing years of the pallid letters of the alphabet

Behind the desks of tubercular school

From the moment the children could write The word "stone" on the board

And the startled starlings flew off the ancient tree

I come from among the roots of carnivorous plants

And my brain is still brimming

With the terrified cry of a butterfly

Crucified

With a pin to a notebook

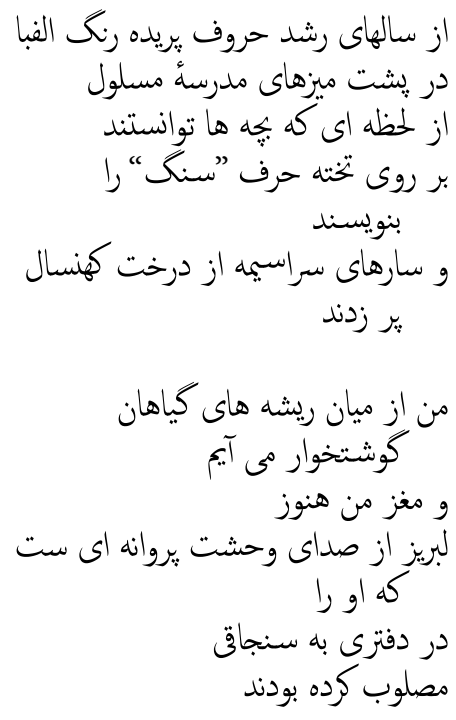

When my trust was hanging from the slack rope of justice

And through the entire city

They were tearing my lamp's heart into shreds

When they were blindfolding my love's childish eyes

With the dark kerchief of law

And from the agitated temples of my desire

The blood jets were spurting out

When my life was nothing any longer

Nothing but the tick tock of a wall clock

I realized that I must, I must, I must

Love madly

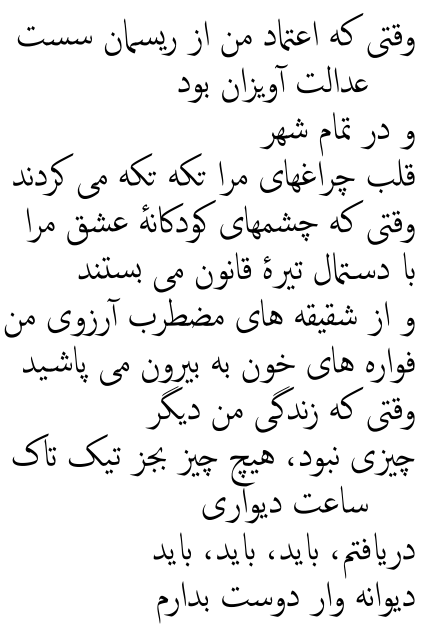

One window is enough for me,

One window into the moment of consciousness, seeing, and silence

Now the walnut sapling has grown tall enough

To define

The meaning of wall to its young leaves

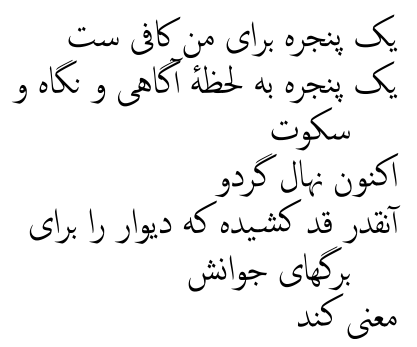


Ask the mirror

The name of your saviour

Isn't the earth trembling beneath your feet

Lonelier than you?

The prophets brought with them into our century

The mission of destruction

Are these constant explosions

And poisonous clouds,

The echoes of Holy Scriptures?

$\mathrm{O}$ friend, O brother, O blood fellow

When you reach the moon

Inscribe the date of the flowers' massacre

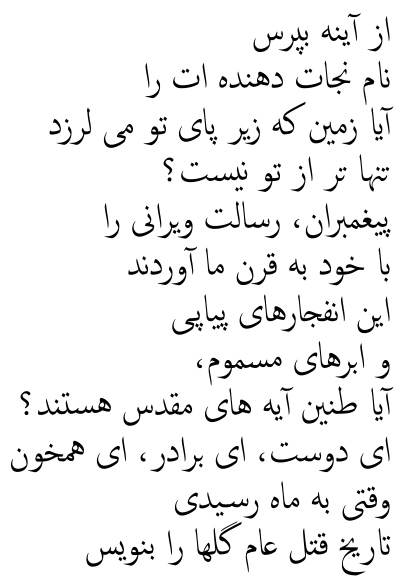

Dreams always fall

From the heights of their naïveté and die

I smell a four-leaf clover

Sprouting upon the grave of archaic concepts

Was the woman who mouldered to dust in the shroud of her expectation and chastity my youth?

Will I ever again climb the stairs of my curiosity

To greet the good God pacing on my roof?

I sense that time has passed

I sense that from the leaves of history "the moment" is my share

I sense that the table is a false distance between my tresses and this sorrowful stranger's hands

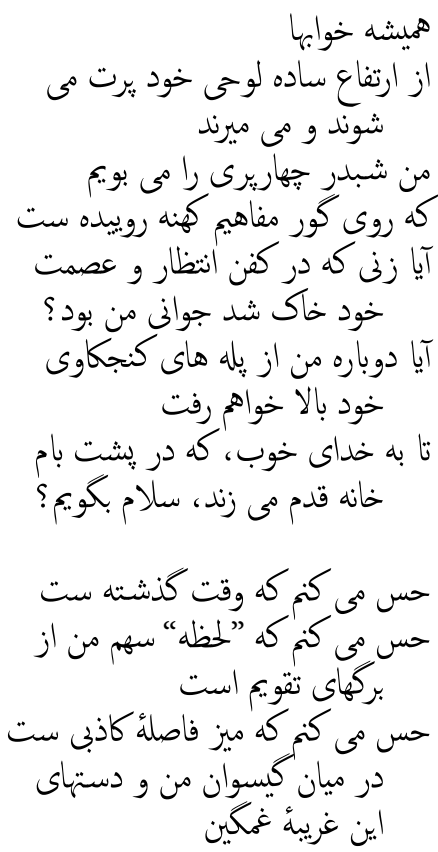

Say something to me

What does the one offering you a living body's kindness want in return

Other than the sensation of being alive?

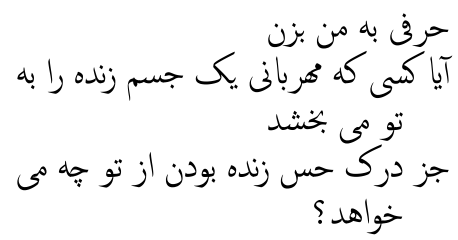


300 Mirrors of Entrapment and Emancipation

Say something to me

I am in the window's shelter

I have relation with the sun

حرفى به من بزن

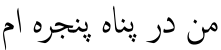

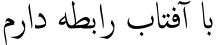




\section{Notes}

\section{Introduction}

1 Jonathan Miller, On Reflection (London: National Gallery Publications Limited, 1998), 142.

2 Marie-Madeleine Martinet in her Le Miroir de l'esprit dans le théâtre élisabéthain discusses how the terms "mirror," "glass" and "looking glass" have not always been used equivalently. In the Renaissance, the term "mirror" was used to convey a more metaphorical and symbolic meaning, while "glass" was used to convey a purely material sense. This distinction gradually vanishes, and today these terms can be used interchangeably. See: Arnaud Maillet, The Claude Glass: Use and Meaning of the Black Mirror in Western Art, trans. Jeff Fort (New York: Zone Books, 2004), 31.

3 J.E. Cirlot, A Dictionary of Symbols, trans. Jack Sage (London: Routledge and Kegan Paul, 1962), 201-202. For an introductory study of the mirror and its historio-cultural background see: Mark Pendergrast, Mirror|Mirror: A History of the Human Love Affair with Reflection (New York: Basic Books, 2004); Benjamin Goldberg, The Mirror and Man (Charlottesville: University Press of Virginia, 1985); Sabine Melchior-Bonnet, The Mirror: A History, trans. Katharine H. Jewett (New York: Routledge, 2001); and Jurgis Baltrušaitis, Der Spiegel: Entdeckungen, Täuschungen, Phantasien (Giessen: Anabas-Verlag, 1986).

4 See: Jenijoy La Belle, Herself Beheld: The Literature of the Looking Glass (Ithaca: Cornell University Press, 1988), 14. La Belle's work is a study of women's mirror confrontation in the novels, poems and short stories of British and American authors within the last two hundred years. For a study of the mirror motif in Victorian women's poetry see: Penny Paparunas, "Trouble with the I/Eye: Mirrors in Victorian Women Poetry," Präsenz ohne Substanz: Beiträge zur Symbolik des Spiegels, ed. Paul Michel (Zürich: Pano Verlag, 2003), 213-250; and for a study of the mirror motif 
in German literature focusing on the nineteenth and twentieth centuries see: Heide Witthöft, Von Angesicht zu Angesicht. Literarische Spiegelszenen (New York: Peter Lang, 1998).

5 Diana Tietjens Meyers, Gender in the Mirror: Cultural Imagery and Women's Agency (Oxford and New York: Oxford University Press, 2002), i and 25 .

6 Ibid., 100.

7 Julia Kristeva, Black Sun: Depression and Melancholia, trans. Leon S. Roudiez (New York: Columbia University Press, 1989), 74.

8 Meyers, Gender in the Mirror, 100.

9 Aptly, the French word for a boudoir mirror or the cheval glass is psyché.

10 Laura Gutiérrez Spencer, "Mirrors and Masks: Female Subjectivity in Chicana Poetry," Frontiers: A Journal of Women Studies, vol. 15, no. 2 (1994), 70.

11 Elaine Showalter, The Female Malady: Women, Madness, and the English Culture, 1830-1980 (New York: Pantheon Books, 1985), 212.

12 Kristeva, Black Sun, 74.

13 Meyers, Gender in the Mirror, i and 101.

14 Karla Schultz, "In Defense of Narcissus: Lou Andreas-Salomé and Julia Kristeva," The German Quarterly, vol. 67, no. 2 (Spring 1944): 193.

15 By English literature, I mean the literature written world-wide in the English language.

\section{Chapter One}

1 Ovid, Metamorphoses, trans. A.D. Melville (Oxford and New York: Oxford University Press, 1986), 61: 350.

2 The ancient Greek aphorism "Know yourself!" was inscribed along with "Nothing to excess!" in the pronaos of Apollo's temple at Delphi. These two aphorisms are believed by many scholars of antiquity to summarize the whole of Greek thought and culture.

3 Ovid [Melville], Metamorphoses, 62: 357.

4 Ibid., 62: 358-374.

5 Ibid., 62: 382-384.

6 Ibid., 63: 398-399.

7 Ibid., 63: 418 .

8 Ibid., 64: 432 . 
9 Though the closer translation from Ovid's Latin "Iste ego sum" would be "I am that," giving neutrality to the image, Melville has chosen to translate it as "I am he." Ibid., 64: 463. By choosing the neutral inhuman "that" for his mirror image, the image's difference in the material, its insubstantiality versus the substantiality of the subject in front of it, as well as a sense of alienation towards the image as the Other has been discerned. For a discussion of the "untranslatability" of the "Iste ego sum" into English see: A.D. Nuttall, “Ovid's Narcissus and Shakespeare's Richard II: the Reflected Self," Ovid Renewed: Ovidian Influences on Literature and Art from the Middle Ages to the Twentieth Century, ed. Charles Martindale (New York: Cambridge University Press, 1990), 143-144.

10 Ovid [Melville], Metamorphoses, 64-65: 463-465.

11 Ibid., 65: 496, 500 and 66: 501, 502.

12 Ibid., 66: 510.

13 Gayatri Chakravorty Spivak, "Echo," New Literary History, vol. 24, no. 1 (Winter 1993): 27. Simone de Beauvoir, The Second Sex, trans. H.M. Parshley (New York: Vintage Books, 1989). De Beauvoir juxtaposes women's immanence with its constraints, immobility, passivity, and objectness against men's transcendence with its freedom, activity, and indefinability. De Beauvoir explains "Every time transcendence falls back into immanence, stagnation, there is a degradation of existence into the 'en-soi' [being-in-itself] — the brutish life of subjection to given conditions-and of liberty into constraint and contingence." (xxxv)

14 Among others see: Charles Theodore Seltman, Women in Antiquity (New York: Thames and Hudson, 1956); Helene P. Foley (Ed.), Reflections of Women in Antiquity (New York: Gordon and Breach Science Publishers, 1981); Charles Anthon, A Manual of Grecian Antiquities (New York: Harper and Brothers, 1852); Richard Hawley and Barbara Levick (Eds.), Women in Antiquity: New Assessments (London and New York: Routledge, 1995); Elaine Fantham, Helene Peet Foley, Natalie Boymel Kampen, Sarah B. Pomeroy and H. Alan Shapiro, Women in the Classical World: Image and Text (Oxford and New York: Oxford University Press, 1994).

15 Elizabeth Grosz, Jacques Lacan: A Feminist Introduction (London and New York: Routledge, 1990), 37.

16 Nuttall, “Ovid's Narcissus," 142.

17 Ovid [Melville], Metamorphoses, 65: 474.

18 Ovid, Metamorphoses, ed. Hugo Magnus, Book 3: 430, accessed on April o8, 2014, http://www.perseus.tufts.edu/hopper/text?doc=Perseus\%3Atext 
\%3A1999.02.0029\%3Abook\%3D3\%3Acard\%3D337; Cf. Ovid [Melville], Metamorphoses, 64: 434.

19 Julia Kristeva, Tales of Love, trans. Leon Roudiez (New York: Columbia University Press, 1987), 104.

20 Ibid.

21 Meyers, Gender in the Mirror, 106.

22 Spivak, "Echo," 37. Juliet Mitchell, Psychoanalysis and Feminism (Harmondsworth: Penguin Books, 1974), 39.

23 Ibid., 19 and 23 [my emphasis]. Aporia, a recurrent term in the works of Jacques Derrida and Deconstructuralists, is derived from classical rhetoric, meaning "perplexity," "doubt" and "difficulty." Aporia refers to moments in a text when the knowledge enters a crisis, the meaning becomes ambiguous or contradictory and the reader faces a dilemma.

24 Ibid., 34.

25 André Green, Narcissisme de vie, narcissisme de mort (Paris: Editions de Minuit, 1983), 127. Cf. Spivak, "Echo," 34.

26 Juliet Mitchell, Women, The Longest Revolution: on Feminism, Literature and Psychoanalysis (New York: Pantheon, 1984), 109.

27 Kristeva, Tales of Love, 30.

28 Ibid., 116 (Kristeva's emphasis).

29 Lou Andreas-Salomé, “The Dual Orientation of Narcissism," trans. Stanley A. Leavy, The Psychoanalytic Quarterly, vol. 31 (1962): 7 and 8. This is a translation from the German original: Lou Andreas-Salomé, "Narzissmus als Doppelrichtung," Imago, vol. 7 (1921).

30 Schultz, "In Defense of Narcissus," 193 and 196, note 26.

31 Ibid., 192.

32 For a succinct study of this switch in the concept of narcissism from a male trait to a feminine vice and the rigidification of heterosexual norms see: Meyers, Gender in the Mirror, 100-106.

33 See: Annemarie Schimmel, A Two-Colored Brocade: The Imagery of Persian Poetry (Chapel Hill and London: The University of North Carolina Press, 1992), 41-42, 162, 164-166.

34 "من عرف نقسه عرف ربه 34 . This saying has been frequently referred to in the Sufi literature. For a discussion of the saying see: Abū Hāmid Al-Ghazāli, The Alchemy of Happiness, trans. Claud Field (Charleston, South Carolina: Forgotten Books, 2008), 11-28.

35 Bram Dijkstra, Idols of Perversity: Fantasies of Feminine Evil in Fin-DeSiècle Culture (New York and London: Oxford University Press, 1986), 138. 
36 While some sources say that she was raped by him, others hold that she dallied with Poseidon of her own volition.

37 Sigmund Freud, "Medusa's Head," The Standard Edition of the Complete Psychological Works of Sigmund Freud, ed. and trans. James Strachey (London: Hogarth, 1953-1974), vol. 18, 273-274.

38 Neil Hertz, "Medusa's Head: Male Hysteria under Political Pressure," The End of the Line: Essays on Psychoanalysis and the Sublime (New York: Columbia University Press, 1985), 161.

39 Hélèn Cixous, “The Laugh of the Medusa," trans. Keith Cohen and Paula Cohen, Signs, vol. 1, no. 4 (Summer, 1976), 885.

40 See: Coluccio Salutati, "On the Labors of Hercules," trans. Lesly Lundeen, The Medusa Reader, eds. Marjorie Garber and Nancy J. Vickers (New York and London: Routledge, 2003), 54-56. There it is mentioned that, "Part of Medusa's effect is dazzling artful speech, striking the listener dumb." (54). For a discussion of the association of Medusa with artful eloquence see: Nancy Vickers, “'The Blazon of Sweet Beauty's Best': Shakespeare's Lucrece," Shakespeare and the Question of Theory, eds. Patricia Parker and Geoffrey Hartman (New York: Methuen, 1985): 95-115. Patricia Klindienst Joplin in her essay, "The Voice of the Shuttle Is Ours," argues that “... Medusa has become a central figure for the woman artist to struggle with ... because, herself a silenced woman, she has been used to silence other women." The Medusa Reader, 202.

41 Paparunas, "Trouble with the I/Eye," 224-225.

42 Some feminists, particularly in film theories, have argued that the gaze is ultimately always masculine while the image remains feminine. Elizabeth Grosz exhorts us not to mistake the look - "a perceptual mode"-with the "gaze"- "a mode of desire": "When they [some feminists] state baldly that "vision" is male, the look is masculine, or the visual is a phallocentric mode of perception, these feminists confuse a perceptual facility open to both sexes ... with sexually coded positions of desire within visual (or any other perceptual) functions ... vision is not, cannot be, masculine ... rather, certain ways of using vision (for example, to objectify) may confirm and help produce patriarchal power relations." Elizabeth Grosz, "Voyeurism, Exhibitionism, the Gaze," Feminism and Psychoanalysis: A Critical Dictionary, ed. Elizabeth Wright (Oxford: Blackwell, 1992), 449.

43 Meyers, Gender in the Mirror, 115.

44 Havelock Ellis, "Auto-eroticism: A Psychological Study", Alienist and Neurologist, 19 (1898), cited in Robert Raskin and Howard Terry, "A PrincipalComponents Analysis of the Narcissistic Personality Inventory and Fur- 
ther Evidence of Its Construct Validity," Journal of Personality and Social Psychology, vol. 54, no. 5 (1988), 890.

45 Paul Näcke, "Die sexuellen Perversitäten in der Irrenanstalt," Wiener klinische Rundschau, 1899, no. 27-30 [Translation mine]. Cf. with the original: "schwerste Form des Autoerotismus."

46 On the historical development of the concept of Narcissism see: Havelock Ellis, “The Conception of Narcissism," Psychoanalytic Review, 14 (1924): 129-153; also reprinted in Studies in Psychology of Sex, no. VII (Philadelphia: F.A. Davis, 1928): 346-375.

47 Freud, "On Narcissism: An Introduction," The Standard Edition, vol. XIV (1914-1916), 73-74. For the original paper see: Sigmund Freud, "Zur Einführung des Narzissmus" Gesammelte Werke, vol. X (Frankfurt am Main: S. Fischer Verlag, 1946), 137-170.

48 See: Freud, “On Narcissism," 76.

49 Ibid., 75 .

50 Ibid., 88-89.

51 Ibid., 91.

52 Mitchell, Women, The Longest Revolution, 113.

53 Grosz, Jacques Lacan, 128.

54 By the French poet, Jean Nicolas Arthur Rimbaud, in his letter to Paul Demeny May 15, 1871; quoted in Jacques Lacan, "Aggressiveness in Psychoanalysis," Écrits: The First Complete Edition in English, trans. Bruce Fink (New York and London: W.W. Norton \& Company, 2006), 96.

55 The first version of Lacan's paper in 1949 was entitled "Le stade du miroir comme formateur de la fonction du Je." It was initially translated into English by Alan Sheridan under the title, "The Mirror Stage as Formative of the Function of the I As Revealed in Psychoanalytic Experience," Ecrits: A Selection, trans. Alan Sheridan (London: Tavistock Publications, 1977): 1-8. It was also translated by Bruce Fink as, "The Mirror Stage as Formative of the I Function as Revealed in Psychoanalytic Experience," Ecrits: The First Complete Edition in English, 75-81; all my references are to Fink's translation.

Raymond Tallis, Not Saussure: A Critique of Post-Saussurean Literary Theory (Basingstoke: Macmillan, 1988), 133.

56 "Binary opposition," a pair of terms coined by structuralism, explains the entity of a centre and existence of an opposing centre. It is systematically criticized by Jacques Derrida in his deconstructive studies. His argument is to reveal and hence reverse the hierarchical, and not symmetrical, nature of the binary oppositions. The emphasis is on the superior position of an 
entity while the others become inferior. Derrida argues, "Very schematically: an opposition of metaphysical concepts (e.g., speech/writing, presence/absence, etc.) is never the confrontation of two terms, but a hierarchy and the order of a subordination. Deconstruction cannot be restricted to immediately pass to a neutralization: it must, through a double gesture, a double science, a double writing - put into practice a reversal of the classical opposition and a general displacement of the system." Jacques Derrida, "Signature Event Context," Limited Inc, trans. Samuel Weber and Jeffrey Mehlman (Evanston, Illinois: Northwestern University Press, 1988), 21. In this regard femininity and masculinity are considered to be homogenous and fixed binary opposites.

For Wallon's theory see: Henri Wallon, "Comment se développe chez l'enfant la notion de corps propre," Journal de psychologie, vol. 28 (November-December 1931): 705-748; and his Les origines du caractère chez l'enfant (Paris: Presses Universitaires de France, 1973). For a more detailed study of influences and the development of Lacan's theory refer to: Elisabeth Roudinesco, "The mirror stage: an obliterated archive," The Cambridge Companion to Lacan, ed. Jean-Michel Rabaté (Cambridge: Cambridge University Press, 2003): 25-34; and Émile Jalley, Freud, Wallon, Lacan: L'enfant au miroir (Paris: EPEL, 1998).

57 Lacan, "The Freudian Thing, or the Meaning of the Return to Freud in Psychoanalysis," Ecrits: The First Complete Edition in English: 334-363; also see: Samuel Weber, Return to Freud: Jacques Lacan's Dislocation of Psychoanalysis, trans. Michael Levine (Cambridge: Cambridge University Press, 1991); Richard Feldstein, Bruce Fink, and Maire Jaanus (Eds.), Reading Seminars I and II: Lacan's Return to Freud (Albany: State University of New York Press, 1996); Richard Boothby, Death and Desire: Psychoanalytic Theory in Lacan's Return to Freud (New York: Routledge, 1991); Philippe Julien, Jacques Lacan's Return to Freud: The Real, the Symbolic, and the Imaginary, trans. Devra Beck Simiu (New York: New York University Press, 1994).

58 In his essay "On Narcissism," Freud argues, "We are bound to suppose that a unity comparable to the ego cannot exist in the individual from the start; the ego has to be developed." 76-77.

59 Lacan, "The Mirror Stage," 76.

60 Ibid.

61 Ibid., 75 .

62 Elizabeth Grosz, "Contemporary Theories of Power and Subjectivity," Feminist Knowledge: Critique and Construct, ed. Sneja Gunew (London and New York: Routledge, 1990), 74. 
63 Lacan, "Variations on the Standard Treatment," Écrits: The First Complete Edition in English, 286.

64 Ellie Ragland-Sullivan, "Jacques Lacan: Feminism and the Problem of Gender Identity," SubStance, vol. 11, no. 3, Issue 36 (1982), 11.

65 Ibid.

66 Grosz, "Contemporary Theories of Power and Subjectivity," 74.

67 Dylan Evans, An Introductory Dictionary of Lacanian Psychoanalysis (London: Routledge, 2006), 118.

68 Lacan, “The Mirror Stage”, 79.

69 Toril Moi, Sexual/Textual Politics: Feminist Literary Theory (London: Routledge, 1985), 99.

70 Mitchell, Women, The Longest Revolution, 290.

71 Grosz, "Contemporary Theories of Power and Subjectivity," 73.

72 Lacanian Other, always with a capital O, is closer to Freud's Ideal. The capital O marks the absoluteness of its otherness. The Lacanian Other is not a person. It is a locus for the emanation of language and its meanings. "Misidentified with God, the Other is incarnated in human experience in the figure of the Symbolic Father-the authority that real fathers invoke to institute the law." Grosz, "Contemporary Theories of Power and Subjectivity," 73. On the other hand, Object is the Lacanian equivalent of the other, with small o.

73 See: Lacan, “The Mirror Stage," 76.

74 Juliet Mitchell, "Introduction-I," Feminine Sexuality: Jacques Lacan and the école freudienne, eds. Juliet Mitchell and Jacqueline Rose, trans. Jacqueline Rose (London: W.W. Norton and Pantheon Books, 1982), 25.

75 Mitchell, Women, The Longest Revolution, 254; See also R.D. Laing, The Divided Self: An Existential Study in Sanity and Madness (Harmondsworth: Penguin, 1960).

76 Lacan, “The Mirror Stage," 75.

77 Ibid., 78 .

78 Jane Gallop, Reading Lacan (Ithaca and London: Cornell University Press, 1985), 79.

79 Lacan, “The Mirror Stage," 78.

80 Ibid., 77; Lacan calls it a captation because the image actually "captures" or "seizes" the psyche and turns into a significant formative agent of the psyche as well as a function in the formation of the psychosis.

81 Ibid., 91. In his rejection of Cartesian Cogito philosophy, Lacan was extensively influenced by Alexandre Kojève, the Russian-born Marxist and Hegelian political philosopher. Kojève suggests that in order to become 
modern in the thirties, one should move beyond the Cartesian philosophy of "I think" to that of the Freudian and Hegelian philosophy of "I desire." This move is marked by a schism, a split between the $I$ of thought and desire, which he calls a true I ( $j e$ ), and that of the ego ( $m o i)$, which is regarded as a site of error, illusion and "mere representations." Roudinesco, "The Mirror Stage," 28.

It should be noted here that Freud's desire is Wunsch, which is different from Hegel's Begierde. Roudinesco's short discussion of their differences is summed up in the following: "Begierde is the desire through which the relation of consciousness to the self is expressed: the issue is to acknowledge the other or otherness insofar as consciousness finds itself in this very movement. The other is the object of desire that the consciousness desires in a negative mirror-relationship that allows it to recognize itself in it. Wunsch, or desire in the Freudian sense, is more simply an inclination, an aspiration, the fulfillment of an unconscious wish." Ibid.

82 Lacan, "The Mirror Stage," 81.

83 See: Julia Kristeva, Revolution in Poetic Language, trans. Margaret Waller (New York: Columbia University Press, 1984); Julia Kristeva, Desire in Language: A Semiotic Approach to Literature and Art, ed. Leon S. Roudiez (New York: Columbia University Press, 1980).

84 Mary Jacobus, "The Difference of View," The Feminist Reader: Essays in Gender and the Politics of Literary Criticism, eds. Catherine Belsey and Jane Moore (London: The Macmillan Press Ltd, 1977), 68.

85 Susan Sellers, Language and Sexual Difference: Feminist Writing in France (New York: St. Martin's Press, 1991), 15.

86 Mitchell, Women, The Longest Revolution, 291.

87 Lacan, "The Mirror Stage," 78. The term imago alludes to a Judeo-Christian doctrine in which humans are being made in the image of God-in the Imago Dei (See: Genesis 1: 26, 27). Augustine suggests that humans must strive to restore the divine image in their selves. Therefore, Lacan's mirror stage can be understood as an ironic version of this theology, that is we are the creation of our own image.

88 Meyers, Gender in the Mirror, 25.

89 The perceptual distortion of body image or body-size/weight, in aggravated cases, may lead to anorexia nervosa, where the subject suffers from an eating disorder. There is a vast amount of literature on anorexia nervousa refering to this body-image distortion. Inter alia see: D.M. Garner and P.E. Garfinkel, "Body Image in Anorexia Nervosa: Measurement, Theory and Clinical Implications," International Journal of Psychiatry in 
Medicine, vol. 11 (1981): 263-284; R. Lynn Horne, J.C. Van Vactor, et al., "Distorted Body Image in Patients with Eating Disorders," American Journal of Psychiatry, vol. 148, no. 2 (1991); 211-215; Mirja Kalliopuska, "BodyImage Disturbance in Patients with Anorexia Nervosa," Psychological Reports, vol. 51 (1982): 715-722; and Morag MacSween, Anorexic Bodies: A Feminist and Sociological Perspective on Anorexia Nervosa (New York: Routledge, 1995).

90 Hélène Cixous, "Sorties: Out and Out: Attacks/Ways Out/Forays," The Newly Born Woman, eds. Hélène Cixous and Catherine Clément, trans. Betsy Wing (London: I.B. Tauris, 1996), 82; The original text is also translated by Ann Liddle under the title "Sorties" in New French Feminisms: An Anthology, eds. Elaine Marks and Isabelle de Courtivron (Amherst: The University of Massachusetts, 1980), 95.

For a study of the centrality of vision as the basis of human knowledge see: Suzanne Conklin Akbari, Seeing through the Veil: Optical Theory and Medieval Allegory (Toronto, Buffalo and London: University of Toronto Press, 2004).

91 Luce Irigaray, Speculum of the Other Woman, trans. Gillian C. Gill (Ithaca and New York: Cornell University Press, 1985). This work, first published in 1974, led to her expulsion from Lacan's “école freudienne". The text provides a deconstructive reading of patriarchal discourse. It reverses the historical order by taking a speculum-like structure, starting with Freud and ending with Plato.

92 Paparunas, "Trouble with the I/Eye" 226.

93 See: Luce Irigaray, This Sex Which Is Not One, trans. Catherine Porter (Ithaca and New York: Cornell University Press, 1985), 23-33 and 205-218; Bracha Lichtenberg Ettinger, "Matrix and Metramorphosis," Differences: A Journal of Feminist Cultural Studies [Trouble in the Archives], vol. 4, no. 3 (1992): 176-208; See also: Cathryn Vasseleu, “The Face Before the Mirror-Stage," Hypatia: Special Issue, Feminism and the Body, ed. Elizabeth Grosz, vol. 6, no. 3 (Fall 1991): 140-155. Vasseleu discusses the ethical limitations of Lacan's account of subjectivity and the mirror stage, basing her study of the metaphors of vision and touch upon the works of Luce Irigaray and Emmanuel Levinas.

94 Grosz, Jacques Lacan, 38.

95 For an elaborate discussion of Lacan's and Freud's “ocularcentrism” see: Grosz, Jacques Lacan, 35-41.

96 Gallop, Reading Lacan, 79.

97 Irigaray, This Sex Which is Not One, 116. 
98 Jane Gallop, The Daughter's Seduction: Feminism and Psychoanalysis (Ithaca and New York: Cornell University Press, 1982), 81.

99 Lacan, “The Mirror Stage," 77.

100 It is no coincidence that the full-length mirror, mounted on a movable frame, which became popular in the early nineteenth century, is in French called a psyché.

101 Michel Foucault, "Of Other Spaces," trans. Jay Miskowiec, Diacritics, vol. 16, no. 1 (Spring, 1986), 24.

102 Ibid.

103 Ibid.

104 Ibid.

105 Edward S. Casey, "The Time of the Glance: Toward Becoming Otherwise," Becomings: Explorations in Time, Memory, and Futures, ed. Elizabeth Grosz (Ithaca and London: Cornell University Press 1999), 86 [Italics in the original].

106 Ibid., 85 .

107 Ibid., 83 [Italics in the original].

108 Julia Kristeva, “A Question of Subjectivity: An interview," Feminist Literary Theory: A Reader, ed. Mary Eagleton (Oxford: Blackwell, 1996), 351.

109 Gilles Deleuze, Cinema 1: The Movement-Image, trans. Hugh Tomlinson and Barbara Habberjam (Minneapolis: University of Minnesota Press, 1986), 10.

110 Casey, "The Time of the Glance," 87.

111 Henri Bergson, Mind-Energy: Lectures and Essays, trans. H. Wildon Carr, eds. Keith Ansell-Pearson and Michael Kolkman (Basingstoke: Palgrave Macmillan, 2007), 132.

112 Henri Bergson, Creative Evolution, trans. Arthur Mitchell (New York: Cosimo, 2007), 7-8 [Italics in the original].

113 Ovid, Metamorphoses, Book IV: 234, accessed on April o8, 2014, http:// www.perseus.tufts.edu/hopper/text?doc=Perseus\%3Atext\%3A1999.02 .oo29\%3Abook\%32D15\%3Acard\%3 D153

114 Leonard Shengold, “The Metaphor of the Mirror," Journal of the American Psychoanalytic Association, vol. 22, no. 1 (1974), 99.

115 For a discussion of the psychological internality of the memory see: C.B. Martin, and Max Deutscher, "Remembering," Philosophical Review, vol. 75 (1966): 161-196.

116 Jacqueline Rose in her discussion of Adrienne Rich's poem "Go, Girl”. Jacqueline Rose, On Not Being Able to Sleep: Psychoanalysis and the Modern World (London: Chatto \& Windus, 2003), 47. 
117 Gallop, The Daughter's Seduction, 113.

118 Irigaray, This Sex Which Is Not One, 139.

119 De Beauvoir, The Second Sex, 281-282.

120 Adrienne Rich, Of Woman Born: Motherhood as Experience and Institution (New York: W.W. Norton \& Co., 1976), 220.

121 Roberta Rubenstein, Boundaries of the Self: Gender, Culture, Fiction (Urbana: University of Illinois Press, 1987), 235.

122 Nancy J. Chodorow, The Reproduction of Mothering: Psychoanalysis and the Sociology of Gender (Berkeley and Los Angeles: University of California Press, 1978), 169.

123 Ibid. Here Nancy Chodorow presents a neo-Freudian analysis of the mother/daughter relationship. For her other works on this subject see: Nancy J. Chodorow, "Family Structure and Feminine Personality," Woman, Culture and Society, eds. Michelle Zimbalist Rosaldo and Louise Lamphere (Stanford, California: Stanford University Press, 1974), 43-66; idem, "Mothering, Object-Relations and the Female Oedipal Configuration," Feminist Studies, vol. 4, no. 1 (February 1978): 137-158; idem, "Feminism and Difference: Gender, Relation and Difference in Psychoanalytic Perspective," Socialist Review, vol. 46 (July-August 1979): 51-70; also reprinted in The Future of Difference, eds. Hester Eisenstein and Alice Jardine (Boston: G.K. Hall, 1980), 3-20. For other Freudian/neo-Freudian studies on the topic see: Dorothy Dinnerstein, The Mermaid and the Minotaur: Sexual Arrangements and Human Malaise (New York: Harper and Row, 1976); Jean Baker Miller, Toward a New Psychology of Women (Boston: Beacon Press, 1976); Also see: Janneke Van Mens-Verhulst, Karlein Schreurs, and Liesbeth Woertman (Eds.), Daughtering and Mothering: Female Subjectivity Reanalysed (London: Routledge, 1993).

124 La Belle, Herself Beheld, 80 [Italics mine].

125 Jane Flax, "Mother-Daughter Relationships: Psychodynamics, Politics, and Philosophy," The Future of Difference, eds. Hester Eisenstein and Alice Jardine (Boston: G.K. Hall, 1980), 23.

126 Ibid. For Jane Flax's further studies on the subject see: Jane Flax, “The Conflict between Nurturance and Autonomy in Mother-Daughter Relationships and within Feminism," Feminist Studies, vol. 4, no. 1 (February 1978): 171-189.

127 Julia Kristeva, “About Chinese Women," trans. Sean Hand, The Kristeva Reader, ed. Toril Moi (New York: Columbia University Press, 1986), 149.

128 Shengold, "The Metaphor of the Mirror," 98.

129 Luce Irigaray, “And the One Doesn’t Stir without the Other," trans. Hélène 
Vivienne Wenzel, Signs: Journal of Women in Culture and Society, vol. 7, no. 1 (Autumn, 1981), 60.

130 Ibid., 63.

131 Ibid., 61.

132 Ibid.

133 Carl G. Jung and Carl Kerényi, Essays on a Science of Mythology: The Myth of the Divine Child and the Mysteries of Eleusis (Princeton and New Jersey: Princeton University Press, 1969), 162. For a Jungian analysis of the mother/daughter relationship refer to: Nor Hall, The Moon and the Virgin: Reflections on the Archetypal Feminine (New York: Harper \& Row, 1980); Erich Neumann, The Great Mother: An Analysis of the Archetype, trans. Ralph Manheim (Princeton and New Jersey: Princeton University Press, 1955); Carl Kerényi, Eleusis: Archetypal Image of Mother and Daughter, trans. Ralph Manheim (New York: Schocken Books, 1976).

134 This clairvoyant mirror falls within the broader category of magic mirrors which have been recurrent topoi in many literatures of the world. These clairvoyant surfaces were often revered for their endowment with magical and mantic powers, for their "powers of temporal and spatial clairvoyance." Theodore Ziolkowski, Disenchanted Images: A Literary Iconology (Princeton, New Jersey: Princeton University Press, 1977), 160. Ziolkowski, based on folklorists' categorization, divides magic mirrors into two different categories of cognizant (wissend) and causative (wirkend). See: Ibid., 162-168.

135 Lynn Sukenick, "Feeling and Reason in Doris Lessing's Fiction," Contemporary Literature, vol. 14, no. 4 (Autumn 1973): 515. This article is a discussion of Doris Lessing's central female characters.

136 Ibid., 519.

137 Rich, Of Woman Born, 236. For a more elaborate study of "matrophobia" and its effects see: Judith Kegan Gardiner, "A Wake for Mother: The Maternal Deathbed in Women's Fiction," Feminist Studies, vol. 4, no. 2 (June 1978): 146-165.

138 Irigaray, "And the One Doesn't Stir without the Other," 61.

139 Ibid., 64.

140 Ibid., 67. For more on the mother's mirroring function see: Donald Woods Winnicott's chapter on "Mirror-Role of Mother and Family in Child Development," in his Playing and Reality (New York: Routledge, 2005): 149-159. Here, Winnicott explains how the individual embarks on the first experience of human relatedness through the mirror experience. He begins his chapter with these words: "In individual emotional development the 
precursor of the mirror is the mother's face." 149 . For feministic study of the subject see: Julia Kristeva, Revolution in Poetic Language, trans. Margaret Waller (New York: Columbia University Press, 1984); Marianne Hirsch, The Mother/Daughter Plot: Narrative, Psychoanalysis, Feminism (Bloomington: Indiana University Press, 1989); For studies on this motherdaughter mirroring relationship in literature see: Cathy N. Davidson and E.M. Broner (Eds.), The Lost Tradition: Mothers and Daughters in Literature (New York: F. Ungar Pub Co, 1980); Mickey Pearlman (Ed.), Mother Puzzles: Daughters and Mothers in Contemporary American Literature (New York: Greenwood Press, 1989).

141 For more see: Meyer Howard Abrams, The Mirror and the Lamp: Romantic Theory and the Critical Tradition (London: Oxford University Press, 1953).

142 'Ayn-ol-Qożāt Hamadānī, Nāmehā-ye 'Ayn-ol-Qożāt-e Hamadānī, eds. 'Alī-Naqī Monzawī and 'Afíf 'Osayrān (Tehran: Bonyād-e farhang-e Iran, 1350/1970) vol. I, 206 [Translation mine]; Cf. the Persian original:

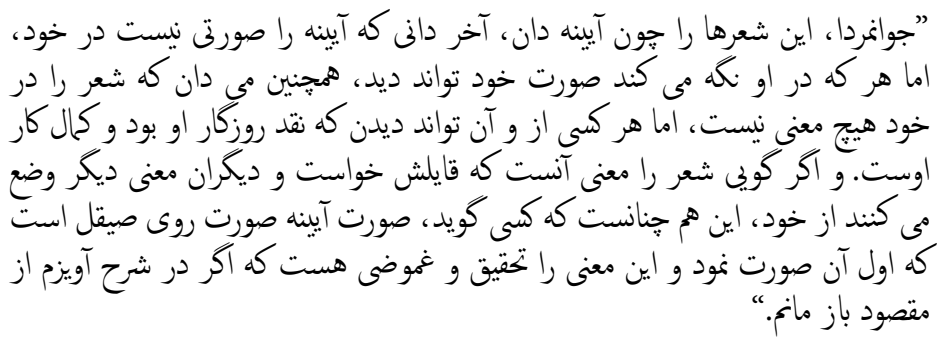

Arthur Schopenhauer says: "Books are like a mirror. If an ass looks in, you can't expect an angel to look out." And Oscar Wilde in his Preface to The Picture of Dorian Gray writes, "It is the spectator, and not life, that art really mirrors." (Clayton, Delaware: Prestwick House, 2007), 11.

143 Roland Barthes, "The Death of the Author," Modern Criticism and Theory: A Reader, ed. David Lodge, revised and expanded by Nigel Wood (Essex and New York: Longman, 2000), 146-147.

144 Ibid., 148-149.

145 "Poetry is Not a Luxury" is the title of an article by Audre Lorde first published in Chrysalis: A Magazine of Female Culture, no. 3 (1977); reprinted in Sister Outsider: Essays and Speeches (Trumansburg, New York: Crossing Press, 1984). In this article, Lorde explains: "For women, then, poetry is not a luxury. It is a vital necessity of our existence. It forms the quality of the light within which we predicate our hopes and dreams toward survival 
and change, first made into language, then into idea, then into more tangible action. Poetry is the way we help give name to the nameless so it can be thought. The farthest external horizons of our hopes and fears are cobbled by our poems, carved from the rock experiences of our daily lives." Lorde, Sister Outsider, 37.

146 Carmen Birkle, Women's Stories of the Looking Glass: Autobiographical Reflections and Self-Representations in the Poetry of Sylvia Plath, Adrienne Rich, and Audre Lorde (Munich: Wilhelm Fink Verlag, 1996), 41.

147 La Belle, Herself Beheld, 180 [Information within the brackets mine].

148 The idea of "reflection" of the poet in poetry can be traced back to the Romantic definition of poetry. For an elaborate study refer to: Abrams, The Mirror and the Lamp.

149 La Belle, Herself Beheld, 160-161.

150 James Olney, Metaphors of Self: The Meaning of Autobiography (Princeton and New Jersey: Princeton University Press, 1972), 44.

151 Andreas-Salomé, "The Dual Orientation of Narcissism," 13.

152 Ibid., 27.

153 Certainly, there exist some autobiographical writings by female authors that do not repudiate or even question patriarchal laws and their inherent phallocentrism; for example, autobiographies written by women who have made careers out of their unquestioning social femininity, such as movie stars. They are often happy with their success built on the cultural definitions of womanhood and beauty.

154 Judith Butler, Gender Trouble: Feminism and the Subversion of Identity (New York: Routledge, 1990), 147.

155 Mitchell, Women, The Longest Revolution, 294.

156 Meyers, Gender in the Mirror, i.

157 Sandra M. Gilbert and Susan Gubar, The Madwoman in the Attic: The Woman Writer and the Nineteenth-Century Literary Imagination (New Haven and London: Yale University Press, 200o), 16-17. For the original source of Woolf's quoted argument see: Virginia Woolf, "Professions for Women," The Death of the Moth and Other Essays (New York: Harcourt, Brace, 1942), 236-288.

158 For a detailed discussion of the tripartite relationship between experience, text and female subjectivity see: Liz Yorke, Impertinent Voices: Subversive Strategies in Contemporary Women's Poetry (London: Routledge, 1991).

159 Cixous, "The Laugh of the Medusa," 880.

160 Melchior-Bonnet, The Mirror, 261.

161 Sellers, Language and Sexual Difference, 51. 
162 Ruth Robbins, Literary Feminisms (New York: St. Martin's Press, 2000), 116.

163 Brunhilde Wehinger, “'Die Frucht ist fleckig und der Spiegel trübe’: Lyrikerinnen im 19. Jahrhundert," Frauen Literatur Geschichte: Schreibende Frauen vom Mittelalter bis zur Gegenwart, eds. Hiltrud Gnüg and Renate Möhrmann (Stuttgart and Weimar: J.B. Metzler, 1999), 306 [Translation mine]. Cf. with the original: "Die Besonderheit der lyrischen Sprechweise privilegiert das Subjekt und erlaubt ihm-gemessen an der Sprache des Alltags-die Freiheit, die zweite Person zu modifizieren und alles anzureden, Menschen und Objekte ebenso wie Naturphänomene oder Phantome, nicht zuletzt das eigene Spiegelbild."

164 Celeste Schenck, "All of a Piece: Women's Poetry and Autobiography," Life/Lines: Theorizing Women's Autobiography, eds. Bella Brodzki and Celeste Schenck (Ithaca and New York: Cornell University Press, 1988), 292.

165 James Olney, "Autobiography and the Cultural Moment: A Thematic Historical, and Bibliographical Introduction," Autobiography: Essays Theoretical and Critical, ed. James Olney (Princeton and New Jersey: Princeton University Press, 1980), 25.

166 Robert Folkenflik, "The Self as Other," The Culture of Autobiography: Constructions of Self-Representation, ed. Robert Folkenflik (Stanford: Stanford University Press, 1993), 234.

\section{Chapter Two}

1 Šams ed-Dīn Moḥammad Hāfez, Dīvān-e Hāfez-e Šìrāzī, eds. Moḥammad Qazvīnī and Qāsem Ġanī (Tehran: Anjoman-e hošnevīsān-e Irān, 1368/ 1989), 86. The translations are mine unless otherwise indicated.

2 Rowson explains šähed-bāzi in the following words: "From a relatively early period-probably the mid-ninth century-some Muslim mystics claimed to see in the beauty of adolescent boy a 'testimony' to the beauty and goodness of God, and initiated the practice of gazing at such a boy as a form of spiritual exercise. The boy was thus known in Sufi parlance as a 'witness' (šăhed)." Everett K. Rowson, "Homosexuality in the Medieval Islamic World: Literary Celebrations vs. Legal Condemnation." Paper presented at the conference "Gender and Alterity in Near Eastern Societies" (Princeton University, 6 April 1995), 24; Quoted in Afsaneh Najmabadi, Women with Mustaches and Men without Beards: Gender and 
Sexual Anxieties of Iranian Modernity (London: University of California Press, 2005), 17. For an extensive study on šahed-bāzī in Persian literature, see: Sīrūs Šamīsā, Šāhed-bāzì dar adabìyāt-e fārsī (Tehran: Entešāāāt-e ferdous, 1381/2002-2003); Also see: Annemarie Schimmel, Mystical Dimensions of Islam (Chapel Hill: University of North Carolina Press, 1975), 289291.

Walker uses the phrase "the chiasmus of perception" in her study of the presentations of women in the works of Spenser, Shakespeare and Milton. Julia M. Walker, Medusa's Mirrors: Spenser, Shakespeare, Milton, and the Metamorphosis of the Female Self (London: Associated University Press, 1998), 45.

For the study of the representation of women in Persian literature see: Zeynab Yazdānī, Zan dar še $e^{c}$-e fārsī: dìrūz-emrūz (Tehran: Entešāāt-e ferdous, 1378/1999-2000); Maryam Hosseīnī, Rīše-hā-ye zan-setīzī dar adabìyāt-e kelāsīk-e fārsī (Tehran: Našr-e češme, 1387/2008-2009).

For more see: Janet Afary, Sexual Politics in Modern Iran (Cambridge and New York: Cambridge University Press, 2009); Najmabadi, Women with Mustaches and Men without Beards.

See: Farzaneh Milani, Veils and Words: The Emerging Voices of Iranian Women Writers (New York: Syracuse University Press, 1992); idem, Words, Not Swords: Iranian Women Writers and the Freedom of Movement (New York: Syracuse University Press, 2011); Afsaneh Najmabadi (Ed.), Women's Autobiographies in Contemporary Iran (Cambridge, Massachusetts: Harvard University Press, 1990); Dominic Parviz Brookshaw, "Women in Praise of Women: Female Poets and Female Patrons in Qajar Iran," Iranian Studies, vol. 46, issue 1 (2013), 17-48. Robbins, Literary Feminisms, 122-123.

8 Forugh Farrokhzad, Mağmū'a āșār-e Forugh Farrokhzad, ed. Behnām Bāvandpūr (Essen: Nima Verlag, 2002).

9 Spencer, "Mirrors and Masks," 72.

10 Ibid., 70.

11 As Millani argues, Farrokhzad's whole canon of work can fit into the genre of Bildungsroman, though a female one and in verse: “... the first Bildungsroman written by and about a woman in Iran. Although a genre of novel, and although its tradition is almost exclusively associated with male characters, the category Bildungsroman best defines Forugh's ceaseless developmental journey. Her five collections of poetry, viewed as a whole, constitute nothing less than a tale of self-discovery and growth." Farzaneh Millani, "Forugh Farrokhzād," Persian Literature, ed. Ehsan Yar- 
shater (New York: The Persian Heritage Foundation, 1988), 368. See also: Milani, Veils and Words, 136-137. Here, Milani discusses how Farrokhzad's poetic oeuvre "best embodies Farrokhzad's emergence from cultural conditioning and her struggle to come to self-realization, warranting its adaptation to her journey and to her awakening." (136) Milani further states that these poems are "the chronicle of an evolving consciousness, the testament of growing awareness." (136-137)

12 See: Farzaneh Milani, "Forugh Farrokhzad: A Feminist Perspective” (Ph.D. dissertation, University of California at Los Angeles, 1979).

13 John Berger, Ways of Seeing (London: Penguin Books, 1972), 47.

14 Laura Mulvey, Visual and Other Pleasures (Bloomington and Indianapolis: Indiana University Press, 1989), 19.

15 Girdhari Tikku has translated Asir as The Prisoner. Girdhari Tikku, "Furūgh-i Farrokhzād: a new direction in Persian poetry," Studia Islamica, 26 (1967): 149-173.

16 Ibid., 153.

17 The complete versions of the poems together with their translations can be found in the Appendix.

18 Forugh Farrokhzad, Mağmū'a āsār-e Forugh Farrokhzad, ed. Behnām Bāvandpūr (Essen: Nima Verlag, 2002), 1: 69. All the references are to this book. The translations are mine. For the Persian orthography of the poems, I have also followed this book.

19 Ibid.

20 Freud, "On Narcissism," 88-89.

21 For the various meanings of the Persian word dīdār see: 'Aliakbar Dehhodā, s.v. "dīdār," Loġatnāme, eds. Moḥammad Mo'īn and Ğacfar Šahīdī (Tehran: Tehran University Press, 1377/1998), vol. 8, pp. 11359-11362.

22 Farrokhzad, Mağmī̄a àsāàr, 1: 69.

23 The Persian word hìre can also be translated as "bewildering at" (bewildering at my wet eyes).

24 Farrokhzad, Mağmū'a āsāàr, 1: 70.

25 This is reminiscent of a very popular classical Persian poem of Arabic origin, Neẓāmī Ganğavīs Laylī o Mağnūn. Mağnūn, literally "the insane or the obsessed," becomes a poet-singer after losing his beloved Layli and becoming insane. The motif of creativity and madness out of lost love has become a tradition in Persian literature and Farrokhzad in this poem draws upon the same tradition. See: As'ad E. Khairallah, Love, Madness, and Poetry: An Interpretation of the Mağnūn Legend (Beirut: Franz Steiner Verlag, 1980); Ali Asghar Seyed-Gohrab, Layli and Majnun: Love, Madness 
and Mystic Longing in Nizami's Epic Romance (Boston: Brill Academic Publishers, 2003).

26 Shengold, "The Metaphor of the Mirror," 101.

27 Persian literary tradition holds that sorme (collyrium or antimony) is originally a person who was pounded in the mortar of love until he lost his original stony nature. It is believed that it enhances beauty as well as improving eyesight. Annemarie Schimmel, As through a Veil: Mystical Poetry in Islam (New York: Columbia University Press, 1982), 122.

28 Gallop, The Daughter's Seduction, 115.

29 Irigaray, "And the One Doesn't Stir without the Other," 65.

30 Farrokhzad, Mağmū'a āsāàr, 1: 70.

31 Irigaray, "And the One Doesn't Stir Without the Other," 66.

32 Luce Irigaray, “Divine Women," trans. Gillian C. Gill, Women, Knowledge, and Reality: Explorations in Feminist Philosophy, eds. Ann Garry and Marilyn Pearsall (London and New York: Routledge, 1996), 477-478 [Italics in the original].

33 Farrokhzad, Mă̆mī̄a àșār, 1: 70.

34 Ibid., 1: 75.

35 Melchior-Bonnet, The Mirror, 233.

36 Farrokhzad, Mă̆mū'a āsāār, 1: 75.

37 Ibid.

38 Virginia Woolf, A Room of One's Own (Orlando, Florida: Harcourt, 2005), 35.

39 As in English literature, the theme of "speaking mirror" is abundant in Persian literature. The ability to speak and to provide the beholder with an answer is regarded as one of the powers of the mirror. For an example see: Nasrollah Pourjavady, Zabān-e ḥāl dar 'erfān o adabīyāt-e pārsì (Tehran: Entešārāt-e Hermes, 1385/2006-2007), 158, 650-651. Here, Pourjavady cites an example of a mirror and a comb getting into the debate over the nature of true love.

40 Farrokhzad, Mağmū'a āsāàr, 1: 76.

41 Ibid.

$42 \breve{G} \bar{a} m$-e ğam, and all its other equivalents, $\breve{g} \bar{a} m$-e ğamšì

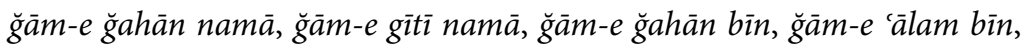
ğām-e ğahān ārā, à'ine-ye soleymān (Solomon's mirror), ä'īne-ye eskandar (sekandar or sekandarī) have a magical or surreal aura around them. Over time they have acquired rich metaphorical connotations, all orbiting round the centre of reflection, mental or visual. Ğām in Persian means a cup but it also denotes "clean" and "pure." Furthermore, ğam also means a 
"great king," again having purity in its denotation. In addition, Ğām refers to the legendary Persian king Ğamšìd, Keyhosro or Solomon. For more detailed study of this topos in Persian literature see: Mohammad Mo'īn, “Ğām-e ğahān namā," Mağmū'a maqālāt-e doktor Mohammad-e Mo'īn, ed. Mahdoht Mo'īn, vol. I (Tehran: Entešārāt-e Mo'īn, 1368/ 1989-199o), 345366; Sağād Āīdenlū, "Ǧām-e Keyhosro o Ǧamšīd," Nāme-ye Pārsī, year 9, no. 4 (Winter 1983/2004-2005): 5-24. Seyede Farībā Mūsavī, "Ā'īne dar šāhkār-hā-ye adabī tā qarn-e haštom," MA dissertation (Tehran: Tarbiat Moallem University, 1374/1995), 48-53. Moḥtaram Ǵamangīz's MA dissertation, "Ā'īne dar adab-e șūfīyāne-ye fārsī bā tekīye bar āsāar-e Sanā'ī, 'Aț̣āar, Neẓāmī, Molānā, S‘adī, 'Ayn-ol-Qożāt,' (Zanjan: Zanjan University, 1386/2007) is heavily based on Mūsavī's dissertation, mentioned above. Some Persian sources recount that Alexander installed a huge mirror on a tower to destroy a sea serpent. Like Basilisk, the legendary king of serpents, the sight of this serpent was deadly to any mortal onlooker and the serpent would also die should it see its own reflection. See: Schimmel, $A$ Two-Colored Brocade, 115. In this version of the story, one can see the vast overlap with the key elements of the Greek mythological story of Medusa, such as the deadly look and the mirror as a lethal and liberating instrument. For a study of the "mirror-magic" see: Géza Róheim, Spiegelzauber (Leipzig-Wien: Internationaler Psychoanalytischer Verlag: 1919).

It is worth noting here that the vast medieval encyclopaedias that set out to catalogue all knowledge were often called specula. For the study of speculum or mirror as titles see: Ritamary Bradley, "Backgrounds of the Title Speculum in Medieval Literature," Speculum 29 (1954), 100-115; see also Herbert Grabes, The Mutable Glass: Mirror-Imagery in Titles and Texts of the Middle Ages and English Renaissance (Cambridge: Cambridge University Press, 1982).

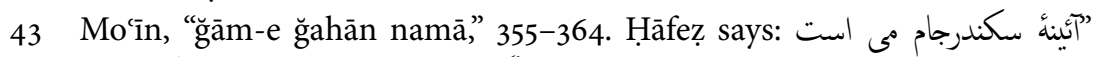
“ بنكر /تا بر تو عرضه دارد احوال مُلكى دارا. Hāāğe Šams ed-Dīn Moḥammad Hāfez, Dìvān-e Hāâfez, ed. Parvīz Nātel Huānlarī, vol. I (Tehran: Entešārāt-e Hưāazazmī, 1359/1980-1981), 26. “The cup of wine is Sikandar's mirror / Behold, so that it may show thee the state of Dārās kingdom." Translated by Henry Wilberforce Clarke in: Khwāja Shamsu-d-Dīn Muhammad-i-Hāfiz-i-Shīrāzì, The Dìvān-i-Hāfiz (New York: Samuel Weiser, 1970), vol. I, 31. (Dārā refers to Dariush the king of Achaemenid Empire of Persia who was killed after the Alexander's invasion). A recurrent Persian literary topos holds that through the wine, the esoteric knowledge which remains veiled to the sober is unveiled to the drunken. For a detailed study of $\breve{g} \bar{a} m-e ~ \breve{g} a m$ in the 
Dīvān of Hāfez see: Ǧavād Brūmand Sa'eed, Hāfez o ğām-e ğam (Tehran: Pāžang, 1367/1988-1989).

44 See: Mūsavī, "Ā'īne dar šāhkār-hā-ye adabī", 48-53.

45 One of such popular mirror motifs is the burning mirror, which has had a great fascination for Persian poets. In Persian it is called harrāqa or ā'ine-ye $s \bar{u} z \bar{a} n$. It is a concave mirror that concentrates the rays of the sun and with enough intensity to set anything burnable in its focal point on fire. It is sometimes referred to as "Alexander's mirror." See: Hoseyn Ma'ṣūmī Hamadānī, "Ā'īne-ye sūzān-e aflāțūn," Našr-e dāneš, year: 7, no. I (Spring 1379/2000): 3-15. Mohammad Mo'īn, in his article "Alexander’s Mirror," collected some of the old Arabic and Persian texts recounting the story of Alexander's mirror and how it was ruined. These works reaching back to the tenth century, and some of them fitting in the genre of travelogue, appear to be more fictive, mixing various myths into the accounts of what they actually visited. Moḥammad Mo'īn, "Ā'ine-ye sekandar," Mağmū'a maqālāt-e doktor Mohammad-e Mo'īn, ed. Mahdoht Mo'īn, vol. II (Tehran: Entešārāt-e Mo'īn, 1367/1988-1989): 465-494. Also See: Mūsavī, "Ā'īne dar šāhkār-hā-ye adabî̀," 35-37 and 42-53.

46 Farrokhzad, Mağmū'a āsār 1 , 146.

47 Ibid., 147.

48 Ibid.

49 In the poem "Afsāne-ye talh" ("Bitter Myth"), Farrokhzad openly acknowledges this cultural conceptualization of woman in order to vehemently reject it:

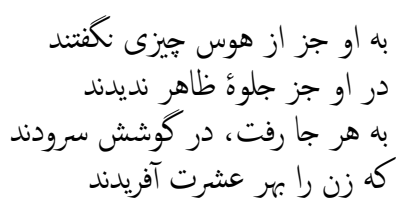

She was told nothing but the lust

She was regarded as nothing but the manifestations of

appearances

Wherever she went, it was sung in her ears

Woman is created for voluptuousness. Farrokhzad, 1: 52

By astutely entitling her poem "Bitter Myth," Farrokhzad discloses her full awareness to the unreality of the image of womanhood which her phallocenteric culture provides. 
50 Melchior-Bonnet, The Mirror, 230.

51 The round shape of the mirror in old times is asserted by Melchior-Bonnet, "Nearly always rounded, these mirrors were either concave or convex." Melchior-Bonnet, The Mirror, 10.

52 Riccardo Zipoli, "Semiotics and the Tradition of the Image," Persica, vol. 20 (2005), 166.

53 Farrokhzad, Mağmūica āsār , 1: 212.

54 Ibid.

55 Ibid., 213.

56 Ibid., 214.

57 For the metaphor of the mirror of the heart in its non-mystical sense see: Mūsavī, "Ā'īne dar šāhkār-hā-ye adabī", 77.

58 Farrokhzad, Mağmū'a āsāàr, 1: 135. "the smile of wine cup” alludes to Hāfeẓ’s couplet in which he uses "wine's smile”: “عكس روى تو جو در آينهُ جام افتاد" "When Thy image was reflected on the mirror of cup/The 'āref from the smile of the wine fell into vain desires." $\bar{A}$ 'ine-ye $\breve{g} \bar{a} m$, here simply translated into "the mirror of cup," associates itself with the recurrent Persian motif of $\breve{g} \bar{a} m-e$ gam. The verse implies that the image in the cup deludes the mystic into a vain and impossible desire, confusing the image with the prior reality, the signified with the signifier, and the manifestation with God. The word hām, literally meaning "raw" and "baseless," also designates "novice" or "inexperienced" in the language of Sufi poetry, thereby hinting at the inexperienced mystic who may mistake the images with the reality of God. Hāfeẓ, Dīvān-e Hāfeẓ-e Šīrāzì, eds. Moḥammad Qazvīnī and Qāsem Ġanī, 86. [Translation mine]

59 The mythological Antigone, Shakespeare's Ophelia, Charlotte Brontës Jane Eyre, and Mary Wollstonecraft's Maria are among many other love-mad female literary figures in the western literary tradition. For more on lovemad women see: Gilbert and Gubar, The Madwoman in the Attic; Helen Small, Love's Madness: Medicine, the Novel, and Female Insanity 180o-1865 (New York: Oxford University Press, 1996).

$60 \quad$ Farrokhzad, Mă̆mū'a āsāàr, 1: 136.

61 Farrokhzad explicitly refers to the "psychological interiority" of the mirror in a collaborative poem with Yadollāh Ro’yāì (born in 1932), another Persian poet. The poem, composed in 1966, is entitled "Deltang $\vec{\imath}$ " "Depression"). In the collection, the parts composed by Farrokhzad are printed in bold letters. Here Farrokhzad perspicaciously presents the psychology of mirroring: 


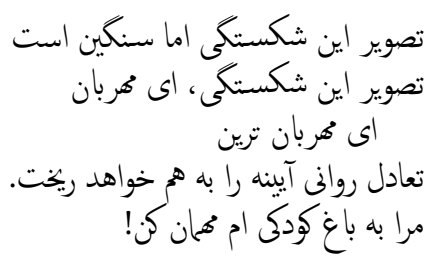

The depiction of this fracture is incredibly excruciating

The depiction of this fracture, $\mathrm{O}$ kind one

O the kindest one

Will upset the equilibrium of the mirror.

Invite me to the garden of my childhood!

Farrokhzad, Mağmū'a āsāar, 1: 377

"Tașvirr," here translated as depiction, also means image in Persian. By anthropomorphizing the mirror, onto which the persona projects her inner fragmentation, it has also been given a psychological interiority. The persona nostalgically seeks refuge in the psychological security of her paradise-like childhood years.

62 The term "speculation" is linked to "speculum." Through the medium of speculum, one can meditate on the case of an effect reflected on a surface. See: Melchior-Bonnet, 113-114.

63 Cixous, "The Laugh of the Medusa," 886.

64 In her poems, Farrokhzad does not reject her physicality, despite the long tradition of body-rejection, particularly female body-rejection, in Persian literature. One of the many poems by Farrokhzad that explicitly reveal her anti-transcendental views is "Rūy-e hāk" ("Upon the Earth"), 1: 249-250. In this poem, Farrokhzad declares that she has never wished to change her place on earth for that of the stars, the chosen, or even the angels. She claims that she is nothing but an echo, an aural reflection of an echo-an image of an image in the Lacanic sense. The window is significant in this poem (and is studied more elaborately later in this work). For the full text of the poem and its translation refer to the Appendix.

65 Farrokhzad, Mağmū'a āșär, 1: 136.

66 Ibid.

67 Mitchell, Women, the Longest Revolution, 294.

68 For more on key metaphor and its function see: Zdravko Radman, Metaphors: Figures of the Mind (Dordrecht: Kluwer Academic Publishers, 2010); Stephen C. Pepper, "The Root Metaphor Theory of Metaphysics," Essays 
on Metaphor, ed. Warren Shibles (Whitewater, Wisconsin: The Language Press, 1972): 15-26.

69 The parable of the mirror of the heart has also been recurrently referred to by many mystical philosophers in their explanation and criticism of the famous ecstatic utterances (šathīyyāt) of some mystics. Among these ecstatic utterances are: Hosayn ebn-e Manșūr al-Hallāj’s (executed in 922) declaration of "I am the Truth," and Bāyazīd Basțāmī’s (d. ca. 874) declaration "Glory be to me! How great is my majesty!" and "I am He!" See: Nasrollah Pourjavady, Ešrāq o 'erfān: maqāle-hā o naqd-hā (Tehran: Našre dānešgāhī, 1380/2001-2002), 25-28 and 105-110.

70 Ziolkowski argues that this metaphoric thought "descends from Plato and the Bible by way of Christian Platonism. This syncretic analogy, which was first publicized by Augustine and his commentators, is based principally on two passages in the New Testament" [1Corinthians 13: 12 and James 1: 23-24]. Ziolkowski, Disenchanted Images, 152. Melchior-Bonnet discusses the origin and the development of this metaphoric thought, "The mirror became part of the religious vocabulary of the Middle Ages, which developed its symbolic meanings from scriptural writings, Neoplatonic texts, and the patristic tradition (the writings of the church fathers)." Melchior-Bonnet, The Mirror, 108. Also See: Hans Leisegang, "Die Erkenntnis Gottes im Spiegel der Seele und der Natur," Zeitschrift für philosophische Forschung, vol. 4 (1950), 163-183.

71 For a succinct study of this mirror metaphor in the works of Avicenna and Sohrawardī see: Pourjavady, Ešrāq o 'erfān, 25-28. For mirror metaphor in the works of Abū Hāmed Ghazzalī’s see: Hava Lazarus-Yafeh, Studies in Al-Ghazzali (Jerusalem: The Magnes Press, 1975), 314-320. Lazarus-Yafeh in her thematic study of Ghazzalīs Arabic works devotes a section to "The Parable of the Mirror." Here, she has compiled the passages in which the parable of the mirror in the different Arabic works of Ghazzali appears.

72 Titus Burckhardt, "Die Symbolik des Spiegels in der islamischen Mystik," Symbolon: Jahrbuch für Symbolforschung, ed. Julius Schwabe, vol. I (Basel und Stuttgart: Benno Schwabe \& Co. Verlag, 1960): 12 [Translation mine]. Compare with the original: "weil es [das Sinnbild des Spiegels] wie kaum ein anderes dazu geeignet ist, das Wesen dieser Mystik, ihren vornehmlich erkenntnishaften Charakter zu zeigen; der Spiegel ist in der Tat das unmittelbarste Sinnbild der geistigen Schau, der contemplatio, und ganz allgemein der Erkenntnis, denn durch ihn wird die Angleichung von Subjekt und Objekt veranschaulicht." It should be noted here that the philosophical polarity between the subject and object did not exist at the time. The idea 
first emerged in the works of Descartes and then was further developed by the following generations of the Western philosophers. The relationship between the mirror and the reality it reflected was comprehended in the form of "speculation."

73 Burckhardt, "Die Symbolik des Spiegels," 13 [Translation mine]. Compare with the original: "Wenn das Herz zum reinen Spiegel geworden ist, so spiegelt sich in ihm einerseits die Welt, so wie sie wirklich ist, nämlich ohne die Verzerrungen, die das leidenschaftliche Denken verschuldet. Anderseits spiegelt das Herz die göttliche Wahrheit mehr oder weniger unmittelbar, das heißt zunächst in der Gestalt von Sinnbildern (ǐšărāt), dann in der Gestalt der geistigen Eigenschaften (șfät) oder Wesenheiten ('ayān), die den Sinnbildern zugrunde liegen, und schließlich als göttliche Wirklichkeit (haqiqa)."

74 The following well-known prophet sayings ( $a h \bar{a} \bar{d} \bar{i} \underline{\underline{s}}$ ) may arguably be inter-

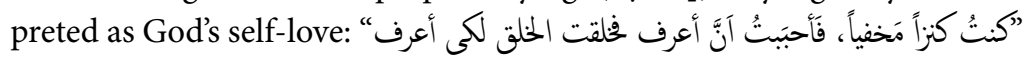
(I was a hidden treasure and I longed to be known. So I created the creation so that I may be known) and “"إن السه جميل و يحب الجمال" (God is beautiful and loves beauty).

75 See: Mūsavī, "Ā'īne dar šāhkār-hā-ye adabī", 67-75 and 86-89.

76 For a discussion of the mirror of the heart in classical Persian literature see: Zipoli, "Semiotics and the Tradition of the Image," 155-172. In this study Zipoli traces the development of mirror image in the works of three stylistically representative authors in the history of classic Persian poetry, Farrohī, Haăfeẓ, and Sā’eb. For the Persian version see: Riccardo Zipoli, A'ìne dar še'r-e Farrohñ, Sa'dī o Hāfez (Tehran: Entešārāt-e Ferdoūsī, 1366/ 1987-1988); also under the title "Ā'īne dar āščàr-e Farrohī, Sa'dī, Hậfeẓ hamrāh bā pīšnehād-ì dar zamīne-ye barresī-ye āmārī-tațbịī̄, Zekr-e ğamìl-e Sa'dī: mağmū'a-ye maqālāt o aš̀ār be monāsebat-e bozorgdāšt-e haštșadomin sālgard-e tavallod-e šeyh-e ağal Sa'dì 'alayho al-raḥma, vol. 2 (Tehran: Sāzmān-e čāp o entešārāt-e vezārat-e farhang o eršād-e eslāmī, 1373/1994): 229-256. Also see: Mūsavī, "Ā'̄ine dar šāhkār-hā-ye adabī”, 75-86.

Bīdel Dehlavi's poetry, famous for its stylistic opacity and obfuscatory ambiguities, is a plethora of mirror imagery. Šafíī-Kadkanī aptly titles his anthology of Bidel's poems "The Poet of the Mirrors." At the end of this book, he provides us with an understandably far from comprehensive glossary of the poet's mirror associations and interpretation. See: MohammadReżā Šafíīi-Kadkanī, Šā'er-e à'īne-hā: barresī-ye sabk-e hendī o še'r-e Bīdel (Tehran: Mo'asese-ye entešārāt-e āgāh, 1371/1992-1993). For the study of Bīdel's mirror imagery also see: Daniela Meneghini, "A new approach to 
analyzing the use of the word âyine (mirror) in Bīdel's ghazals" Annali di Ca' Foscari, vol. 43, Serie orientale 35 (2004): 157-171; Riccardo Zipoli, "Āyine (Mirror) in Bīdel's Ghazals. Lexical Solidarities: Āyine (Mirror) and Dāg (Brand)," Annali di Ca' Foscari, vol. 47, no. 3 (2008): 115-129; Riccardo Zipoli, "A Computer-Assisted Analysis of Bidel's Tur-e Mar'efat," Annali di Ca' Foscari, vol. 44, no. 3 (2005): 123-138.

77 "Essyān" has also been translated into "The Revolt." See: Massud Farzan, "Contemporary Poetry in Iran," Persian Literature, ed. Ehsan Yarshater (New York: The Persian Heritage Foundation, 1988), 355; and Tikku, "Furūgh-i Farrokhzād," 149-173.

78 Farrokhzad, Mağmū'a àșār, 1: 179.

79 Ibid., 180.

80 Ibid.

81 Ibid., 181.

82 Ibid., 182.

83 Ibid.

84 Ibid., 185.

85 Ibid., 182.

86 Ibid.

87 Ibid., 183.

88 In a later poem, "Esyann-e hodā" ("Divine Rebellion"), the I-narrator (Farrokhzad herself) even seeks refuge in the sexual union with Satan (206).

89 Farrokhzad, Mağmū'a āsāar, 1: 184. On the traditionally recurrent analogy between feminine beauty and the moon in Persian literature, Milani explains, "The age-old, stereotyped comparison of a woman's beauty to the moon is more than a merely physical analogy for these books. Emotionally, too, the ideal woman, like the moon, revolves around a sun in her life and takes her definition from him. The image of the ideal woman-moonfaced, emotionally moonlike, distant, virginal, silent, living in a world of muted distinctiveness and desire-haunted these autobiographers, as it did the society at large." Farzaneh Milani, "Veiled Voices: Women's Autobiographies in Iran," Women's Autobiographies in Contemporary Iran, ed. Afsaneh Najmabadi (Cambridge, Massachusetts: Harvard University Press, 1990), 15.

90 See pages 76 and 330 , notes 42 and 43 .

91 See: Dehḩodā, s.v. "sāqī-ye rūḥānìyān," Log̉atnāme, vol. 9, p. 13324.

92 Ḥāfez, Dìvān-e Hiâfez-e Šìrāzì, eds. Moḥammad Qazvīnī and Qāsem Ganāi, 86. For more explanation of the lines see page 332, note 58.

93 See: Farrokhzad, Mağmū'a āșār, 1: 183-188. 
94 Ibid., 195. Ğamāl, the mysterium fascinans or the Divine Beauty, and ğalāl, the mysterium tremendum or the Divine Majesty are two of God's attributes, usually cited together.

95 The notion of man as a mirror of God includes within it the cryptic meaning of God as a mirror of man. See: Burckhardt, "Die Symbolik des Spiegels in der islamischen Mystik," 15-16. Also see: Mūsavī, "Ā'īne dar šāhkār-hā-ye adabī," 104-107.

96 Farrokhzad, Mağmū'a āsāār, 1: 194-195.

97 Ibid., 195.

98 Ibid.

99 Employing the idea of God-Satan reciprocal mirroring, Abūbakr Vāsețī, a Sufi master in the tenth century, is reported to have attributed the following statement to Satan addressing God:

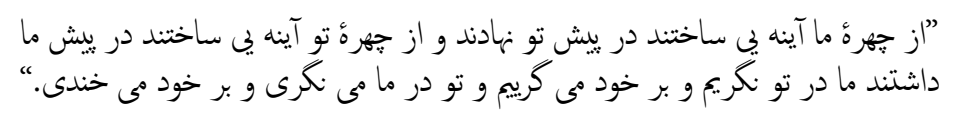

"They made a mirror out of my image and located it in front of you and made a mirror out of your image and located it in front of me. I look at you and cry at myself and you look at me and laugh at yourself."

Šayh Farīd al-Dīn 'Aț̣ār

Nī̌ābūrī, Tažkīrat al-awlīyā', ed. Moḥammad Este'lāmī (Tehran: Entešārāt-e zavvār, 1388/2009-2010), 642-643 [Translation mine].

100 Farrokhzad, Mă̆mū'a āsār, 1: 109.

101 La Belle, Herself Beheld, 22.

102 Farrokhzad, Mağmū'a àsāar, 1: 109.

103 This third person gender-free $\bar{u}$-within the broader gender neutrality of Persian language-is a source of great ambiguity and controversy in Persian literature. It has often been employed by poets shrewdly as a veiling tactic to shroud the sex of their beloved-he, she, or even God-in a cloak of disguise, thereby adding to the figurative richness of their language. Their texts have also given rise to a series of irresolvable contradictory interpretations. They could be read as: mystical or non-mystical, heterosexual or homosexual, and simultaneously all could be valid. The same could be valid in the readings of Farrokhzad. But read in the light of biographical information, I have assumed the masculinity of $\bar{u}$ and translated accordingly. 
104 Melchior-Bonnet, The Mirror, 182.

105 Taken from the title of the book, Präsenz ohne Substanz: Beiträge zur Symbolik des Spiegels, ed. Paul Michel (Zürich: Pano Verlag, 2003).

106 See: Mūsavī, "Ā'īne dar šāhkār-hā-ye adabī", 162. It is worth noting that in English the noun mirror derives from the classical Latin root mīrārī. Sharing the same root as miracle, mìrārì means "to wonder at, to admire."

107 See: Ibid., 156-167.

108 Zipoli, "Semiotics and the Tradition of the Image," 161.

109 Farrokhzad, Mă̆mū'a àsāar, 1: 109.

110 Ibid., 110.

111 Ibid.

112 For some examples of ney (reed) in Persian literature and their interpretations see: Pourjavady, Zabān-e hāl, 823-870. Nicholson chooses the word reed-flute as the English equivalent of Persian ney and marks its association "with the religious services of the Mevlevi Order, in which music and dancing are prominent features. Rūmì uses it as a symbol for the soul emptied of self and filled with the Divine spirit. This blessed soul, during its life on earth, remembers the union with God which it enjoyed in eternity and longs ardently for deliverance from the world where it is a stranger and exile." [Ğalāloddīn] Rumi, A Rumi Anthology, Rumi: Poet and Mystic Tales of Mystic Meaning, trans. Reynold A. Nicholson (Oxford: Oneworld, 2000), 31, note 1 .

113 In the poem "Donyā-ye sāye-hā" ("The World of Shadows"), Farrokhzad draws upon the shadow-another form of human double-as the version of self repressed back into the unconsciousness-a Jungian shadow. Here, the speaker wonders if she is a shadow of her own shadow; the replica, the image assimilated:

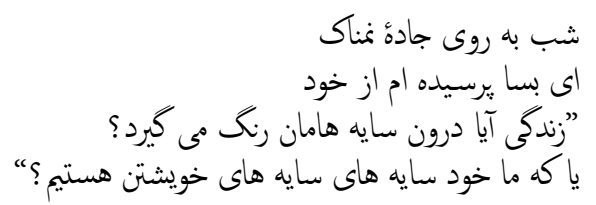

At night on the damp road

Oft have I asked myself

"Does life assume colours within our shadows?

Or are we ourselves the shadows of our shadows?"

Farrokhzad, Mă̆mū'a āsāar, 1: 169 
114 Farrokhzad, Mağmūica āsār 1 : 130.

115 Ibid.

116 Gilbert and Gubar, The Madwoman in the Attic, 78 [Italics in the original].

117 See: Donald Woods Winnicott, "Ego Distortion in Terms of True and False Self," The Maturational Process and the Facilitating Environment: Studies in the Theory of Emotional Development (New York: International University Press, 1965), 140-152.

118 Meyers, Gender in the Mirror, i and 25.

119 “Zan-hā yek dande kam dārand," $H^{w} \bar{a} n d a n \bar{i}-h \bar{a}$, vol. 16, no. 17 (9 Ābān 1955), 37. Quoted in Michael C. Hillmann, A Lonely Woman: Forugh Farrokhzad and Her Poetry (Boulder and London: Lynne Rienner Publishers, 1987), 25.

120 See: Kristeva, “A Question of Subjectivity,” 351.

121 Farrokhzad, Mağmū'a àsār 1 : 130.

122 Ibid.

123 Ibid., 131.

124 Ibid.

125 "Dar dīyārī dīgar," Ferdowsī (Mehr-Bahman, 1336/Sep.1957-Feb.58), nos. 313-320; reprinted in Farrokhzad, Mağmū'a āsār, 2: 161-204.

126 Farrokhzad, Mă̆mū'a āsāàr, 1: 223.

127 “The Nightmare Life-in-Death was she," William Wordsworth and Samuel Taylor Coleridge, Lyrical Ballads and Other Poems (Hertfordshire: Wordsworth Editions, 2003), 213.

128 Farrokhzad, Mağmū'a āsāar , 1: 224.

129 Ibid., 224-225.

130 Melchior-Bonnet, The Mirror, 195.

131 Farrokhzad, Mağmū'a āsāàr, 1: 224-225.

132 Ibid., 225.

133 Walker, Medusa's Mirrors, 45.

134 In classical Persian literature, the most popular story in which the mirror as a feminine catoptric device of deception has been invoked is the story of Yūsof and Zolīhā. Originally a Qur’ānīc story, it was adopted by some classical poets. In this story, the close intimacy of women with their mirrors and the deceptive nature of the mirror have been drawn upon to entrap the subject within the self and within the physical world of appearances. The mirror is turned into a feminine weapon of the femme fatale and has been recurrently associated with sin, and for that reason with Eve, the original sinner and seducer. For the mirror as a powerful tool of deception and temptation to sin in the story of Yūsof and Zolīhā see: Firdausî of Țûs, Yûsuf 
and Zalîkhâ: The Biblical Legend of Joseph and Potiphar's Wife in the Persian Version, ed. Hermann Ethé (Amsterdam: Philo Press, 1970), 349-355, 361-362. In this story, in order to invite Yūsof to have physical intimacy and sex with her, Zolīhā builds a palace whose interior is covered with mirrors on all sides, thereby creating a private world of solipsism. For a study of the "feminine guile" in the Qurānic story of Yūsof and Zolīhā see: Gayane K. Merguerian, and Afsaneh Najmabadi, "Zulaykha and Yusuf: whose 'best story?"' International Journal of Middle East Studies, no. 29 (1997): 485-508.

Melchior-Bonnet in her book The Mirror writes, "[The mirror] became the extravagant tool of women's coquetry and even an instrument of pleasure that certain Roman citizens, like Hostius Quadra, liked to surround themselves with to multiply and increase their lover's sexual attributes." (p. 107)

135 In the poem "Gereh" ("The Knot") (pp. 220-222), Farrokhzad highlights the distorted and asymmetrical character of the mirror image by metaphorizing the mirror to a fog: "لغزيده بود در مه آينه/ تصوير ما شكسته و بي آهنك "Slipped into the fog of the mirror/our images crooked and out of harmony." The poem depicts the persona's confused and disharmonic relation to her subjectivity, extended to her beloved and the world around her by resorting to a mirror.

136 See: Sirous Shamisa, "Forugh Farrokhzad's Apocalyptic Visions," Forugh Farrokhzad, Poet of Modern Iran: Iconic Woman and Feminine Pioneer of New Persian Poetry, eds. Dominic Parviz Brookshaw and Nasrin Rahimieh (London and New York: I.B. Tauris, 2010): 109-124.

137 See: Farrokhzad, Mağmū'a àșār, 1: 289-29o.

138 Ibid., 290.

139 For more on the mirror and eye see pp. 79-81.

140 Radio interview with Hasan Honarmandī, Tehran 1341/1962-1963; published in Farrokhzad, Mağmū'a āsārr, 2: 26. Compare with the original:

$$
\begin{aligned}
& \text { اكر شا دقت كرده باشيد مى بينيد توى زمانى داريم زندكى مى كنيم كه تمام مفاهيم و مقياسها }
\end{aligned}
$$

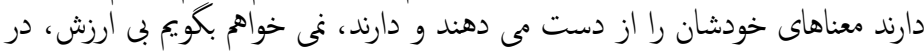

$$
\begin{aligned}
& \text { حال متزلزل شدن هستند. }
\end{aligned}
$$

141 Interview with Sīrūs TTāhbāz and Ġolām-Hosseyn Sāedī, Spring 1343/1964; reprinted in Farrokhzad, Mağmū'a āṣār, 2: 40. Compare with the original:

$$
\text { “دنياى بيرون ... آنقدر وارونه است كهنى خواهم باورش كن." }
$$

142 Farrokhzad, Mağmū'a āșār, 1: 293. 
143 Lacan, “The Mirror Stage," 76.

144 Rivanne Sandler, "Words of Attachment: Literary Antecedents of Expatriate Iranian Women," Iran. Questions et connaissances, vol. III: Cultures et sociétés contemporaines, ed. Bernard Hourcade (Paris: Peeters Publishing, 2004), 131-132 [Italics in the original].

145 Farrokhzad, Mağmū'a āsārr, 1: 295, 299 and 300.

146 Sigmund Freud, “The 'Uncanny"' The Standard Edition, 226.

147 Farrokhzad, Mağmū'a àsāar, 1: 295.

148 It is noteworthy here that myriad meanings can be attached to the word haqq, making the sentence "haqq bā kasi-st ke mìbinad" ambiguous. Haqq not only means "right" and "just," but can also stand for "the Truth (= God)," particularly in the Sufi context. Therefore, the sentence can also be rendered as: "The Truth is with the one who sees," making "haqq" the subject of the sentence. However, considering that Farrokhzad was an anti-transcendental poet, this is unlikely to have been her intention.

149 Farrokhzad, Măğmū'a àsāar, 1: 295-296.

150 La Belle, Herself Beheld, 119.

151 Farrokhzad, Mağmū'a àsāàr, 1: 296.

152 See: Carl Gustav Jung, Aion: Researches into the Phenomenology of the Self, trans. R.F.C. Hull (Princeton, N.J.: Princeton University Press, 1978), 8-10.

153 Ibid., 9.

154 See pp. 73 and 144.

155 Farrokhzad, Mă̆mū'a àsāàr, 1: 296.

156 Shengold, “The Metaphor of the Mirror," 100.

157 Farrokhzad, Mağmū'a āsāār, 1: 296-297.

158 Ibid., 297.

159 See: Ibid., 297-298.

160 Ibid., 298.

161 See: Michael Ferber, s.v. "Raven," A Dictionary of Literary Symbols (Cambridge and New York: Cambridge University Press, 2007), 167-169.

162 Milani, Veils and Words, 151.

163 See: Schimmel, As Through a Veil, 76.

164 Categorizing this poem as a symbolic one, Šamīsā indicates that here "the mirror is a symbol for mind and memories," while "the shutter can be a symbol for seeing, communication and understanding." These interpretations, though valid and illuminating for the reader, fail to expose the complexities of the poem. Sīrūs Šamīsā, Rāhnamā-ye adabìyāt-e mo'āṣer: šarḥ o taḥlīl-e gozīde-ye še re fārsī (Tehran: Entešārāt-e mītrā, 2004), 291.

165 Farrokhzad, Mă̆mū'a āsāàr, 1: 229.

166 Lacan, “The Mirror Stage," 78. 
167 Forugh Farrokhzad, Avvalīn tapeš-hā-ye 'āšeqāne-ye qalbam: nāme-hāye Forugh Farrokhzad be hamsaraš Parvīz Šāpūr, ed. Kāmyār Šāpūr and 'Omrān Șāleḥi (Tehran: Entešārāt-e morvārīd, 1381/2003), 228-230. Compare with Persian original:

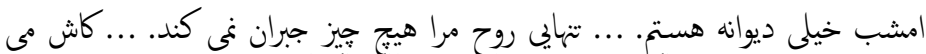

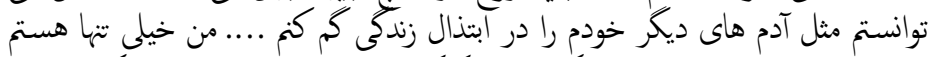

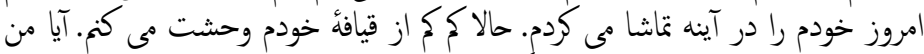

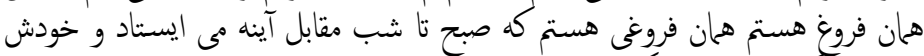

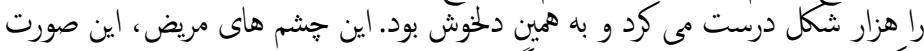

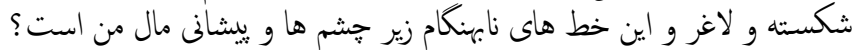

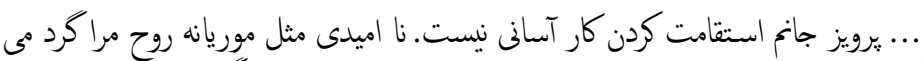

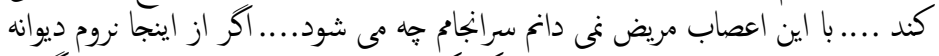

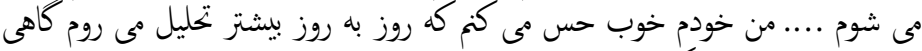

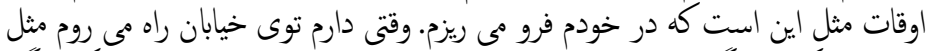

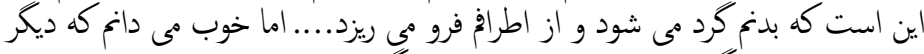

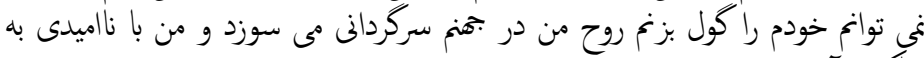

$$
\begin{aligned}
& \text { خاكستر آن خيره مى شوم. }
\end{aligned}
$$

168 Farrokhzad, Mă̆mū'a āsāàr, 1: 299.

169 Ibid., 300.

170 In Persian dar-i-čce literally means a small door. Dar means door and -če (like the suffix -let in English language) is a diminutive suffix. Here the words shutter and window are used as equivalents for dar-ī-če. See: Farrokhzad, Mağmū'a āsārr, 1: 295 and 299. On the use of panğare (window), it is pertinent to note that the word originally meant a lattice or cage; in that sense, although it seems far from Farrokhzad's intention, panğare can also signify the poet's feelings of confinement and entrapment. See: Dehhodā, s.v. "panğare”, Log̀atnāme, vol. 4, pp. 5743-5744.

171 Interview with Sīrūs Ṭāhbāz and Ġolām-Hosseyn Sāeedī, Spring 1343/1964; reprinted in Farrokhzad, Mağmū'a āsāar, 2: 40 [Translation mine]. Compare with the original:

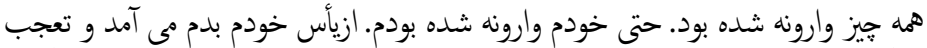

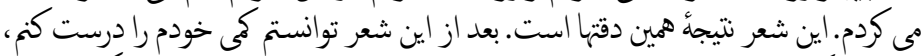

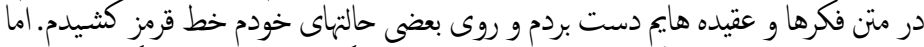

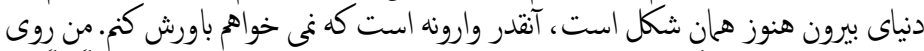

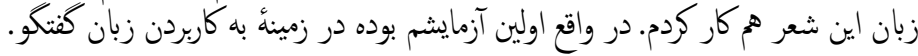


172 Amin Banani and Jascha Kessler translated vahm as "terror". "Green Terror" Gramercy Review, A Journal of Contemporary Poetry and Fiction, vol. 2 (1978), 53; Hasan Javadi and Susan Sallée into "illusion". Another Birth and Other Poems, 83; and David Martin into "Fantasy". A Rebirth, 66. All these meanings are contained within the Persian world vahm.

173 Farrokhzad, Mağmū'a āsārr, 1: 301.

174 Milani, Veils and Words, 69.

175 La Belle, Herself Beheld, 161.

176 C.G. Jung, "Commentary," in Richard Wilhelm, The Secret of the Golden Flower (New York: Harcourt Brace Jovanovich, 1962), 91.

177 Farrokhzad, Mă̆mū'a āsār $, 1:$ 301-302.

178 Ibid., 302.

179 Ibid.

180 Ibid., 302-303.

181 Milani, Veils and Words, 66.

182 Farrokhzad, Mağmū'a āsār, 1: 303. For the explanation of the $\bar{a} b$-e $\breve{g} \bar{a} d \bar{u}$, translated as "talismanic water" by Javadi and Sallée, they have provided thus: "When a man took a second wife, it was important to the first wife that she safeguard her hold upon the man's affections, and to do so she would employ various superstitious devices. One such device was to sprinkle specially prepared water over the nuptial bed of the new bride, a custom to which Forugh refers in this line." Farrokhzad, Another Birth and Other Poems, 87.

183 See: Dehhodā, s.v. “taṣarrof," Loġatnāme, vol. 5, pp. 6770-6771.

184 Note that if the term is read as $\check{s} e k \bar{a} k$, though not in common usage, it means "the houses in one row." However, this reading of the word would not fit with the meter of the poem. See: Dehhodā, s.v. "šekāk" Logiatnāme, vol. 9, p. 14356.

185 "The Road Not Taken" a poem by Robert Frost.

186 Barbara Johnson, The Critical Difference: Essays in the Contemporary Rhetoric of Reading (Baltimore and London: The Johns Hopkins University Press, 1980), 106.

187 Ibid.

188 Farrokhzad, Mă̆mū'a āsāar, 1: 303-304.

189 Woolf, A Room of One's Own, 75.

190 Farrokhzad, Mağmū'a àsāàr, 1: 324.

191 Irigaray, Speculum of the Other Woman, 189 [Italics in the original].

192 See: Cixous, “The Laugh of the Medusa," 881.

193 Rich, Of Woman Born, 220. 
194 Gallop, The Daughter's Seduction, 116.

195 Kristeva, Desire in Language, 195 [Italics in the original].

196 Ibid.

197 Irigaray, "And the One Doesn't Stir without the Other," 63.

198 Birkle, Women's Stories of the Looking Glass, 16.

199 Kristeva, Desire in Language, 194-195.

200 Ibid., 195 [Italics in the original].

201 Farrokhzad, Mağmūica āsār , 1: 324.

202 Paula Bennett, My Life a Loaded Gun: Female Creativity and Feminist Poetics (Boston: Beacon Press, 1986), 5.

203 Mitchell, Women, the Longest Revolution, 294.

204 See: Farrokhzad's poem "Meeting at Night”, Mă̆mū'a āsāar, 1: 296.

205 Hélène Cixous, "Coming to Writing” and Other Essays, ed. Deborah Jenson (Massachusetts: Harvard University Press, 1991), 36.

206 Melchior-Bonnet, The Mirror, 162.

207 The phrase "new woman" was popularized by Sarah Grand (1854-1943), an Irish-born feminist writer. The "new woman," as a modern feminist ideal of the liberated woman, emerged at the end of the nineteenth century.

208 Winnifred Harper Cooley, The New Womanhood (New York: Broadway Publishing Company, 1904), 31.

209 Milani, "Veiled Voices," 50.

210 Farrokhzad, Mă̆mū'a āsāar, 1: 337.

211 Ibid., 340.

212 Ibid., 338 and 340.

213 Ibid., 337-338. The Persian month Dey is the first month of winter, corresponding to December-January.

214 Ibid., 338.

215 Ibid., 339.

216 Ibid. Farrokhzad evokes the image of the garden once again at the end of the poem. This time she addresses her reader, soliciting him/her to believe in the "ruins of imagination's gardens" (ibid., 347). For a study of Forugh Farrokhzad's spatial dynamics of "home" and "garden" and their evolution see: Dominic Parviz Brookshaw, "Places of Confinement, Liberation, and Decay: The Home and the Garden in the Poetry of Forugh Farrokhzad," Forugh Farrokhzad, Poet of Modern Iran: Iconic Woman and Feminine Pioneer of New Persian Poetry, eds. Dominic Parviz Brookshaw and Nasrin Rahimieh (London and New York: I.B. Tauris, 2010): 35-52.

217 Ibid., 339. 
218 Ibid., 339-340.

219 See pp. 73 and 115.

220 Farrokhzad, Mă̆mū'a āsāàr, 1: 341.

221 Ibid., 345.

222 Lacan, “The Mirror Stage," 78.

223 Farrokhzad, Mağmū'a āsār $r$ 1: 341.

224 Shengold, "The Metaphor of the Mirror," 101.

225 Farrokhzad, Mağmū'a āsār $r$ 1: 342.

226 Irigaray, "And the One Doesn't Stir without the Other," 66.

227 Melchior-Bonnet, The Mirror, 102. For mirror as a symbol of purity in Persian literature see: Mūsavī, "Ā'īne dar šāhkār-hā-ye adabīi," 55 and 77. "Speculum sine macula" is one of the popular attributes of the Virgin Mary, signifying her immaculate purity. Hans Biedermann explains, "the mirror is also associated with VIRGIN MARY, because she gives us God's image and reflection, Jesus Christ, without the mirror (Mary herself) being changed or broken in the process". Dictionary of Symbolism, trans. James Hulbert (New York: Facts On File, 1992), 223.

228 Farrokhzad, Mă̆mū'a āsāar, 1: 342.

229 See: Farrokhzad, "İmān bīyāvarīm, 1: 337, 342, 344 and 347; "Bāzgašt,"

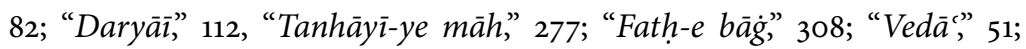
"Panğare," 355; “Ān rūz-hā", 244; "Enteqām," 57; among others.

230 The word simmorg consists of two parts: $s \bar{l}$ meaning thirty and morg meaning bird. The Persian Sufi poet, Farīd od-Dīn 'Ațtār (d. ca. 1221), based his allegorical work, Manteq-ot-teir (1177), on the existing pun in the word simorg. The work is translated into English as The Conference of the Birds. For more about sīmorg see: Hanns-Peter Schmidt, "The Sēnmurw, Of Birds and Dogs and Bats," Persica, vol. 9 (1980): 1-85.

231 Irigaray, Speculum of the Other Woman, 19 and 47.

232 Farrokhzad, Mă̆mū'a àsār $1: 345$.

233 Ibid., 344.

234 Ibid., 355.

235 Ibid., 355-356. In the poem "Arūsak-e kūkì" (“The Clockwork Doll”), Farrokhzad has metaphorized women of her society to dolls to highlight their passive, mechanical position. Ibid., 274-276. Cf. Sylvia Plath's poem "The Munich Mannequins".

236 Ibid., 356.

237 Ibid., 356-357.

238 The traditional, particularly medieval, concept of the mirror held that its surface should reflect nothing but the divine Truth, i.e., the image of God. 
If the mirror failed to reiterate the image of God, it was generally vilified by theologians and moralists as the wellspring of human desire, vanity and demonic presences. On the other hand, in arguing the mirror's instructing capacities, some refer to Socrates' mirror. According to Diogenes, Socrates "recommended to the young the constant use of the mirror, to the end that handsome men might acquire a corresponding behaviour, and ugly men conceal their defects by education." Diogenes Laertius, Lives of Eminent Philosophers, trans. Robert Drew Hicks (Cambridge, Massachusetts: Harvard University Press and London: William Heinemann, 1950), vol. I, 165.

239 Šamīsā suggests that the mirror in the poem "Window" stands for the self, heart, mind and the interior (Šamīsā, Rāhnamā-ye adabīyāt-e mo'āṣer, 335). In this sense, Farrokhzad seems to be drawing upon the popularly recurrent motif in Persian classic literature: the mirror as a symbol standing for the heart, soul and interior, as discussed earlier. Therefore, the oxymoronic nature of the mirror, revealing to the person in front of it exactly what it cannot in fact reflect, is utilized.

240 Freud, “The 'Uncanny”, 236.

241 Farrokhzad, Mağmū'a āsāàr, 1:338: “"نجات دهنده در كور خفته است "The saviour is hibernating in the grave").

242 Ibid., 357.

243 Ibid.

244 Susan Squier, "Mirroring and Mothering: Reflections on the Mirror Encounter Metaphor in Virginia Woolf's Works," Twentieth Century Literature, vol. 27, no. 3 (Autumn, 1981), 284.

245 Interview with Sīrūs Ṭāhbāz and Ġolām-Hosseyn Sāeedī, Spring 1343/1964; reprinted in Farrokhzad, Mağmū' $a$ āsār $2: 35$.

246 Ibid., 36 [Translation mine]. Cf. with the original:

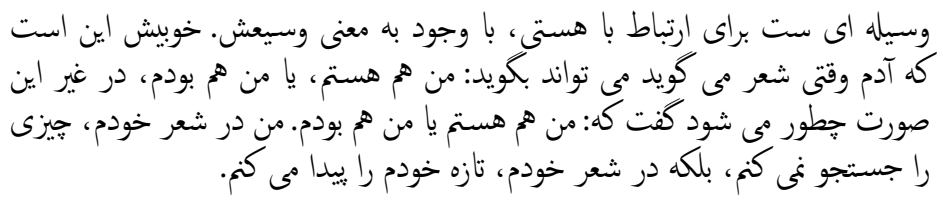

247 Ibid., 51-52 [Translation mine]. Cf. with the original:

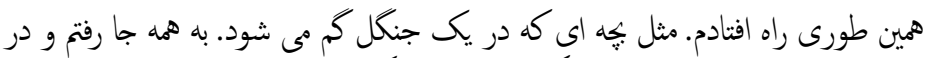

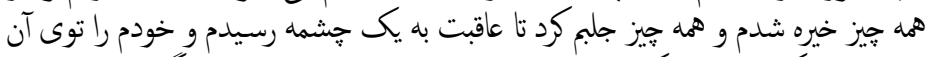

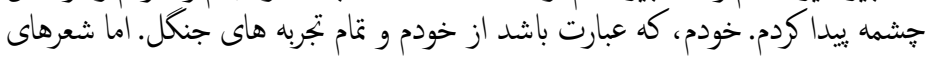




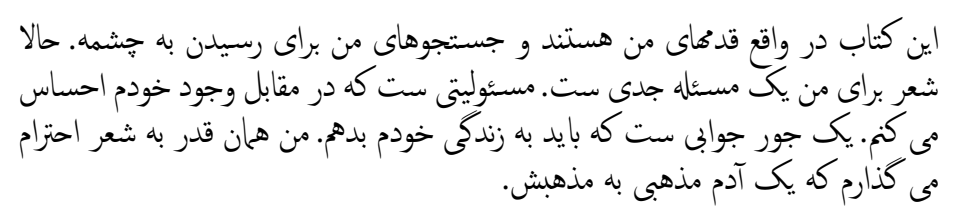

248 Cixous, “The Laugh of the Medusa," 879-88o.

249 Forugh Farrokhzad's Interview with Șadr od-Dīn Elāhī (5 Esfand 1345/24 February 1967); reprinted in Farrokhzad, Mă̆mū'a āsār, 2: 70. Cf. with the original:

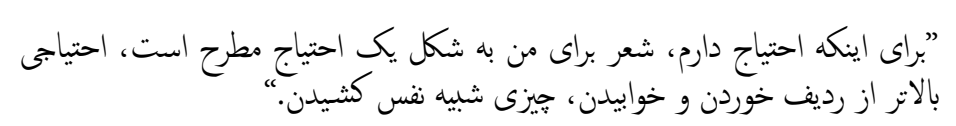

250 Milani, Veils and Words, xv.

251 Ibid., 6.

\section{Chapter Three}

$1 \quad$ James George Frazer, “The Perils of the Soul," The Golden Bough: A Study in Magic and Religion, abridged ed. (New York: Macmillan, 1943): 178-193. Otto Rank, “The Double as Immortal Self," Beyond Psychology (New York: Dover, 1958), 62-101; Sigmund Freud, “The 'Uncanny," The Standard Edition: 217-252. See: Steven Gould Axelrod, “The Mirror and the Shadow: Plath's Poetics of Self-Doubt," Contemporary Literature, vol. 26, no. 3 (Fall 1985): 287-289.

2 Sylvia Plath, The Magic Mirror: A Study of the Double in Two of Dostoevsky's Novels, Unpublished BA Honor Thesis (Northampton, Massachusetts: Smith College, Mortimer Rare Book Room [MRBR], 1955), 2; Quoted in Nephie Christodoulides, Out of the Cradle Endlessly Rocking: Motherhood in Sylvia Plath's Work (New York: Rodopi, 2005), 180-181.

3 Plath, op. cit., 59-60; Quoted in Pamela J. Annas, A Disturbance in Mirrors: The Poetry of Sylvia Plath (Amsterdam and New York, Connecticut and London: Greenwood Press, 1988), 5; and in Christodoulides, op. cit., 34.

4 Axelrod, "The Mirror and the Shadow," 301.

5 Ibid, 286-287.

6 Dijkstra, Idols of Perversity, 143-144. For a more detailed study of the topoi of femmes fatales see: Helen Hanson and Catherine O'Rawe (eds.), The Femme Fatale: Images, Histories, Contexts (Hampshire, UK: Palgrave 
Macmillan, 2010); Virginia M. Allen, The Femme Fatale: Erotic Icon (Troy, NY: Whitston, 1983).

7 Gemini was a literary magazine established by Cambridge and Oxford faculty and students in 1957. See: Edward Butscher, Sylvia Plath: Method and Madness (Tucson: Schaffner Press, 2003), 195.

8 Jane M. Ussher, Women's Madness: Misogyny or Mental Illness? (New York and London: Harvester, 1991), 80.

9 Meyers, Gender in the Mirror, i.

10 Sylvia Plath, "Vanity Fair" and "Spinster," The Collected Poems, ed. Ted Hughes (New York: HarperPerennial, 1992), 32-33 and 49-50. All the references to Sylvia Plath's poems are to this book.

11 Ibid., 32.

12 Melchior-Bonnet, The Mirror, 204-205.

13 Julia Kristeva, Powers of Horror: An Essay on Abjection, trans. Leon S. Roudiez (New York: Columbia University Press, 1982), 2.

14 See: J.C. Cooper, An Illustrated Encyclopaedia of Traditional Symbols (London: Thames and Hudson, 1978), 47.

15 Cooper, An Illustrated Encyclopaedia of Traditional Symbols, 137.

16 Plath, The Collected Poems, 32-33.

17 Ibid., 33 .

18 Grillot de Givry, Witchcraft, Magic and Alchemy, trans. J. Courtenay Locke (New York: Dover Publications, 1971), 54.

19 Ibid., 51.

20 Plath, The Collected Poems, 33.

21 Sabine Melchior-Bonnet, "Figures de miroirs dans la culture médiévale," Miroirs: Jeux et reflets depuis l'antiquité (Paris: Somogy Editions d'Art, 2000), 108-109; translated and quoted in Maillet, The Claude Glass, 47-49.

22 That is why it is considered inappropriate for nuns to carry mirrors or to look at them. In countries like Iran, which have based their education system on religious and traditional teachings, the mirror is among those items most strongly forbidden for young girls to carry with them in school, because it is seen as facilitating vanity and self-idolatry. Furthermore, the mirror has the power to grant individuality, a distinctive self-image, which is feared most in female subjects and consistently repressed in fundamental religious contexts.

23 See: Al Alvarez, "How Black Magic Killed Sylvia Plath," The Guardian, G2, 15 September 1999; accessed on March 18, 2012, http://www.theguardian .com/theguardian/1999/sep/15/features11.g2

24 Melchior-Bonnet, The Mirror, 187. 
25 Ibid., 129.

26 Plath, The Collected Poems, 325.

27 Freud, “On Narcissism," 89.

28 Ibid., 91.

29 Plath, The Collected Poems, 259.

30 Ibid.

31 See: Ferber, A Dictionary of Literary Symbols, 198.

32 Plath, The Collected Poems, 259.

33 Hieronymus Bosch, Garden of Delights, ca. 1500, The Prado Musem, Madrid.

34 Melchior-Bonnet, The Mirror, 208.

35 William Shakespeare, "The Merchant of Venice," The Complete Works (London: Abbey Library, 1974), (3.2.124-127), 203.

36 See: Ferber, A Dictionary of Literary Symbols, 198-199.

37 Shakespeare, "The Famous History of King Henry the Eighth," The Complete Works, (1.1.63), 621.

38 In the 1963 poem "Totem," Plath depicts the spiritual barenness of the self with resort to the same symbolic elements of the mirror and the weaving spider:

There is no terminus, only suitcases

Out of which the same self unfolds like a suit

Bald and shiny, with pockets of wishes,

Notions and tickets, short circuits and folding mirrors.

I am mad, calls the spider, weaving itself many arms.

Plath, The Collected Poems, 264-265

39 Plath, The Collected Poems, 259.

40 For instance see the poem "Three Women" in which Plath invariably refers to pregnancy through the metaphor of a hill (Ibid., 176, 180, 183 and 186).

41 Plath, The Collected Poems, 157.

42 Plato, The Republic, trans. Benjamin Jowett (Mineola, New York: Dover Publications, 2000), 253.

43 Plath, The Collected Poems, 157.

44 Susan Bassnett, Sylvia Plath: An Introduction to the Poetry (Hampshire and New York: Palgrave Macmillan, 2005), 84.

45 Plath, The Collected Poems, 267. 
46 Tim Kendall, Sylvia Plath: A Critical Study (London and New York: Faber and Faber, 2001), 197.

47 Plath, The Collected Poems, 267.

48 Oates links the gigolo's ever-lasting youth to Plath's “ideal self." He remarks that the gigolo "will never age because-like Plath's ideal self-he is a perfect narcissus, self-gratified. He has successfully dehumanized himself." Joyce Carol Oates, "The Death Throes of Romanticism: The Poetry of Sylvia Plath," Ariel Ascending: Writings about Sylvia Plath, ed. Paul Alexander (New York: Harper and Row, 1985), 43; reprinted in The Southern Review, vol. IX, no. 3 (Summer, 1973): 501-522.

49 Plath, The Collected Poems, 268.

50 Ibid.

51 Jack Tresidder, s.v. "oyster," The Watkins Dictionary of Symbols (London: Watkins, 2008), 141.

52 Plath, The Collected Poems, 268.

53 Jeanne A. Nightingale, "From Mirror to Metamorphosis: Echoes of Ovid's Narcissus in Chrétien's Erec et Enide," The Mythographic Art: Classical Fable and the Rise of the Vernacular in Early France and England, ed. Jane Chance (Gainesville: University Press of Florida, 1990), 57.

54 Philippa Berry, Of Chastity and Power: Elizabethan Literature and the Unmarried Queen (London: Routledge, 1989), 2 [Emphasis in the original].

55 Lucy Hutchinson, Memoirs of the Life of Colonel Hutchinson, with Fragment of an Autobiography of Mrs. Hutchinson, ed. James Sutherland (London: Oxford University Press, 1973), 10. The book was first published in 1806. Hutchinson applies the mirror metaphor for her husband, too. But interestingly this time he is "the mirror that reflected the creator's excellence." (Ibid., 2). Hutchinson is an illuminating example of the firm puritan ideological faith in the subjection of men to God and women to the God in their men ("He for God only, she for God in him"). (Ibid., xviii).

56 Ibid., 32-33.

57 Ibid., 33. For a more detailed study see: N.H. Keeble, “'The Colonel's Shadow': Lucy Hutchinson, Women's Writing, and the Civil War," Literature and the English Civil War, eds. Thomas Healy and Jonathan Sawday (Cambridge: Cambridge University Press, 1990): 227-247.

58 Hutchinson, Memoirs of the Life of Colonel Hutchinson, 31.

59 Goethe's letter dated 8 January 1781 is as follows: "Schweer enthalt ich mich noch einmal in meinen liebsten Spiegel zu sehen, die schöne Dämmerung lockt mich aus der Stube. Wenn Sie nur auch sähen wie lieblich es iezt um mich herum ist. Gute Nacht meine beste. Ich habe keine zusammen- 
hängende Gedancken, sie hängen aber alle zusammen an Ihnen. Addio." Johann Wolfgang von Goethe, Goethes Briefe an Charlotte von Stein, ed. Jonas Fränkel (Berlin: Akademie Verlag, 1960), vol. I, 264.

60 See: Dijkstra, Idols of Perversity, 127.

61 Woolf, A Room of One's Own, 35-36.

62 For a detailed study of Virginia Woolf's mirror metaphors see: Squier, "Mirroring and Mothering," 272-288. The analogy of the mirror and woman's face has also been the cornerstone of Winnicott's study of the psychology of individual development which sees "the mother's face" as "the precursor of the mirror." Winnicott, "Mirror-Role of Mother and Family in Child Development," 149. In both the child and adult experiences, the woman's face provides mirroring essential for the psychological sustenance.

63 Irigaray, "And the One Doesn't Stir without the Other," 66.

64 Irigaray, Speculum of the Other Woman, 22 and 335 [Italics in the original].

65 Mary Daly, Beyond God the Father: Toward a Philosophy of Women's Liberation (Boston: Beacon Press, 1985), 62. By "the Other," Daly was specifically referring to Jews, women and Vietnamese.

66 Butscher, Sylvia Plath: Method and Madness, 330.

67 Ibid., 330.

68 Marjorie Perloff, "The Two Ariels: The (Re)Making of the Sylvia Plath Canon," Poems in Their Place: The Intertextuality and Order of Poetic Collections, ed. Neil Fraistat (Chapel Hill and London: The University of North Carolina Press, 1986), 326.

69 For the various meanings and usages of the Persian word parde see: Dehḩodā, s.v. "parde," Loġatnāme, vol. 4, pp. 5484-5492.

70 Milani explains, "Like Parde-ye Bekärat [the hymen or, more literary, the virginity curtain] that stands for and becomes an instrument of regulation of women's sexuality, the veil reasserts men's control over the gateway to women's bodies." Milani, Veils and Words, 23.

71 In Persian musicology, parde pertains to stringed instruments. For more on parde in musicology see: Taqī Bīneš and Hūman Asadī, "Parde," The Great Islamic Encyclopaedia, ed. Kāzem Mūsavī Boğnūrdī (Tehran: The Centre for the Great Islamic Encyclopaedia, 2005), vol. XIII, 591-592. The multiple meanings of the word parde invited much punning and ambiguity. The Persian poet, Rūmī (d. 1273) at the beginning of his Mathnavi, referring to the reed, says: “برده هايش يرده هاى ما دريد": His pardes (reed’s melodies) tore apart our pardes (this-worldly veils coming between him and his lord). (Mathnavi, I, line 11). 
72 See: Mūsavī, "Ā'īne dar šāhkār-hā-ye adabî,"159.

73 Maillet, The Claude Glass, 19.

74 Gilbert and Gubar, The Madwoman in the Attic, 468-469.

75 Ibid., 472.

76 For instance, Abū Hāmed Ghazālī, the renowned Muslim philosopher (1050-1111) in his Ihyā' 'olūm al-dīn claims that "the look is fornication of the eye." See: Fatima Mernissi, Beyond the Veil: Male-Female Dynamics in Modern Muslim Society (Bloomington: Indiana University Press, 1987), 141.

77 For an elaborate study of the veil's function in text see: Patricia Oster, Der Schleier im Text: Funktionsgeschichte eines Bildes für die neuzeitliche Erfahrung des Imaginären (Munich: Wilhelm Fink Verlag, 2002).

78 See: Kendall, Sylvia Plath, 68 and 166.

79 Plath, The Collected Poems, 242.

80 Kroll, Chapters in a Mythology, 164. Neẓāmī Ganğavī (d. between 1210 and 1215), the famous Persian classic poet, mimicking the dominant cultural belief on the nature of the women and punning on the Persian word rāst,

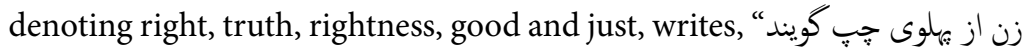
"برخاست/نيايد هركز از جֶٍ راستى راست "Woman, it is said, rose from the left side/Never did rightness come out of the left"). The same pun is evoked by Nūr ed-Dīn 'Abd ar-Raḥmān Jāmī (d. 1492) to reiterate the same meaning,

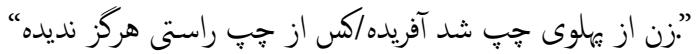

81 See: s.v. “jade.” Merriam-Webster.com. Merriam-Webster, n.d. Web. 14 Mar. 2014. http://www.merriam-webster.com/dictionary/jade.

82 Freud, "On Narcissism," 89.

83 Ibid. For an elaborate study of Freud's figuration of women as enigmatic beings see: Sarah Kofman, L'Énigme de la femme: La femme dans les textes de Freud (Paris: Editions Galilée, 1980).

84 Plath employs the association of the cat and woman in some of her poems. See the poems: "Aerialist," "A Sorcerer Bids Farewell to Seem," "Ella Mason and Her Eleven Cats," "Face Lift," "Insomniac," “The Other," "The Jailer," "Lesbos" and "Lady Lazarus."

85 Gilbert and Gubar, The Madwoman in the Attic, 471.

86 Plath, The Collected Poems, 242.

87 Ibid., 259.

88 Irigaray, Speculum of the Other Woman, 47 [Italics in the original].

89 Kroll, Chapters in a Mythology, 163. For more about the centrality of the image of the Moon in Plath's poems refer to this book.

90 Irigaray, The Sex Which Is Not One, 28 [Italics in the origin]. 
91 Plath, The Collected Poems, 242-243.

92 Aristotle, Rhetoric, trans. W. Rhys Roberts, ed. W.D. Ross (New York: Cosimo, 2010), 126-127.

93 Plath, The Collected Poems, 243.

94 Dijkstra, Idols of Perversity, 132.

95 Plath, The Collected Poems, 243.

96 Ibid.

97 See: Ferber, s.v. "peacock," A Dictionary of Literary Symbols, 151.

98 The American edition of Winter Trees, also confirmed by Plath's voice recording of the poem, her handwritten drafts and her typescripts, has the word "plies" instead of "flies." See: Tracy Brain, The Other Sylvia Plath (London: Longman, 2001), 25.

99 Plath, The Collected Poems, 243-244.

100 Aeschylus, Oresteia, trans. Christopher Collard (New York: Oxford University Press, 2002), 35 .

101 Christina Britzolakis, "Ariel and Other Poems," The Cambridge Companion to Sylvia Plath, ed. Jo Gill (Cambridge: Cambridge University Press, 2006), 120.

102 Bassnett, Sylvia Plath: An Introduction to the Poetry, 112; Steven Gould Axelrod, Sylvia Plath: The Wound and the Cure of Words (London: The Johns Hopkins University Press, 1990), 232.

103 Margaret Dickie Uroff, Sylvia Plath and Ted Hughes (Urbana: University of Illinois Press, 1979), 164-165.

104 See: Plath, The Collected Poems, 244-247. It is important to note that Plath completed her poem "Lady Lazarus" within the same day she wrote "Purdah".

105 Al Strangeways, Sylvia Plath: The Shaping of Shadows (Cranbury, NJ, and London: Associated University Presses, 1998), 172.

106 J.D. O’Hara, "Plath's Comedy," Sylvia Plath: New Views on the Poetry, ed. Gary Lane (Baltimore and London: The Johns Hopkins University Press, 1979), 85.

107 Leonard Sanazaro, “The Transfiguring Self: Sylvia Plath, a Reconsideration," Critical Essays on Sylvia Plath, ed. Linda W. Wagner (Massachusetts: G.K. Hall \& Company, 1984), 88-89. Also in: Centennial Review, vol. 27 (Winter 1983): 62-74.

108 O'Hara, "Plath's Comedy," 86.

109 See: Winnicott, "Ego Distortion in Terms of True and False Self," 140-152.

110 Judith Butler, Bodies That Matter: On the Discursive Limits of "Sex" (New York: Routledge, 1993), 233. 
111 On the metaphorical topos of the woman as a mirror to male ego, I have benefited from Corey M. Werner's study of Shakespeare's mirror imagery in his "The Mirror Cracked: Femininity and the Rhetoric of Castration in Shakespeare's 'The Rape of Lucrece', a paper presented at the 2oth International Literature and Psychology Conference (University of Greenwich, London: 2003), accessed on 6 February 2009, http://www .clas.ufl.edu/ipsa/2003/IPSAarticle.html.

112 Butscher, Sylvia Plath: Method and Madness, 204.

113 Sylvia Plath, Letters Home: Correspondence 1950-1963, ed. Aurelia Schober Plath (London and Boston: Faber and Faber, 1988), 306.

114 Plath, The Collected Poems, 70.

115 Ibid.

116 Ibid.

117 Foucault, "Of Other Spaces," 24.

118 Ibid.

119 See: Maillet, The Claude Glass, 50.

120 Christodoulides, Out of the Cradle Endlessly Rocking, 154.

121 Plath's vehement resentment of her mother's powerful grip over her is also the subject of her 1962 poem, "Medusa." Here Plath depicts her mother in terms of a Medusan figure, linking her name Aurelia to aurela, the jellyfish medusa. At the end of the poem, she assertively rejects any sort of relationship between herself and her mother: "There is nothing between us." Plath, The Collected Poems, 226.

122 Christodoulides, Out of the Cradle Endlessly Rocking, 158.

123 Plath, The Collected Poems, 210.

124 Ibid.

125 Simone de Beauvoir, Hard Times: Force of Circumstance, II, 1952-1962 (New York: Paragon House, 1992), 378.

126 Plath, The Collected Poems, 71.

127 Gary Lane, "Influence and Originality in Plath's Poems," Sylvia Plath: New Views on the Poetry, ed. Gary Lane (Baltimore and London: The Johns Hopkins University Press, 1979), 122.

128 Butscher, Sylvia Plath: Method and Madness, 13.

129 C. G Jung, "The Archetypes and the Collective Unconscious," trans. R.F.C. Hull, vol. 9, The Collected Works of C.G. Jung (Princeton: Princeton University Press, 1968), 24-25.

130 Plath, The Collected Poems, 71.

131 Ovid, Metamorphoses, 15: 234; Shakespeare, sonnet XIX.

132 Plath, The Collected Poems, 71. 
133 Kristeva, Desire in Language, 195.

134 Murray M. Schwartz and Christopher Bollas, "The Absence at the Center: Sylvia Plath and Suicide," Sylvia Plath: New Views on the Poetry, ed. Gary Lane (Baltimore and London: The Johns Hopkins University Press, 1979), 191.

135 See: Diane Middlebrook, Her Husband: Ted Hughes and Sylvia Plath-A Marriage (New York: Penguin Books, 2004), 60 and 79-81.

136 Sylvia Plath, "All the Dead Dears," Johnny Panic and the Bible of Dreams (London: Faber and Faber, 1979), 183 [Italics in the original]. For the preliminary sketch of the story in Plath's journals see: Sylvia Plath, The Unabridged Journals of Sylvia Plath: 1950-1962, ed. Karen V. Kukil (New York: Anchor Books, 2000), 579-580.

137 Gilbert and Gubar, The Madwoman in the Attic, 51.

138 Judith Kroll, Chapters in a Mythology: The Poetry of Sylvia Plath (Stroud: Sutton Publishing, 2007), 282, n. 56.

139 Plath, The Collected Poems, 173.

140 Ibid.

141 Axelrod, “The Mirror and the Shadow" 291.

142 La Belle, Herself Beheld, 39.

143 Plath, The Collected Poems, 198.

144 Jack Folsom, "Death and Rebirth in Sylvia Plath's 'Berck-Plage"' Journal of Modern Literature, vol. 17, no. 4 (1991), 527.

145 Plath, The Collected Poems, 173.

146 See: Ferber, s.v. “silver," A Dictionary of Literary Symbols, 196-197.

147 Plath, The Collected Poems, 94 and 242.

148 Ibid., 174.

149 Ibid., 127.

150 See: Ferber, A Dictionary of Literary Symbols, 196-197.

151 Plath, The Collected Poems, 174.

152 Kroll, Chapters in a Mythology, 282, n. 56.

153 Plath, The Collected Poems, 316.

154 Ibid., 174.

155 Ibid.

156 Ibid., 156.

157 Biedermann, Dictionary of Symbolism, 131.

158 John H. Timmerman, “Plath's 'Mirror,' Explicator, vol. 45, no. 2 (1987), 63-64.

159 Ibid., 64.

160 Timmerman cites the following two passages from Jung's The Archetypes 
and the Collective Unconscious as the possible source of Plath's poem: "True, whoever looks into the mirror of the water will see first of all his own face. Whoever goes to himself risks a confrontation with himself. The mirror does not flatter, it faithfully shows whatever looks into it; namely, the face we never show to the world because we cover it with the persona, the mask of the actor. But the mirror lies behind the mask and shows the true face." Carl Gustav Jung, The Archetypes and the Collective Unconscious, trans. R.F.C. Hull (Princeton, NJ: Princeton University Press, 1990), 20. And the second passage: "Whoever looks into the water sees his own image, but behind it living creatures soon loom up; fishes, presumably, harmless dwellers of the deep-harmless, if only the lake were not haunted. They are water-beings of a peculiar sort. Sometimes a nixie gets into the fisherman's net, a female, half-human fish. Nixies are entrancing creatures .... The nixie is an even more instinctive version of a magical feminine being whom I call the anima. She can also be a siren, melusina (mermaid), wood-nymph, Grace, or Erlking's daughter, or a lamia or succubus, who infatuates young men and sucks the life out of them." Ibid., 24-25. See: Timmerman, "Plath's 'Mirror," 64.

161 Cooper, An Illustrated Encyclopaedia of Traditional Symbols, 106.

162 William Freedman, “The Monster in Plath's 'Mirror"' Papers on Language and Literature, vol. 108, no. 5 (October, 1993), 166.

163 Freedman, “The Monster in Plath's 'Mirror," 166.

164 For an example see: Vickers, “'The Blazon of Sweet Beauty's Best”, 95-115.

165 Barbara Johnson, A World of Difference (Baltimore and London: The Johns Hopkins University Press, 1987), 198.

166 See: Jo Gill, "The Colossus and Crossing the Water," The Cambridge Companion to Sylvia Plath, 103-104.

167 Plath, The Collected Poems, 325.

168 Ibid.

169 Melchior-Bonnet, The Mirror, 205-206.

170 Maillet, The Claude Glass, 234, n. 5.

171 Plath, The Collected Poems, 325.

172 Maillet, The Claude Glass, 49; See also pp. 47-55.

173 s.v. "scorch." Merriam-Webster.com. Merriam-Webster, n.d. Web. 14 Mar. 2014. http://www.merriam-webster.com/dictionary/scorch.

174 Plath, The Collected Poems, 325.

175 s.v. "char." Merriam-Webster.com. Merriam-Webster, n.d. Web. 14 Mar. 2014. http://www.merriam-webster.com/dictionary/char. 
176 Fan Jinghua, “Sylvia Plath's Visual Poetics," Eye Rhymes: Sylvia Plath's Art of the Visual, eds. Kathleen Connors and Sally Bayley (Oxford and New York: Oxford University Press, 2007), 210.

177 Johnson, The Critical Difference, 106.

178 Freud, "The 'Uncanny," 245 [brackets in the original].

179 Cixous, “The Laugh of the Medusa," 885.

180 In her 1960 poem "You're," Plath portrays the child through a series of similes and metaphors, including "vague as fog." Addressing the child, Plath concludes the poem with a mirror image: "A clean slate, with your own face on." Plath, The Collected Poems, 141. Here, the child is metaphorized into the mirror. This clean reflecting surface has no trace of the mother or anything from the world outside whatsoever. All it can reflect is the face of the child itself, stressing solipsism of the baby or enfant. In her 1962 poem "For a Fatherless Son," addressed to her then eight-month-old son Nicholas, Plath conveys the imbrication of mother-child identity. She describes the dumb stupidity of her baby in terms of a "blind mirror" on whose surface only the solacing image of the mother is reflected:

But right now you are dumb.

And I love your stupidity,

The blind mirror of it. I look in

And find no face but my own, and you think that's funny.

Ibid., 205

Plath addressed her 1963 Poem "Child" to her daughter Frieda Rebecca, who would soon be three, describing her "clear eye" in terms of empty space which the mother wishes to fill with "color and ducks,/the zoo of the new," with "April snowdrop" (alluding to her birth month), and with "Indian pipe." Ultimately, Plath metaphorizes her daughter's "clear eye" into a "Pool in which images/should be grand and classical." (Ibid., 265)

181 Ibid., 156.

182 In ancient classical thought, the essential four constitutive elements of life are earth, water, air and fire. To them Aristotle adds a fifth element or quintessence (after "quint" meaning "fifth"), the aether. The atmospheric elements are: temperature, humidity, precipitation, winds, pressure and clouds.

183 Diane Middlebrook, "The Poetry of Sylvia Plath and Ted Hughes: Call and Response," The Cambridge Companion to Sylvia Plath, 162. 
184 Plath, The Collected Poems, 157.

185 Ibid.

186 Gina Wisker, "Viciousness in the Kitchen: Sylvia Plath's Gothic," Gothic Studies, vol. 6, no. 1 (May 2004), 108.

187 Plath, The Collected Poems, 157.

188 Ibid.

189 Sally Bayley, "Sylvia Plath and the Costume of Femininity," Eye Rhyme, 248, note 84 . In a letter to her mother, dated 12 October 1962, Plath writes: "I miss brains, hate this cow life, am dying to surround myself with intelligent, good people." Here, the cow not only refers to rural, "brainless" Devon, but also to her domestic life limited to housewifery and motherhood. Plath, Letters Home, 466.

190 Plath, The Collected Poems, 157.

191 Heather Clark, The Grief of Influence: Sylvia Plath and Ted Hughes (Oxford and New York: Oxford University Press, 2011), 30.

192 Nietzsche always used the term "Übermensch" in the singular. The only exception in which he used it in its plural meaning was when he used it ironically. See: Walter Kaufmann, "Nietzsche, Friedrich," The Encyclopedia of Philosophy, ed. Paul Edwards (New York and London: Macmillan and The Free Press, 1967), 511.

193 The depictions of the winged man represent him with a ring around his waist and holding another one in his hand. Its precise meaning remains controversial. His face turning to one side represents the winged man's turning away from evil towards good. The winged man has two wings at each side and each wing has three rows of feathers, depicting the tripartite principle at the heart of Zoroastrianism: the good reflection, the good words and the good deed. At the same time, the wings represent the winged man's will to fly, to exalt. For more see: Mary Boyce, "Fravaši," Encyclopoedia Iranica, ed. Ehsan Yarshater, vol. X (New York: Bibliotheca Persica Press, 2001) 195-199.

194 Plath, The Collected Poems, 258.

195 Ibid.

196 Ibid., 258-259.

197 Kendall, Sylvia Plath, 124.

198 After reading an article in The Nation entitled "Juggernaut, the Warfare State", Plath writes in a letter to her mother, dated 15 December 1961, "I began to wonder if there was any point in trying to bring up children in such a mad, self-destructive world. The sad thing is that the power for destruction is real and universal." Plath, Letters Home, 438. 
199 The New Testament recounts that at Jesus' baptism the Holy Spirit descended upon him "like a dove" (Matt. 3. 16).

200 La Belle, Herself Beheld, 125.

201 Sylvia Plath, The Bell Jar (London: Faber and Faber, 1966), 3.

202 Ibid., 23.

203 Ibid., 3.

204 Ibid.

205 Ibid.

206 Ibid., 95 .

207 Ibid.

208 Lynda K. Bundtzen, "Women in The Bell Jar: Two Allegories," Sylvia Plath: Modern Critical Views, ed. Harold Bloom (New York: Chelsea House Publishers, 1989), 130.

209 Plath, The Bell Jar, 96.

210 Showalter, The Female Malady, 212.

211 Melchior-Bonnet, The Mirror, 264.

212 La Belle, Herself Beheld, 91.

213 Bundtzen, "Women in The Bell Jar: Two Allegories," 130.

214 Meyers, Gender in the Mirror, i.

215 Plath, The Bell Jar, 95.

216 Ibid.

217 Ibid., 96.

218 Ibid., 1.

219 Ibid., 96.

220 For a comprehensive study of "dybbuk" see: Jeffrey Howard Chajes, Between Worlds: Dybbuks, Exorcists, and Early Modern Judaism (Philadelphia: University of Pennsylvania Press, 2003).

221 Spivak, "Echo," 27.

222 Plath, The Bell Jar, 97.

223 Ibid.

224 Craig Owens, Beyond Recognition: Representation, Power, and Culture, eds. Scott Bryson, Barbara Kruger, Lynne Tillman, and Jane Weinstock (Berkeley, Los Angeles and London: University of California Press, 1994), 198 [Emphasis in the original].

225 Ibid., 202.

226 Ulla Haselstein, "Selbstporträts im Konvexspiegel: Parmigianino und Ashbery," Manier-Manieren-Manierismus, eds. Erika Greber and Bettine Menke (Tübingen: Gunter Narr Verlag, 2003), 50-51 [Translation mine]. Cf. with the original: "der Blick auf das eigene Spiegelbild lädt sich mit 
dem imaginierten Blick der anderen auf; das fremd anmutende Gesicht und der Betrachter bilden ein gespaltenes Ganzes. Gesicht wie Rede erscheinen als Zonen der Vermittlung zwischen privatem Selbstvorbehalt und öffentlicher Selbstentäußerung, das heißt als Räume einer doppelt kodierten Schrift, die auf die Sedimentierungen des Selbst als und im Spiegel der anderen verweist."

227 Plath, The Bell Jar, 98

228 Barrie M. Biven, True Pretences: Psychodynamic Work with the Lost, the Angry and the Depressed (Leicester: Matador, 2005), 96.

229 La Belle, Herself Beheld, 158-159.

230 Plath, The Collected Poems, 337.

231 Ibid.

232 Ibid.

233 Ibid., 337-338.

234 Plath, The Collected Poems, 210.

235 Plath, The Unabridged Journals, 526.

236 Plath, The Collected Poems, 137-138.

237 Ibid., 138.

238 Sergius Pankejeff, The Wolf-Man, by the Wolf-man. With the Case of the Wolf-Man, by Sigmund Freud and a Supplement by Ruth Mack Brunswick, foreword by Anna Freud and ed. Muriel Gardiner (New York: Basic Books, 1971), 139.

239 Donald Kuspit, "A Mighty Metaphor: The Analogy of Archaeology and Psychoanalysis," Sigmund Freud and Art: His Personal Collection of Antiquities, eds. Lynn Gamwell and Richard Wells (Binghamton: State University of New York Press; London: Freud Museum, 1989), 133-151. For more study on this Freudian metaphor see: Donald P. Spence, The Freudian Metaphor: Towards Paradigm Change in Psychoanalysis (New York: Norton, 1978); Kenneth Reinhard, "The Freudian Things: Construction and the Archaeological Metaphor," Excavations and Their Objects: Freud's Collection of Antiquity, ed. Stephen Barker (Albany: State University of New York Press, 1996): 57-80; and Karl Stockreiter, "Am Rand der Aufklärungsmetapher: Korrespondenzen zwischen Archäologie und Psychoanalyse," "Meine ... alten und dreckigen Götter": Aus Sigmund Freuds Sammlung, ed. Lydia Marinelli (Frankfort: Stroemfeld, 1998): 81-93.

240 Plath, The Collected Poems, 138.

241 Ibid.

242 s.v. "blue." Merriam-Webster.com. Merriam-Webster, n.d. Web. 27 Mar. 2014. http://www.merriam-webster.com/dictionary/blue. 
243 Christodoulides, Out of the Cradle Endlessly Rocking, 174.

244 Ibid., 173-174. Christodoulides further elaborates, "clearly the poem follows the Kristevan pattern (Revolution in Poetic Language) and is now in the 'thetic' phase. In the signifying process this phase operates like the threshold that follows the mirror stage where the child recognizes itself as a separate object; in the poem the spring is the mirror where the speaking persona recognizes herself as other ('It is not I'), and the mother's green, clean doorstep that leads in and out is the threshold. The doorstep is an allusion to effraction, a breach, which Kristeva mentions in Revolution: entering a place, like breaching a law, and housebreaking are suggestive of the multiple strategies implicit in breaking through the thetic, a disruption most clearly marked in poetic language." (Ibid., 247-249). "The persona seems to be hinting that she does not dare break into the mother's house to go back to the semiotic fusion with her, as there is a 'stream', a buffer that divides them, the symbolic order which cannot give her, however, any 'nourishment or cure' either, even if she wishes to enter it. Finally, the prodigal child has revealed her predicament: neither the semiotic nor the symbolic: solace is nowhere [sic] to be found-neither with the mother nor the imaginary father." (Ibid., 174).

245 Plath, The Collected Poems, 138.

246 Butscher, Sylvia Plath: Method and Madness, 249-250.

247 Ibid., 250.

248 Plath, The Collected Poems, 24.

249 s.v. "put on" Merriam-Webster.com. Merriam-Webster, n.d. Web. 27 Mar. 2014. http://www.merriam-webster.com/dictionary/puton.

250 Plath, The Collected Poems, 210.

251 Ibid., 24.

252 Idid., 25.

253 Ibid.

254 For a further study of skin imagery, skin metaphor or its substitutes in Plath's works see: Biven, True Pretences, 70-97.

255 Plath, The Collected Poems, 25.

256 Birkle, Women's Stories of the Looking Glass, 21.

257 Plath, The Collected Poems, 25.

258 La Belle, Herself Beheld, 23. La Belle juxtaposes some interesting examples of the mirror experience by male authors to those of female ones to illuminate the huge discrepancies in their usage. Male authors and poets employ the mirror mainly for purely daily practical ends. Any act beyond 
utilitarian practice by a male character or persona is generally considered a "lapse ... in an essentially feminine activity." The rhetoric turns out to be not merely descriptive, but also prescriptive, i.e., it specifies how a man or a woman should act in front of the mirror and react to the phenomena of mirroring. See: ibid., 20-24.

259 Harold Bloom, Wallace Stevens: The Poems of Our Climate (New York: Cornell University Press, 1977), 199.

260 During one of his trips to London Ted Hughes leaves a note to Assia Wevill saying, "I have come to see you, despite all marriages." Quoted in Middlebrook, Her Husband, 167.

261 See: Axelrod, Sylvia Plath: The Wound and the Cure of Words, 185-186.

262 See: Butscher, Sylvia Plath: Method and Madness, 333.

263 Axelrod, Sylvia Plath: The Wound and the Cure of Words, 186.

264 See: Christodoulides, Out of the Cradle Endlessly Rocking, 201-204.

265 Johnson, The Critical Difference, 106.

266 David John Wood, A Critical Study of the Birth Imagery of Sylvia Plath, American Poet 1932-1963 (New York: The Edwin Mellen Press, 1992), 100.

267 Jinghua, "Sylvia Plath's Visual Poetics," 220.

268 Plath, The Collected Poems, 201.

269 Ibid., 202.

270 Britzolakis, “Ariel and Other Poems," 109.

271 Plath, The Collected Poems, 202.

272 See: Lacan, “The Mirror Stage," 76.

273 Butscher, Sylvia Plath: Method and Madness, 333.

274 Ovid [Melville], Metamorphoses, 65: 474.

275 Irigaray, "Divine Women," 477-478.

276 Kristeva, Powers of Horror, 4.

277 Ibid.

278 Plath, The Collected Poems, $2 \mathrm{O}$.

279 Ibid.

280 Johnson, The Critical Difference, 106.

281 Cixous, "The Laugh of the Medusa," 885.

282 Plath, The Bell Jar, 17.

283 Ibid.

284 Ibid.

285 Ibid., 18.

286 Ibid., 107.

287 Ibid., 108.

288 Johnson, The Critical Difference, 106. 
289 See: Plath, Johnny Panic and the Bible of Dreams (London: Farber and Farber, 1979), 117.

\section{Conclusion}

Kristeva, Desire in Language, 195.

\section{Appendix}

1 An allusion to the Qur'ān: "(Allah) said: 'What prevented thee from prostrating when I commanded thee?' He said: 'I am better than he: Thou didst create me from fire, and him from clay." (7:12). All the references are to Abdullah Yusuf Ali’s translation of the Qur'ān, accessed 8 May 2011. http:// search-the-quran.com.

2 Allusion to the Qur'ān: "As to the Samūd, We gave them Guidance, but they preferred blindness (of heart) to Guidance: so the stunning Punishment of humiliation seized them, because of what they had earned." (41: 17).

3 Allusion to the Qur'annic verses: "Is that the better entertainment or the Tree of Zaqqūm? For We have truly made it (as) a trial for the wrong-doers. For it is a tree that springs out of the bottom of Hell-Fire: The shoots of its fruit-stalks are like the heads of devils: Truly they will eat thereof and fill their bellies therewith." (37: 62-66). And "'Ye will surely taste of the Tree of Zaqqūm. Then will ye fill your insides therewith, And drink Boiling Water on top of it." (56:52-54). Hamìm is also mentioned in the Qur'ān in: "Nothing cool shall they taste therein, nor any drink, Save a boiling fluid and a fluid, dark, murky, intensely cold. A fitting recompense (for them)". (78: 24-26).

4 Qur'ānic allusion: "(They will be) in the midst of a Fierce Blast of Fire and in Boiling Water" (56: 42). Samūm literally means hot wind and also miasma.

5 Allusion to the Qur'ān: "In front of such a one is Hell, and he is given, for drink, boiling fetid water." (14: 16).

6 Allusion to the Qur'ān: "But he whose balance (of good deeds) will be (found) light, Will have his home in a (bottomless) Pit. And what will explain to thee what this is? (It is) a Fire Blazing fiercely!" (101: 8-11).

7 Qur'annic allusion: “To them will be passed round, dishes and goblets of gold: there will be there all that the souls could desire, all that their eyes 
could delight in: and ye shall abide therein (for eye)." (43: 71). And "(Here is) a Parable of the Garden which the righteous are promised: in it are rivers of water incorruptible; rivers of milk of which the taste never changes; rivers of wine, a joy to those who drink; and rivers of honey pure and clear. In it there are for them all kinds of fruits; and Grace from their Lord. (Can those in such Bliss) be compared to such as shall dwell for ever in the Fire, and be given, to drink, boiling water, so that it cuts up their bowels (to pieces)?" (47: 15).

8 Qur'ānic allusion: "So; and We shall join them to [houris] fair women with beautiful, big, and lustrous eyes." (44: 54).

9 Qur'ānic allusion: "A fountain there [in the Garden], called Salsabil." (76: 18).

10 Qurānic allusion: "The Companions of the Right Hand,-what will be the Companions of the Right Hand? (They will be) among Lote-trees without thorns, In shade long-extended." (56: 27-30).

11 Allusion to Haafeẓ's couplet:

$$
\text { "يدرم روضهُ رضوان بدو كندم بفروخت /ناخلف باشم اكر من به جوى نفرشم" }
$$

("My father sold the garden of paradise for two grains of wheat/I shall be unworthy of him if I wouldn't sell it for a barleycorn.") In Persian "a grain of barley" is a metaphor for a very little, trifling amount. See: Dehḩodā, s.v. "ğo," Loġatnāme, vol. 5, pp. 7885-7886.

12 Qurānic allusion: "Round about them will (serve) [male] youths of perpetual (freshness)." (56:17). Sabz hațān literally means those with green, fresh lines, referring to young boys whose facial hair has just grown. See: Dehhodā, s.v. "hatțte sabz," Loġatnāme, vol. 7, pp. 9875-9876.

13 Quraanic allusion: "Whom Allah doth guide, he is on the right path: whom He rejects from His guidance,-such are the persons who perish." (7: 178).

14 In this line, Farrokhzad uses the word hăr (thorn); however, the homophonic $h^{w} \bar{a} r$ (debased) would also make sense in this context.

15 Ayeh or āyat in Persian means sign, miracle, proof as well as verses of the Qữān. 


\section{Bibliography}

Abrams, Meyer Howard. The Mirror and the Lamp: Romantic Theory and the Critical Tradition. London: Oxford University Press, 1953.

Aeschylus. Oresteia. Translated by Christopher Collard. New York: Oxford University Press, 2002.

Afary, Janet. Sexual Politics in Modern Iran. Cambridge and New York: Cambridge University Press, 2009.

Āīdenlū, Sağād. “Ğām-e Keyhosro o Ǧamšīd." Nāme-ye Pārsī. Year 9. No. 4 (Winter 1983/2004-2005): 5-24.

Akbari, Suzanne Conklin. Seeing through the Veil: Optical Theory and Medieval Allegory. Toronto, Buffalo and London: University of Toronto Press, 2004.

Allen, Virginia M. The Femme Fatale: Erotic Icon. Troy, NY: Whitston, 1983.

Alvarez, Al. "How Black Magic Killed Sylvia Plath." The Guardian. G2. 15 September 1999; Accessed on March 18, 2012, http://www.theguardian.com/ theguardian/1999/sep/15/features11.g2

Andreas-Salomé, Lou. “The Dual Orientation of Narcissism.” The Psychoanalytic Quarterly. Translated by Stanley A. Leavy. Vol. 31 (1962): 1-30.

Annas, Pamela J. A Disturbance in Mirrors: The Poetry of Sylvia Plath. New York, Connecticut and London: Greenwood Press, 1988.

Anthon, Charles. A Manual of Grecian Antiquities. New York: Harper and Brothers, 1852.

Aristotle. Rhetoric. Translated by W. Rhys Roberts and Edited by W.D. Ross. New York: Cosimo, 2010.

'Aț̣ār Nīšābūrī, Šayh Farīd al-Dīn. Tazkīrat al-awlīyā'. Edited by Moḥammad Este lāmī. Tehran: Entešārāt-e zavvār, 1388/2009-2010.

Axelrod, Steven Gould. "The Mirror and the Shadow: Plath's Poetics of SelfDoubt.” Contemporary Literature. Vol. 26. No. 3 (Fall 1985): 286-301.

- Sylvia Plath: The Wound and the Cure of Words. London: The Johns Hopkins University Press, 1990.

Baltrušaitis, Jurgis. Der Spiegel: Entdeckungen, Täuschungen, Phantasien. Giessen: Anabas-Verlag, 1986. 
Barthes, Roland. "The Death of the Author." Modern Criticism and Theory: A Reader. Edited by David Lodge. Revised and expanded by Nigel Wood. Essex and New York: Longman, 2000: 146-150.

Bassnett, Susan. Sylvia Plath: An Introduction to the Poetry. Hampshire and New York: Palgrave Macmillan, 2005.

Bayley, Sally. "Sylvia Plath and the Costume of Femininity." Eye Rhymes: Sylvia Plath's Art of the Visual. Edited by Kathleen Connors and Sally Bayley. Oxford and New York: Oxford University Press, 2007: 183-204.

Bennett, Paula. My Life a Loaded Gun: Female Creativity and Feminist Poetics. Boston: Beacon Press, 1986.

Berger, John. Ways of Seeing. London: Penguin Books, 1972.

Bergson, Henri. Creative Evolution. Translated by Arthur Mitchell. New York: Cosimo, 2007.

- Mind-Energy: Lectures and Essays. Translated by H. Wildon Carr. Edited by Keith Ansell-Pearson and Michael Kolkman. Basingstoke: Palgrave Macmillan, 2007.

Berry, Philippa. Of Chastity and Power: Elizabethan Literature and the Unmarried Queen. London: Routledge, 1989.

Biedermann, Hans. Dictionary of Symbolism. Translated by James Hulbert. New York: Facts On File, 1992.

Bīneš, Taqī and Asadī, Hūman. "Parde." The Great Islamic Encyclopaedia. Edited by Kāzem Mūsavī Boğnūrdī. Tehran: The Centre for the Great Islamic Encyclopaedia, 2005. Vol. XIII: 591-592.

Birkle, Carmen. Women's Stories of the Looking Glass: Autobiographical Reflections and Self-Representations in the Poetry of Sylvia Plath, Adrienne Rich, and Audre Lorde. Munich: Wilhelm Fink Verlag, 1996.

Biven, Barrie M. True Pretences: Psychodynamic Work with the Lost, the Angry and the Depressed. Leicester: Matador, 2005.

Bloom, Harold. Wallace Stevens: The Poems of Our Climate. New York: Cornell University Press, 1977.

Boothby, Richard. Death and Desire: Psychoanalytic Theory in Lacan's Return to Freud. New York: Routledge, 1991.

Boyce, Mary. "Fravaši." Encyclopoedia Iranica. Edited by Ehsan Yarshater. Vol. X, New York: Bibliotheca Persica Press, 2001: 195-199.

Bradley, Ritamary. "Backgrounds of the Title Speculum in Medieval Literature." Speculum 29 (1954), 100-115.

Brain, Tracy. The Other Sylvia Plath. London: Longman, 2001.

Britzolakis, Christina. "Ariel and Other Poems." The Cambridge Companion to Sylvia Plath. Edited by Jo Gill. Cambridge: Cambridge University Press, 2006: 107-123. 
Brookshaw, Dominic Parviz. "Places of Confinement, Liberation, and Decay: The Home and the Garden in the Poetry of Forugh Farrokhzad." Forugh Farrokhzad, Poet of Modern Iran: Iconic Woman and Feminine Pioneer of New Persian Poetry. Edited by Dominic Parviz Brookshaw and Nasrin Rahimieh. London and New York: I.B. Tauris, 2010: 35-52.

- "Women in Praise of Women: Female Poets and Female Patrons in Qajar Iran." Iranian Studies. Vol. 46. Issue 1 (2013): 17-48.

Brūmand Sa'eed, Ǧavād. Hāfez o ğām-e ğam. Tehran: Pāžang, 1367/1988-1989.

Bundtzen, Lynda K. "Women in The Bell Jar: Two Allegories." Sylvia Plath: Modern Critical Views. Edited by Harold Bloom. New York: Chelsea House Publishers, 1989: 121-131.

Burckhardt, Titus. "Die Symbolik des Spiegels in der islamischen Mystik." Symbolon: Jahrbuch für Symbolforschung. Edited by Julius Schwabe, Vol. I. Basel und Stuttgart: Benno Schwabe \& Co. Verlag, 1960: 12-16.

Butscher, Edward. Sylvia Plath: Method and Madness. Tucson: Schaffner Press, 2003.

Butler, Judith. Bodies That Matter: On the Discursive Limits of "Sex." New York: Routledge, 1993.

- Gender Trouble: Feminism and the Subversion of Identity. New York: Routledge, 1990.

Carroll, Lewis. The Complete Stories and Poems of Lewis Carroll. New York: Gramercy Books, 2002.

Casey, Edward S. "The Time of the Glance: Toward Becoming Otherwise." Becomings: Explorations in Time, Memory, and Futures. Edited by Elizabeth Grosz. Ithaca and London: Cornell University Press 1999: 79-97.

Chajes, Jeffrey Howard. Between Worlds: Dybbuks, Exorcists, and Early Modern Judaism. Philadelphia: University of Pennsylvania Press, 2003.

Chodorow, Nancy J. "Family Structure and Feminine Personality.” Woman, Culture and Society. Edited by Michelle Zimbalist Rosaldo and Louise Lamphere. Stanford, California: Stanford University Press, 1974: 43-66.

- "Feminism and Difference: Gender, Relation and Difference in Psychoanalytic Perspective." The Future of Difference. Edited by Hester Eisenstein and Alice Jardine. Boston: G.K. Hall, 1980: 3-20.

_. "Feminism and Difference: Gender, Relation and Difference in Psychoanalytic Perspective." Socialist Review. Vol. 46 (July-August 1979) 51-70.

_. "Mothering, Object-Relations and the Female Oedipal Configuration." Feminist Studies. Vol. 4. No. 1 (February 1978): 137-158.

- The Reproduction of Mothering: Psychoanalysis and the Sociology of Gender. Berkeley and Los Angeles: University of California Press, 1978. 
Christodoulides, Nephie. Out of the Cradle Endlessly Rocking: Motherhood in Sylvia Plath's Work. Amsterdam and New York: Rodopi, 2005.

Cirlot, Juan Eduardo. A Dictionary of Symbols. Translated by Jack Sage. London: Routledge and Kegan Paul, 1962.

Cixous, Hélène. "Coming to Writing" and Other Essays. Edited by Deborah Jenson. Massachusetts: Harvard University Press, 1991.

—. "The Laugh of the Medusa." Translated by Keith Cohen and Paula Cohen. Signs. Vol. 1. No. 4 (Summer, 1976): 875-893.

- "Sorties." Translated by Ann Liddle in New French Feminisms: An Anthology, Edited by Elaine Marks and Isabelle de Courtivron. Amherst: The University of Massachusetts, 1980: 90-98.

—. "Sorties: Out and Out: Attacks/Ways Out/Forays." The Newly Born Woman. Edited by Hélène Cixous and Catherine Clément. Translated by Betsy Wing. London: I.B. Tauris, 1996: 63-134.

Clark, Heather. The Grief of Influence: Sylvia Plath and Ted Hughes. Oxford and New York: Oxford University Press, 2011.

Cooley, Winnifred Harper. The New Womanhood. New York: Broadway Publishing Company, 1904.

Cooper, J.C. An Illustrated Encyclopaedia of Traditional Symbols. London: Thames and Hudson, 1978.

Daly, Mary. Beyond God the Father: Toward a Philosophy of Women's Liberation. Boston: Beacon Press, 1985.

Davidson, Cathy N. and Broner, E.M. (Eds.) The Lost Tradition: Mothers and Daughters in Literature. New York: F. Ungar Pub Co, 1980.

De Beauvoir, Simone. The Second Sex. Translated by H.M. Parshley. New York: Vintage Books, 1989.

- Hard Times: Force of Circumstance, II: 1952-1962. New York: Paragon House, 1992.

De Givry, Grillot. Witchcraft, Magic and Alchemy. Translated by J. Courtenay Locke. New York: Dover Publications, 1971.

Dehhodā, 'Alīakbar. Log̀atnāme. Edited by Moḥammad Mo'īn and Ğáfar Šahīdī. Tehran: Tehran University Press, 1377/1998.

Deleuze, Gilles. Cinema 1: The Movement-Image. Translated by Hugh Tomlinson and Barbara Habberjam. Minneapolis: University of Minnesota Press, 1986.

Derrida, Jacques. "Signature Event Context." Limited Inc. Translated by Samuel Weber and Jeffrey Mehlman. Evanston, Illinois: Northwestern University Press, 1988: 1-23.

Dijkstra, Bram. Idols of Perversity: Fantasies of Feminine Evil in Fin-De-Siècle Culture. New York and London: Oxford University Press, 1986. 
Dinnerstein, Dorothy. The Mermaid and the Minotaur: Sexual Arrangements and Human Malaise. New York: Harper and Row, 1976.

Ellis, Havelock. “The Conception of Narcissism." Psychoanalytic Review, No. 14 (1924): 129-153.

- "The Conception of Narcissism." Studies in Psychology of Sex, No. 7. Philadelphia: F.A. Davis, 1928: 346-375.

Evans, Dylan. An Introductory Dictionary of Lacanian Psychoanalysis. London: Routledge, 2006.

Fantham, Elaine et al. Women in the Classical World: Image and Text. Oxford and New York: Oxford University Press, 1994.

Farrokhzad, Forough. A Rebirth: Poems by Foroogh Farrokhzaad. Translated by David Martin. Lexington, Ky.: Mazda Press, 1985.

- Another Birth: Selected Poems. Translated by Ismail Salami. Tehran: Zabānkade, 1381/2002-2003.

Another Birth and Other Poems. Translated by Hassan Javadi and Susan Sallée. Washington, DC: Mage Publishers, 2010.

_. Avvalīn tapeš-hā-ye ‘āšeqāne-ye qalbam: nāme-hā-ye Forugh Farrokhzad be hamsaraš Parvīz Šāpūr. Edited by Kāmyār Šāpūr and 'Omrān Ṣālehī. Tehran: Entešārāt-e morvārīd, 1381/2003.

- Bride of Acacias: Selected Poems of Forugh Farrokhzad. Translated by Jascha Kessler and Amin Banani. New York: Caravan Books, 1982.

- "Green Terror." Gramercy Review, A Journal of Contemporary Poetry and Fiction. Translated by Amin Banani and Jascha Kessler. Vol. 2 (1978): 53 .

—. Mağmū'a āsār-e Forugh Farrokhzad. Edited by Behnām Bāvandpūr. 2 Vols. Essen: Nima Verlag, 2002.

- Sin: Selected Poems of Forugh Farrokhzad. Translated by Sholeh Wolpé. Fayetteville: The University of Arkansas Press, 2007.

Farzan, Massud. “Contemporary Poetry in Iran.” Persian Literature. Edited by Ehsan Yarshater. New York: The Persian Heritage Foundation, 1988: 336-366.

Feldstein, Richard; Fink, Bruce; and Jaanus, Maire (Eds.). Reading Seminars I and II: Lacan's Return to Freud. Albany: State University of New York Press, 1996.

Ferber, Michael. A Dictionary of Literary Symbols. Cambridge and New York: Cambridge University Press, 2007.

Firdausî of Țûs. Yûsuf and Zalîkhâ: The Biblical Legend of Joseph and Potiphar's Wife in the Persian Version. Edited by Hermann Ethé. Amsterdam: Philo Press, 1970.

Flax, Jane. "The Conflict between Nurturance and Autonomy in Mother- 
Daughter Relationships and within Feminism.” Feminist Studies. Vol. 4. No. 1 (February 1978): 171-189.

- "Mother-Daughter Relationships: Psychodynamics, Politics, and Philosophy." The Future of Difference. Edited by Hester Eisenstein and Alice Jardine. Boston: G.K. Hall, 1980: 20-40.

Foley, Helene P. (Ed.). Reflections of Women in Antiquity. New York: Gordon and Breach Science Publishers, 1981.

Folkenflik, Robert. “The Self as Other." The Culture of Autobiography: Constructions of Self-Representation. Edited by Robert Folkenflik. Stanford: Stanford University Press, 1993: 215-234.

Folsom, Jack. "Death and Rebirth in Sylvia Plath's 'Berck-Plage"' Journal of Modern Literature. Vol. 17. No. 4 (1991): 521-535.

Foucault, Michel. "Of Other Spaces." Translated by Jay Miskowiec. Diacritics. Vol. 16. No. 1 (Spring, 1986): 22-27.

Frazer, James George. “The Perils of the Soul." The Golden Bough: A Study in Magic and Religion. Abridged Edition. New York: Macmillan, 1943: 178193.

Freedman, William. “The Monster in Plath's 'Mirror.” Papers on Language and Literature. Vol. 108. No. 5 (October, 1993): 152-169.

Freud, Sigmund. "Medusa's Head." The Standard Edition of the Complete Psychological Works of Sigmund Freud. Edited and Translated by James Strachey. London: The Hogarth Press and the Institute of Psycho-Analysis. Vol. XVIII (1953-1974): 273-274.

- "On Narcissism: An Introduction." The Standard Edition of the Complete Psychological Works of Sigmund Freud. Edited and Translated by James Strachey. Vol. XIV (1914-1916). London: The Hogarth Press and the Institute of Psycho-Analysis, 1953-1974: 73-102.

. "The 'Uncanny"' The Standard Edition of the Complete Psychological Works of Sigmund Freud. Edited and Translated by James Strachey. Vol. XVII (1917-1919). London: The Hogarth Press and the Institute of PsychoAnalysis, 1953-1974: 217-252.

_. "Zur Einführung des Narzissmus.” Gesammelte Werke. Vol. X. Frankfurt am Main: S. Fischer Verlag, 1946: 137-170.

Gallop, Jane. The Daughter's Seduction: Feminism and Psychoanalysis. Ithaca and New York: Cornell University Press, 1982.

- Reading Lacan. Ithaca and New York: Cornell University Press, 1985.

Ǵamangīz, Moḥtaram. "Ā'īne dar adab-e șūfīyāne-ye fārsī bā tekīye bar ās̄ār-e Sanā'ī, 'Ațtāā, Neẓāmī, Molānā, S‘adī, 'Ayn-ol-Qożāt.” MA thesis. Zanjan: Zanjan University, 1386/2007. 
Garber, Marjorie and Vickers, Nancy J. (Ed.) The Medusa Reader. New York and London: Routledge, 2003.

Gardiner, Judith Kegan. "A Wake for Mother: The Maternal Deathbed in Women's Fiction.” Feminist Studies. Vol. 4. No. 2 (June 1978): 146-165.

Garner, D.M. and Garfinkel, P.E. "Body Image in Anorexia Nervosa: Measurement, Theory and Clinical Implications." International Journal of Psychiatry in Medicine. Vol. 11 (1981): 263-284.

Al-Ghazāli, Abū Hāmid. The Alchemy of Happiness. Translated by Claud Field. Charleston, South Carolina: Forgotten Books, 2008.

Gilbert, Sandra M. and Gubar, Susan. The Madwoman in the Attic: The Woman Writer and the Nineteenth-Century Literary Imagination. New Haven and London: Yale University Press, 2000.

Gill, Jo. "The Colossus and Crossing the Water." The Cambridge Companion to Sylvia Plath. Edited by Jo Gill. Cambridge: Cambridge University Press, 2006.

Goethe, Johann Wolfgang von. Goethes Briefe an Charlotte von Stein. Edited by Jonas Fränkel. Berlin: Akademie Verlag, 1960.

Goldberg, Benjamin. The Mirror and Man. Charlottesville: University Press of Virginia, 1985.

Grabes, Herbert. The Mutable Glass: Mirror-Imagery in Titles and Texts of the Middle Ages and English Renaissance. Cambridge: Cambridge University Press, 1982.

Green, André. Narcissisme de vie, narcissisme de mort. Paris: Editions de Minuit, 1983.

Grosz, Elizabeth A. "Contemporary Theories of Power and Subjectivity." Feminist Knowledge: Critique and Construct. Edited by Sneja Gunew. London and New York: Routledge, 1990: 59-121.

. Jacques Lacan: A Feminist Introduction. London and New York: Routledge, 1990.

- "Voyeurism, Exhibitionism, the Gaze." Feminism and Psychoanalysis: A Critical Dictionary. Edited by Elizabeth Wright. Oxford: Blackwell, 1992: 447-450.

Hạfez, Hūāğe Šams ed-Dīn Moḥammad. Dīvān-e Hāfez. Edited by Parvīz Nātel Huānlarī. Tehran: Entešārāt-e Hữārazmī, 1359/1980-1981.

.The Dīvān-i-Häfiz. Translated by Henry Wilberforce Clarke. New York: Samuel Weiser, 1970.

—. Dīvān-e Hâfez-e Šìrāzì. Edited by Moḥammad Qazvīnī and Qāsem Ġanī. Tehran: Anjoman-e hošnevīsān-e Irān, 1368/1989.

Hall, Nor. The Moon and the Virgin: Reflections on the Archetypal Feminine. New York: Harper \& Row, 1980. 
Hamadānī, 'Ayn-ol-Qożāt. Nāmehā-ye 'Ayn-ol-qożāt-e Hamadānī. Edited by 'Alī-Naqī Monzawī and 'Afîf 'Osayrān. Tehran: Bonyād-e farhang-e Iran, 1350/1970.

Hanson, Helen and O'Rawe, Catherine (Eds.). The Femme Fatale: Images, Histories, Contexts. Hampshire, UK: Palgrave Macmillan, 2010.

Haselstein, Ulla. "Selbstporträts im Konvexspiegel: Parmigianino und Ashbery." Manier-Manieren-Manierismus. Eds. Erika Greber and Bettine Menke. Tübingen: Gunter Narr Verlag, 2003: 41-62.

Hawley, Richard, and Levick, Barbara (Eds.). Women in Antiquity: New Assessments. London and New York: Routledge, 1995.

Hertz, Neil. "Medusa's Head: Male Hysteria under Political Pressure," The End of the Line: Essays on Psychoanalysis and the Sublime. New York: Columbia University Press, 1985.

Hillmann, Michael C. A Lonely Woman: Forugh Farrokhzad and Her Poetry. Boulder and London: Lynne Rienner Publishers, 1987.

Hirsch, Marianne. The Mother/Daughter Plot: Narrative, Psychoanalysis, Feminism. Bloomington: Indiana University Press, 1989.

Horne, R. Lynn; Van Vactor, J.C.; et al. "Distorted Body Image in Patients with Eating Disorders." American Journal of Psychiatry. Vol. 148. No. 2 (1991): 211-215.

Ḥosseīnī, Maryam. Rìše-hā-ye zan-setìzì dar adabīyāt-e kelāsīk-e fārsī. Tehran: Našr-e češme, 1387/2008-2009.

Hutchinson, Lucy. Memoirs of the Life of Colonel Hutchinson, with Fragment of an Autobiography of Mrs. Hutchinson. Edited by James Sutherland. London: Oxford University Press, 1973.

Irigaray, Luce. "And the One Doesn't Stir without the Other." Translated by Hélène Vivienne Wenzel. Signs: Journal of Women in Culture and Society. Vol. 7. No. 1 (Autumn, 1981): 60-67.

- . "Divine Women." Translated by Gillian C. Gill. Women, Knowledge, and Reality: Explorations in Feminist Philosophy. Edited by Ann Garry and Marilyn Pearsall. London and New York: Routledge, 1996: 471-484.

- Speculum of the Other Woman. Translated by Gillian C. Gill. Ithaca and New York: Cornell University Press, 1985.

- This Sex Which Is Not One. Translated by Catherine Porter. Ithaca and New York: Cornell University Press, 1985.

Jacobus, Mary. "The Difference of View." The Feminist Reader: Essays in Gender and the Politics of Literary Criticism. Edited by Catherine Belsey and Jane Moore, London: The Macmillan Press Ltd, 1977: 66-76.

Jalley, Émile. Freud, Wallon, Lacan: L'enfant au miroir. Paris: EPEL, 1998. 
Jinghua, Fan. "Sylvia Plath's Visual Poetics." Eye Rhymes: Sylvia Plath's Art of the Visual. Edited by Kathleen Connors and Sally Bayley. Oxford and New York: Oxford University Press, 2007: 205-222.

Johnson, Barbara. The Critical Difference: Essays in the Contemporary Rhetoric of Reading. Baltimore and London: The Johns Hopkins University Press, 1980.

—. A World of Difference. Baltimore and London: The Johns Hopkins University Press, 1987.

Julien, Philippe. Jacques Lacan's Return to Freud: The Real, the Symbolic, and the Imaginary. Translated by Devra Beck Simiu. New York: New York University Press, 1994.

Jung, Carl Gustav. Aion: Researches into the Phenomenology of the Self. Translated by R.F.C. Hull. Princeton, N.J.: Princeton University Press, 1978.

—. "The Archetypes and the Collective Unconscious." Translated by R.F.C. Hull. The Collected Works of C.G. Jung. Vol. 9. Princeton, NJ: Princeton University Press, 1968.

—. "The Psychological Aspects of the Kore." Carl G. Jung and Carl Kerényi. Essays on a Science of Mythology: The Myth of the Divine Child and the Mysteries of Eleusis. Princeton and New Jersey: Princeton University Press, 1969: 156-177.

Kalliopuska, Mirja. "Body-Image Disturbance in Patients with Anorexia Nervosa." Psychological Reports. Vol. 51 (1982): 715-722.

Karimi-Hakkak, Ahmad. An Anthology of Modern Persian Poetry. Boulder, Colorado: Westview Press, 1978.

Kaufmann, Walter. "Nietzsche, Friedrich." The Encyclopedia of Philosophy. Edited by Paul Edwards. New York and London: Macmillan and The Free Press, 1967: 504-514.

Keeble, N.H. "'The Colonel's Shadow': Lucy Hutchinson, Women's Writing, and the Civil War." Literature and the English Civil War. Edited by Thomas Healy and Jonathan Sawday. Cambridge: Cambridge University Press, 1990: 227-247.

Kendall, Tim. Sylvia Plath: A Critical Study. London and New York: Faber and Faber, 2001.

Kerényi, Carl. Eleusis: Archetypal Image of Mother and Daughter. Translated by Ralph Manheim. New York: Schocken Books, 1976.

Khairallah, As'ad E., Love, Madness, and Poetry: An Interpretation of the Mağnūn Legend. Beirut: Franz Steiner Verlag, 1980.

Kofman, Sarah. L'Énigme de la femme: La femme dans les textes de Freud. Paris: Editions Galilée, 1980.

Kristeva, Julia. "A Question of Subjectivity: An interview." Feminist Literary The- 
ory: A Reader. Edited by Mary Eagleton. Oxford: Blackwell, 1996: 351-353. . "About Chinese Women." Translated by Sean Hand. The Kristeva Reader. Edited by Toril Moi. New York: Columbia University Press, 1986: 138-159. - Black Sun: Depression and Melancholia. Translated by Leon S. Roudiez. New York: Columbia University Press, 1989.

- Desire in Language: A Semiotic Approach to Literature and Art. Translated by Thomas Gora, Alice Jardine, and Leon S. Roudiez and Edited by Leon S. Roudiez. New York: Columbia University Press, 1980.

- Powers of Horror: An Essay on Abjection. Translated by Leon S. Roudiez. New York: Columbia University Press, 1982.

Revolution in Poetic Language. Translated by Margaret Waller. New York: Columbia University Press, 1984.

- Tales of Love. Translated by Leon Roudiez. New York: Columbia University Press, 1987.

Kroll, Judith. Chapters in a Mythology: The Poetry of Sylvia Plath. Stroud: Sutton Publishing, 2007.

Kuspit, Donald. "A Mighty Metaphor: The Analogy of Archaeology and Psychoanalysis." Sigmund Freud and Art: His Personal Collection of Antiquities. Edited by Lynn Gamwell and Richard Wells. Binghamton: State University of New York Press; London: Freud Museum, 1989: 133-151.

La Belle, Jenijoy. Herself Beheld: The Literature of the Looking Glass. Ithaca: Cornell University Press, 1988.

Lacan, Jacques. Écrits: The First Complete Edition in English. Translated by Bruce Fink. New York and London: W.W. Norton \& Company, 2006.

- Écrits, A Selection. Translated by Alan Sheridan. London: Tavistock Publications, 1977.

Laertius, Diogenes. Lives of Eminent Philosophers. Translated by Robert Drew Hicks. Cambridge, Massachusetts: Harvard University Press and London: William Heinemann, 1950.

Laing, R.D. The Divided Self: An Existential Study in Sanity and Madness. Harmondsworth: Penguin, 1960.

Lane, Gary. "Influence and Originality in Plath's Poems." Sylvia Plath: New Views on the Poetry. Edited by Gary Lane. Baltimore and London: The Johns Hopkins University Press, 1979: 116-137.

Lazarus-Yafeh, Hava. Studies in Al-Ghazzali. Jerusalem: The Magnes Press, 1975.

Leisegang, Hans. "Die Erkenntnis Gottes im Spiegel der Seele und der Natur." Zeitschrift für philosophische Forschung. Vol. 4 (1950): 163-183.

Lichtenberg Ettinger, Bracha. "Matrix and Metramorphosis." Differences: A 
Journal of Feminist Cultural Studies [Trouble in the Archives]. Vol. 4. No. 3 (1992): 176-208.

Lorde, Audre. "Poetry is Not a Luxury," Chrysalis: A Magazine of Female Culture. No. 3 (1977).

- Sister Outsider: Essays and Speeches. Trumansburg, New York: Crossing Press, 1984.

MacSween, Morag. Anorexic Bodies: A Feminist and Sociological Perspective on Anorexia Nervosa. New York: Routledge, 1995.

Maillet, Arnaud. The Claude Glass: Use and Meaning of the Black Mirror in Western Art. Translated by Jeff Fort. New York: Zone Books, 2004.

Martin, C.B. and Deutscher, M. "Remembering." Philosophical Review. Vol. 75 (1966): 161-196.

Ma'ṣūmī Hamadānī, Ḥoseyn. "Ā'īne-ye sūzān-e aflāțūn." Našr-e dāneš. Year 7. No. I (Spring 1379/2000): 3-15.

Melchior-Bonnet, Sabine. "Figures de miroirs dans la culture médiévale." Miroirs: Jeux et reflets depuis l'antiquité. Paris: Somogy Editions d'Art, 2000.

- The Mirror: A History. Translated by Katharine H. Jewett. New York: Routledge, 2001.

Meneghini, Daniela. "A new approach to analyzing the use of the word âyine (mirror) in Bidel's ghazals." Annali di Ca' Foscari. Vol. 43. Serie orientale 35 (2004): 157-171.

Mens-Verhulst, Janneke Van; Schreurs, Karlein; and Woertman, Liesbeth. (Eds.) Daughtering and Mothering: Female Subjectivity Reanalysed. London: Routledge, 1993.

Merguerian, Gayane K. and Najmabadi, Afsaneh. "Zulaykha and Yusuf: whose 'best story?'” International Journal of Middle East Studies (IJMES). No. 29 (1997): 485-508.

Mernissi, Fatima. Beyond the Veil: Male-Female Dynamics in Modern Muslim Society. Bloomington: Indiana University Press, 1987.

Meyers, Diana Tietjens. Gender in the Mirror: Cultural Imagery and Women's Agency. Oxford and New York: Oxford University Press, 2002.

Michel, Paul (Ed.). Präsenz ohne Substanz: Beiträge zur Symbolik des Spiegels. Zürich: Pano Verlag, 2003.

Middlebrook, Diane. Her Husband: Ted Hughes and Sylvia Plath-A Marriage. New York: Penguin Books, 2004.

- "The Poetry of Sylvia Plath and Ted Hughes: Call and Response." The Cambridge Companion to Sylvia Plath. Edited by Jo Gill. New York: Cambridge University Press, 2006: 156-171. 
Milani, Farzaneh. "Forugh Farrokhzād.” Persian Literature. Edited by Ehsan Yarshater. New York: The Persian Heritage Foundation, 1988: 367-38o.

_. "Forugh Farrokhzad: A Feminist Perspective." Ph.D. dissertation, University of California at Los Angeles, 1979.

- "Veiled Voices: Women's Autobiographies in Iran." Women's Autobiographies in Contemporary Iran. Edited by Afsaneh Najmabadi. Cambridge, Massachusetts: Harvard University Press, 1990: 1-16.

.Veils and Words: The Emerging Voices of Iranian Women Writers. New York: Syracuse University Press, 1992.

Words, Not Swords: Iranian Women Writers and the Freedom of Movement. New York: Syracuse University Press, 2011.

Miller, Jean Baker. Toward a New Psychology of Women. Boston: Beacon Press, 1976.

Miller, Jonathan. On Reflection. London: National Gallery Publications Limited, 1998.

Mitchell, Juliet. "Introduction-I." Feminine Sexuality: Jacques Lacan and the école freudienne. Edited by Juliet Mitchell and Jacqueline Rose. Translated by Jacqueline Rose. London: W.W. Norton and Pantheon Books, 1982: 126.

- Psychoanalysis and Feminism. Harmondsworth: Penguin Books, 1974.

. Women: The Longest Revolution: on Feminism, Literature and Psychoanalysis. New York: Pantheon, 1984.

Moi, Toril. Sexual/Textual Politics: Feminist Literary Theory. London: Routledge, 1985.

Mo'īn, Moḥammad. "Ā'īne-ye sekandar." Mağmū'a maqālāt-e doktor Mohammad-e Mo`īn. Edited by Mahdoht Mơīn. Vol. II. Tehran: Entešārāt-e Mo`īn, 1367/1988-1989: 465-494.

__ "Ğām-e ğahān namā.” Mağmū‘a maqālāt-e doktor Mohammad-e Mo'īn. Edited by Mahdoht Mo`īn. Vol. I. Tehran: Entešārāt-e Mo`īn, 1368/19891990: 345-366.

Mulvey, Laura. Visual and Other Pleasures. Bloomington and Indianapolis: Indiana University Press, 1989.

Mūsavī, Seyede Farībā. "Ā'īne dar šāhkār-hā-ye adabī tā qarn-e haštom.” MA thesis. Tarbiat Moallem University, Tehran 1374/1995.

Näcke, Paul. "Die sexuellen Perversitäten in der Irrenanstalt.” Wiener klinische Rundschau. No. 27-30 (1899).

Najmabadi, Afsaneh. Women with Mustaches and Men without Beards: Gender and Sexual Anxieties of Iranian Modernity. London: University of California Press, 2005. 
-. (Ed.). Women's Autobiographies in Contemporary Iran. Cambridge, Massachusetts: Harvard University Press, 1990.

Neumann, Erich. The Great Mother: An Analysis of the Archetype. Translated by Ralph Manheim. Princeton and New Jersey: Princeton University Press, 1955.

Nightingale, Jeanne A. "From Mirror to Metamorphosis: Echoes of Ovid's Narcissus in Chrétien's Erec et Enide." The Mythographic Art: Classical Fable and the Rise of the Vernacular in Early France and England. Edited by Jane Chance. Gainesville: University Press of Florida, 1990: 47-82.

Nuttall, A.D. “Ovid's Narcissus and Shakespeare's Richard II: the Reflected Self." Ovid Renewed: Ovidian Influences on Literature and Art from the Middle Ages to the Twentieth Century. Edited by Charles Martindale. New York: Cambridge University Press, 1990: 137-150.

Oates, Joyce Carol. “The Death Throes of Romanticism: The Poetry of Sylvia Plath." Ariel Ascending: Writings about Sylvia Plath. Edited by Paul Alexander. New York: Harper and Row, 1985: 26-45.

- "The Death Throes of Romanticism: The Poetry of Sylvia Plath." The Southern Review. Vol. IX. No. 3 (Summer, 1973): 501-522.

O'Hara, J.D. "Plath's Comedy." Sylvia Plath: New Views on the Poetry. Edited by Gary Lane. Baltimore and London: The Johns Hopkins University Press, 1979: 75-96.

Olney, James. "Autobiography and the Cultural Moment: A Thematic Historical, and Bibliographical Introduction." Autobiography: Essays Theoretical and Critical. Edited by James Olney. Princeton and New Jersey: Princeton University Press, 1980: 3-27.

- Metaphors of Self: The Meaning of Autobiography. Princeton and New Jersey: Princeton University Press, 1972.

Oster, Patricia. Der Schleier im Text: Funktionsgeschichte eines Bildes für die neuzeitliche Erfahrung des Imaginären. Munich: Wilhelm Fink Verlag, 2002.

Ovid. Metamorphoses. Edited by Hugo Magnus. Accessed on o8 April 2014 on http://www.perseus.tufts.edu/hopper/text?doc=Perseus\%3atext\%3a1999.02 .0029

- Metamorphoses. Translated by A.D. Melville. Oxford and New York: Oxford University Press, 1986.

Owens, Craig. Beyond Recognition: Representation, Power, and Culture. Edited by Scott Bryson, Barbara Kruger, Lynne Tillman, and Jane Weinstock. Berkeley, Los Angeles and London: University of California Press, 1994.

Pankejeff, Sergius. The Wolf-Man, by the Wolf-man. With the Case of the Wolf- 
Man, by Sigmund Freud and a Supplement by Ruth Mack Brunswick. Foreword by Anna Freud. Edited by Muriel Gardiner. New York: Basic Books, 1971.

Paparunas, Penny. "Trouble with the I/Eye: Mirrors in Victorian Women Poetry." Präsenz ohne Substanz: Beiträge zur Symbolik des Spiegels. Edited by Paul Michel. Zürich: Pano Verlag, 2003: 213-250.

Pearlman, Mickey (Ed.). Mother Puzzles: Daughters and Mothers in Contemporary American Literature. New York: Greenwood Press, 1989.

Pendergrast, Mark. Mirror|Mirror: A History of the Human Love Affair with Reflection. New York: Basic Books, 2004.

Pepper, Stephen C. "The Root Metaphor Theory of Metaphysics." Essays on Metaphor. Edited by Warren Shibles. Whitewater, Wisconsin: The Language Press, 1972: 15-26.

Perloff, Marjorie. "The Two Ariels: The (Re)Making of the Sylvia Plath Canon." Poems in Their Place: The Intertextuality and Order of Poetic Collections. Edited by Neil Fraistat. Chapel Hill and London: The University of North Carolina Press, 1986: 308-334.

Plath, Sylvia. The Bell Jar. London: Faber and Faber, 1966.

- The Collected Poems. Edited by Ted Hughes. New York: HarperPerennial, 1992.

. Johnny Panic and the Bible of Dreams. London: Faber and Faber, 1979.

- Letters Home: Correspondence 1950-1963. Edited by Aurelia Schober Plath. London and Boston: Faber and Faber, 1988.

- The Unabridged Journals of Sylvia Plath: 1950-1962. Edited by Karen V. Kukil. New York: Anchor Books, 2000.

Plato. The Republic. Translated by Benjamin Jowett. Mineola, New York: Dover Publications, 2000.

Pourjavady, Nasrollah. Ešrāq o 'erfān: maqūle-hā o naqd-hā. Tehran: našr-e dānešgāhī, 1380/2001-2002.

Zabān-e hāal dar 'erfān o adabīyāt-e pārsī. Tehran: Entešārāt-e Hermes, 1385/2006-2007.

Qur'ān. Translated by Abdullah Yusuf Ali. Available at http://search-the-quran .com accessed on 08 May 2011.

Radman, Zdravko. Metaphors: Figures of the Mind. Dordrecht: Kluwer Academic Publishers, 2010.

Ragland-Sullivan, Ellie. "Jacques Lacan: Feminism and the Problem of Gender Identity." SubStance. Vol. 11. No. 3, Issue 36 (1982): 6-20.

Rank, Otto. "The Double as Immortal Self." Beyond Psychology. New York: 
Dover, 1958: 62-101.

Raskin, Robert and Terry, Howard. "A Principal-Components Analysis of the Narcissistic Personality Inventory and Further Evidence of Its Construct Validity." Journal of Personality and Social Psychology. Vol. 54. No. 5 (1988): 890-902.

Reinhard, Kenneth. "The Freudian Things: Construction and the Archaeological Metaphor." Excavations and Their Objects: Freud's Collection of Antiquity. Edited by Stephen Barker. Albany: State University of New York Press, 1996: 57-80.

Rich, Adrienne. Of Woman Born: Motherhood as Experience and Institution. New York: W.W. Norton \& Co., 1976.

Robbins, Ruth. Literary Feminisms. New York: St. Martin’s Press, 2000.

Róheim, Géza. Spiegelzauber. Leipzig-Wien: Internationaler Psychoanalytischer Verlag: 1919.

Rose, Jacqueline. On Not Being Able to Sleep: Psychoanalysis and the Modern World. London: Chatto and Windus, 2003.

Roudinesco, Elisabeth. "The mirror stage: an obliterated archive." The Cambridge Companion to Lacan. Edited by Jean-Michel Rabaté. Cambridge: Cambridge University Press, 2003: 25-34.

Rubenstein, Roberta. Boundaries of the Self: Gender, Culture, Fiction. Urbana: University of Illinois Press, 1987.

Rumi, [Jalāloddin]. A Rumi Anthology, Rumi: Poet and Mystic Tales of Mystic Meaning. Translated by Reynold A. Nicholson. Oxford: Oneworld, 2000.

Šafīì-Kadkanī, Mohammad-Reżā. Šāerer-e ā'ìne-hā: baresī-ye sabk-e hendī o šser $r$ e Bīdel. Tehran: Mo’asese-ye entešārāt-e āgāh, 1371/1992-1993.

Šamīsā, Sīrūs. Rāhnamā-ye adabīyāt-e mo'āṣer: šarh o tahlīl-e gozīde-ye šerr-e fārsī. Tehran: Entešārāt-e mītrā, 2004.

_. Šăhed-bāzī dar adabīyāt-e fārsī. Tehran: Entešāāāt-e ferdous, 1381/20022003.

Sanazaro, Leonard. "The Transfiguring Self: Sylvia Plath, a Reconsideration." Centennial Review. Vol. 27 (Winter 1983): 62-74.

. "The Transfiguring Self: Sylvia Plath, a Reconsideration." Critical Essays on Sylvia Plath. Edited by Linda W. Wagner. Massachusetts: G.K. Hall \& Company, 1984: 87-96.

Sandler, Rivanne. "Words of Attachment: Literary Antecedents of Expatriate Iranian Women." Iran. Questions et connaissances. Vol. III: Cultures et sociétés contemporaines. (Cahiers de Studia Iranica, 27). Edited by Bernard Hourcade Paris: Peeters Publishing, 2004: 129-139.

Schenck, Celeste. "All of a Piece: Women's Poetry and Autobiography." Life/ 
Lines: Theorizing Women's Autobiography. Edited by Bella Brodzki and Celeste Schenck. Ithaca and New York: Cornell University Press, 1988: 281305.

Schimmel, Annemarie. A Two-Colored Brocade: The Imagery of Persian Poetry. Chapel Hill and London: The University of North Carolina Press, 1992.

—. As Through a Veil: Mystical Poetry in Islam. New York: Columbia University Press, 1982.

_. Mystical Dimensions of Islam. Chapel Hill: University of North Carolina Press, 1975.

Schmidt, Hanns-Peter. "The Sēnmurv: Of Birds and Dogs and Bats." Persica. Vol. 9 (1980): 1-85.

Schultz, Karla. "In Defense of Narcissus: Lou Andreas-Salomé and Julia Kristeva." The German Quarterly. Vol. 67. No. 2 (Spring 1944): 185-196.

Schwartz, Murray M. and Bollas, Christopher. "The Absence at the Center: Sylvia Plath and suicide." Sylvia Plath: New Views on the Poetry. Edited by Gary Lane. Baltimore and London: The Johns Hopkins University Press, 1979: 179-202.

Sellers, Susan. Language and Sexual Difference: Feminist Writing in France. New York: St. Martin's Press, 1991.

Seltman, Charles Theodore. Women in Antiquity. New York: Thames and Hudson, 1956.

Seyed-Gohrab, Ali Asghar. Layli and Majnun: Love, Madness and Mystic Longing in Nizamis Epic Romance. Boston: Brill Academic Publishers, 2003.

Shakespeare, William. The Complete Works. London: Abbey Library, 1974.

Shamisa, Sirous. "Forugh Farrokhzad's Apocalyptic Visions." Forugh Farrokh$z a d$, Poet of Modern Iran: Iconic Woman and Feminine Pioneer of New Persian Poetry. Edited by Dominic Parviz Brookshaw and Nasrin Rahimieh. London and New York: I.B. Tauris and Co. Ltd., 2010: 109-124.

Shengold, Leonard. "The Metaphor of the Mirror." Journal of the American Psychoanalytic Association. Vol. 22. No. 1 (1974): 97-115.

Showalter, Elaine. The Female Malady: Women, Madness, and the English Culture, 1830-1980. New York: Pantheon Books, 1985.

Small, Helen. Love's Madness: Medicine, the Novel, and Female Insanity 180o1865. New York: Oxford University Press, 1996.

Spence, Donald P. The Freudian Metaphor: Towards Paradigm Change in Psychoanalysis. New York: Norton, 1978.

Spencer, Laura Gutiérrez. "Mirrors and Masks: Female Subjectivity in Chicana Poetry." Frontiers: A Journal of Women Studies. Vol. 15. No. 2 (1994): 69-86. Spivak, Gayatri Chakravorty. "Echo." New Literary History. Vol. 24. No. 1 (Win- 
ter 1993): 17-43.

Squier, Susan. "Mirroring and Mothering: Reflections on the Mirror Encounter Metaphor in Virginia Woolf's Works." Twentieth Century Literature. Vol. 27. No. 3 (Autumn, 1981): 272-288.

Stockreiter, Karl. "Am Rand der Aufklärungsmetapher: Korrespondenzen zwischen Archäologie und Psychoanalyse." "Meine ... alten und dreckigen Götter": Aus Sigmund Freuds Sammlung. Edited by Lydia Marinelli. Frankfort: Stroemfeld, 1998: 81-93.

Strangeways, Al. Sylvia Plath: The Shaping of Shadows. Cranbury, NJ, and London: Associated University Presses, 1998.

Sukenick, Lynn. "Feeling and Reason in Doris Lessing's Fiction." Contemporary Literature. Vol. 14. No. 4 (Autumn, 1973): 515-535.

Tallis, Raymond. Not Saussure: A Critique of Post-Saussurean Literary Theory. Basingstoke: Macmillan, 1988.

Tikku, Girdhari. "Furūgh-i Farrokhzād: a new direction in Persian poetry." Studia Islamica. 26 (1967): 149-173.

Timmerman, John H. "Plath's 'Mirror." The Explicator. Vol. 45. No. 2 (1987): 63-64.

Tresidder, Jack. The Watkins Dictionary of Symbols. London: Watkins, 2008.

Uroff, Margaret Dickie. Sylvia Plath and Ted Hughes. Urbana: University of Illinois Press, 1979.

Ussher, Jane M. Women's Madness: Misogyny or Mental Illness? New York and London: Harvester, 1991.

Vasseleu, Cathryn. “The Face Before the Mirror-Stage." Hypatia: Special Issue, Feminism and the Body. Edited by Elizabeth Grosz, Vol. 6. No. 3 (Fall 1991): 140-155.

Vickers, Nancy. “'The Blazon of Sweet Beauty's Best': Shakespeare's Lucrece." Shakespeare and the Question of Theory. Edited by Patricia Parker and Geoffrey Hartman. New York: Methuen, 1985: 95-115.

Walker, Julia M. Medusa's Mirrors: Spenser, Shakespeare, Milton, and the Metamorphosis of the Female Self. London: Associated University Press, 1998.

Wallon, Henri. “Comment se développe chez l' enfant la notion de corps propre." Journal de psychologie. Vol. 28 (November-December 1931): 705-748.

_. Les origines du caractère chez l'enfant. Paris: Presses Universitaires de France, 1973.

Weber, Samuel. Return to Freud: Jacques Lacan's Dislocation of Psychoanalysis. Translated by Michael Levine. Cambridge: Cambridge University Press, 1991. 
Wehinger, Brunhilde. “'Die Frucht ist fleckig und der Spiegel trübe': Lyrikerinnen im 19. Jahrhundert." Frauen Literatur Geschichte: Schreibende Frauen vom Mittelalter bis zur Gegenwart. Edited by Hiltrud Gnüg and Renate Möhrmann. Stuttgart and Weimar: J.B. Metzler, 1999: 299312.

Werner, Corey M. “The Mirror Cracked: Femininity and the Rhetoric of Castration in Shakespeare's 'The Rape of Lucrece." Available at http://www.clas .ufl.edu/ipsa/2003/IPSAarticle.html, accessed on 6 February 2009.

Wilde, Oscar. The Picture of Dorian Gray. Clayton, Delaware: Prestwick House, 2007.

Wilhelm, Richard. The Secret of the Golden Flower. New York: Harcourt Brace Jovanovich, 1962.

Winnicott, Donald Woods. "Ego Distortion in Terms of True and False Self." The Maturational Process and the Facilitating Environment: Studies in the Theory of Emotional Development. New York: International University Press, 1965: 140-152.

- Playing and Reality. New York: Routledge, 2005.

Wisker, Gina. "Viciousness in the Kitchen: Sylvia Plath's Gothic." Gothic Studies. Vol. 6. No. 1 (May 2004): 103-117.

Witthöft, Heide. Von Angesicht zu Angesicht. Literarische Spiegelszenen. New York: Peter Lang, 1998.

Wood, David John. A Critical Study of the Birth Imagery of Sylvia Plath, American Poet 1932-1963. New York: The Edwin Mellen Press, 1992.

Woolf, Virginia. A Room of One's Own. Orlando, Florida: Harcourt, 2005.

. "Professions for Women." The Death of the Moth and Other Essays. New York: Harcourt, Brace, 1942.

Wordsworth, William and Coleridge, Samuel Taylor. Lyrical Ballads and Other Poems. Hertfordshire: Wordsworth Editions, 2003.

Yazdānī, Zeynab. Zan dar še $e^{c}$-e fārsī: dìrūz-emrūz. Tehran: Entešāāăte ferdous, 1378/1999-2000.

Yorke, Liz. Impertinent Voices: Subversive Strategies in Contemporary Women's Poetry. London: Routledge, 1991.

Ziolkowski, Theodore. Disenchanted Images: A Literary Iconology. Princeton, New Jersey: Princeton University Press, 1977.

Zipoli, Riccardo. “A Computer-Assisted Analysis of Bidel's Tur-e Mar'efat." Annali di Ca' Foscari. Vol. 44. No. 3 (2005): 123-138.

"Ā'īne dar āšcār-e Farrohīi, Sa'dī, Hāfez hamrāh bā pīšnehād-ì dar zamīne-ye barresī-ye āmāri-taṭbīqī" Zekr-e ğamīl-e Sa'dī: mă̆mū'a-ye maqālāt o aš́ār be monāsebat-e bozorgdāšt-e haštṣadomīn sālgard-e tavallod-e 
šeyh-e ağal Sa'dī 'alayho al-rahma. Vol. 2. Tehran: Sāzmān-e čāp o entešārāte vezārat-e farhang o eršad-e eslāmī, 1373/1994: 229-256.

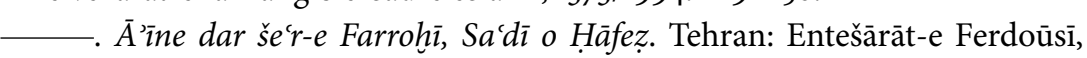
1366/1987-1988.

_. "Āyine (Mirror) in Bidel's Ghazals. Lexical Solidarities: Āyine (Mirror) and Dāg (Brand)." Annali di Ca' Foscari. Vol. 47. No. 3 (2008): 115-129.

"Semiotics and the Tradition of the Image." Persica. Vol. 20 (2005): $155-172$. 



\section{Index}

abjection $164-165,192,200-201$, $207,227,230,235,238,246$

Adam 9o, 143, 181, 183

Aeschylus 187

Agamemnon 187

Alexander's mirror see Jamshid's cup, see also burning mirror

Alvarez, Al 167

Andreas-Salomé, Lou 25, 56

Angel in the house 57, 203

Antigone 322n.59

Apollo 21, 27, 302n.2

Aristotle 184, 347n.182

Athena 27

'Atṭār Nīšābūrī, Šayh Farīd al-Dīn

$87,97,327 n .99,335 n .230$

Augustine 309n.87, 324n.70

autobiography $\quad 55-56,59$

Avicenna 86

Axelrod, Steven Gould 161, 187, 197, 233

ball, crystal $166,192,197,205$

Barthes, Roland 54

Bassnett, Susan 171,187

Bast 187-188

Bāyazīd Basțāmī 324n.69

Bayley, Sally 210

Bennett, Paula 136

Berger, John 66
Bergson, Henri $\quad 47-48$

Berry, Philippa 176

Bible, the $324 n .70$

Bīdel Dehlavi 87, 325-326n.76

Biedermann, Hans 335n.227

Birkle, Carmen 134, 232

Biven, Barrie M. 220

Bloom, Harold 195, 233

Bollas, Christopher 194-195

Bosch, Hieronymus 169

Britzolakis, Christina 187, 236

Brontë, Charlotte 322n.59

Bundtzen, Lynda K. 216

Bunyan, John 162-163

Burckhardt, Titus $86,324-325 n .72$ and n.73, 327n.95

Butler, Judith 56,189

Butscher, Edward 179, 190, 228, 233, 237

Carroll, Lewis $\quad$ 14, 57

Casey, Edward S. 46

Cephisus 21

Chodorow, Nancy J. 50, 312n.123

Christodoulides, Nephie 192,227 , 234, 235, 351n.244

Cixous, Hélène $\quad 28,44,58,83,133$, $138,156,207,238$

Clytemnestra 187

Coleridge, Samuel Taylor 105 
Cooley, Winnifred Harper 139

Cooper, Jean C. 202

cosmetics see make-up

Daly, Mary 178

De Beauvoir, Simone $\quad 23,50,193$, 303n.13

De Givry, Grillot 165

Deleuze, Gilles 47

demon $165,167,202-206,213,217$, 221, 240, 244, 246, 336n.238, see also Satan

Derrida, Jacques 304n.23, 306$307 n .56$

Descartes, René 41,308-309n.81, 324-325n.72

Dijkstra, Bram 162, 177, 185

Diogenes 336n.238

divination by mirror see magic mirror dybbuk 217-218

Echo 17, 21-27, 162, 218, 244

Écriture feminine 28

Ellis, Havelock 29

envy 11, 129, 163-164, 246

penis-envy 32,36

'Erāqī, Faḩr ol-Dīn 87

Evans, Dylan 38

Eve $101,143,181,183,329$ n.134

eye, evil 12,163

Farrar, Edith 195

Farrokhzad, Forugh:

\section{Collected volumes}

Asìr (The Captive) 64, 67, 72, 93

Dìvār (The Wall) 64, 76, 82, 98

'Esyān (Rebellion) 64, 80, 87

İmān bìyāvarīm be āgāàz-e faṣl-e sard ... (Let Us Believe in the
Beginning of the Cold Season

...) 65,139

Tavalod-ī dīgar (Another Birth)

64, 109, 132, 138

\section{Individual poems}

"Afsāne-ye talḩ" (“Bitter Myth”) $321 n .49$

"Āine-ye šekaste" (“The Broken

Mirror") $\quad 72-76,78$

"Ārezū" (“The Wish") 82-85

“'Arūsak-e kūkì" ("The Clockwork

Doll”) 335n.235

"Āye-hā-ye zamīnī" ("Earthly

Verses") 109-110

"Az yād rafte" (“The Forgotten")

$67-72,78$

"Bandegî" ("Servitude") 87-92

"Bāzgašt" ("The Return”) 105108

"Be āftāb salāmī dobāre ḩ⿳亠̄冖ham dād" ("I Shall Salute the Sun

Once Again") 132-137

"Deltangi”" ("Depression") 322-323n.61

"Dīdār dar šab" ("Meeting at Night") 111-122

"Dīr" ("Late") 8o-81

"Donyā-ye sāye-hā" ("The World of Shadows") 328n.113

“Eșyān-e hodā" ("Divine Rebellion") 326n.88

"Gereh" (“The Knot") 330n.135

"Gomšode" (“The Lost") 98-104

"Īmān bīyāvarīm be āgāa-e faṣl-e sard ..." ("Let Us Believe in the Beginning of the Cold Season ...") 139-150, 153

"Panğare" ("Window") 139, 140, 150-154, 336n.239 
"Rūy-e hāk" (“Upon the Earth”) 323n.64

"Ședā'ī dar šab” ("A Sound at Night") 93-98

"Šoq" ("Enthusiasm") 76-79

"vahm-e sabz" (“Green Delusion”) $73,122-131$

\section{Prose}

"Dar dīyārī dīgar" ("In Another Land") 105

Letters 119, 332n.167

\section{Interviews}

109-110, 122, 155-156, 330n.140 and

n.141, 332n.171, 336-337n.246,

n.247 and n.249

Ferdowsī (magazine) 105

Flax, Jane 50

Folkenflik, Robert 59

Folsom, Jack 198

Foucault, Michel 45-46, 192

Frazer, James George 159

Freedman, William 202

Freud, Sigmund $18,19,25,27-28$,

29-36, 38, 41, 44, 45, 68, 78,

$85,100,102,111,112,152,159$,

$160,168,181-182,193,197,202$,

207, 225, 308n.72, 309n.81,

310n.91

Gallop, Jane $40,44-45,49,70$,

$$
\text { 133-134 }
$$

Ġazzālī, Abū Hāāmed 86, 342n.76

Ǵazzālī, Aḥmad 86

Gemini (magazine) 162, 338n.7

Gilbert, Sandra M. 57, 99-100, 180, 182, 195

Goethe, Johann Wolfgang von 177 , 340-341n.59

Green, André 25
Grosz, Elizabeth A. $\quad 24,35,37,38,39$, 305n.42, 308n.72

Gubar, Susan $57,99-100,180,182$, 195

Hạfez, Šams ed-Dīn Moḥammad 61, 87, 90-91, 320-321n.43, 322n.58, 354n.11

al-Hallāj, Hosayn ebn-e Manșūr 324n.69

Hamadānī, 'Ayn-ol-Qożāt 53-54, 314n.142

Haselstein, Ulla 219, 349-350n.226

Hera 186

Hertz, Neil 28

heterotopia $45-46,57,121,122,155$, 170, 190-192, 201, 229, 245, 246

Hughes, Billie 195

Hughes, Frieda Rebecca 208, $347 n .180$

Hughes, Nicholas 211-212, 347n.18o

Hughes, Ted 167, 195, 233, 237,

$352 n .260$

Hutchinson, Lucy 176-178, 340n.55

$H^{w} \bar{a}$ dan $\bar{\imath}-h \bar{a}$ (magazine) 101

Irigaray, Luce $\quad 44-45,49,51-53,71$, 133-134, 146, 148, 178, 183, 237, 310n.91 and n.93

Jacobus, Mary 42 Jāmī, Nūr ed-Dīn 'Abd ar-Raḥmān $342 \mathrm{n} .8 \mathrm{o}$

Jamshid's cup ( $\breve{g} \bar{a} m-e ~ \breve{g} a m) \quad$ 76, 90, 104, 107, 319-320n.42, 320-321n.43, 322n. 58

Jinghua, Fan 206-207, 234

Johnson, Barbara 129-130, 203, 207, 234, 238 
Jung, Carl Gustav 51, 80, 114,

123-124, 193, 202, 328n.113,

345-346n.16o

Juno 21

Kendall, Tim 172

Keyhosro's mirror see Jamshid's cup

Kristeva, Julia 14-16, 24-26, 42, 47, $51,101,120,123,134,135,137,164$, 194, 227, 229, 238, 351n.244

Kroll, Judith $\quad 181,183,196,199$

Kuspit, Donald 225

La Belle, Jenijoy $13,50,56,94,114$, 123, 197, 214, 216, 220, 301n.4, 351-352n. 258

Lacan, Jacques $15,18,35,36-45,49$, $54,96,98,111,118,131,144,160$, $175,209,218,223,227,234,237$, 306n.55, 308n.72 and n.81, 309n.87, 310n.93, 323n.64

Lane, Gary 193

Lichtenberg Ettinger, Bracha 44

Liriope 21

Lorde, Audre 314-315n.145

Maillet, Arnaud 179-180, 205-206 make-up 34, 70, 73, 184, 199, 214-215, 230

Mary, Virgin $\quad 198,213,335$ n.227

matrophobia 52, 192

Medusa 17, 18, 27-29, 57-58, 165, $188,192,203,207-208,227$, 235, 238, 246, 305n.40, 320n.42, 344n.121

Melchior-Bonnet, Sabine 58,73 , $95,138,146,163-164,166-167$, 169-170, 205, 216, 322n.51, 324n.7o, 330n.134
Meyers, Diana Tietjens $\quad$ 13, 24-25, 29, 57

Middle Ages (medieval) 11, 86, 176, 320n.42, 324n.70, 335-336n.238

Middlebrook, Diane 208

Milani, Farzaneh $\quad 65,123,127,139$, 157, 318n.11, 326n.89, 341n.70

mirror

burning 206,321n.45 catoptromantic see magic mirror clairvoyant see magic mirror magic 52, 75, 76, 104, 107, 133, $141,152,159,166,177-178$, 196, 197, 228, 245, 313n.134, 319-320n.42 mantic see magic mirror Mitchell, Juliet $\quad 25,35,39,42,56-57$, 84

Moi, Toril 38-39

Mo'īn, Mohammad 76,321n.45 Monster (also monstrous or monstrosity) $18,19,57,94,113,148$, $161,188,196,202-203,207,224-$ $228,230,239,241,243,245-246$

motherhood 43, 131, 203, 245, 348n.189

Mulvey, Laura 66

Näcke, Paul 29

Narcissus also Narcissa $\quad 13,15,17,19$, 21-27, 29, 33, 35, 74, 156, 162, 171, 173-175, 177, 196, 218, 237, 240, 244, $245,340 n .48$

new woman 138-139, 334n.207

Neẓāmī Ganğavī 318-319n.25

Nietzsche, Friedrich 211-212, 348n.192

Nightingale, Jeanne A. 176

Nike 234-235 
Nuttall, Anthony David 24

Oates, Joyce Carol 340n.48

O’Hara, J.D. 188-189

Olney, James 56,59

Ovid 17, 21-29, 35, 159, 171, 303n.9

Owens, Craig 218

Pahlavi 62, 63

Pankejeff, Sergius 225

Paparunas, Penny 28-29

Perloff, Marjorie 179

Perseus 27

Plath, Aurelia Schober $\quad$ 234, 344n.121

Plath, Sylvia:

\section{Poetry}

"Aerialist" 342n.84

"All the Dead Dears" 190-195, 201

"Barren Woman" 170

"Berck-Plage" 197-198

"Brasilia" 208, 211-214, 241

“The Burnt-out Spa” 224-228, 241

"Child" 208, 347n.18o

"Childless Woman" 168-171, 183, 241

"The Courage of Shutting-Up" 193, 230, 241

"Dark Wood, Dark Water" 199

"Ella Mason and Her Eleven Cats" $342 n .84$

"Epitaph in Three Parts" 220223, 241

"Face Lift" 201, 241, 342n.84

"For a Fatherless Son" 208, $347 n .180$

"Gigolo" 171-175, 240, 340n.48

"Insomniac" 241, 342n.84
“The Jailer" 342n.84

"Lady Lazarus" 188, 342n.84, 343n.104

“Lesbos" 342n.84

"Lorelei" 199

"Medusa" 344n.121

"Mirror" 193, 196-203, 204, 237, 241

"Moonsong at Morning" 199

"Morning Song" 208-211, 212, 229, 241

"On Looking into the Eyes of a Demon Lover" 168, 203-208, 238, 240, 241

“The Other" 233-238, 241, $342 n .84$

"Paralytic" 171

"Purdah" 171, 174, 178-190, 199, 240-241, 343n.104

"A Sorcerer Bids Farewell to Seem" 170, 241, 342n.84

"Spinster" 162

"Stillborn" 170

“Tale of a Tub" 228-233, 241

“Three Women” 339n.40

“Totem" 339n.38

"Vanity Fair" 162-168, 240

"You're" 208, 347n.180

Prose

"All the Dead Dears" (short story) 195, 345n.136

The Bell Jar (novel) 214-220, 239-241

Doreen 214-215

Greenwood, Esther 214-220, 239-240, 241

Hilda 215-220, 241

Lucas, Victoria (pseudonym) 214 
Journals (Diary) 207, 224

Letters Home 190, 348n.189 and n. 198

“The Magic Mirror: A Study of the Double in Two of Dostoevsky's Novels" (undergraduate diss.) 159

"Ocean 1212-W" (short story)

241

Plato $86,171,178,310$ n.91, 324n.70

Plotinus 25, 86

Poseidon 27, 305n.36

purdah (parde) 179-181, 184, 186, 188-189, 341n.70 and n.71, see also veil

Qajar 62

Qur'ann, the 87, 91-92, 109, 32933on.134, 353-354n.1, 2, 3, 4, 5, 6, 7, $8,9,10,12,13$ and 15

Ragland-Sullivan, Ellie 38

Rank, Otto 159

Rich, Adrienne 50, 52

Rimbaud, Jean Nicolas Arthur 36, 41

Robbins, Ruth 58-59, 63

Rosenberg, Julius and Ethel 217

Roudinesco, Elisabeth 309n.81

Ro’yāī, Yadollāh 322-323n.61

Rubenstein, Roberta 50

Rūmī, Jalāloddin $\quad 87,97,328$ n.112, $341 n .71$

Sa'dī 87

Šafīīi-Kadkanī, Moḥammad-Reżā 325n.76

Šamīsā, Sīrūs $\quad 331 n .164,336 n .239$

Sanazaro, Leonard $\quad 188$
Sandler, Rivanne 111

Šāpūr, Kāmyār 106-108

Šāpūr, Parvīz 119

Satan 11, 89-92, 165-167, 205, 244, 326n.88, 327n.99, see also demon

Schenck, Celeste 59

Schopenhauer, Arthur 314n.142

Schultz, Karla 15-16

Schwartz, Murray M. 194-195

Sekhmet $\quad 187-188$

Sellers, Susan $\quad 42,58$

Shakespeare, William 170, 194, 322n. 59

Shengold, Leonard $48,51,69,115$, 145

Showalter, Elaine $\quad$ 14, 216

simurgh (sìmorg) $\quad 147,148$

Socrates $171,336 \mathrm{n} .238$

Sohrawardī 86

Solomon's mirror see Jamshid's cup Spencer, Laura Gutiérrez 14, 63 spider, weaving mirrors $19,169-171$, 245, 339n.38

Spivak, Gayatri Chakravorty $\quad 23,25$, 218

Squier, Susan 154

Strangeways, Al 188

Sufism (Islamic mysticism) 62, 82, 85-88, 90, 91-92, 110, 118, 152, 304n.34, 316n.2, 322n.58, 324n.69, $331 \mathrm{n} .148$

Sukenick, Lynn 52 surgery, cosmetic 34,201

Swift, Jonathan 228

Tallis, Raymond 36 Thackeray, William Makepeace 162-163

Tikku, Girdhari 67 
Timmerman, John H. 202, 345346 n.16o

Tiresias 21

Uroff, Margaret Dickie $\quad$ 187-188

Ussher, Jane M. 162

utopia $45-46,57,73,107,108,192$, $216,224,241,244$

Vāsețī, Abūbakr 327n.99

Vasseleu, Cathryn 310n.93

Veil (also unveiling) 62, 63, 77, 87, 96, 98, 105-107, 110, 157, 179-182, 184, 187-189, 191, 229-231, 237, 320n.43, 341n.70 and n.71, see also purdah

Venus 19, 206-207, 238

Victoria 234
Walker, Julia M. 108, 317n.3

Wallon, Henri 36

Wehinger, Brunhilde $\quad 59,316 \mathrm{n} .163$

Wevill, Assia $\quad 233,352 n .260$

Wevill, David 233

Wilde, Oscar 314n.142

Winnicott, Donald Woods 100, 189, 313-314n.140, 341n.62

Wisker, Gina 209

Wollstonecraft, Mary 322n.59

Wood, David John 234

Woolf, Virginia $57,75,132,177-178$, 184

Ziolkowski, Theodore 313n.134, 324n.70

Zipoli, Riccardo $\quad 79,96,325 n .76$ 


\section{Iranian Studies Series}

J.C. Bürgel \& C. van Ruymbeke (eds.)

Nizāmì: A Key to the Treasure of the Hakim

ISBN 978908728097 O

J. Coumans

The Rubáiyát of Omar Khayyám. An Updated Bibliography

ISBN 9789087280963

N. Fozi

Reclaiming the Faravahar: Zoroastrian Survival in Contemporary Tehran

ISBN 9789087282141

F. Lewis \& S. Sharma (eds.)

The Necklace of the Pleiades. 24 Essays on Persian Literature, Culture and Religion ISBN 9789087280918

M.A. Nematollahi Mahani

The Holy Drama. Persian Passion Plays in Modern Iran

ISBN 9789087281151

C. Pérez González

Local Portraiture. Through the Lens of the 19th-Century Iranian Photographers ISBN 9789087281564

R. Rahmoni \& G. van den Berg

The Epic of Barzu as Narrated by Jura Kamal

ISBN 9789087281168

A. Sedighi

Agreement Restrictions in Persian

ISBN 9789087280932

A.A. Seyed-Gohrab

Courtly Riddles. Enigmatic Embellishments in Early Persian Poetry

ISBN 9789087280871

A.A. Seyed-Gohrab (ed.)

The Great Umar Khayyam: A Global Reception of the Rubáiyat

ISBN 9789087281571 
A.A. Seyed-Gohrab \& S.R.M. McGlinn (eds.)

One Word-Yak Kaleme. 19th-Century Persian Treatise Introducing Western Codified Law ISBN 978908728 o89 5

A.A. Seyed-Gohrab \& S.R.M. McGlinn (eds.)

Safina Revealed. A Compendium of Persian Literature in 14th-Century Tabriz

ISBN 978908728 o88 8

A.A. Seyed-Gohrab, F. Doufikar-Aerts \& S. McGlinn (eds.)

Embodiments of Evil: Gog and Magog. Interdisciplinary Studies of the 'Other' in Literature \& Internet Texts

ISBN 9789087280901

P. Shabani-Jadidi

Processing Compound Verbs in Persian: A Psycholinguistic Approach to Complex Predicates ISBN 978908728208 o

B. Solati

The Reception of Hāfiz: The Sweet Poetic Language of Häfiz in Nineteenth and Twentieth Century Persia

ISBN 9789087281977

S. Tabatabai

Father of Persian Verse. Rudaki and his Poetry

ISBN 9789087280925

K. Talattof \& A.A. Seyed-Gohrab (eds.)

Conflict and Development in Iranian Film

ISBN 9789087281694

\section{Forthcoming titles in the Iranian Studies Series:}

J.T.P. de Bruijn, The Journey of the Faithful to the Place of Return. A Persian Allegory on the Development of the Human Soul by Sanâ'i of Ghazna, Founding Father of Persian Sufism

J.T.L. Cheung, The Nartic Epic Tradition. Remnants of Iranian Lore from the Caucasus

S.R.M. McGlinn, Abdul-Baha's Sermon on the Art of Governance

A. Sedighi, Persian in Use: An Elementary Textbook of Language and Culture

R. Zipoli, Irreverent Persia: Invective, Satirical and Burlesque Poetry from the Origins to the Timurid Period (1oth to 15th centuries) 